التضحية وعلاقتها بالرضا عن الحياة لدى المرأة المتزوجة وغير المتزوجة

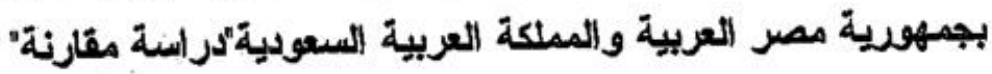

/ مقاء صديق" محمد خريبه" أم/الماتى عبد المتصود عبد الوهاب' ملذص البحث

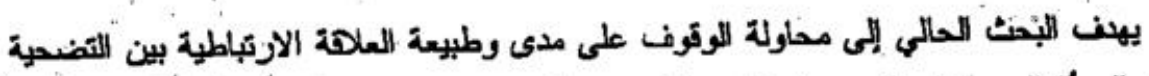

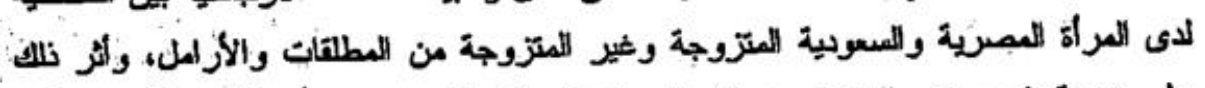

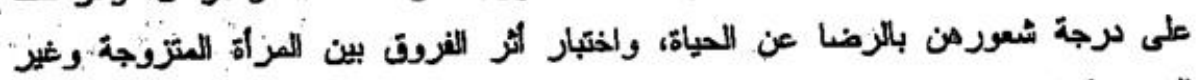

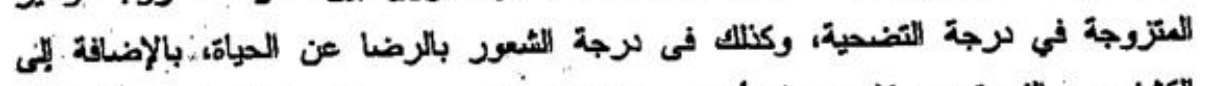

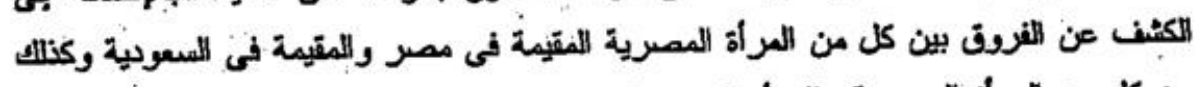

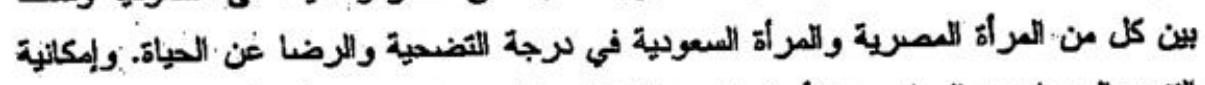

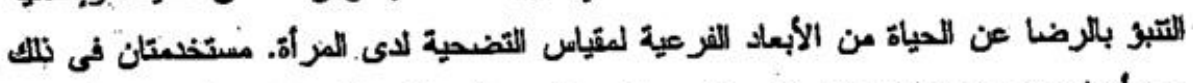

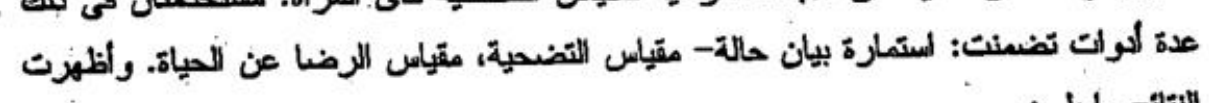
الالثتأتج ما يلى:

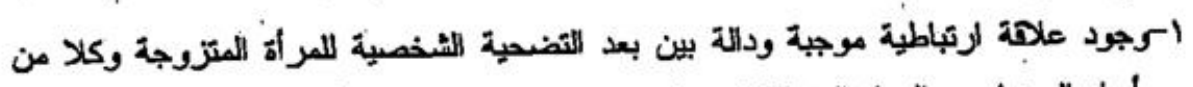

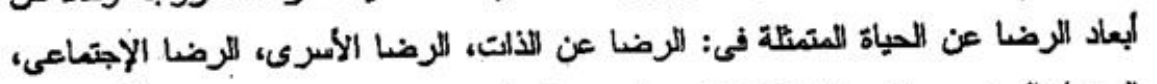

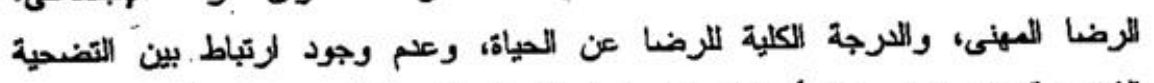

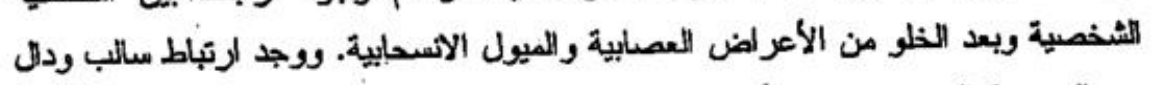

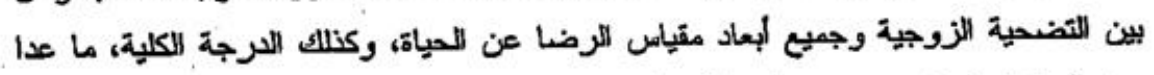

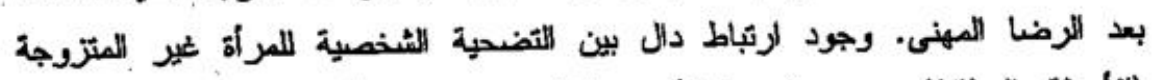

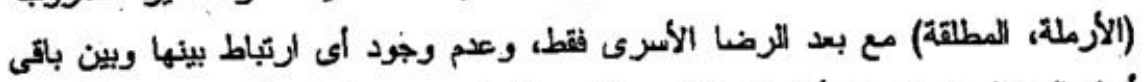

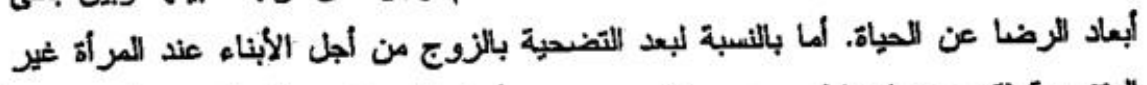

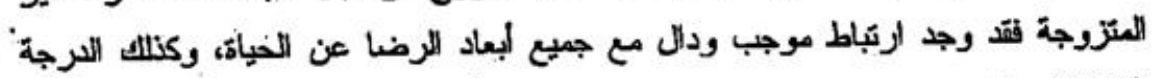
الكلية للزضا.

\title{
$r$
}

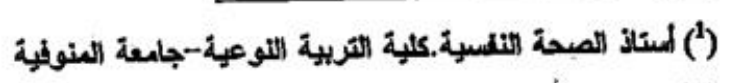

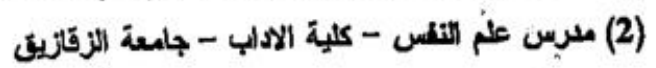


= التضحية وعلافتها بالرضا عن الحياة لدى المرأة المتزوجة وغير المتزوجة=س

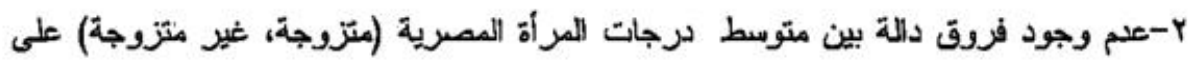
مقياس التضحية.

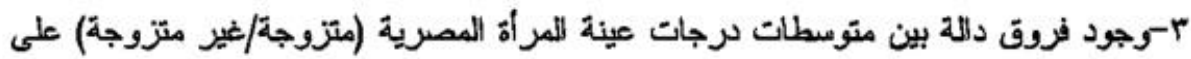
مقياس الرضا عن الحياة لصالح المر أة المصرية المتزوجة.

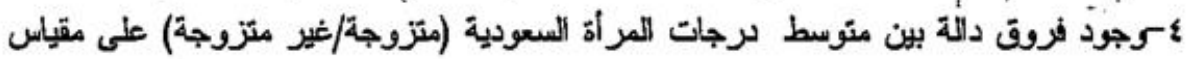
التضحية لصالح المرأة السعودية غير المتزوجة.

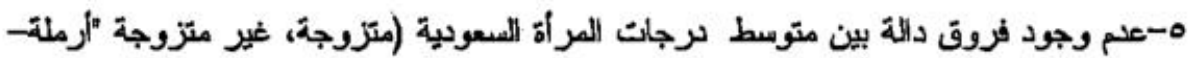

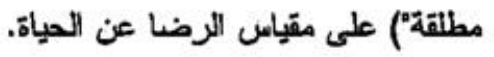

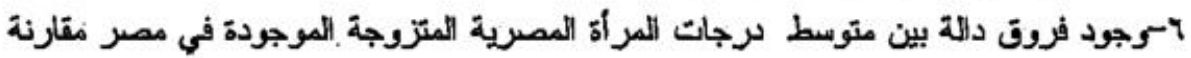
بمثيلتها المقيمة في السعودية على مقياس التضحية لصالح المرأة المصرية الموجودة في المئ

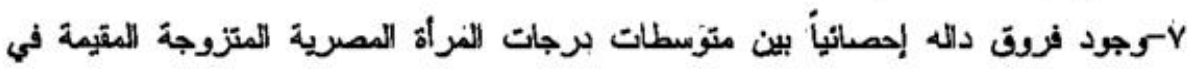

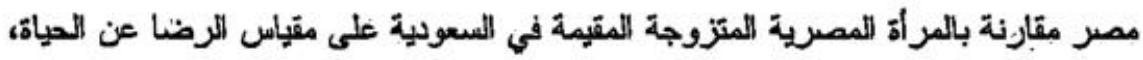
وزيلك لصالح المراة المصرية المقيمة في السعودية.

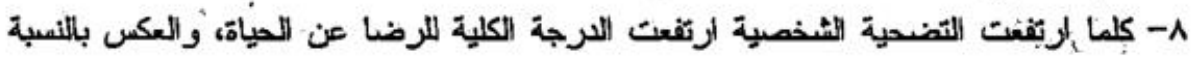

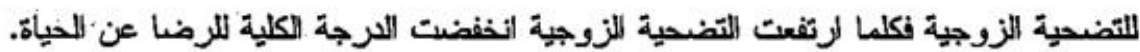




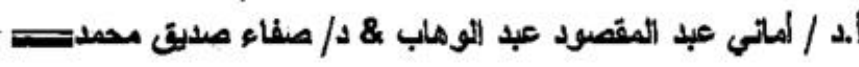

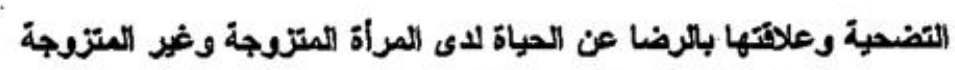

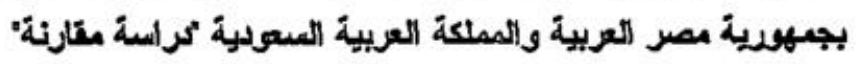

/ مشاء صدئ محس خريجه

ألمانمى عبد المتصوبد عبد التوماب

مinats

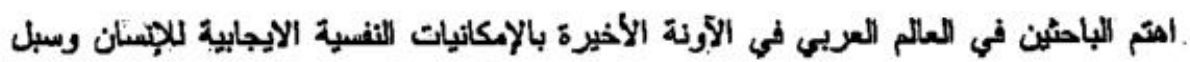

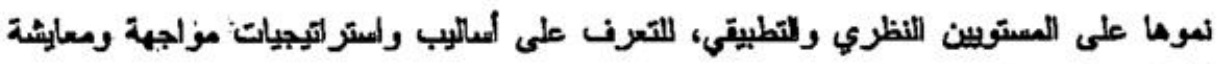

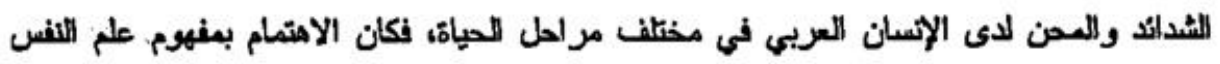

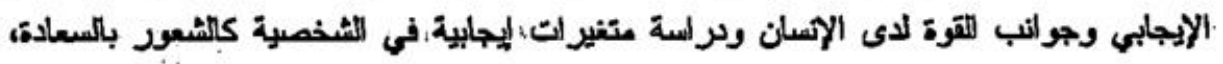

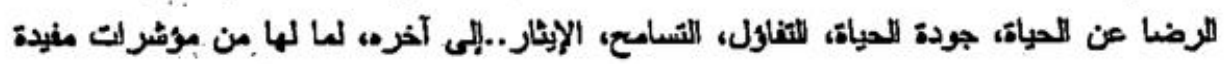

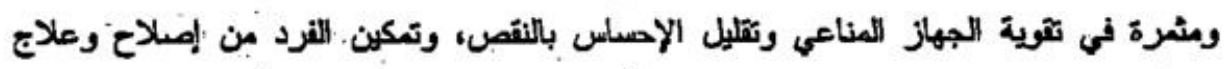

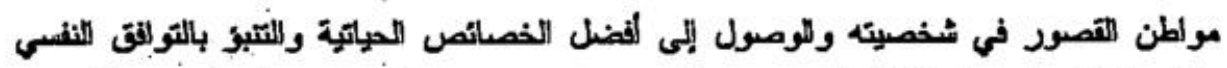

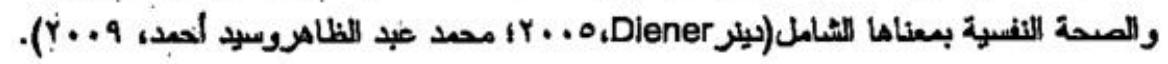
ولياتم الامتمام بالمراة لمواكبة الاهتمام الحليث بتمية إمكانات المراة وتنعيل إسهاماتها

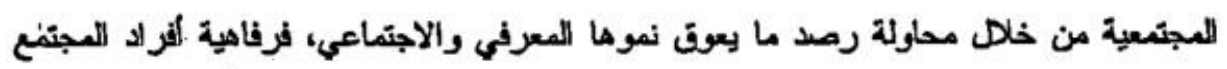

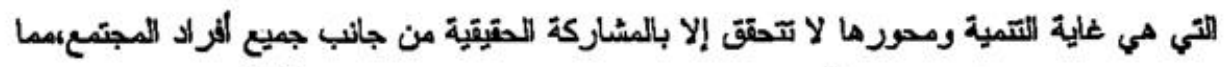

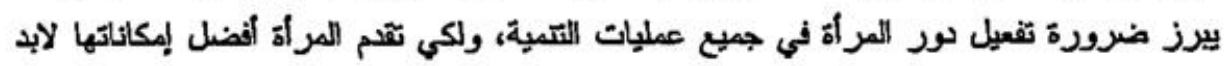

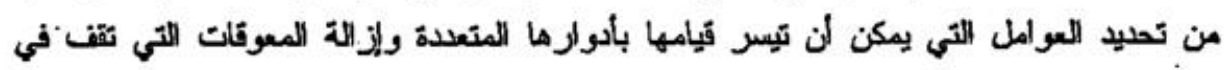

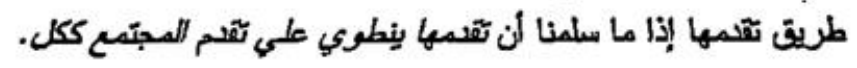

ومن المصطلحات الحديثة نسبياً مفهوم التضحية Sacrifice حيث يشير إلى الرعاية والثقة

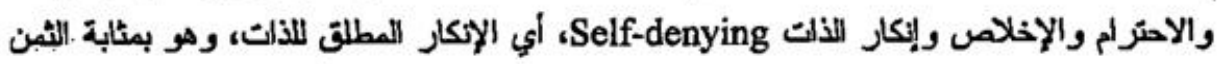

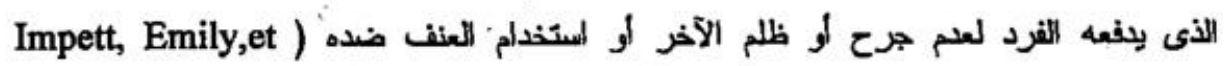

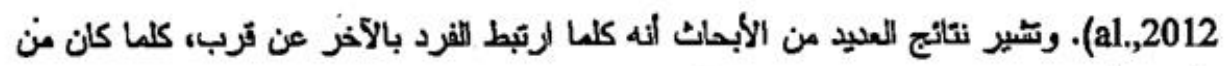
الأرجح أن يتخلى عن شيء ما لمساعدة الآخر (Bar-Tal,1979; Noller, 1996).

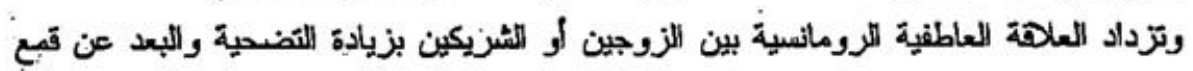

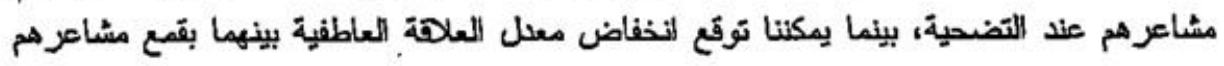
وعدم قرتهما على التضمية أ الرضا عن العلهة بينهما، وتميز براسة التضنحية الايجابية

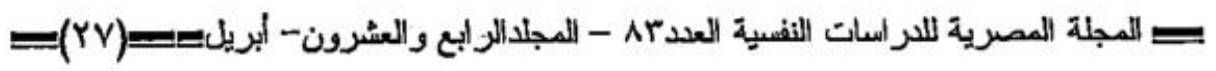


= التضمية وعلاقتها بالرضا عن الحياة لدى المرأة المتزوجة وغير المتزوجة

بالقرة على تتوير الطريق الذى تتمو من خالهه العلاهات الحميمة (Positive-Sacrifice)

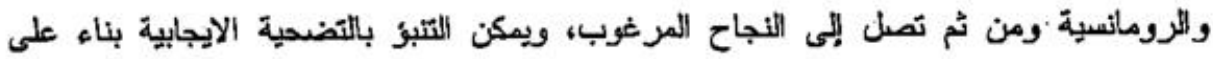

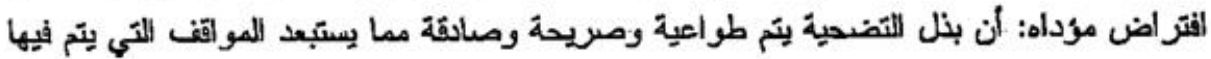

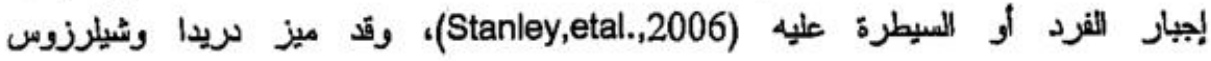
وبئ Derrida;S.\&Schillerthus

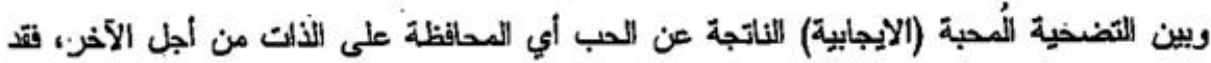

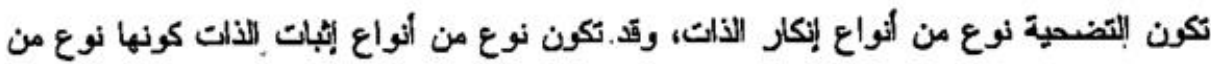

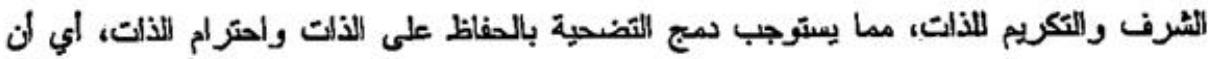

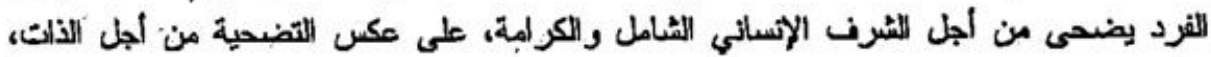

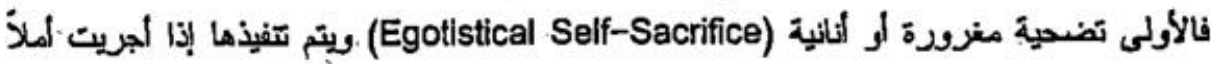
في الخلود، والثانية تضحية غيرية ' (Altruistic Self-Sacrifice) يتم تتفيذها من أجل الآخرين،

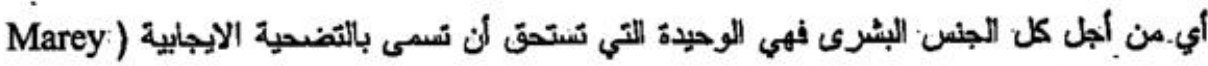

.$($, S.,2011

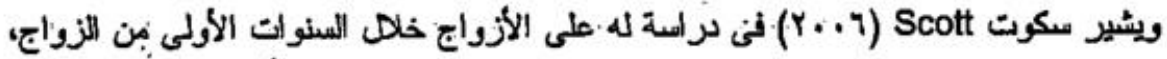
فندما تمبر مخاطر الطلاق أعلى مستوى، أن الاتجاهات الخاصة بالتضصية ستبا بالنجاح

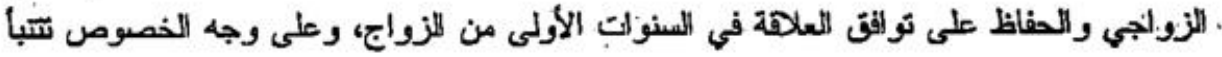

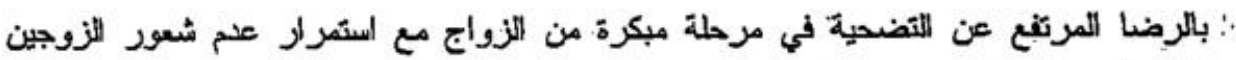

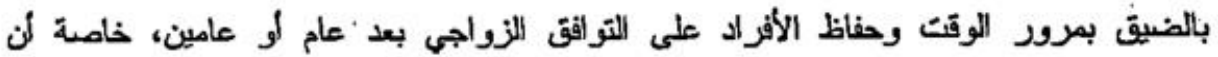
اللتضحية قد يكون لها تأثير مفيد على جودة العاهة الزوجية، وإثارة بارزة للإخلاص اللشريك

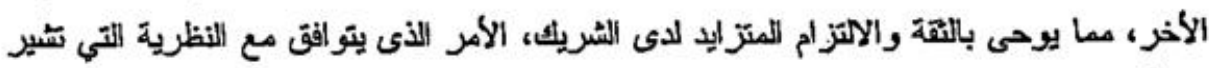

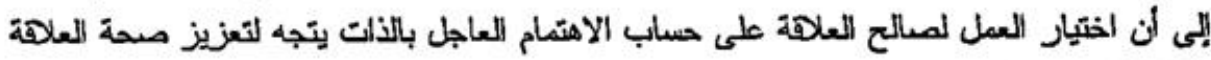
.(Wieseiquist,et al,1999;Kelly\& Thibaut,1978) وقد يسهم الرضا عن الحياة Life Satisfaction بنور متميز في التضحية باعتباره مؤشر هام

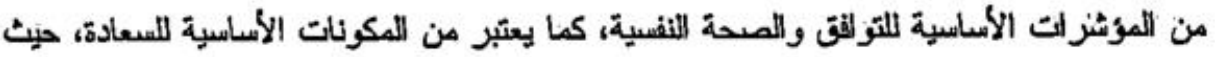

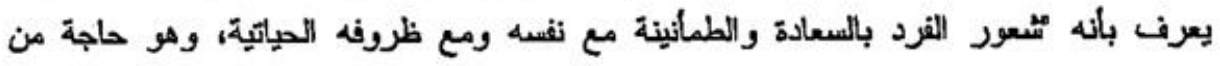

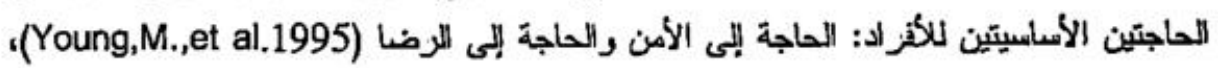

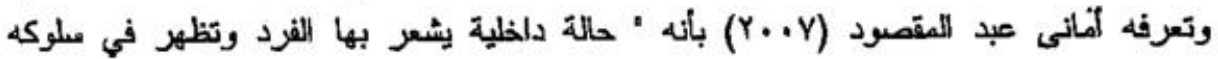

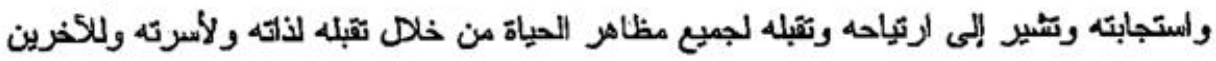

(YN)= 


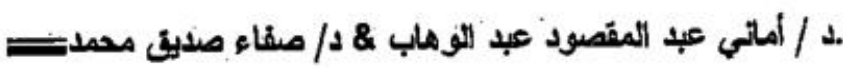

واليئة المركة وتثاعله مع خبر اتها بصورة متو افقهة.

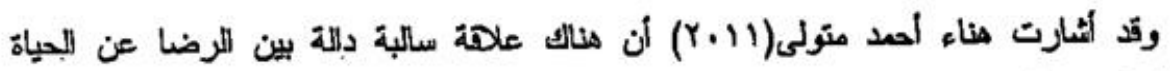

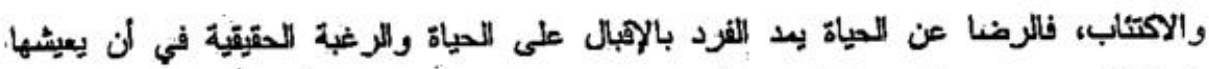

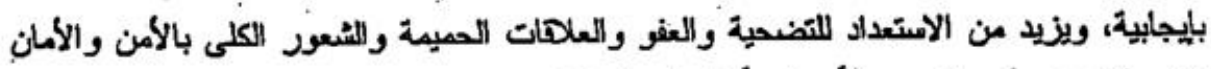

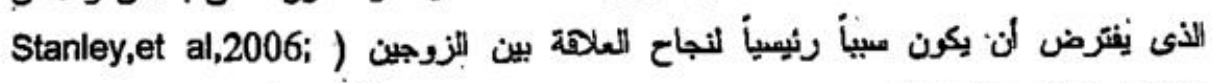

.(Hannon, et al.,2005

\section{مثكلة البحث:}

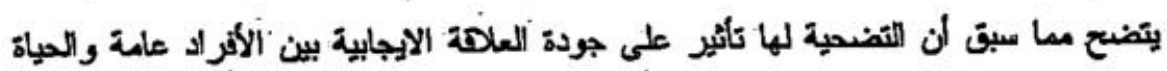

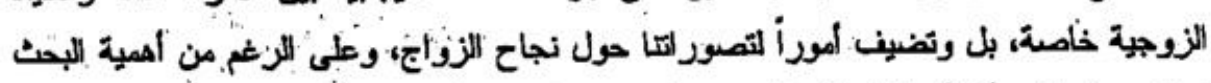

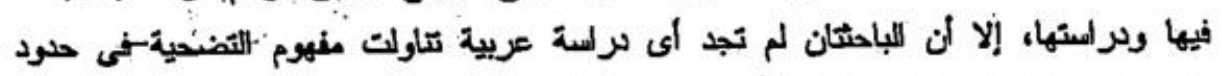

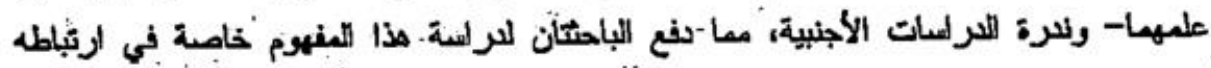

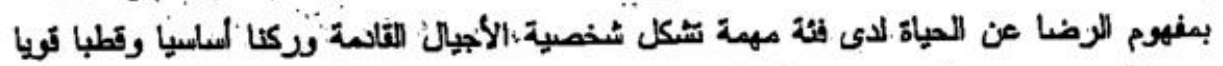

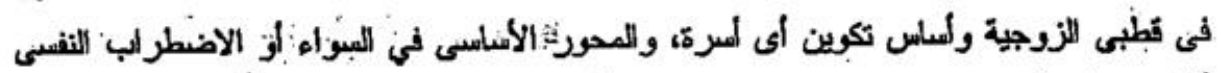
ألا وهى المراة. ويمكن تصليد مثنكة البحث في الأسئة التالية:

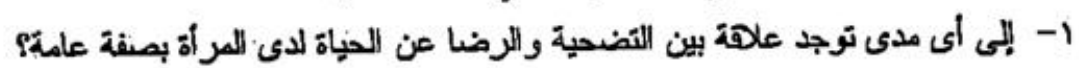

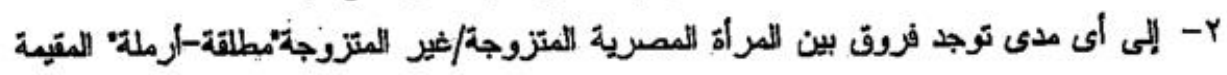
فى مصر على مقياس اللتضحية والرضنا عن الحياة.

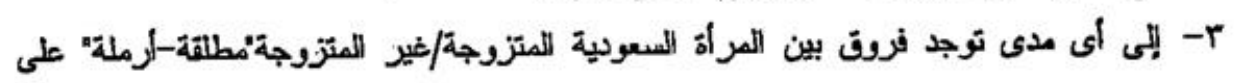

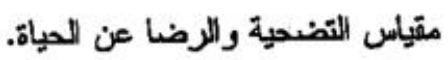

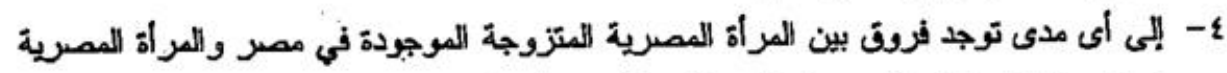

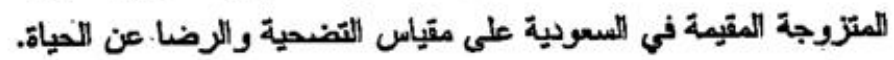

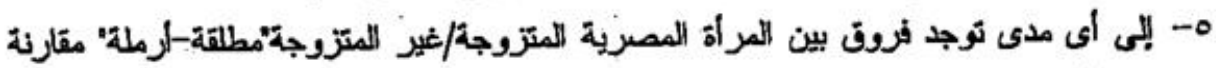

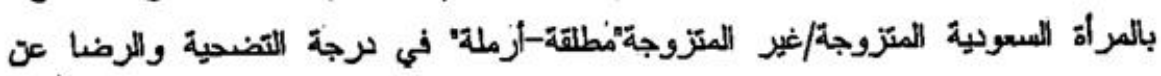
الحياة. צ- إلى أى مدى يمكن التبو بلأرضا عن المباة من خلال الأبعاد الفرعية لمقياس اللضشية لدى المرأم المي

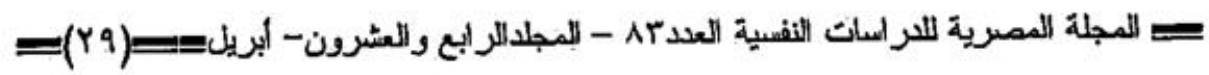




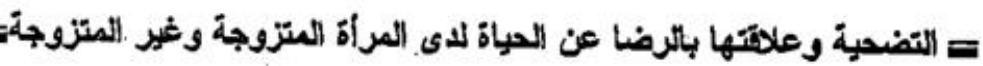

من البحث:

بهنف البحث لاحالي إلى محاولة التوقوف على مدى وطبيعة العلاهة الارتباطية بين التضصية

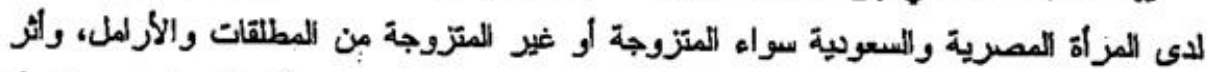
ذلك على ،رجة ثعورهن بالرضا عن الحياة، كما يهذف إلى اختبار الثر الفروق بين المراة

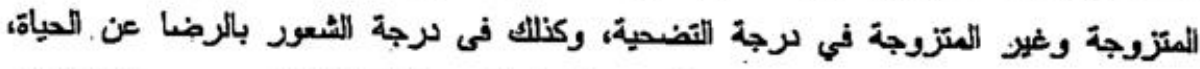
بالاطافة إلى الكثف عن النرق بين كل من المراة الممرية المقيمة فى مصر. والمقيمة فى السعوبية وكنالك ين كل من المراة المصرية والمراة السعوبية في برجة اللتضحية والرضا عن

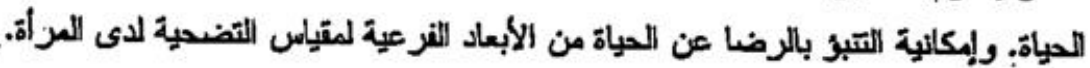

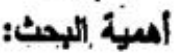

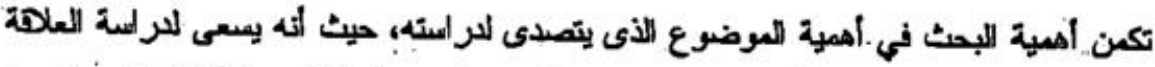

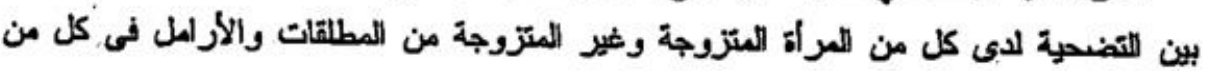

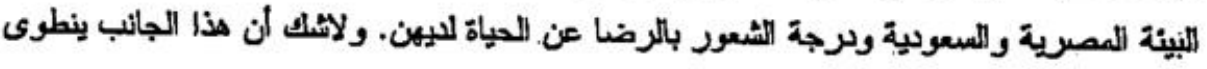

على أهمية كييرة سواه من الناحية الثظرية أو البتطبيقية.

فمن اللاحية النظرية: يعتبر مفهوم التضحية Sacrifice من. المفاهيم الحبيثة التي لم لتم الاهتمام بها في البحوث في للعلم العربى بوصفه مفهوم يشير اللى اللرماية واللقة والاحترام والاخلاص وإنكار الذات Self-denying) (Impett,Emily,A.,et al.,2012)، ولن الاهتمام بعلم النفس الايجابي والمتنيرات الإيجايية في اللشخصية مازلال في مرلحله المبكرة، ومفهوم التضحية مازلل في مرحلة المهد، مما يتطلب إجراه المزيد من الأبحاث النظرية والتطبيقية على التضحية

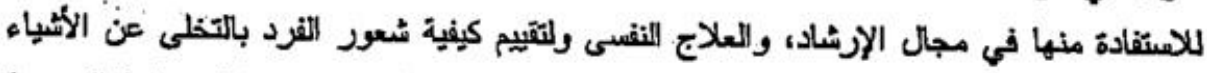

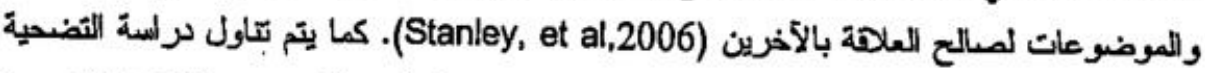
من خلال وجهات نظر متعدة، حيث يتم دراستها.من ناحية البعد الشخصي (الذاتي) للنضحية والبعد الزواجى، إلى جانب تتاولها من وجهة نظر كل من المرأ (للمتزوجة وغير المتزوجة "الممطلقة-الأرملة")، الممرية مقارنة بالمراة السعودية. كما لوحظل مجدوبية اللراسات التى تلارلت اللشعور بالرضا عن الحياة لدى المراة بصفة عامة Huebner,1991;Leung \& Leung, 1992; ) والمرأه المتزوجة وغير المتزوجة بصفة خاصة لوجنة .(Young, M.,etal.1995; Hair,et al., 2003; Henery, 2006 ويتضنح من مراجعة البحوث واللر استات العربية التى لجريت فى مجال الرضا عن الحياة كاثت

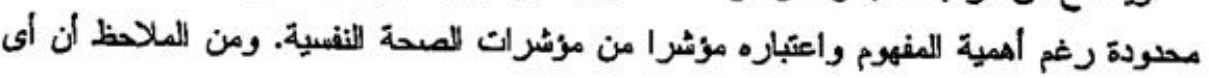

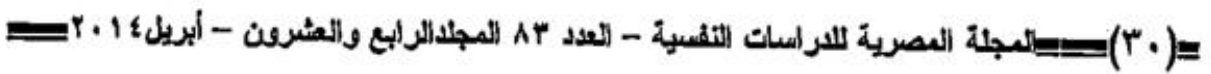




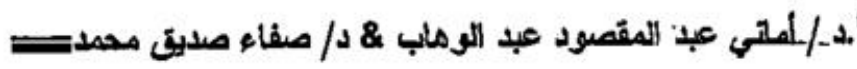

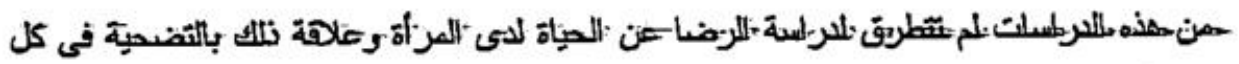

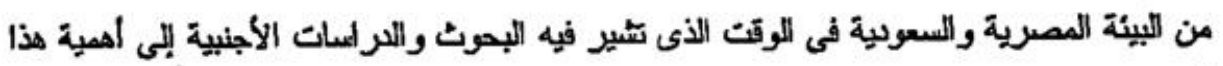
الموضوع.

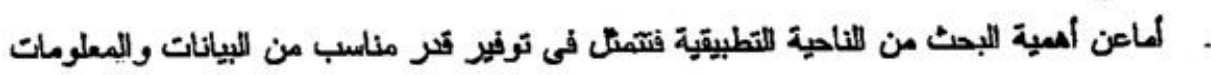

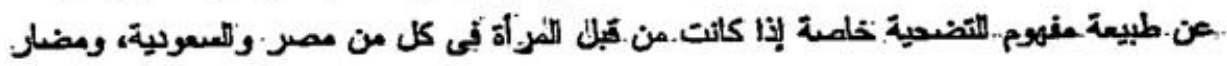

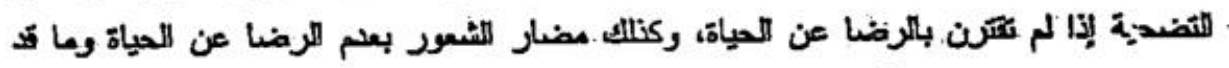

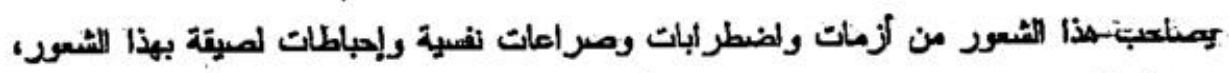

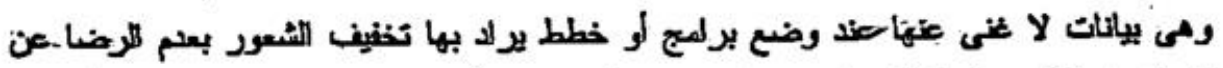

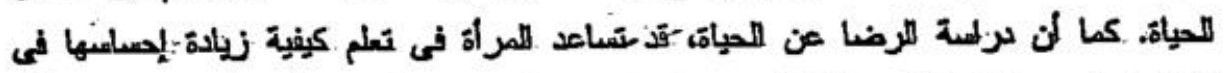

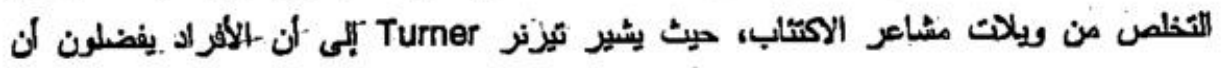

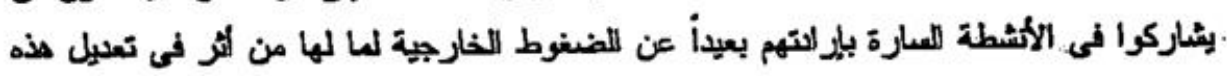

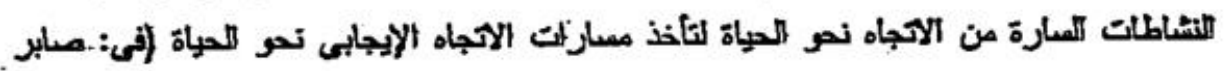
حجازى، 1998 198).

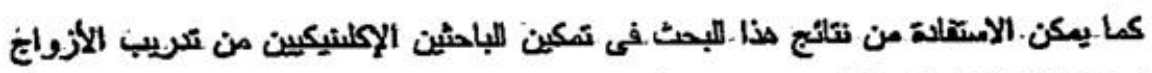

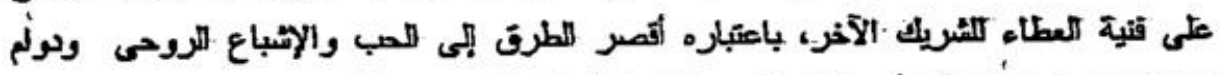

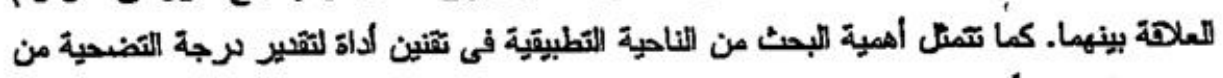

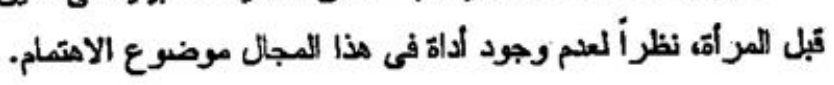

تعلد المصطحلت: |- المتفحية:

تعرن التضبحية بائها "سلوك اليجلبي يقمه الفرد تجاه الآخر، تاتج عن شعود اللقرد يالآخر،

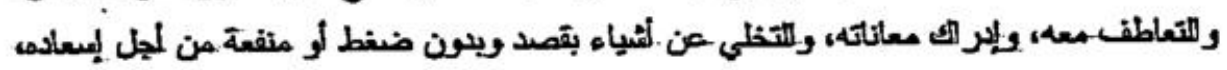

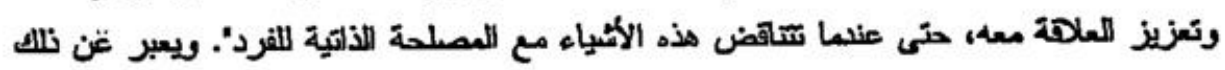

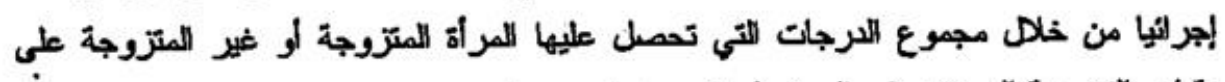

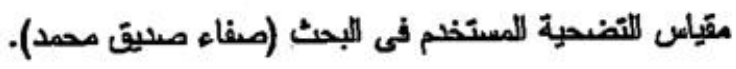
r- برضا عن المياة:

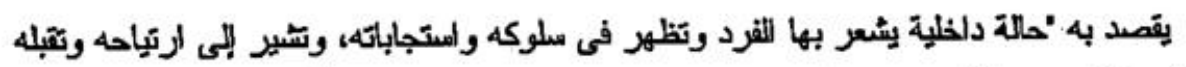

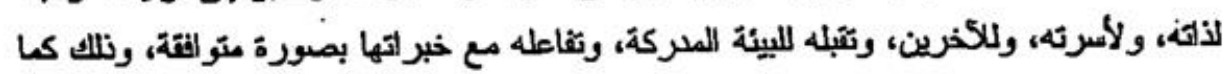

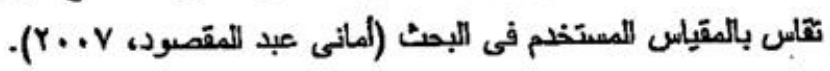
= 
三 التضضحية وعلاقتها بالرضا عن المياة لدى المرأة المتزوجة وغير المتزوجة.

الإطار النظرى والمفاهيم الأسناية:"

1-التضضحية:

تعرف التضحية في اللغة: مصدر ضدى 'بذل الثفس أو العمل لو المال أو المصلحة في سبيل

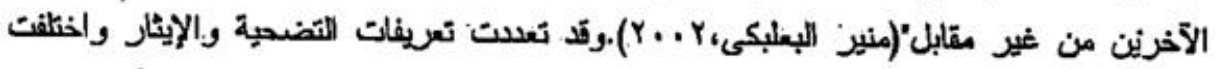

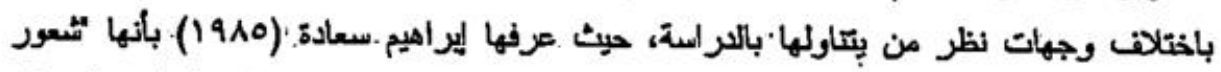

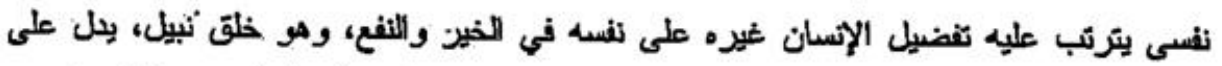

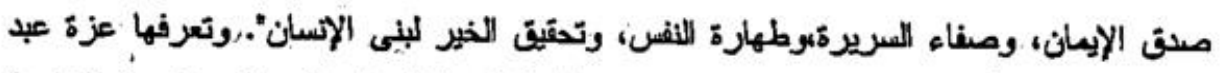

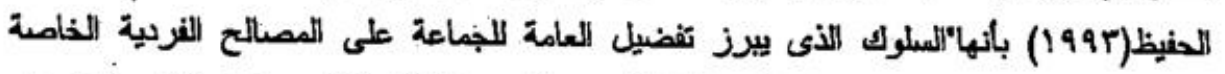

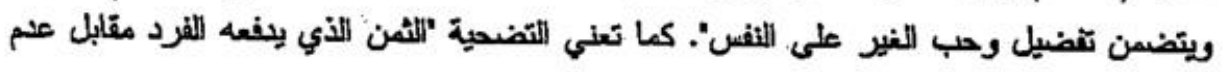

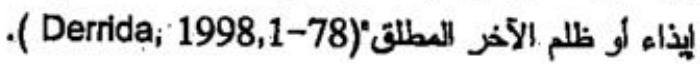

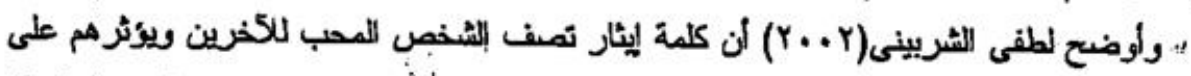

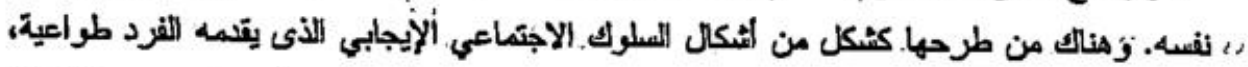

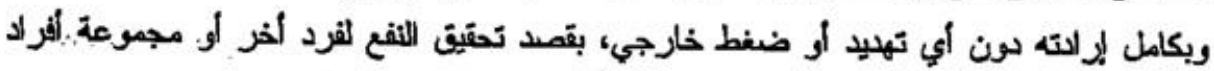

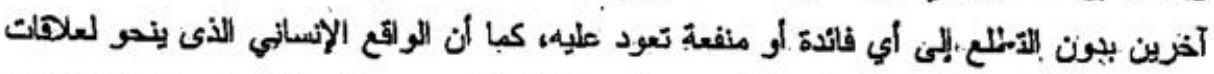

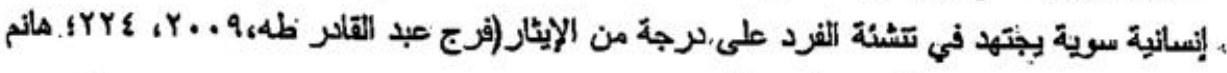

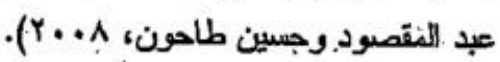
فالسلوك الإيثاري هو السلوك الإنى.يقوم به فاعله. من قمد لنفع الآخر حتى. عندما يخاطر

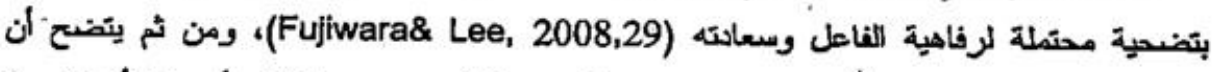

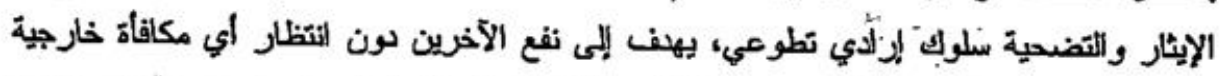

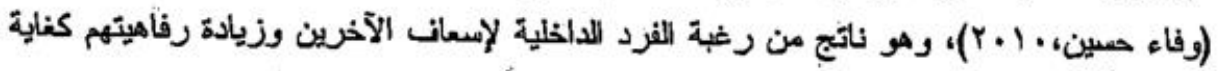

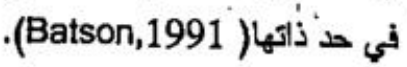

وقد جرت إلعادة أن يكون مفهوم اللفحية موضوبوا سائدا في النظريات العلمية فالتضحية تعتبر

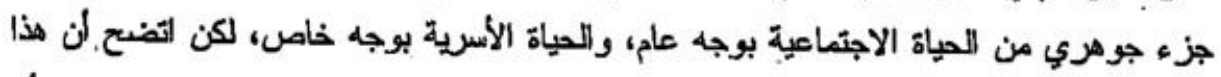

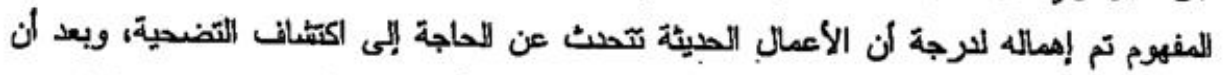

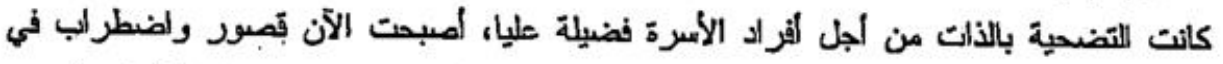

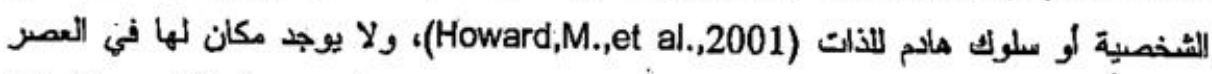

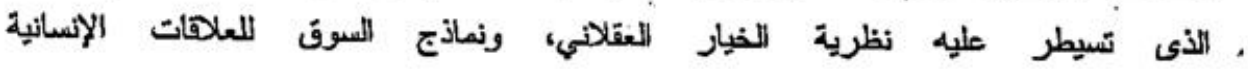
.(Mizruch,1998,29)

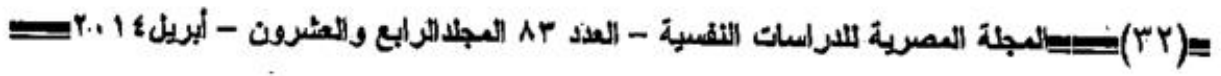


الد / أماتى عبد المقصود عبد الوهاب \& د/ صفاء صذيق محداس

وتعتبر التضحية مفهومأ موجودا في جميع الليانات والثقافاتب، يلل على الرشيد والمعرفة الأنسانية والوصول البى برجة عالية من النضج والكمال اللزوحي، ومفهومه في الإسالم له ميزة

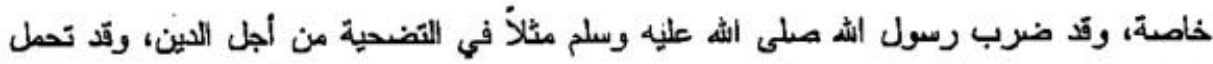

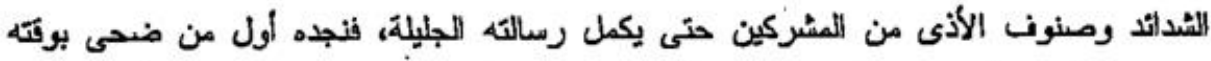

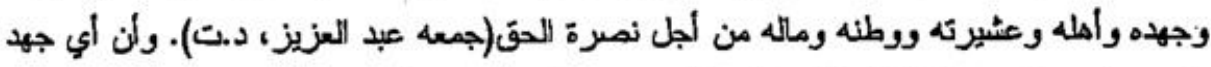

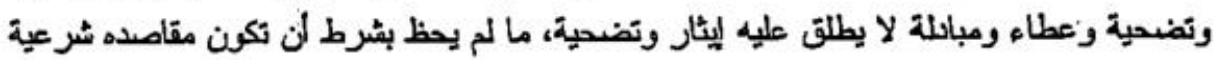

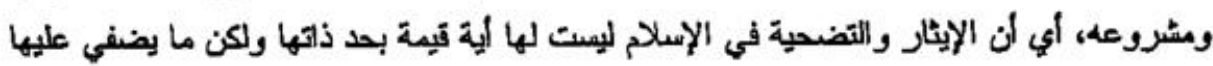

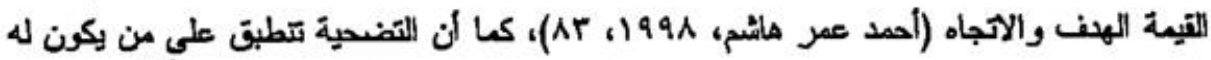

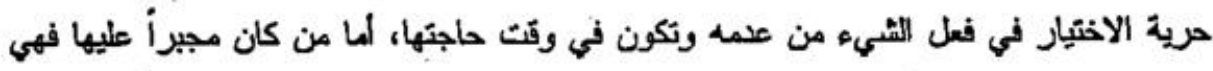

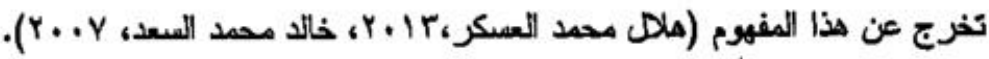

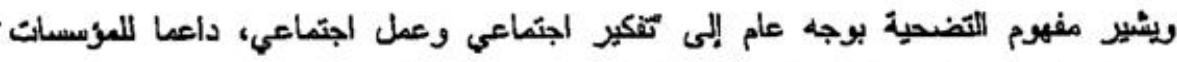

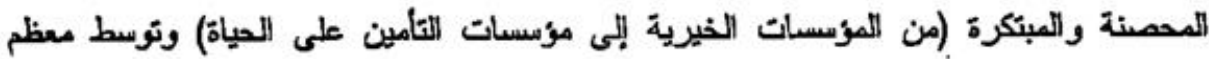
التطورات الأكثر تعقيدا" (Mizruchi, 1998, 23).

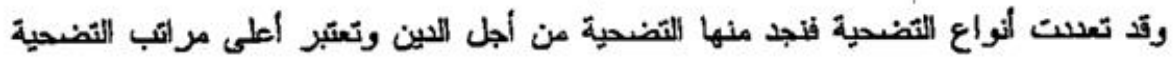

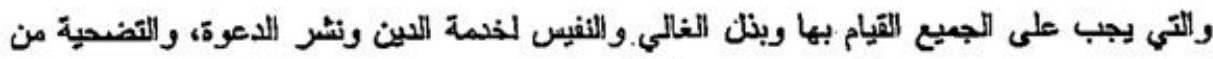

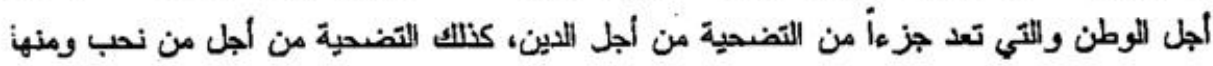

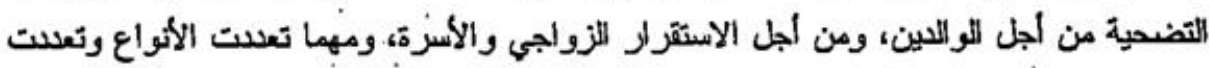

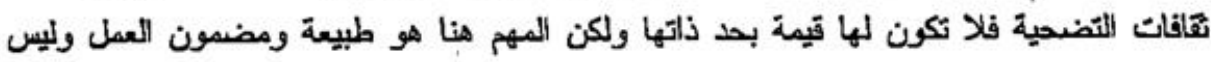

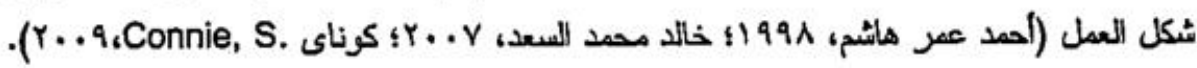

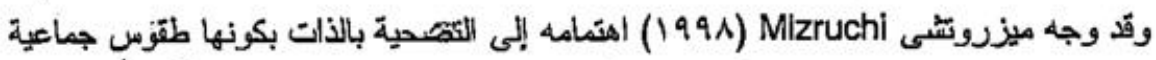

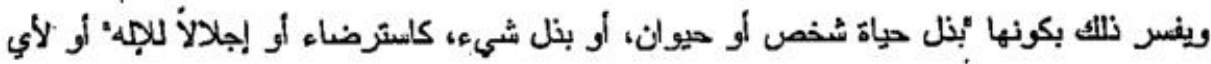
خير الجتماعي يحل محل الإجلال في المجتمعات الحيثئة.

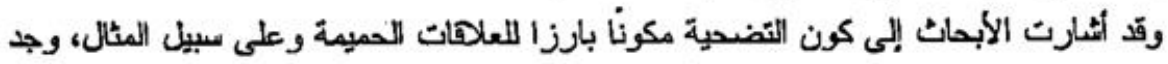

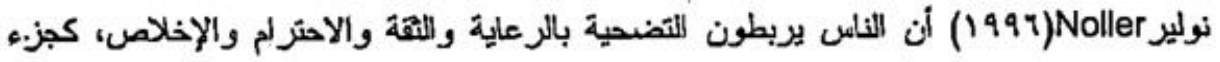
من مفهومهم. لما تعنيه كلمة "الصب". وفوق نلك، تشئر نتانج عليدة من أبحاث "الإيثار" إلى أنه كلما

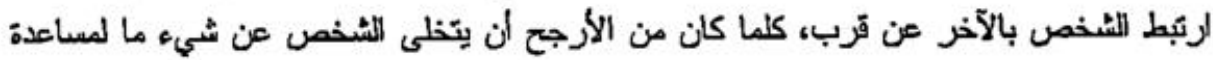

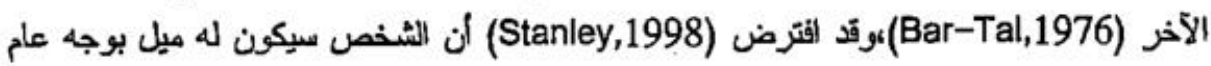
اللتضحية للآخر عند وجود هوية قوية للزوجين ورئية طويلة المدى اللعلهة.

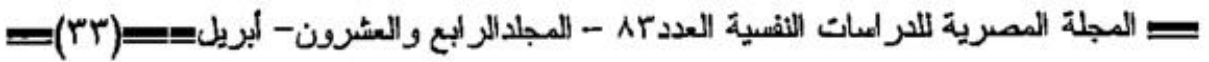


= التضعية وعلاتهها بالرضا عن الحياة لاى المراة المتزوجة وغير المتزوجةت

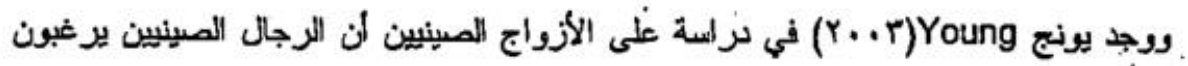

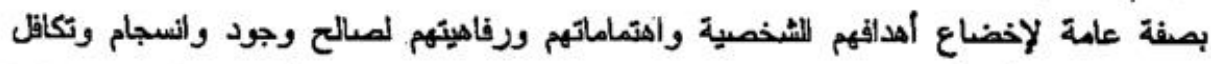

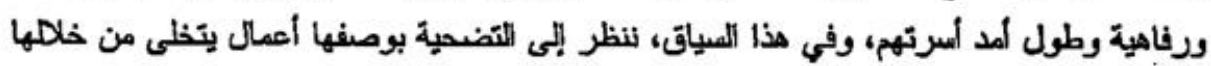

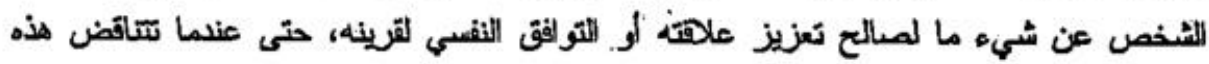

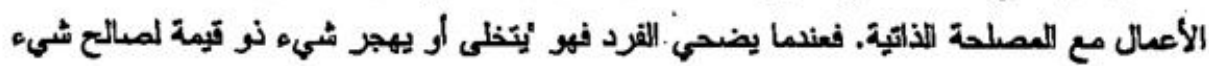

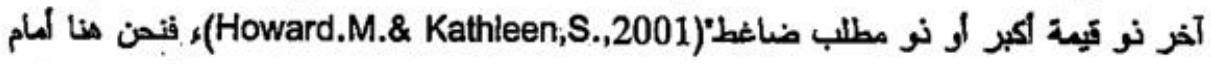

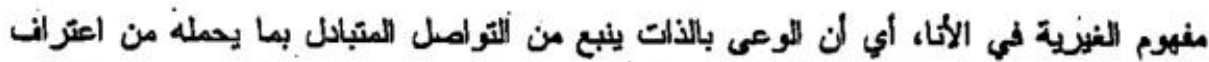

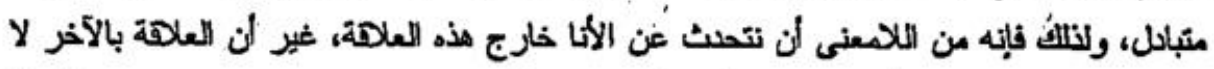

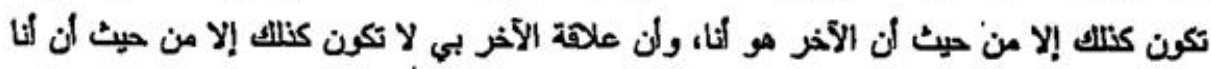

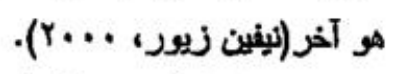

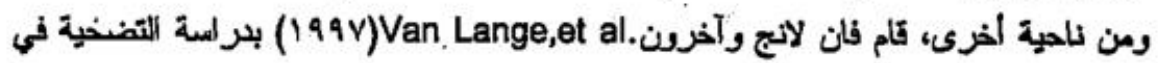

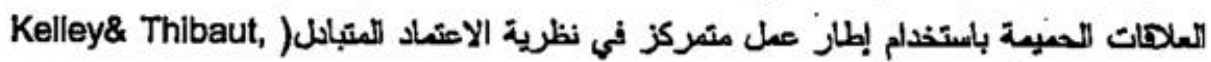

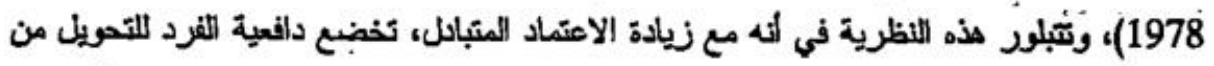

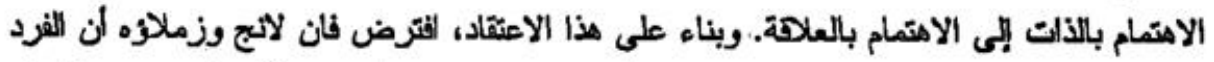

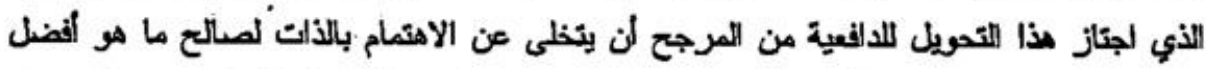

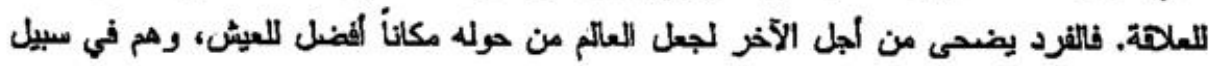

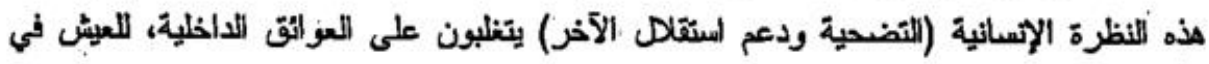

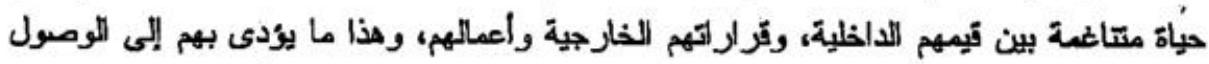

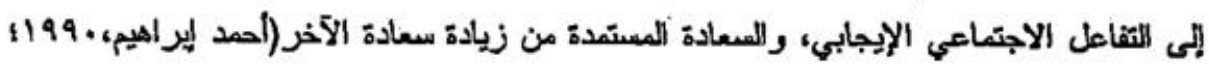

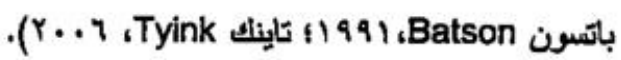

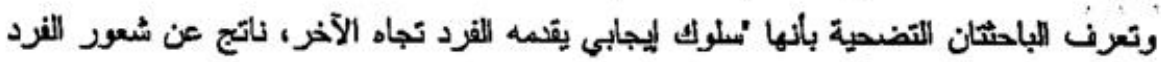

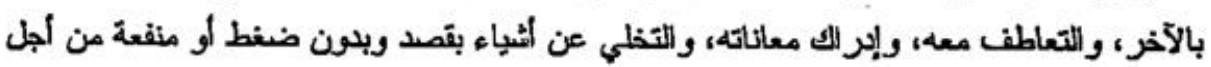

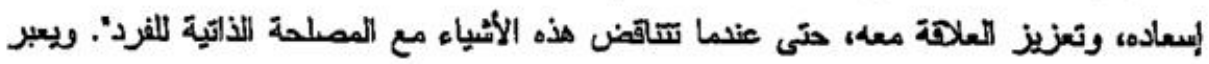

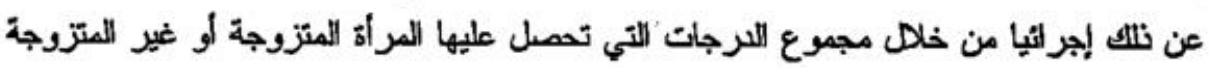
على مقياس التضدية المستخم. التضحية والالتزام بالعلاقة:

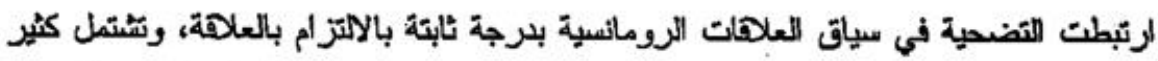

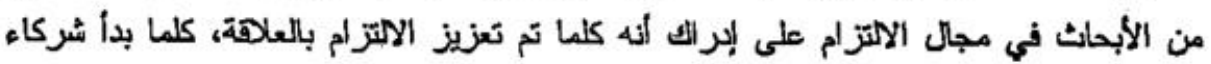

ب) = 


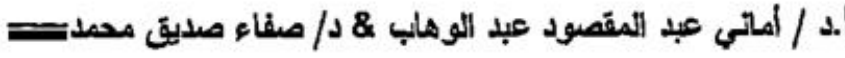

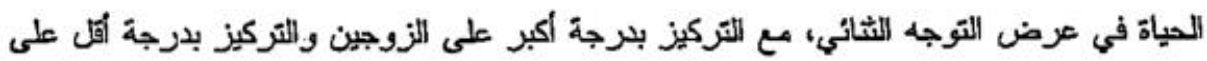

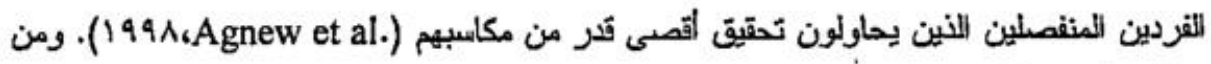

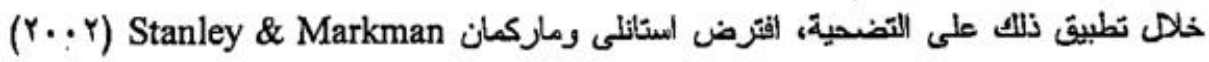

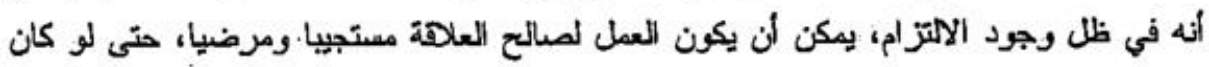

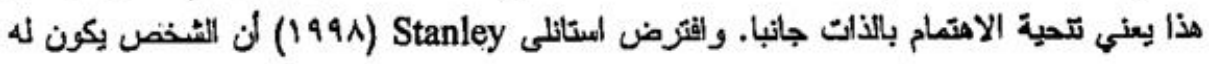

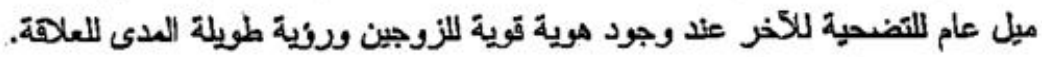

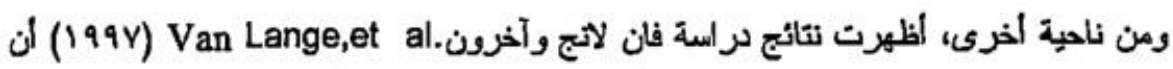

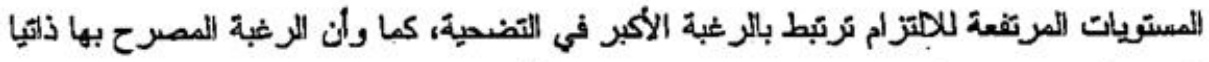

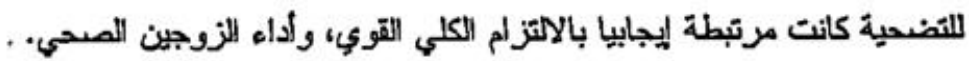

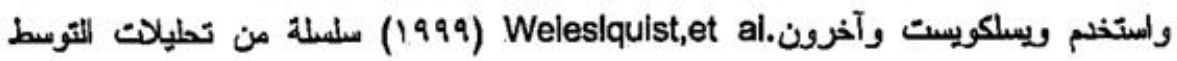

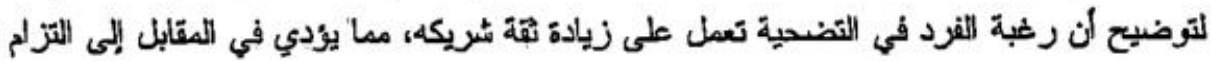
أكبر بالعلهة ورغبة أكبر في التضحية لصالح شريكه. ولنلاك تبدو أهية التضنحية في عملية النمو

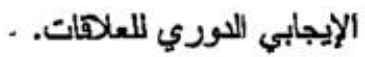
التضحية وجودة العلاقة:

لا ترتبط. التضحية بالآتزام ثقط، لكن. توجد أيضا شواهد 'تشير إلى ارتباطها بالأباء الجيد

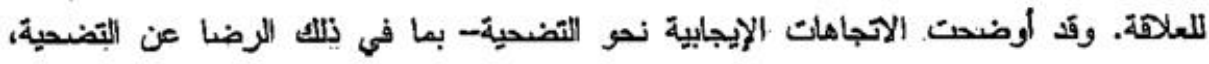

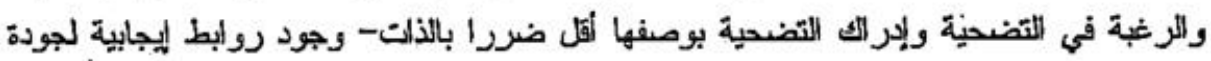

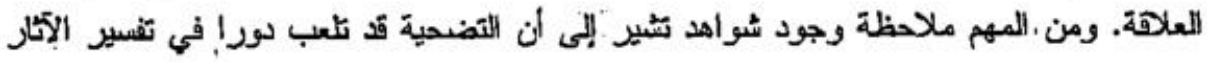

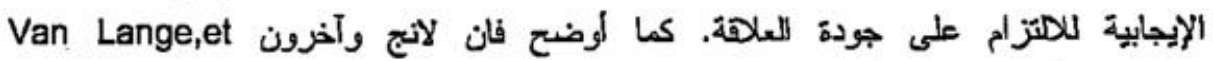

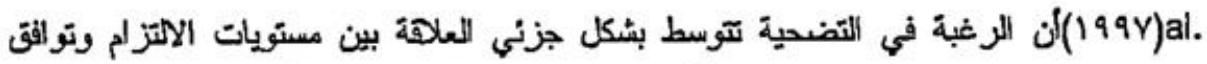

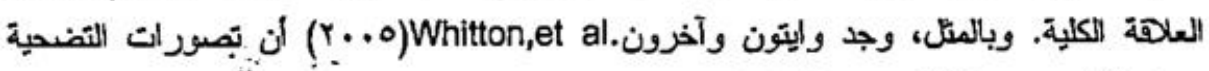

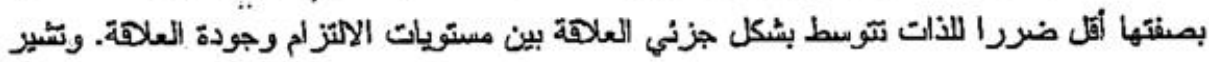

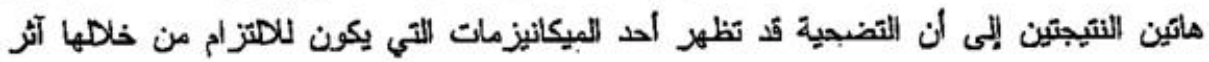
اليجابي على توالفق العلاقة.

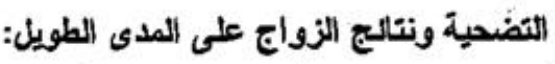

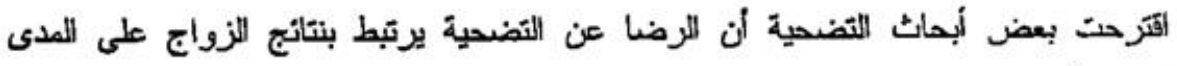

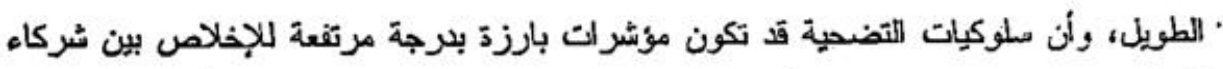

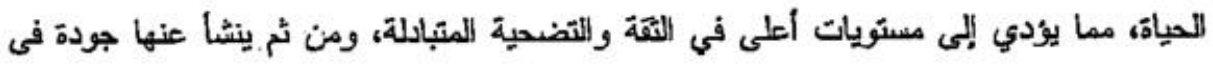

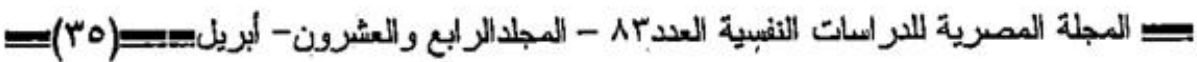


= التضمية وعلاتكها بالرضا عن العياة لدى المرأة المتروجة وغير العتزوجةت

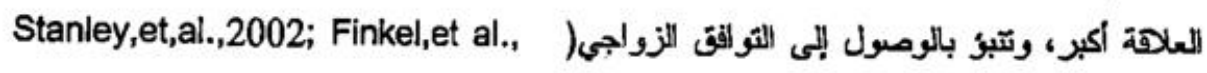

.2006

خصائص التضصية:

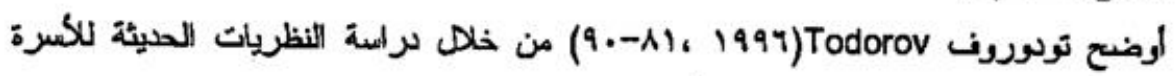
بعض الخصائص الخاصة بالتضحيات كما يلى:

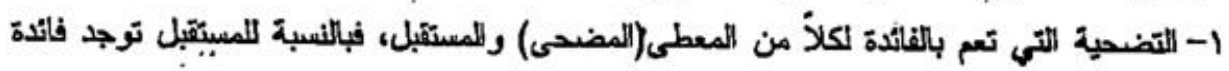

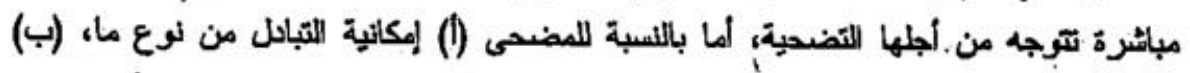

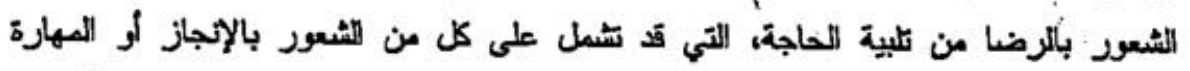

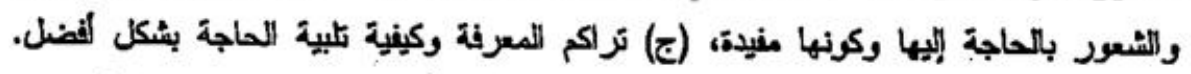

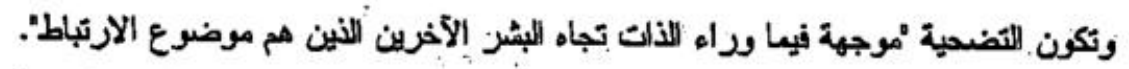

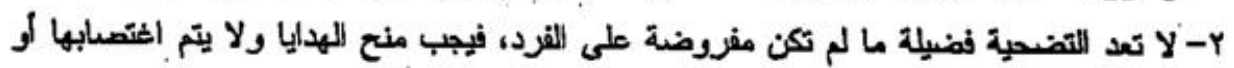
تمتيمها بلا وعى.

r- تساعد التضحية في جعلنا بشر، حيث يحتاج الفرد المشاركة فه المنح والثلقى.

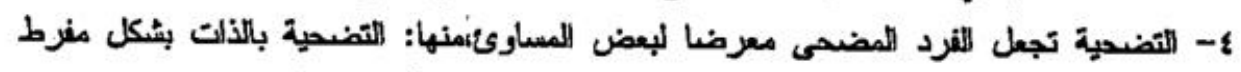

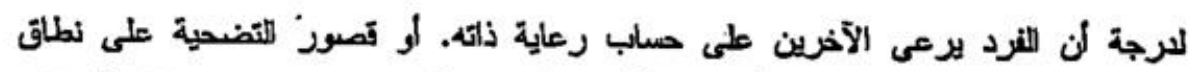

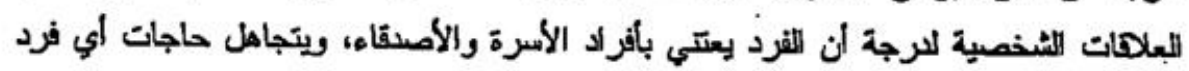

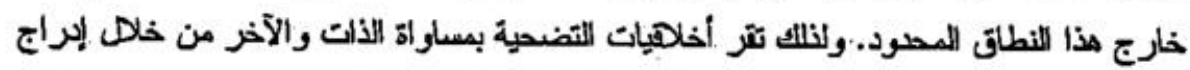

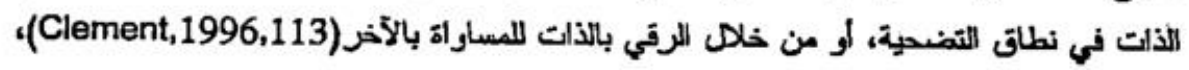

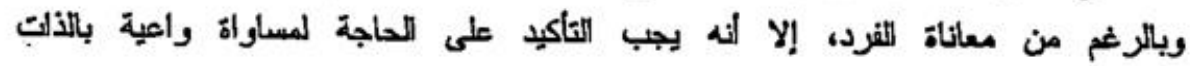

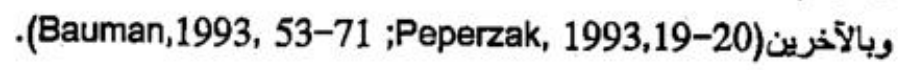

التضحية وعلاتتها بيعض المشاهيم ذات الصطة:

:Forgiveness lل المطو

يعزفه ميشيل وبلزيت Micheal\&Everett

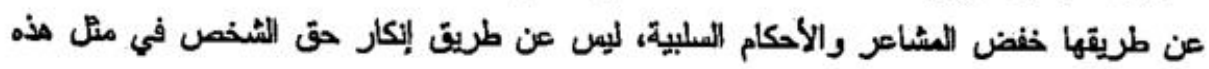

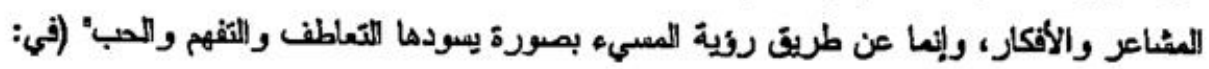

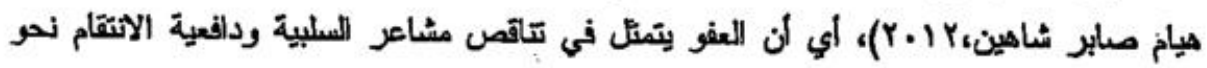

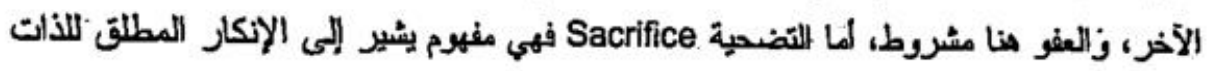
(Impett, Emily ,et al,2012) غير المشروط Self-denying

= 


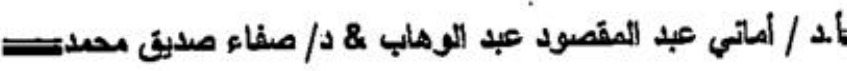

:Tolerance

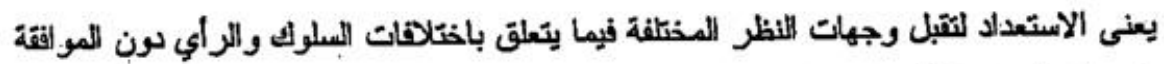

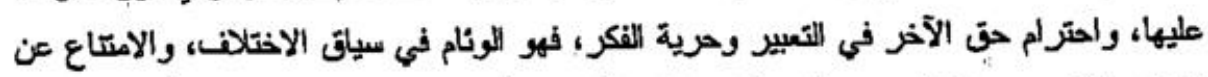

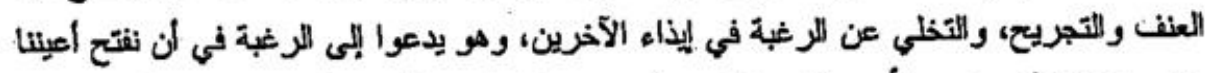

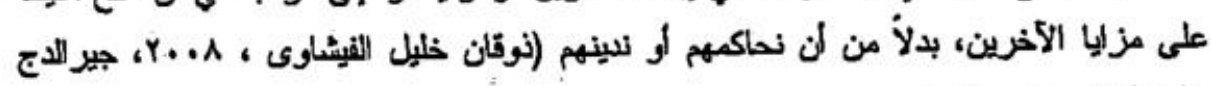

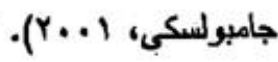

الإكبتية: Egolsm

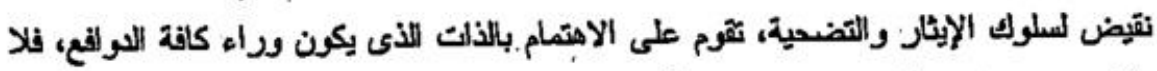

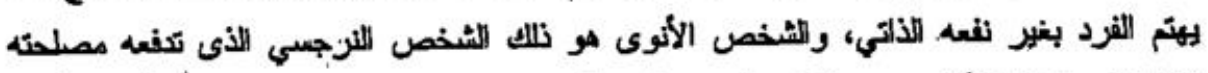

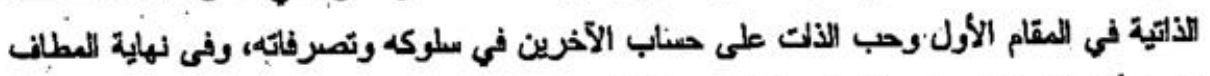

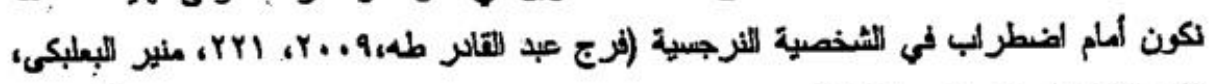

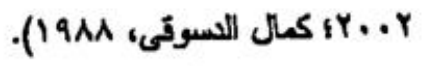
الاحجامات المنظرية لتبنسير لالثضحية: - الاججاه البيولوجئ: يوضح أمحاب هذا الاتجاه أنه يوجد في اللماغ منطقة في الفص الجيهي من المخ بالثصفين

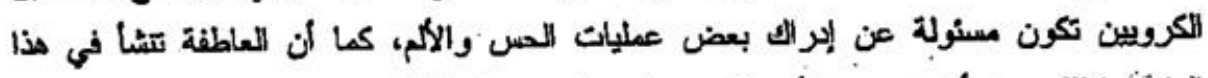

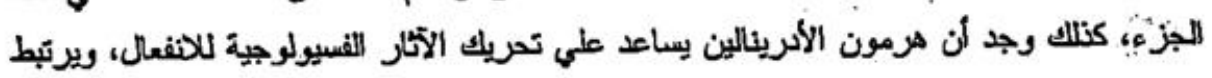

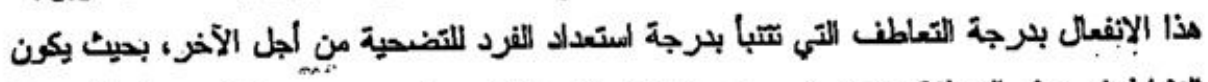

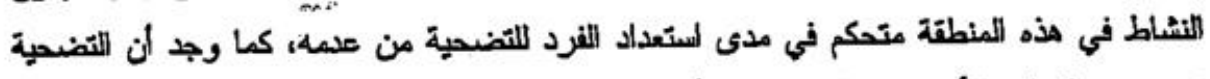

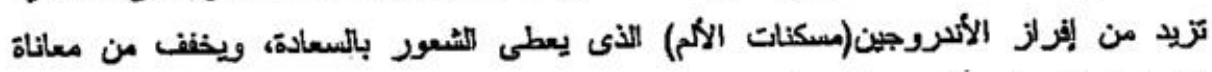

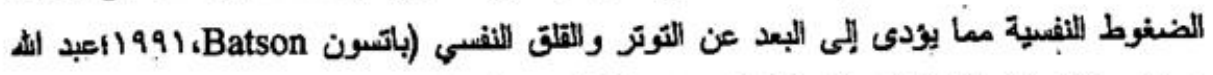

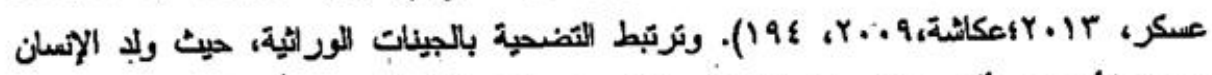

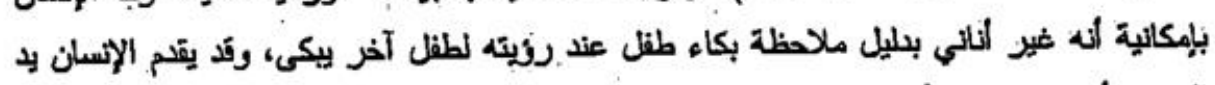

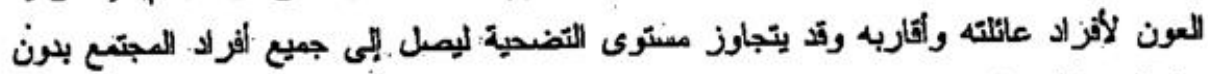

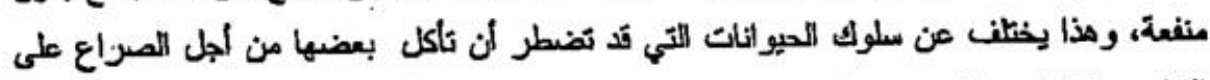

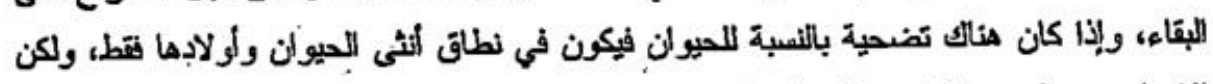

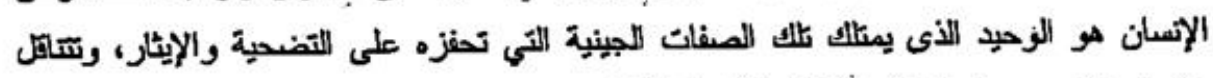

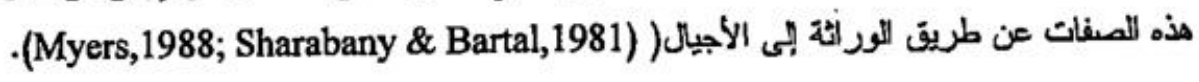
$=$ 
= = التضخية وعلاقتها بلارضنا عن العباة لدى المرأة المتزوجة وغير المتزوجةت

Empathy Induced Altruism المرية التعاطف المؤدى إلى الإيثار(الايثار التعاطفى) ماحب هذه النظرية دانيال باتسون . Batson,D (1991)، حيث يشير إلى أن البشر قادرون

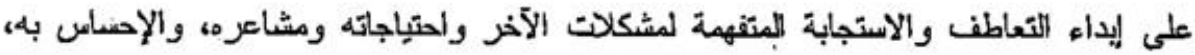

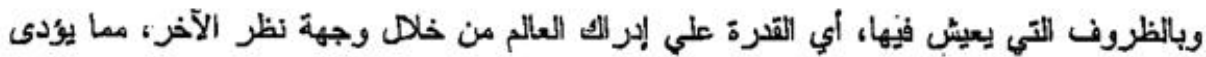

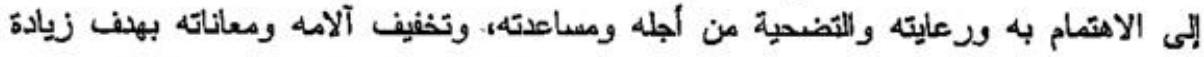

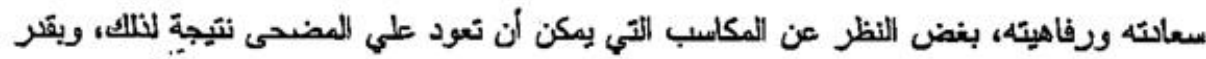

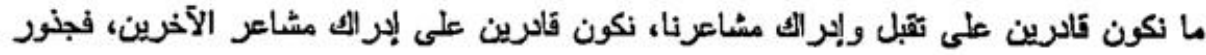

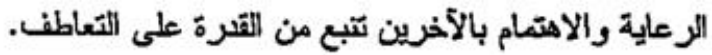

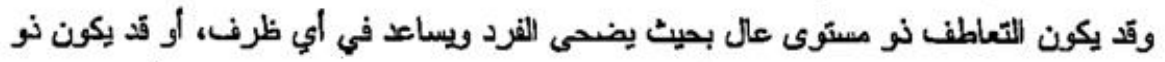

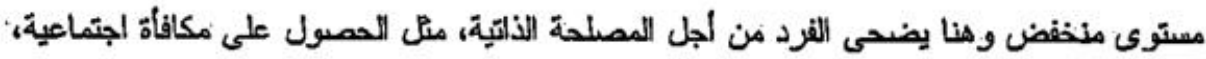

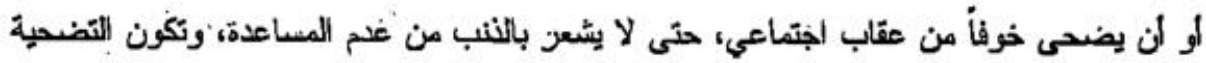

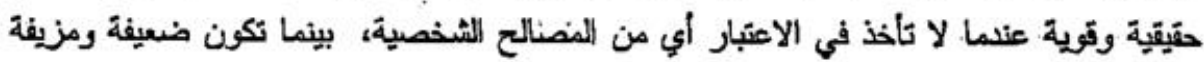

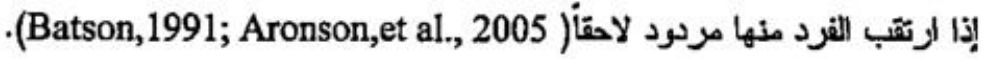

-الاحجاه اللعبكودينامى للتضحية:

يشير "قرويد" إنى لر أولى تضصيات الطفل في المرالحل الأونى لتكوين شخصيتها، هـى المرخطة

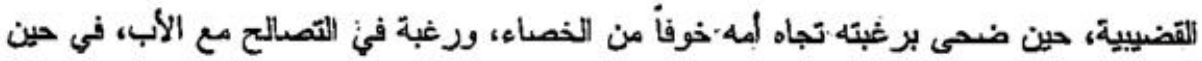

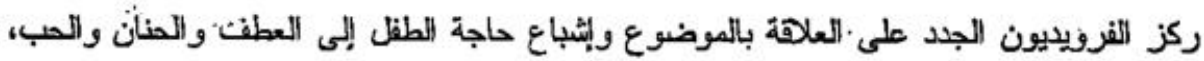

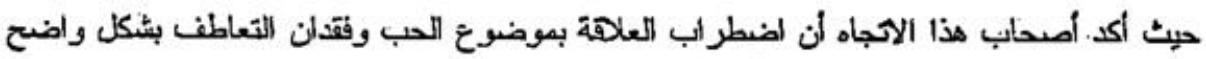
خلال مراحل نمو الطفل يمثل مرجأ في تطور اضطر اب الشخصية الثرجسية، التي تثميز بالأنانية والاقتمار إلى القرة على التعاطف، وغيز مبالية أو مكترثة بمشاعز الآخرين وحاجاتهم، واستغلال

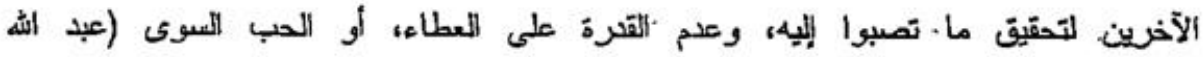

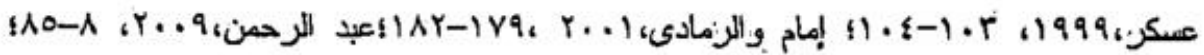

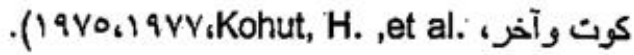

- الاحجاه العلوكي:

يرى أمحاب النظرية السلوكية أن التضحية تكون بمثابة لستجابة ورد فعل يتم تعليه خلا المتشئة الاجتماعية، ناتج عن تقليد ومحاكاة الفرد لسلوك الآخرين المحيطين به عن طريقت الملاخظة، والنمذجة، وهو سلوك استجابى يخضع اللثولب والعقاب عن طريق التعزيز

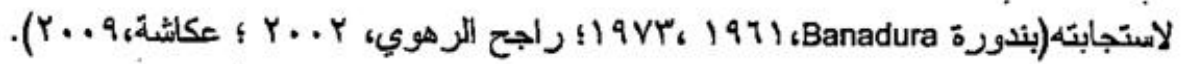

=(r人)= 


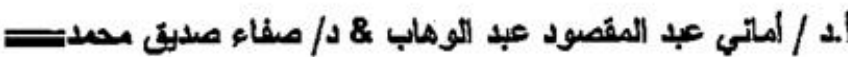

-الاحجاه العلوكي المبرفى: يرى أمحاب هذا الاتجاه التضحية كملوك أخلاهي لمساعدة الآخرين تكون مع نطور نمو

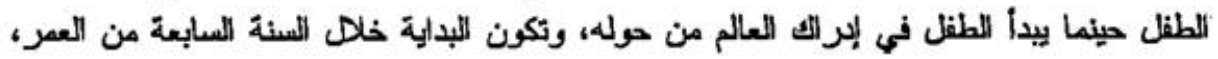

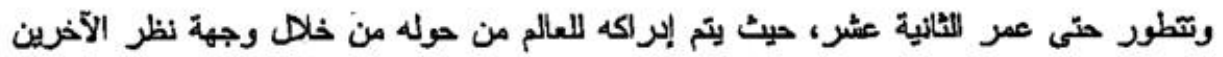

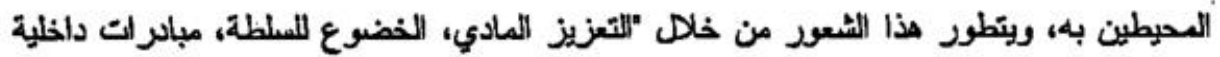

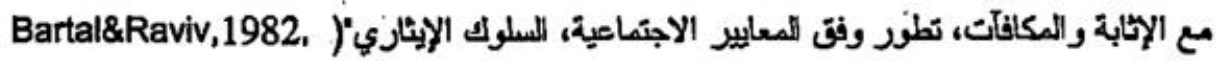

.(Rushton, 1981

تعتبب:

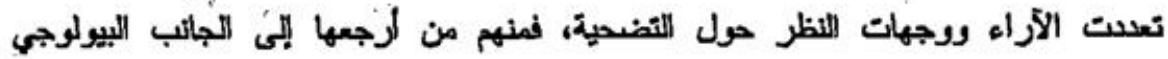

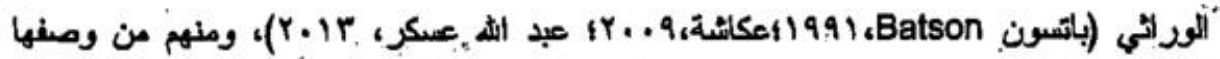

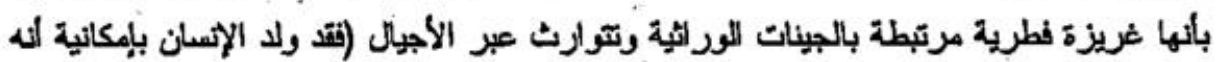

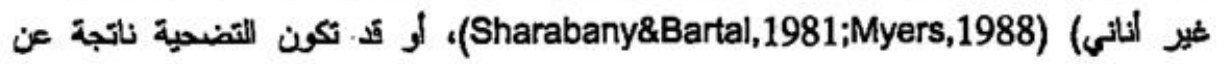
التعاطف مع الأخر، والقرة على إبرالك العالم من خلاله وجهة نظر الآخر، مما يودى إلى الاهتمام

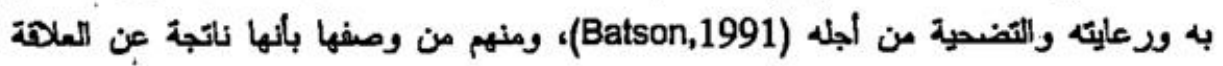

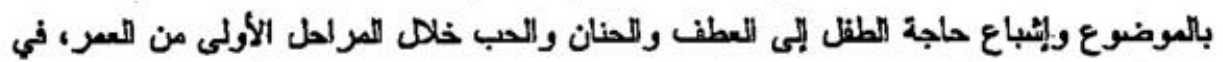

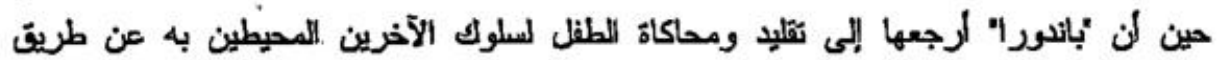

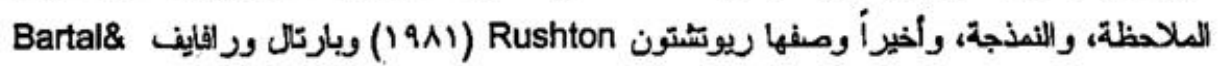

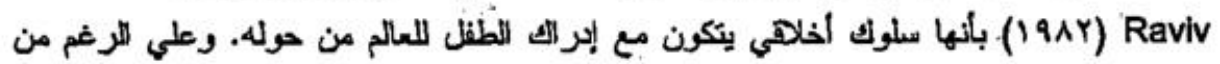
تعد النظريات التي تفسر التصحية إلا أنها جميعا تكل بعضها البعض، فلا يمكن فصل الجائب

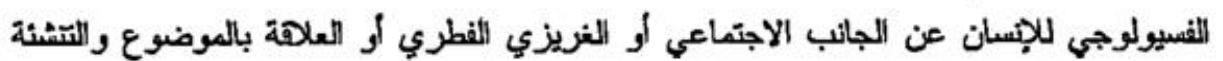
اللواللية للطفل، فالتضصية كسلوك ناتجة عن تفاعل جمبع وجهات النظر في سُكيل شخصية اللفرد.

Lاتياً: الرطا عن الحباة: Life of Satisfaction يعد الشعور بالرضا Satisfaction واحدا من المكونات الأساسية للمعادة، ومؤشرأ من

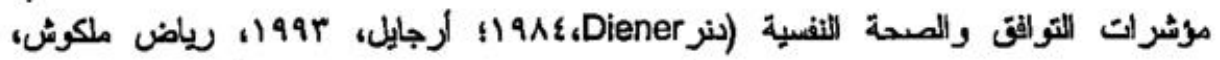

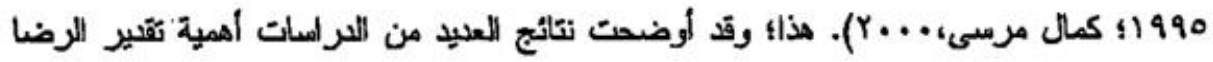
عن الحياة فى فه اللسعادة التفعية. حيث يحلد الشبور بالرضا القروق فى مكونات السعادة الأخرى

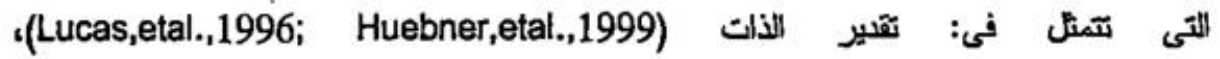

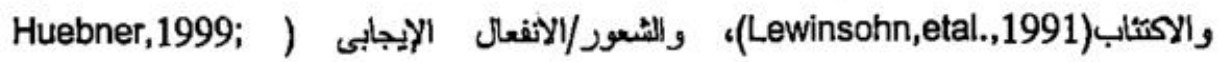

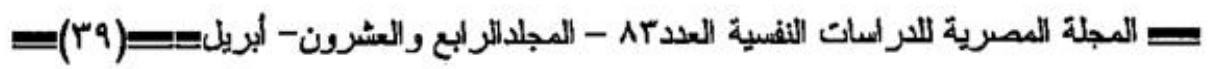


= التضحية وعلافتها بالرضا عن العياة لدى المرأة المتزوجة وغير المتزوجةت

.(Lucas,et al.,1966; Huebner\& Dew, 1996

ويعرن الشعور بالرضا عن الحياة Life of Satisfaction بانه "ثوع من التقدير الهادئ.

والمتامل لمدى حسن سير الأمور". وهو تقدير عقلى لنوعية الحياة التى يعيشها الفرد ككل أو حكم

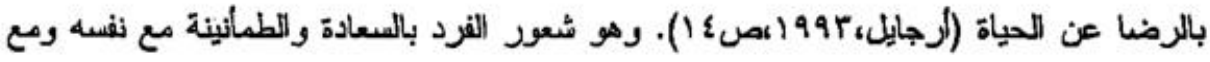

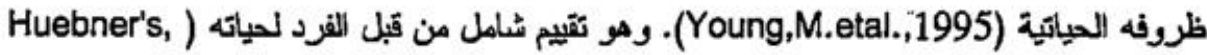

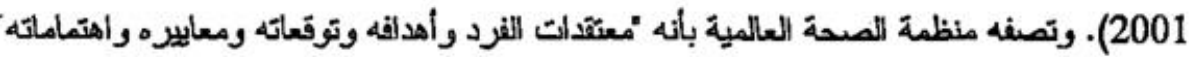

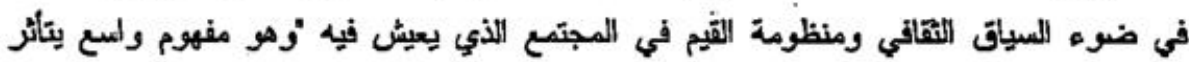

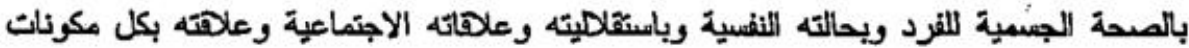
البيئة التي يعيش فيها (The" WHOQOF" Group,1998).

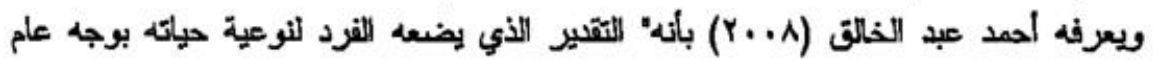

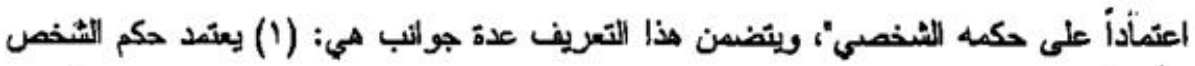
على تقديره الثخصى وليس كما بحده غيره (Y) يحلد الفرد بنفسه المعايير التي يقيم على أساسها

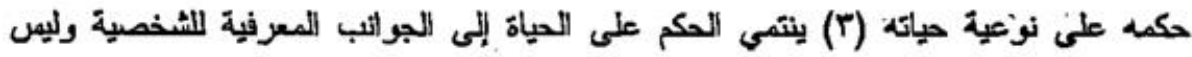

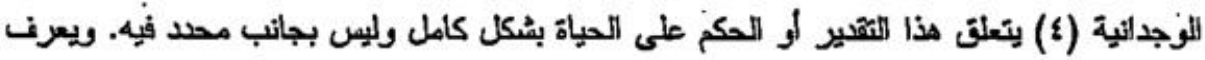

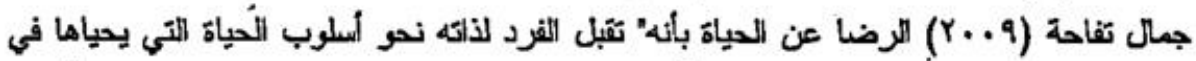

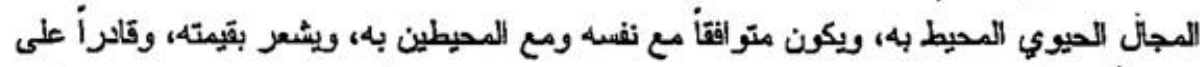

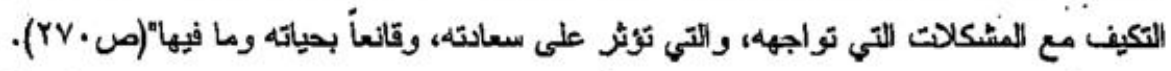

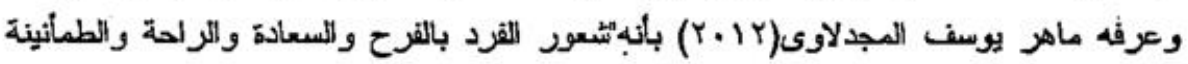

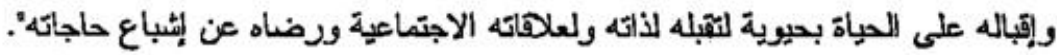
ويرتبط الثعور بالرضا عن الحياة ارتباطل عكسيا بالعديد من الاضطر ابات النفسية وللتى مـن

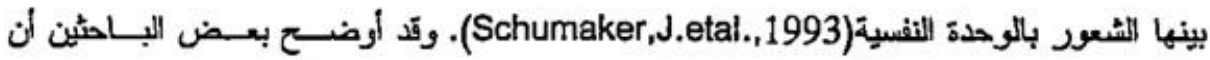

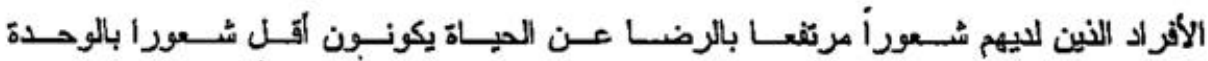

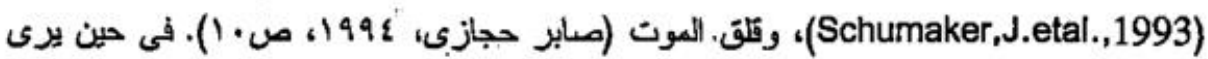

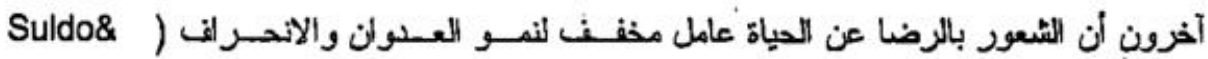
.(Huebner, 2004b

الاحجاهات إنظطرية فى تثعبير الترضا: حاولت بعض النظريات تفسير الرضا وتحيد هصاره، ومن أهم هذه النظريات ما يلى: 


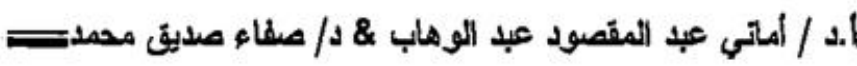

| | نظرية المواتض:Situational Theory

يرى أمحاب هذه النظرية أن الأنسان يرضى عن النياة عندما يعيش فى ظروف طيبة، يشعر فيها بالأمن والنجاح فى تحقيق ما يريد من أهداف: ب) نطرية الخبرات السارة: يرى ألصحاب هذه النظرية أن الأنسان يرضى عن حياته عنما تكون خبراته فيها سارة

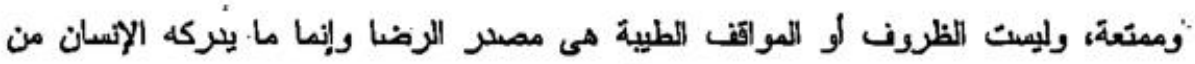

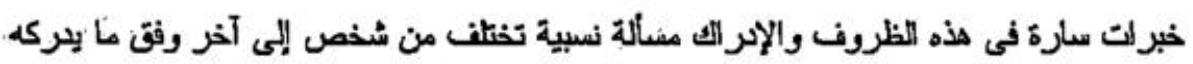

$$
\text { منها فى الموتف من خبرالت ممنعة أو غير ممنعة. }
$$

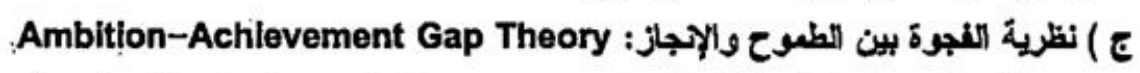

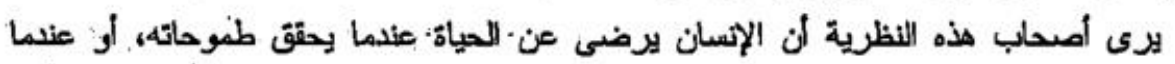

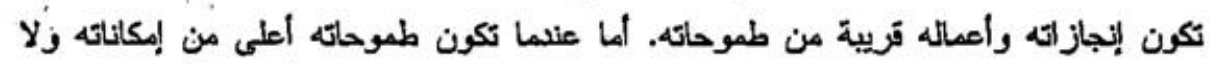

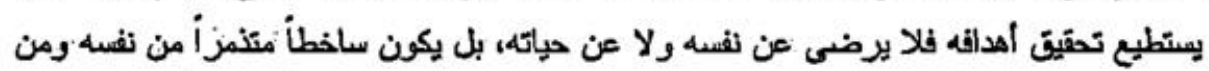

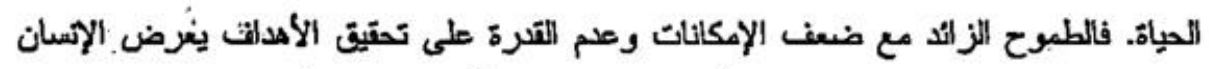

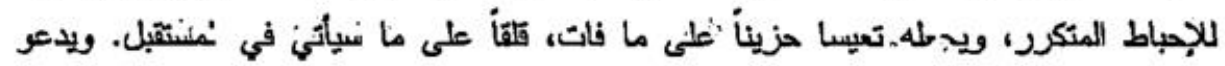

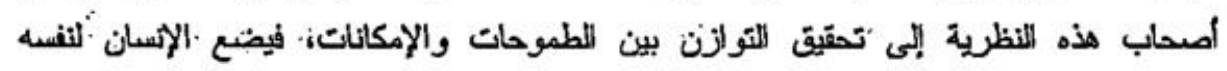

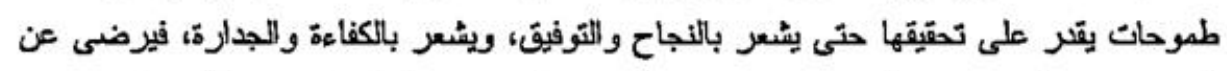
نفسه وعن حياته ويسعد بها.

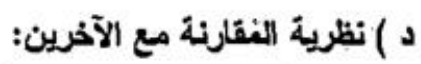

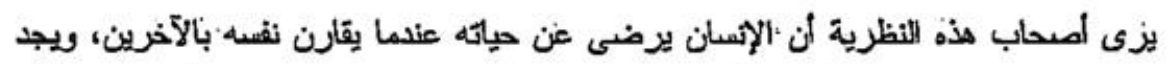

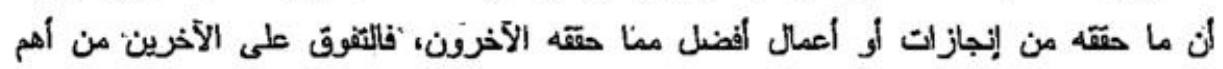
همادر الرضا عن الحياة.

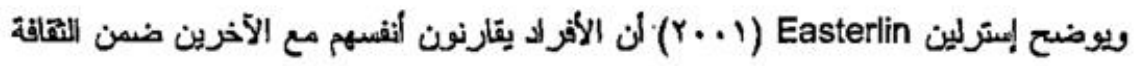

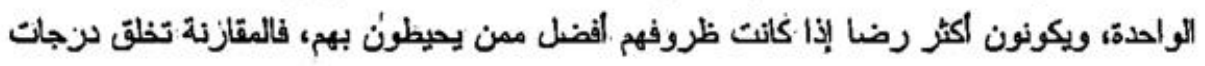

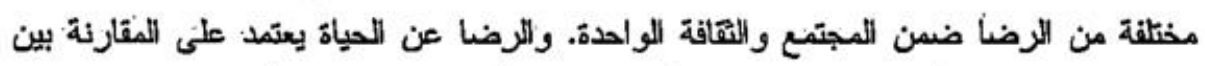

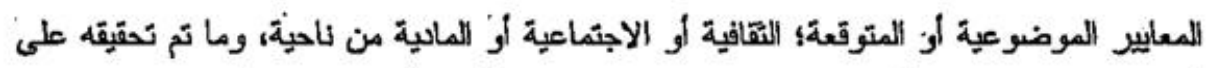

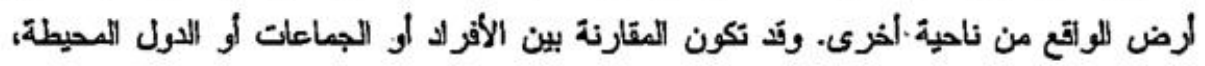
وبالتالي تختلف ررجات الرضا عن الحياة باختاف المعايير الذاثية والاجتماعية والاهمنالية.

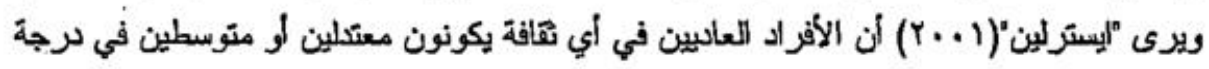

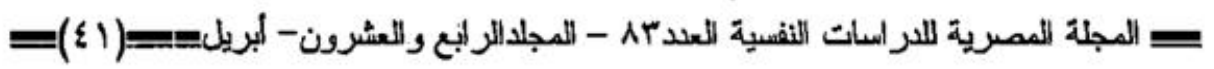


= التضحرة وعلاقتها بالرضا عن العياة للى المراة المتزوجة وغير المتزوجة =

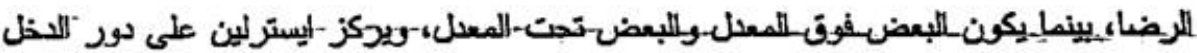

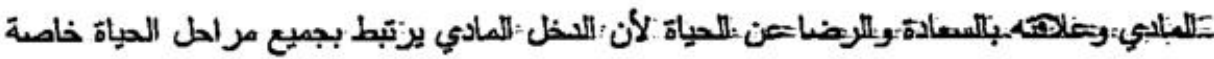

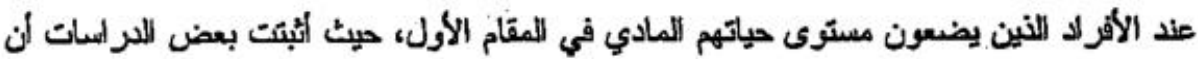

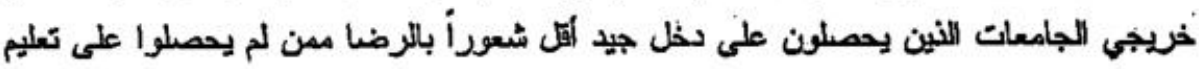

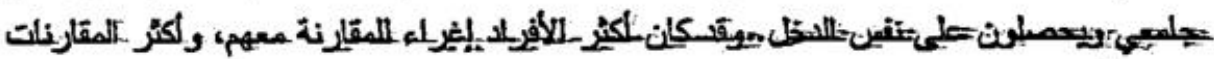

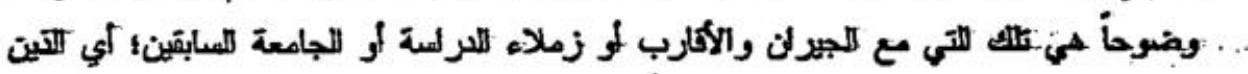

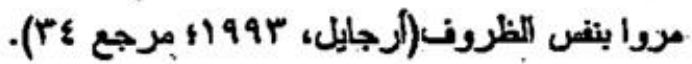

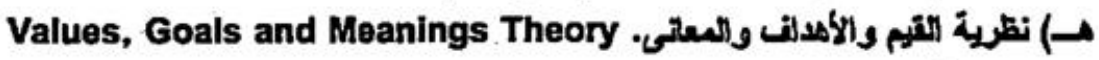

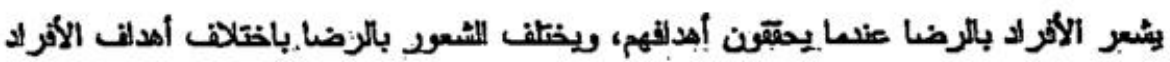

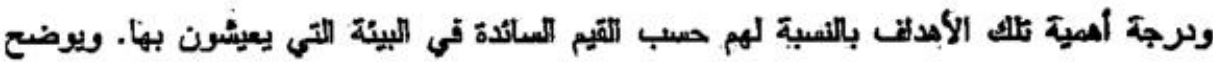

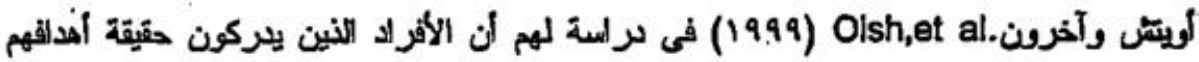

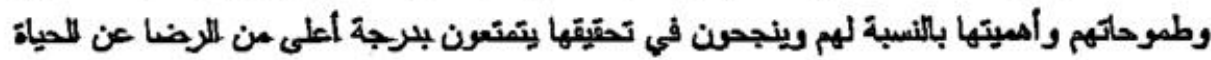

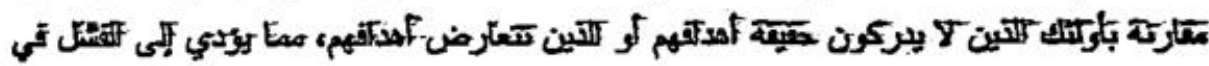

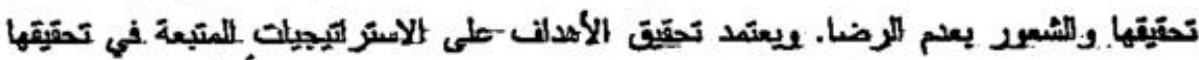

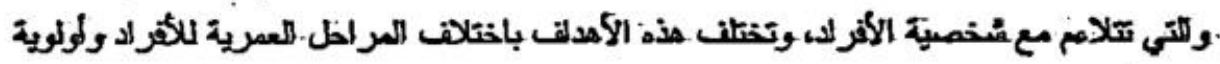
هذه الأهدلف.

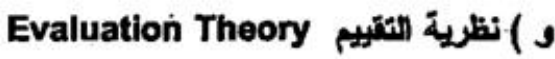

تزى هذه للظظرية أن اللشعرر بالرضا يمكن قياسه من خلا عة معبيير، واحد هذه المعايير

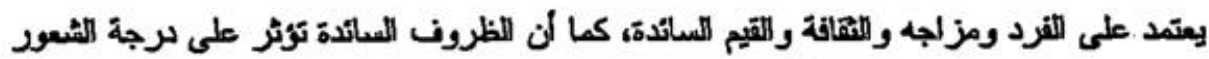

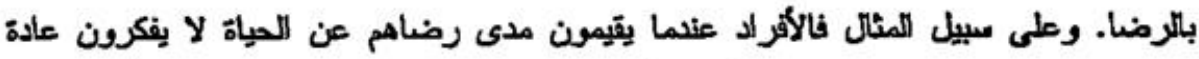

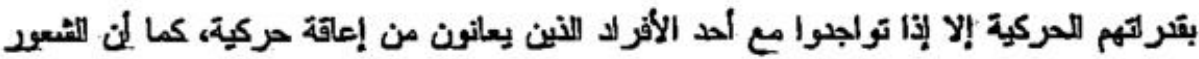

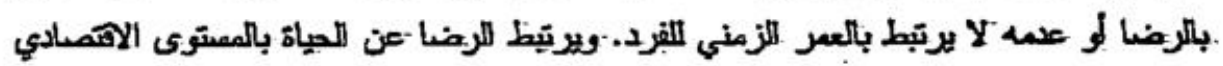

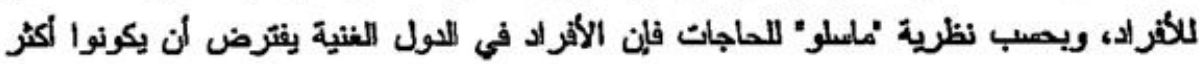

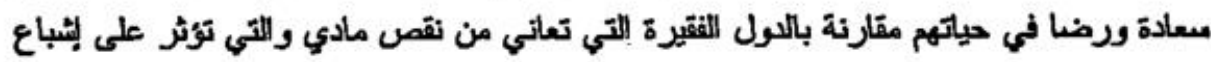

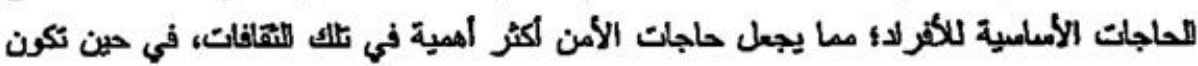

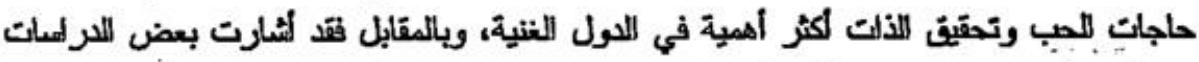

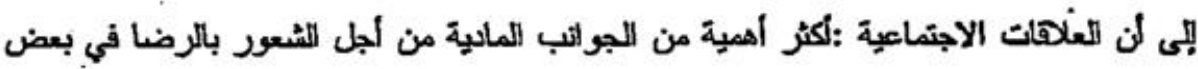

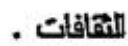

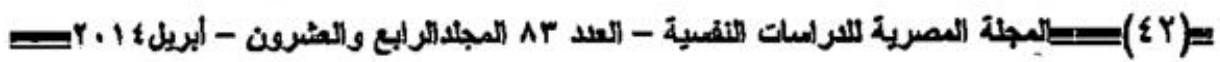




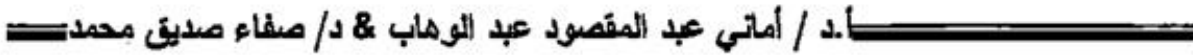

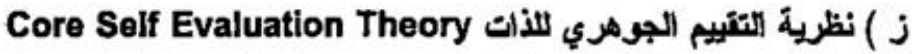

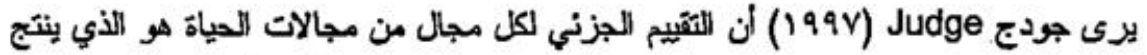

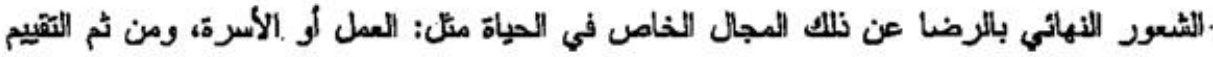

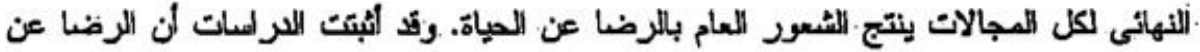

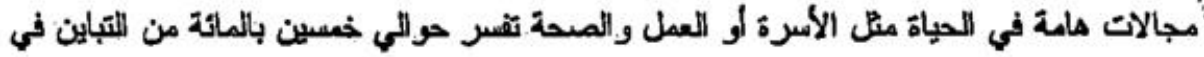

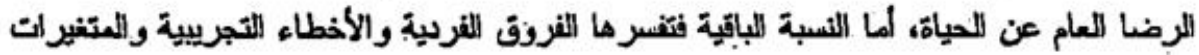

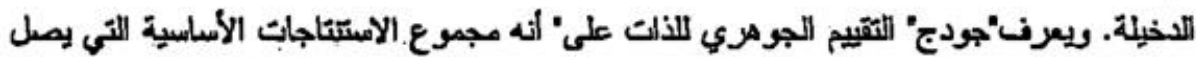

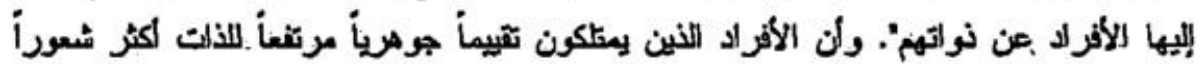

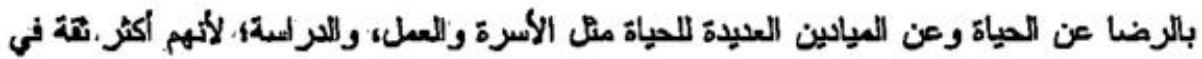

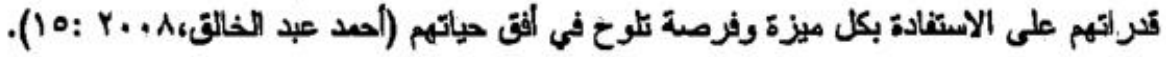

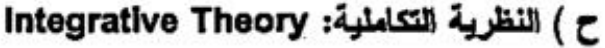

مع اختلاف النظريات السابقة فى تفسير الرضا عن المياة فلن المتامل فى أفكارها يجدها متكاملة

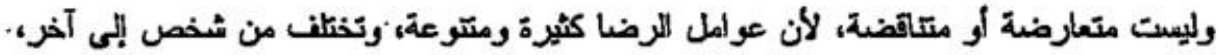
وتختلف فى الهخص الواحد من وقت إلى آذر، فبعض الفاس يرضون عن الحياة عندا تكون ظرون المياة-طيية، وتسير وفق ما يريون، وغيرهم يرضون عنها عندما ينركون الخبرات

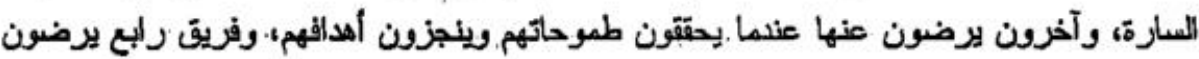

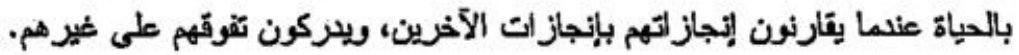

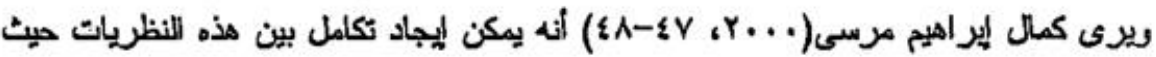

$$
\text { أنها تخرج يبعض عوامل اللرضا عن الحياة وهى:- }
$$
1- أن بعيش الأتسان فى ظروف طيية شعره بالأمن والطمانينة.

r- أن يدرث الخبرات السارة التى تمتعه وتبره. r- أن يحقق أهدافه فى الحياة ويتغلب على الصعبريات التى تواجهيه.

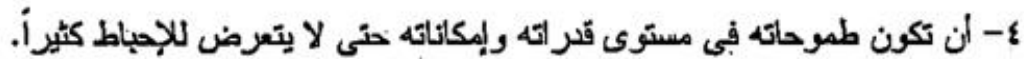

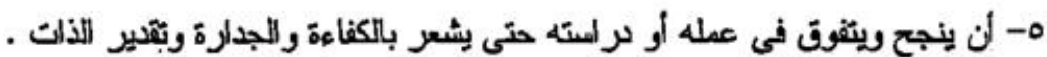
كما يتضح من الدراعات التي تناولت عاهة الشخصية بالرضا عن لالحياة أنه يوجد ثلاثية اتجاهات رئيسية في هذا المجلا، حيث يطلق على الأول اتجاه التاع-القمة، والثاني اتجاه القمة-القاع، ويطلق على الثانث الآجاه الانفعالي.

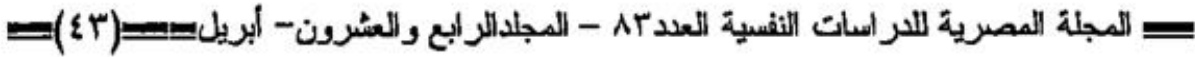


= التضحية وعلانتها بالرضا عن الحياة لدى المرأة المترجة وغير المتزوجة=

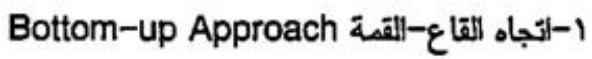

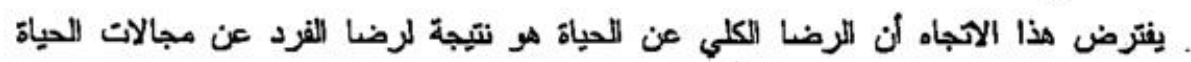

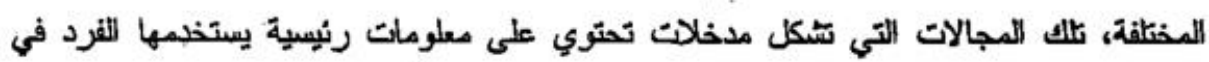

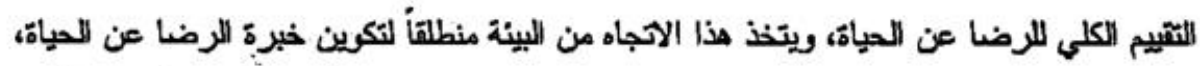

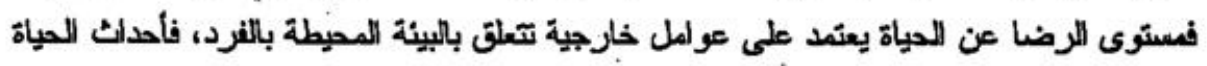

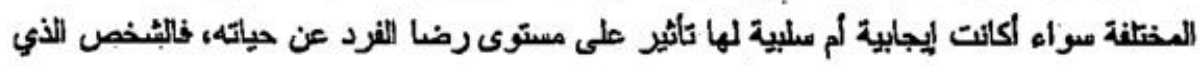

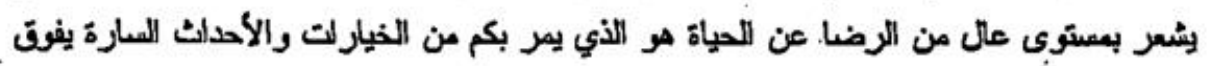

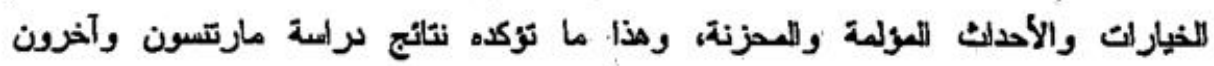
(1910) Martinson,et al.

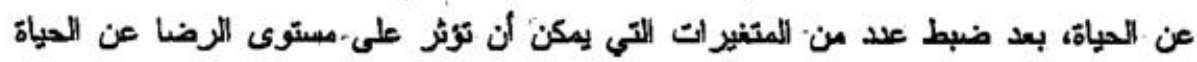

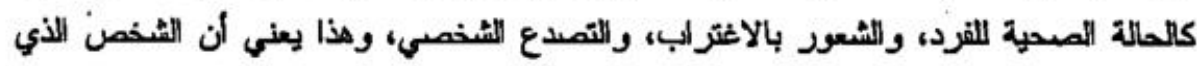

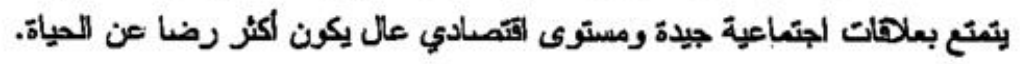

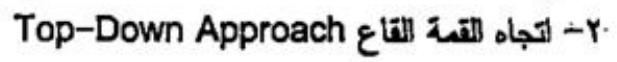

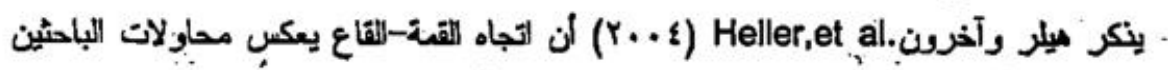

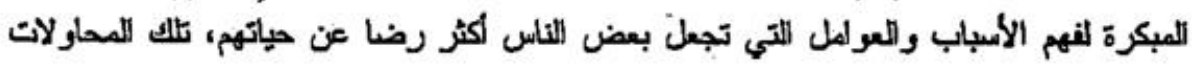

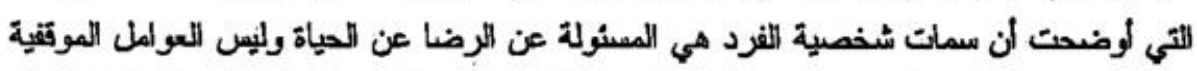

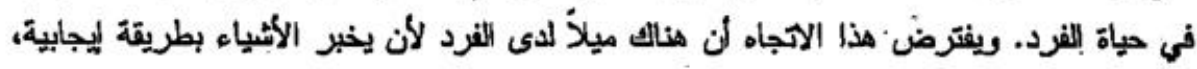

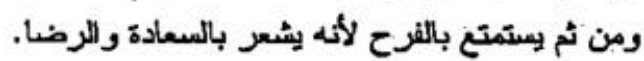

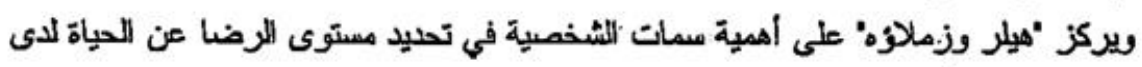

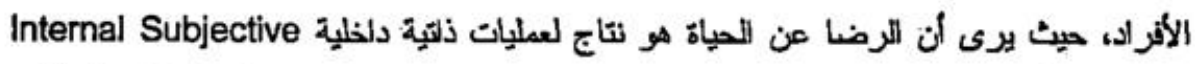

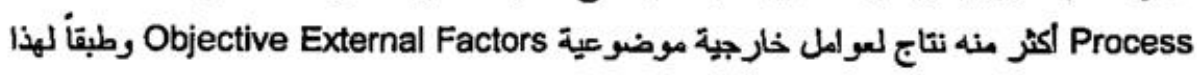

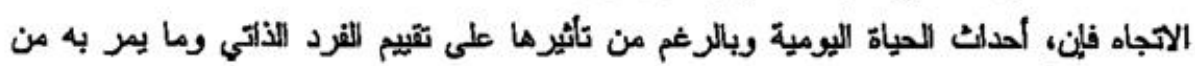

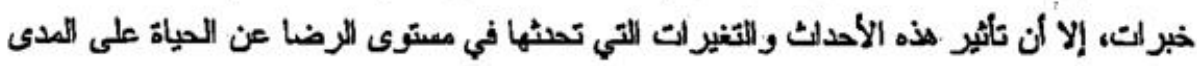

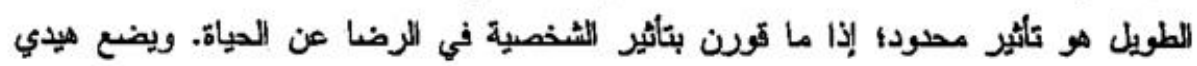

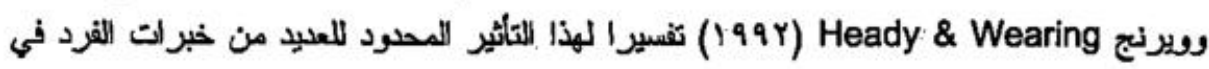

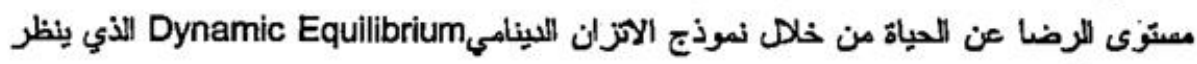

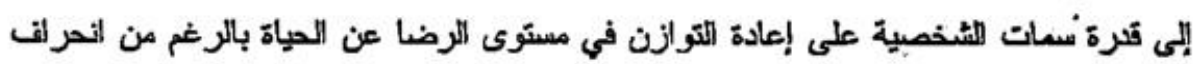

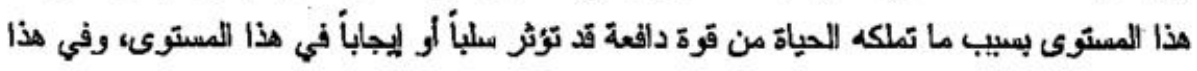

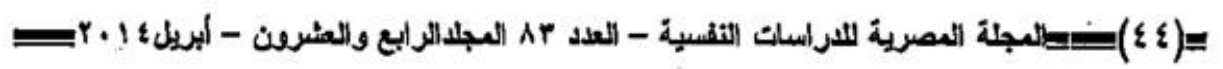




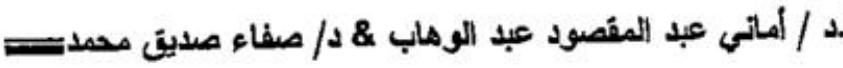

المسد يرى مكري وكوستا McCrae\&Costa (1991) وجود علهة بين عوامل الشخصية

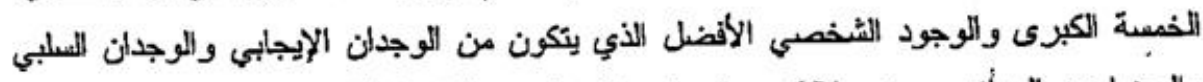

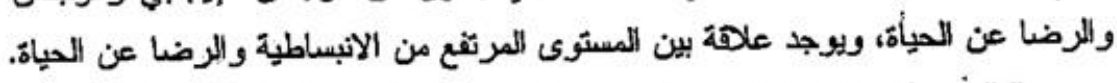

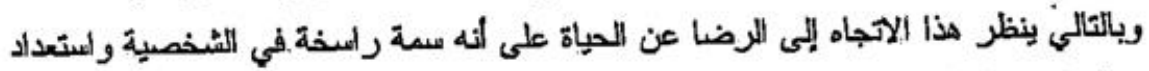

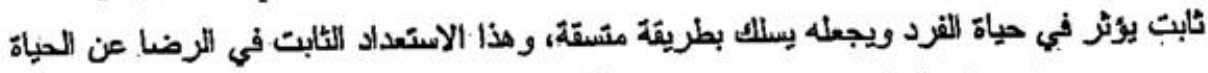

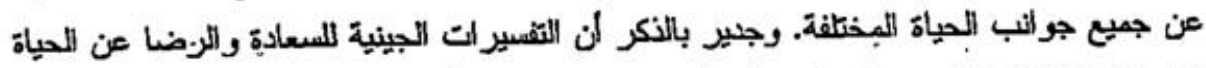

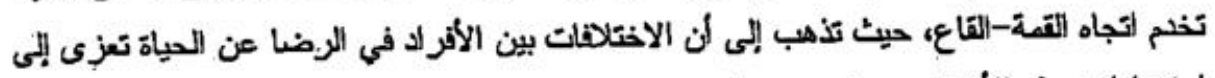
العتعدادات يولد الأشخاص مزودين بها.

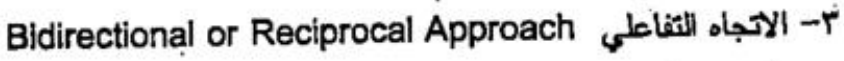

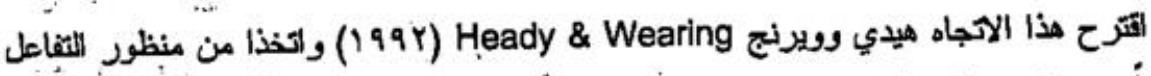

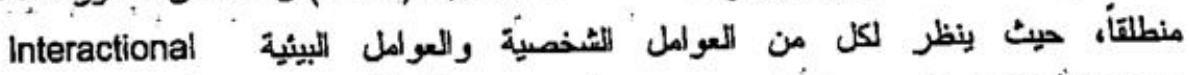

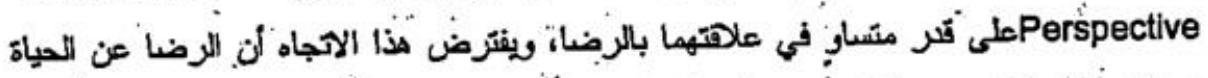

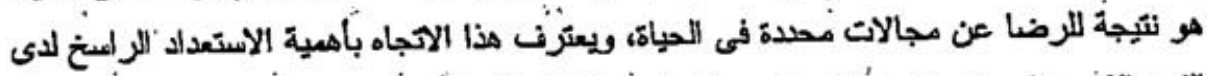

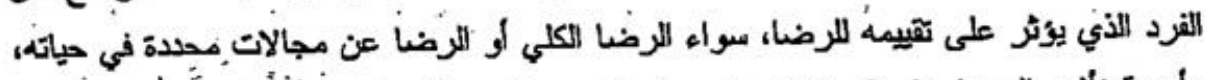

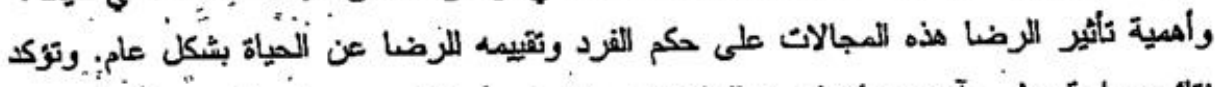

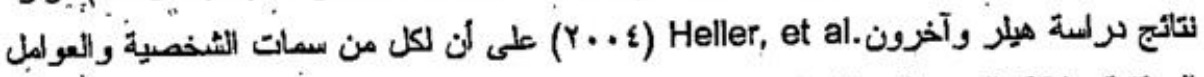

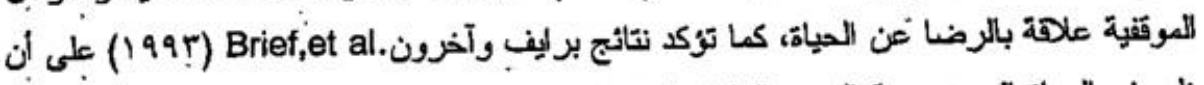

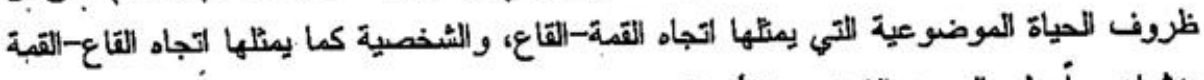
يؤثران معاً على اللوجود اللشخصي الأفضل.

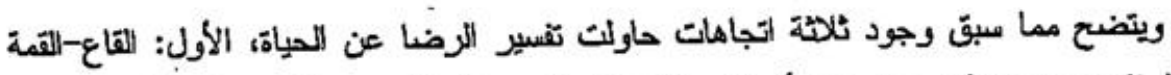

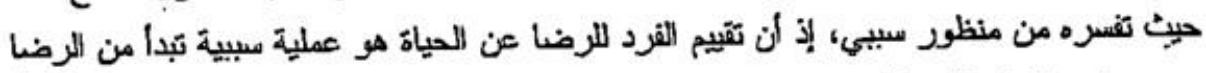

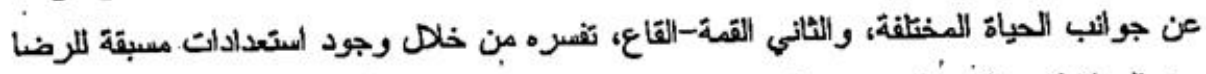

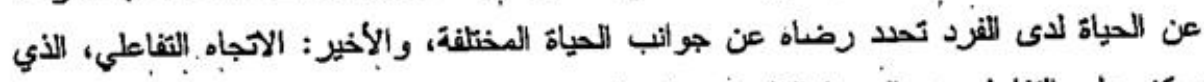

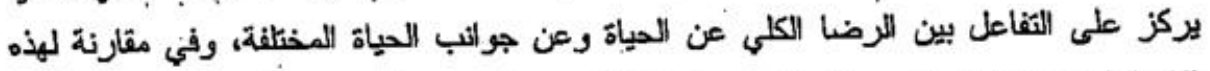

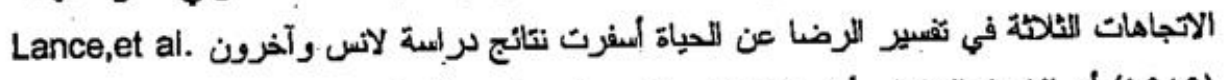

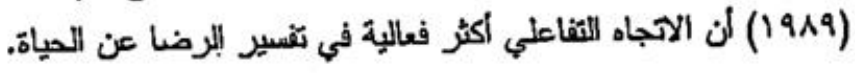

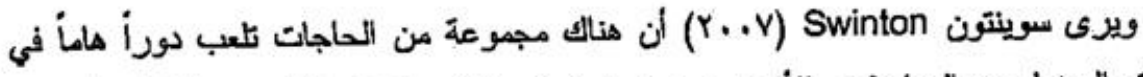

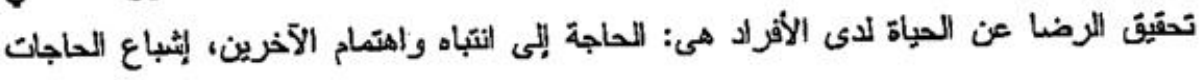


= التضحية وعلافتها بالرضا عن الحياة لاى المرأة المتزوجة وغير المتزوجةت

الجسية والعتلية، القترة على تحتيق الأهداف اللشخصية، القدرة على حل المشكلات، المساهمة في

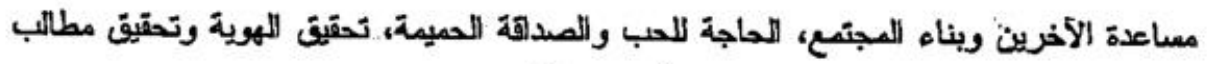
وتوقعات كل مرحلة عمرية، الحاجة إلى الأمن والطمانينة.

Determinants of Life Satisfaction مددات الثبعد بلالرضا عن الحياة يعد الشعور بالرمنا واخدأ من المكونات الأساسية للسعادة، وهو نوع من التقدير التهادى

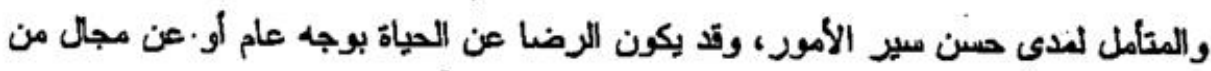

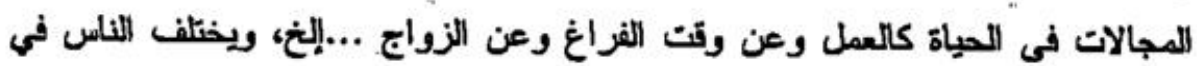

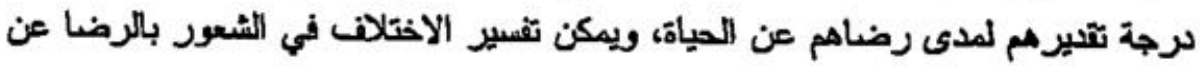
الحياة بين اللاس بعدة محدات أو عوامل منها: 1- تأثير الظروف الموضوعية على الشعور بالرضا:

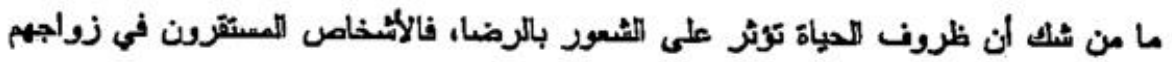

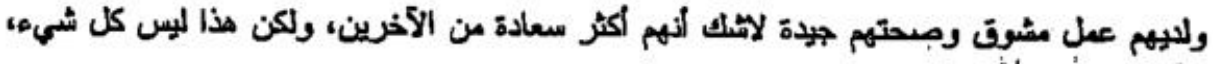
فهذاك الكثر من الثعور بالرضا المعتر من أثنطة ممتعة والكثها لا ترتبط بإثباع للماجات. . ب- خبرة الاحدلث السارة:

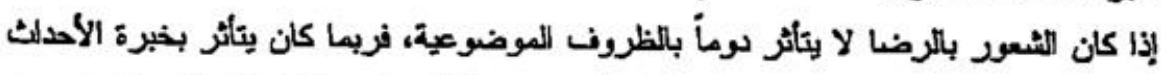

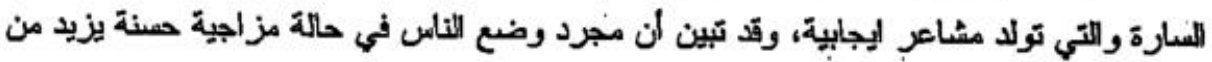
تعبيرهم عن الشعود بالرضا عن الحياة ككل. r- الطموح والاتجاز:

يكرن الأعور بالرضا أكثر عنما تهترب الطموحات من الآجازات ويقل عنما تبتعد عنها، وثقوم الطموحات على المقارنة بالآخرين لو على خبرة الفرد الماضئية.

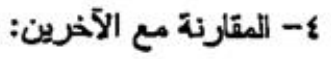

لكى تحلد ما إذا كان القرد قصيرأ أم طويلأ لابد من عقد مقارنات مع الآخرين، وتعتمد كيفية

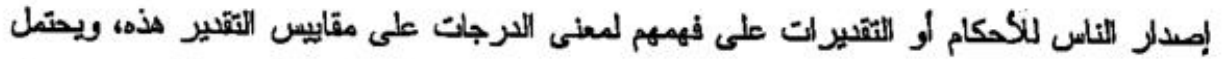

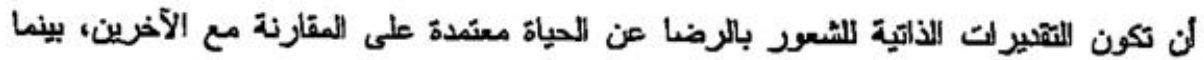

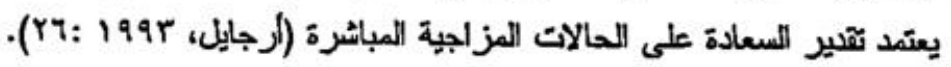

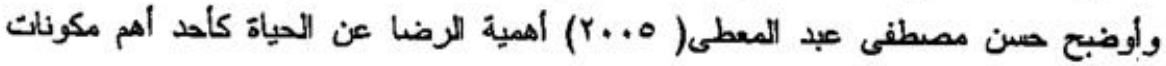

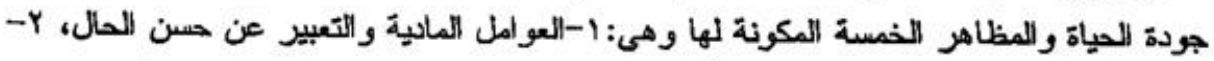
إثباع الحاجات والرضا عن الحياة،r-إبرالك القوى والمتضمنات الحياتية والإحساس بمعنى 


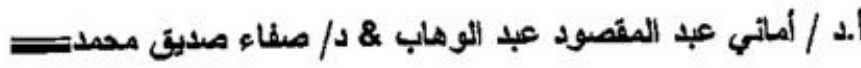

الحياة، ع-الصدة والبناء البيولوجي وإحساس القرد بالسعادة، ه- جودة الحياة الوجودية.

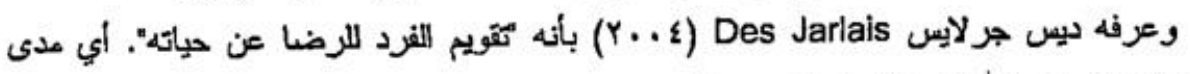
رضا الفرد عن الجواتب الايجابية في حياته.

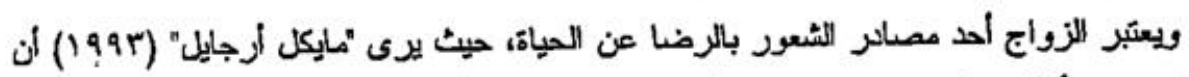

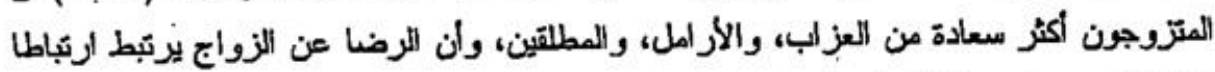
قويا بالشعور بالرخا العام أو بالسعادة.

عراليعات سابكة:

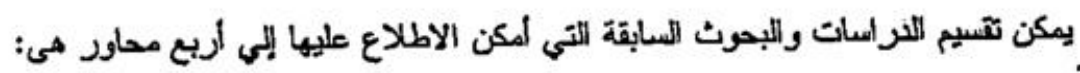

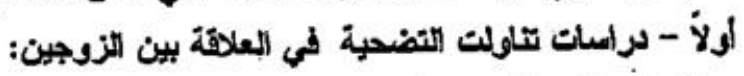

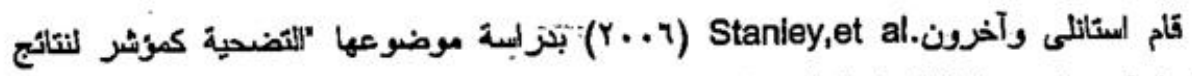

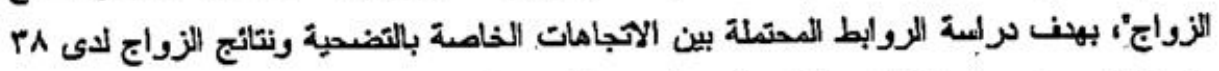

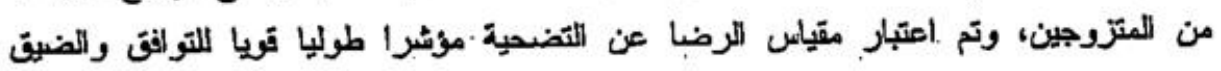

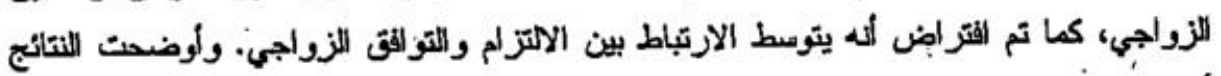

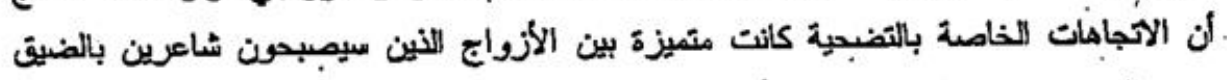

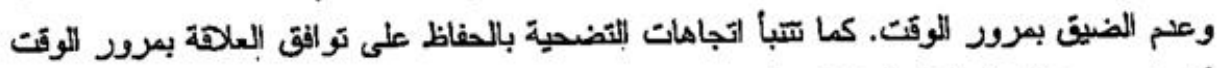

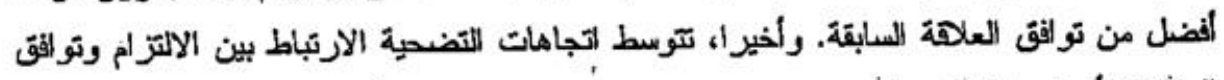
العلاهة للزأواج، لا الزورجات.

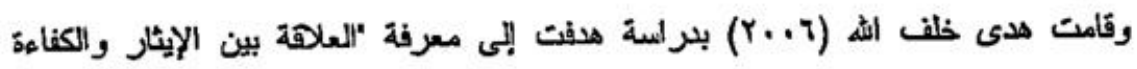

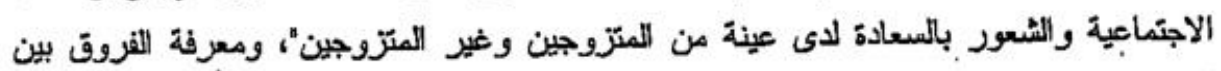

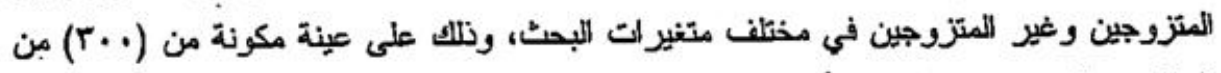

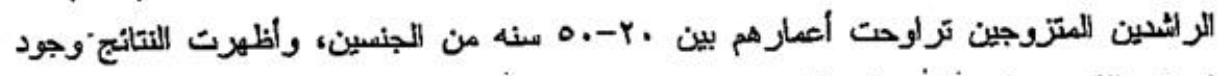

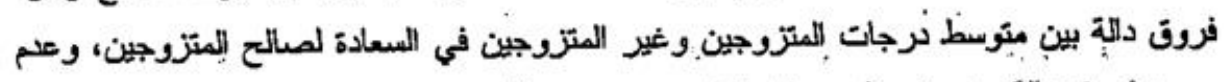

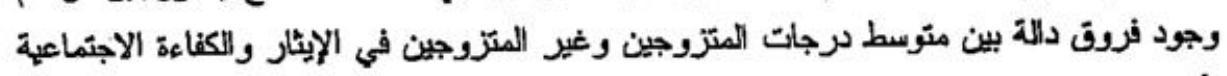

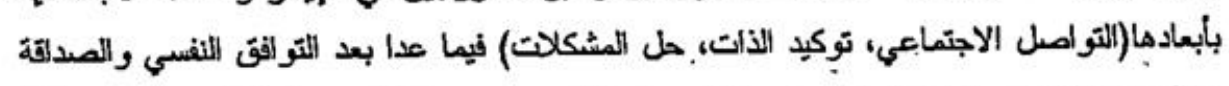

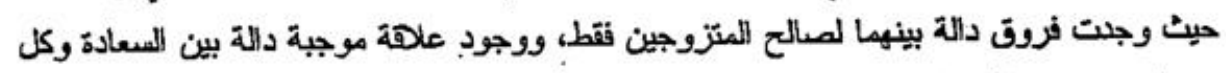

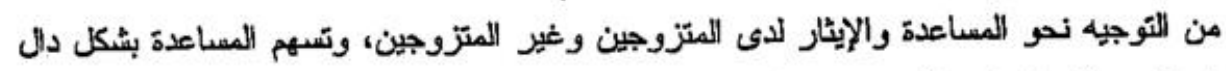

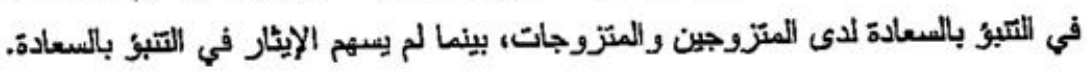

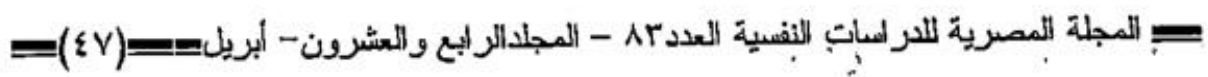


= التضحية وعلاقتها بالرضا عن العياة لدى المرأة المتزوجة وغير المتزوجةتس

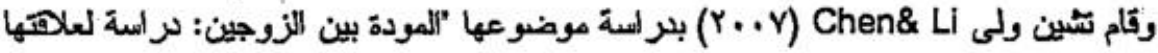

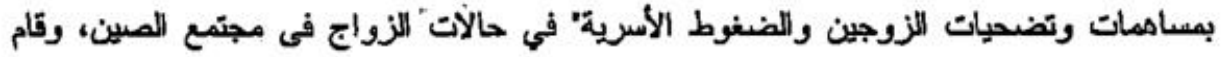

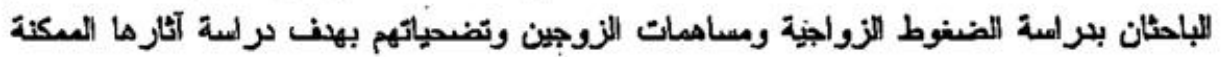

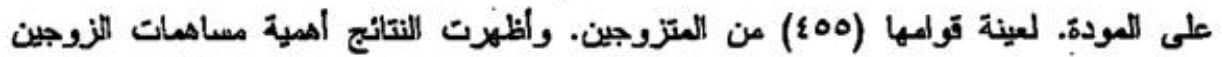

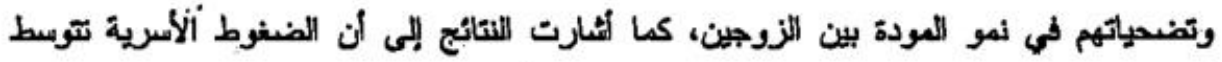

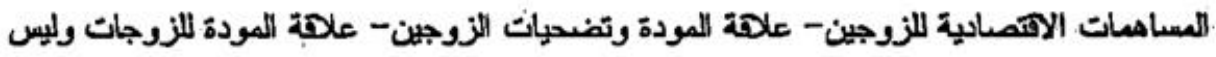

لللزواج.

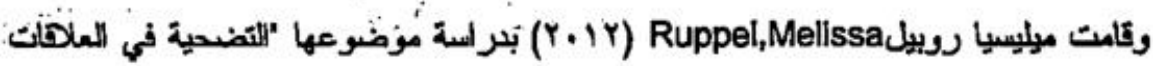
اللرومانسية"، بهف ررلسة تأثير الادافع وراء التضحية على نجاح العلاهة الززوجية، علنى عينة

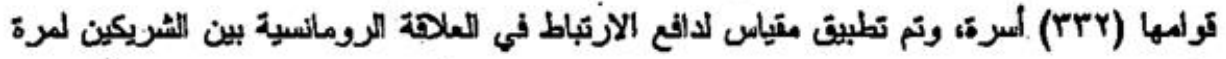
واحدة، ومقياس يومى للرضا عن العلاهة وعدد وصعوبة التضحيات العلاهنية لما يزيد على فترة

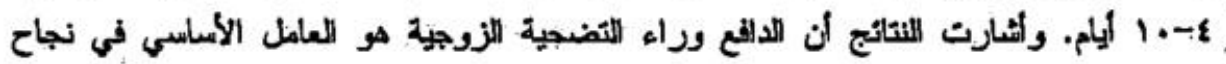

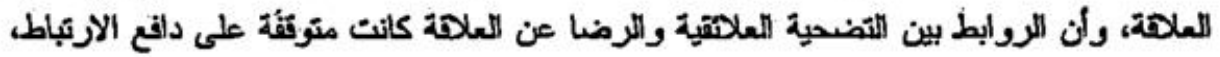
وأن التضحيات العهلة وللمنكررة تد تكون أكثر فائدة اللعلهات.

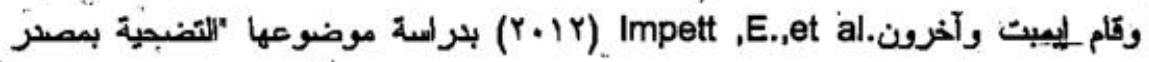
لالكبح"، وذلك للجابة على تساول: ماذا يحثث عندا يقوم الثاس بكبح مثاعر هم عند اللضشحية

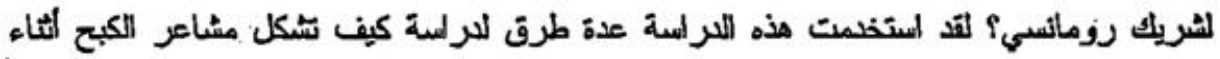

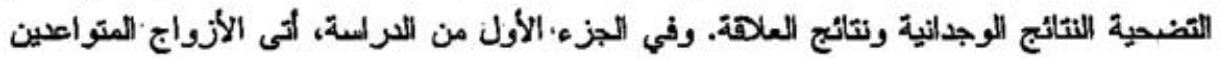

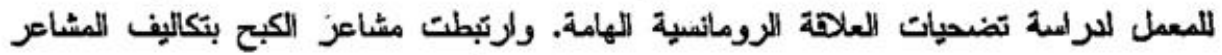

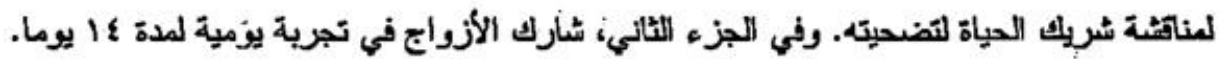

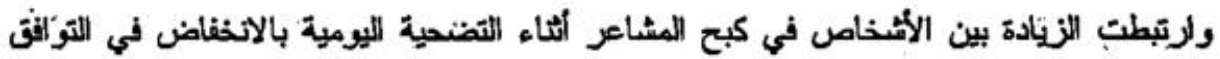

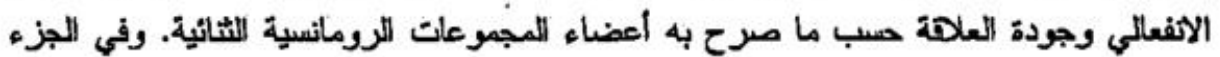

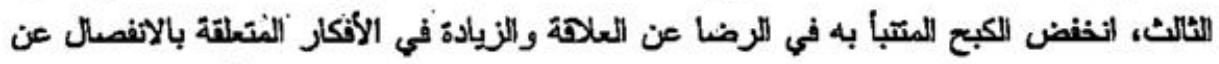

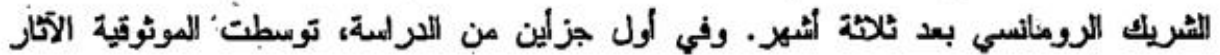
المكلفة للكبح. 


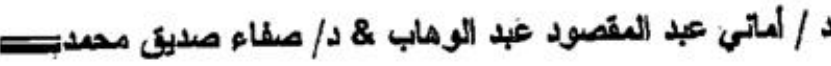

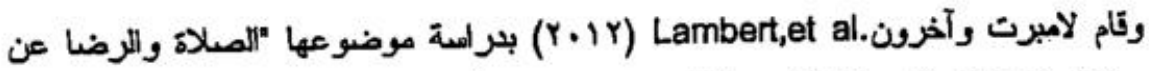

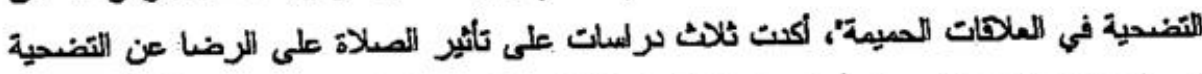

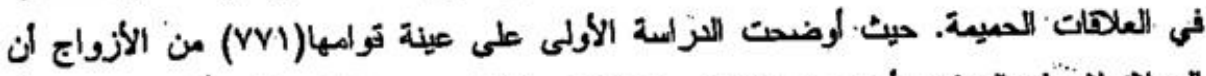

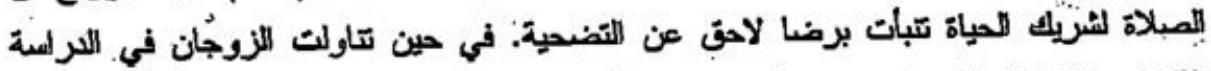

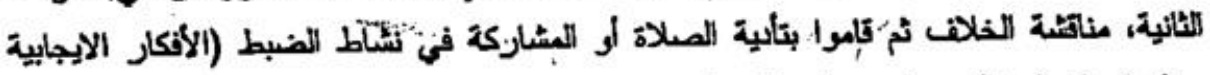

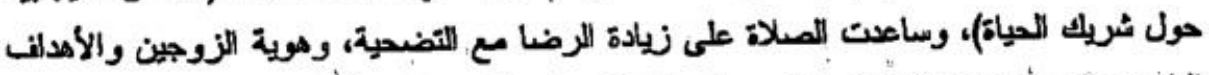

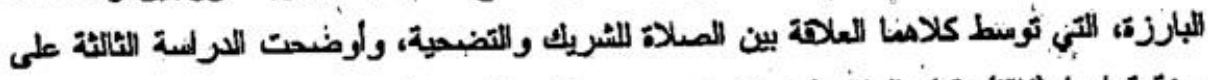

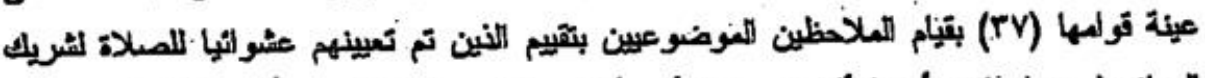

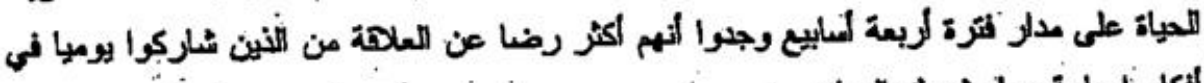
ألكار أيجابية حول شريك المياة.

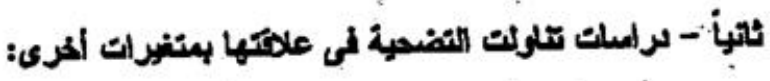

كام كويروز وبازومو Queiroz\&Barroso (1999) بدراسة موضوعها "جودة الحباة للكائ

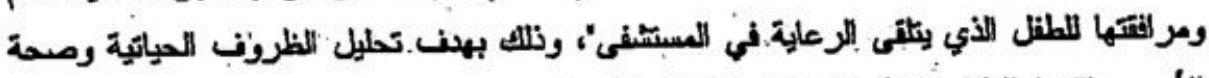

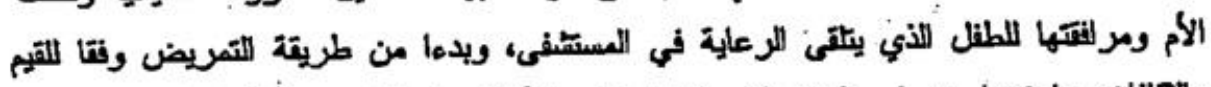

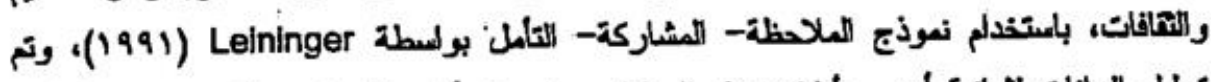

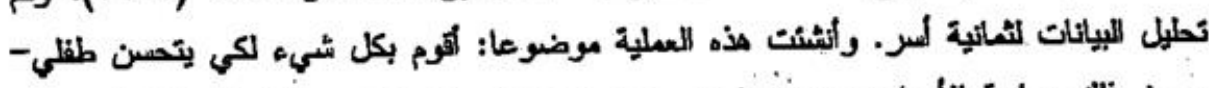

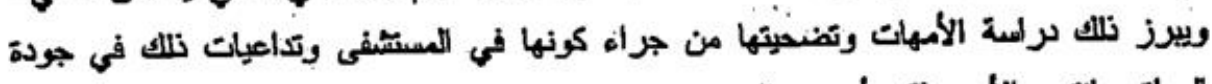

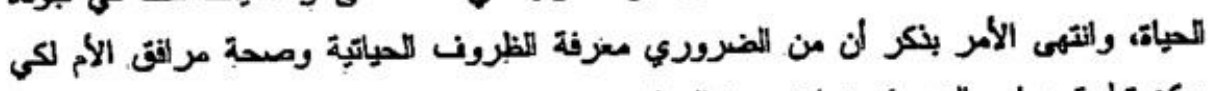

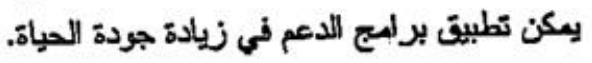

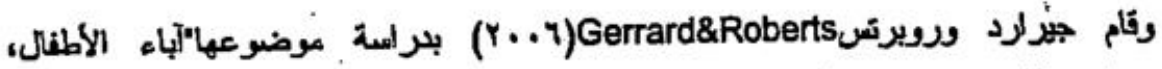

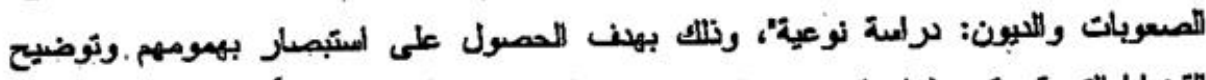

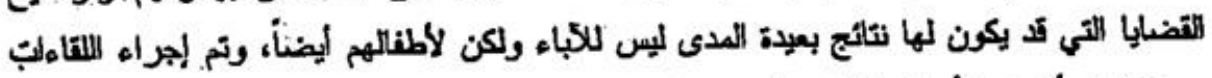

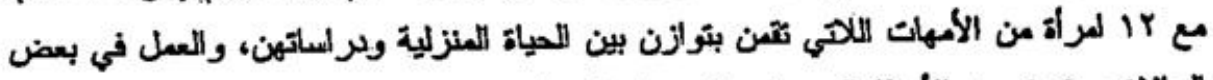

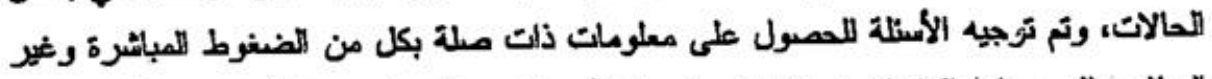

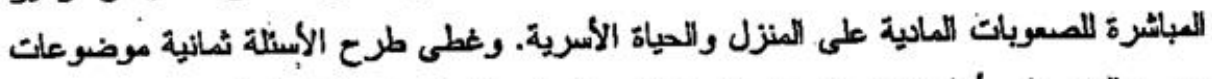

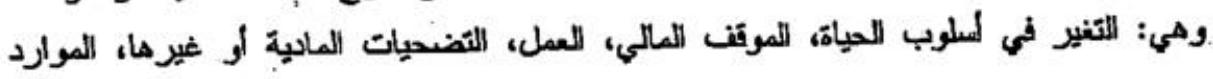

$=$ 
= التضحمية وعلاقتها بالرضا عن الحياة لدى المراة المتزوجة وغير المتزوجة= المادية، اللتأثير المادي على الصحة العقلية لو البننية، التأثير على الأطفال، وأثر التؤوع المادي على توالققهن الثفسي، وفي كثير من الحالات صرح الآباء أن ضغوطهم الثرت عكسيا. على أطفالهه،

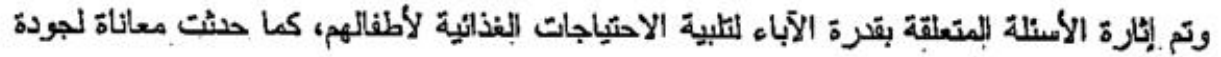

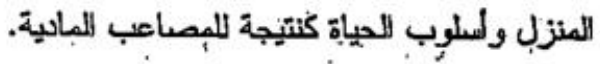

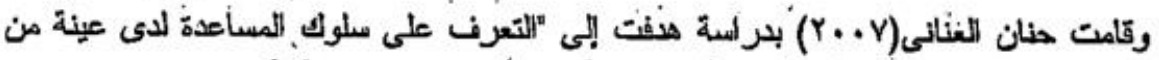

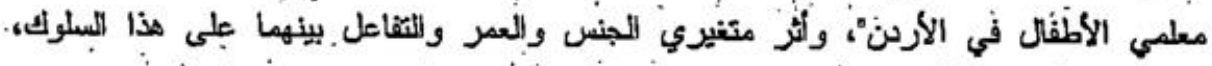

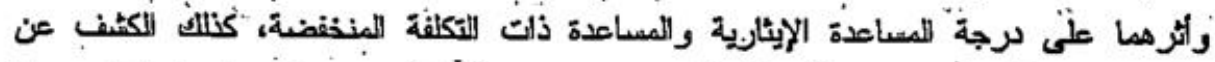

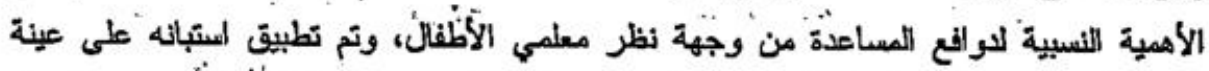

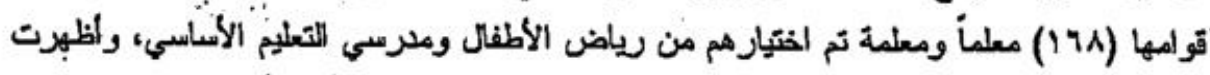

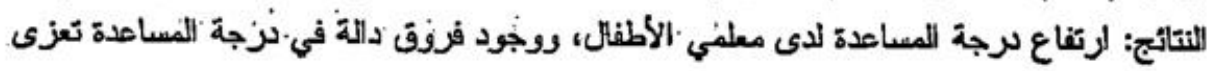

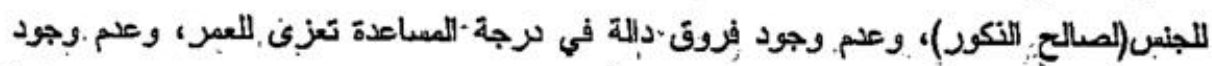

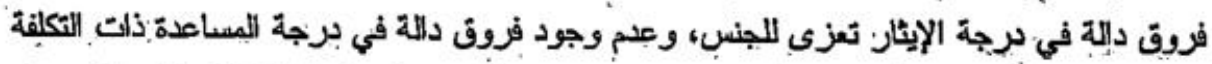

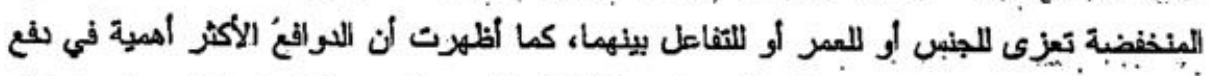
الفردد لبلوك المسابدة من وجهة نظر معلبي الأطفال كانت: اللين، التعزيز الذاتي، المسؤولية؛ الكفاعة، التعاطف.

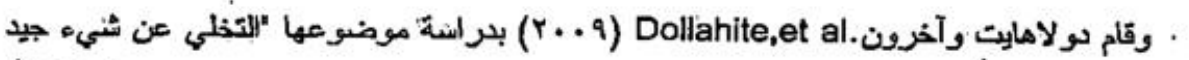

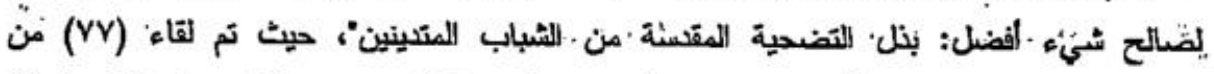

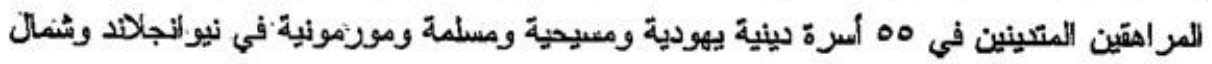

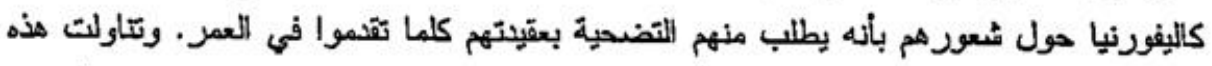

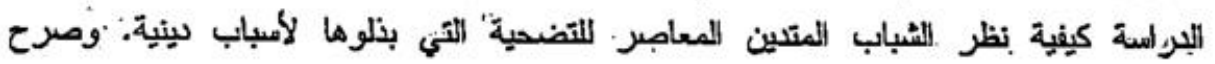

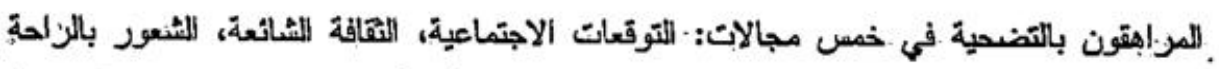

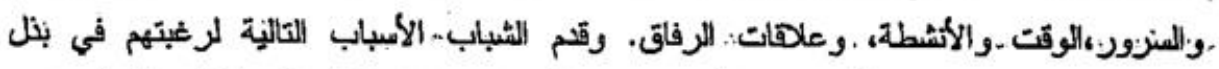

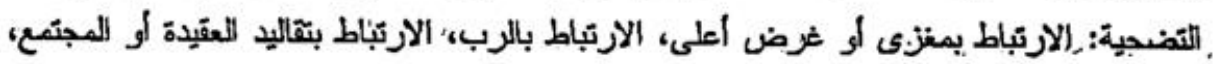
إنجاز .التوقعات، الثعور بفوائد وجدانية، وتجنب المشاكل.

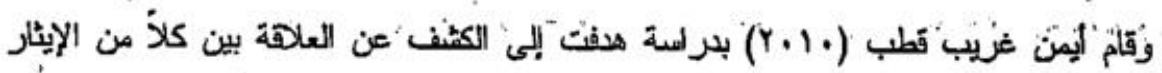

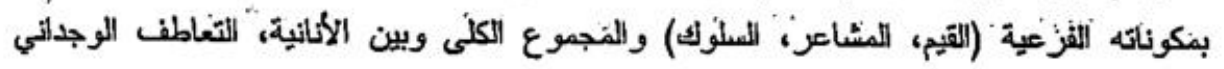

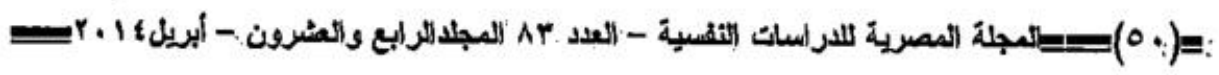




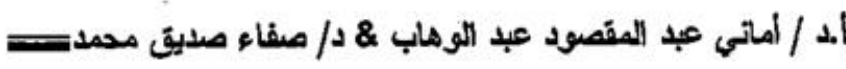

والهوية الخاقية لاى عينة من طلاب ومعلمي الأزهر، والفروق بين الجنسين ودلالتها باختلاف

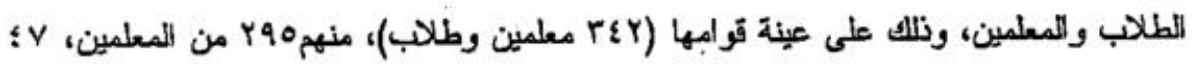

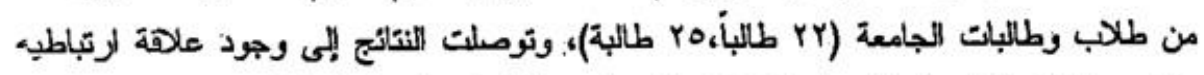

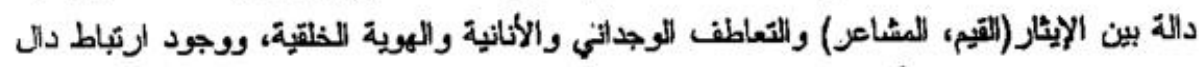

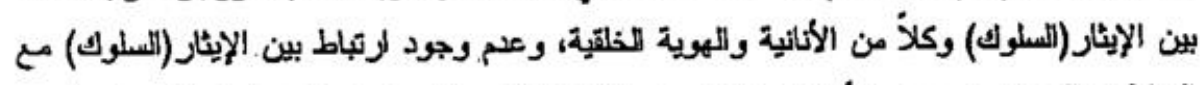

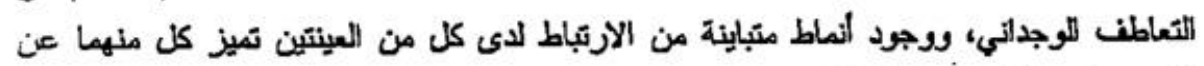

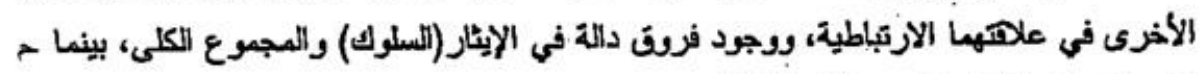
تظهر فروق دلالة فم كل من التهيم والمشاعر.

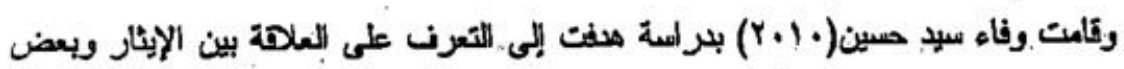

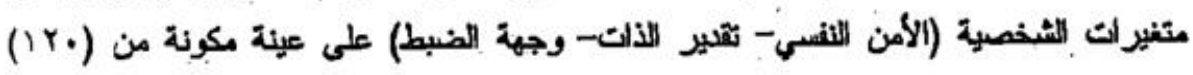

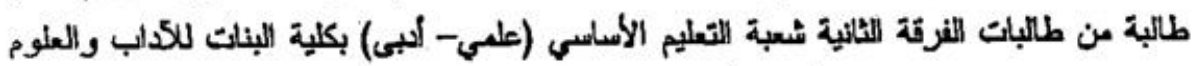

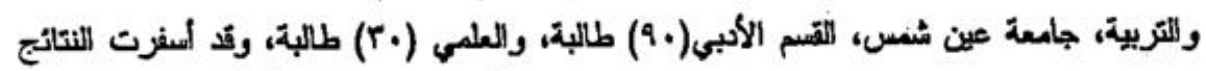

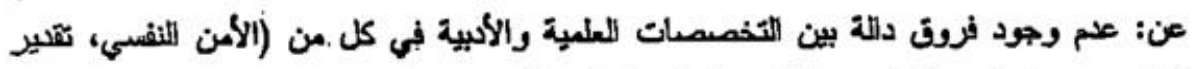

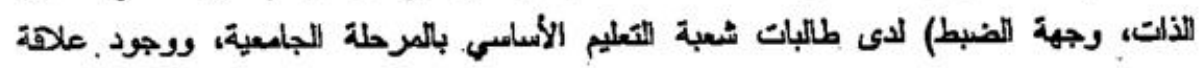

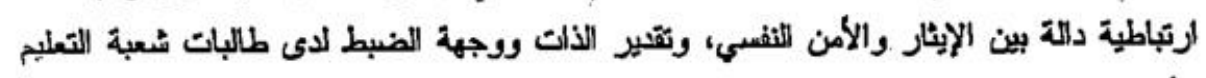
الأساسيى.

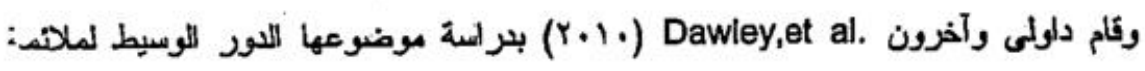

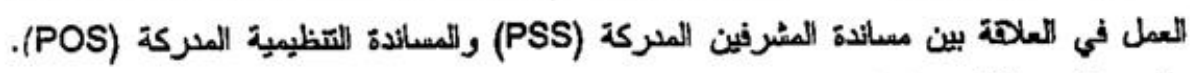

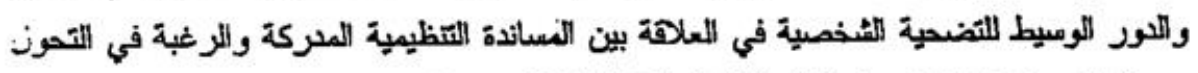

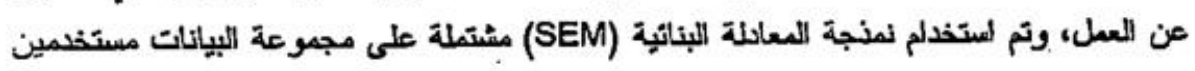

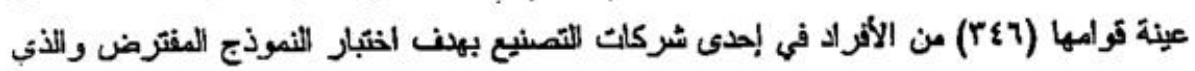

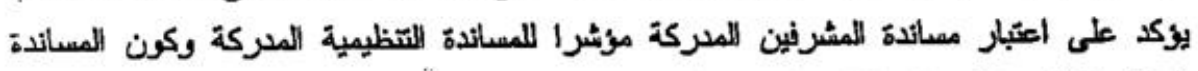

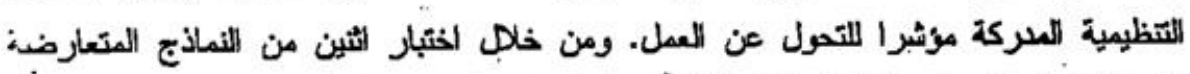

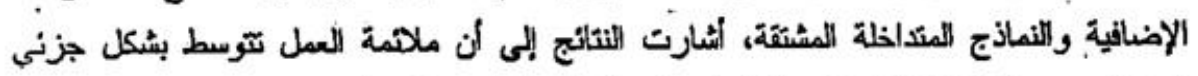

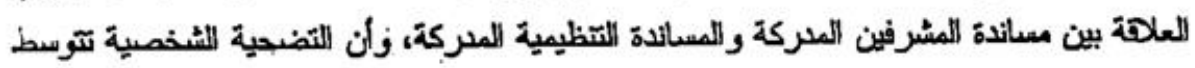

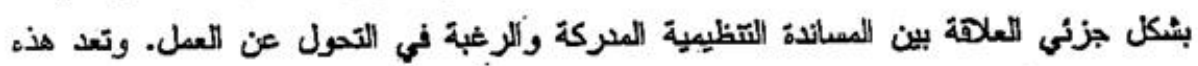

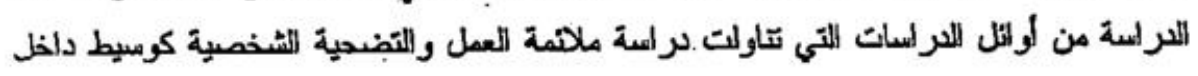


= التضحية وعلاقتها بالرضا عن العياة لاى المرأة المتزوجة وغير المتزوجةً نموذج المساندة التظظيمية المركة - الرغبة في التحول عن العمل.

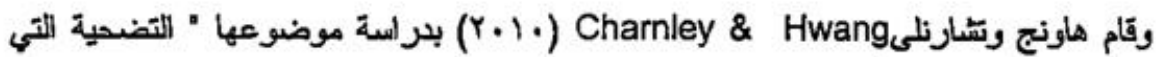

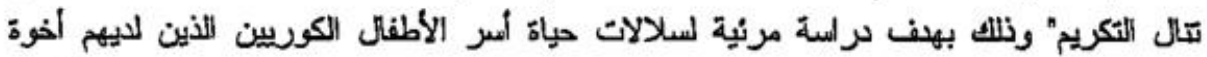

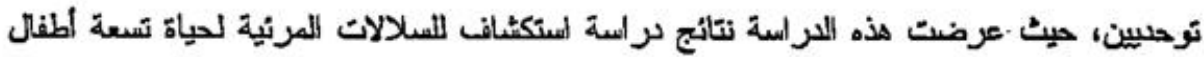

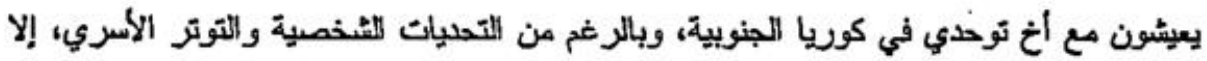

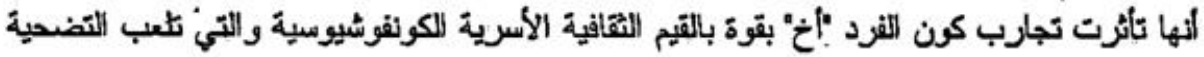
من خلالها بورا رئيسيا في تحقيق البحياة الأسرية المنسجمة .

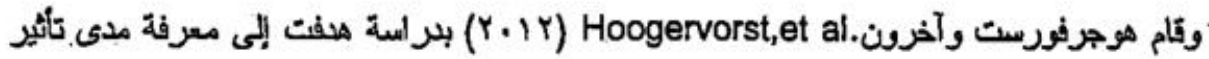

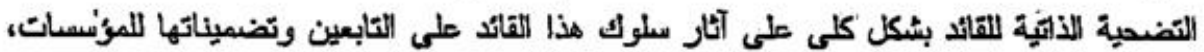

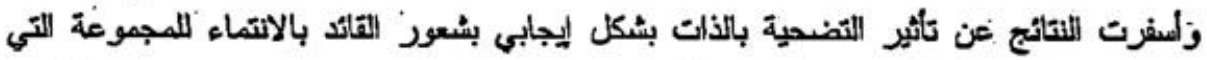

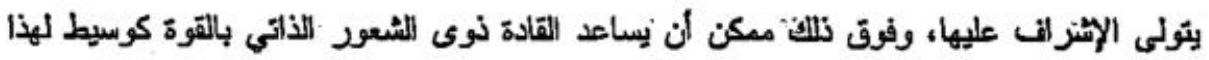

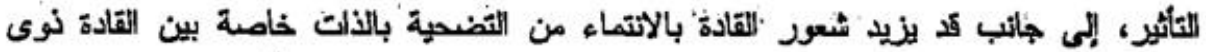

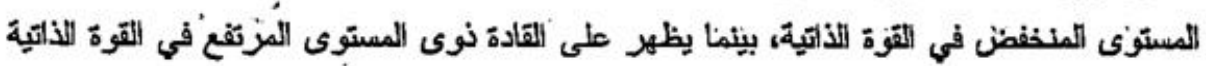
تصنية بالذات بصرن النظر عن شعورهم بالاتثماء.

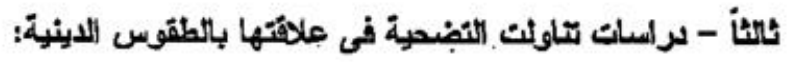

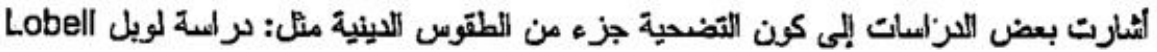

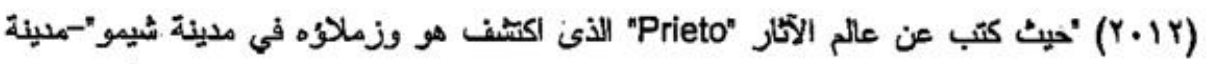

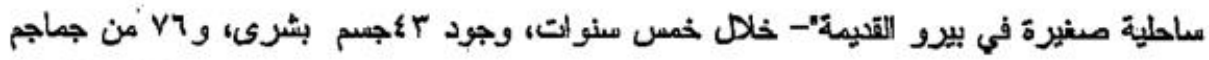

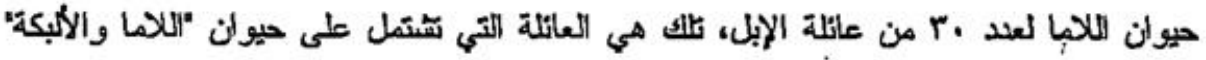

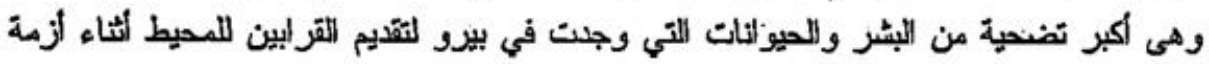

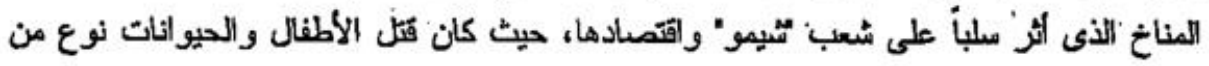

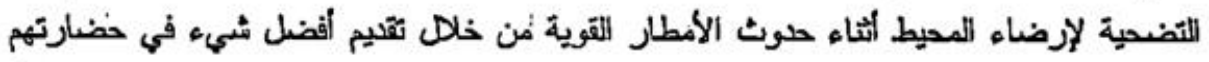

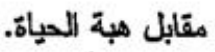

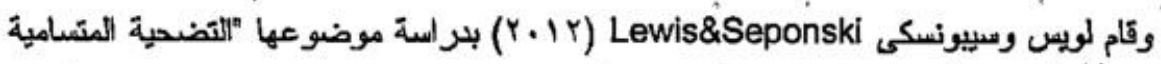
واللروحانية: تربية الأجداد الكمبوبين لأحفادهم الأيثام"، ونلك بهاف تحليل حياة (• (') من الأجداد

=( OY = 


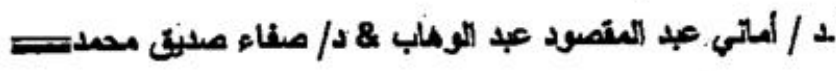

القاتمين على تربية أحفادهم الأيتام في كمبونيا. وباستخدام نظرية التبادل الأسري، أوضحت

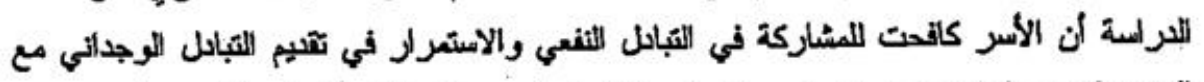

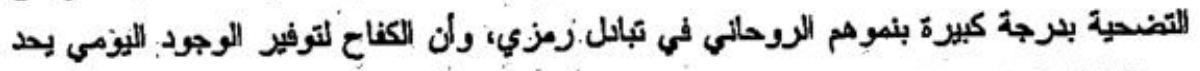

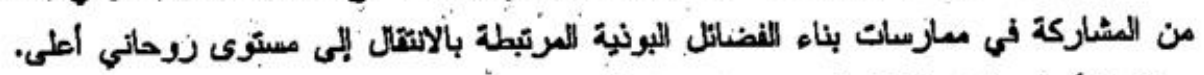

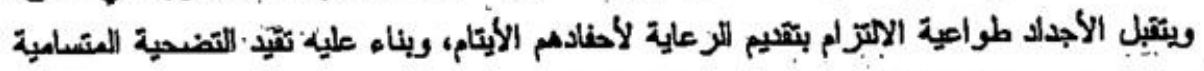
لحتمل للوجود الأففل للأجداد في حياتهم العمنثبلية.

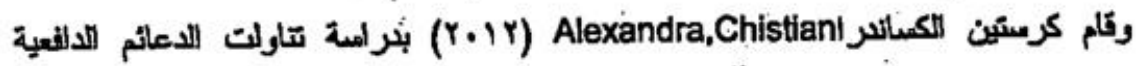

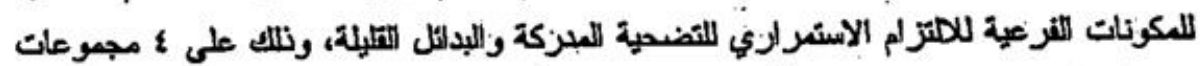

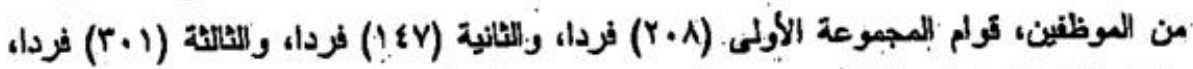

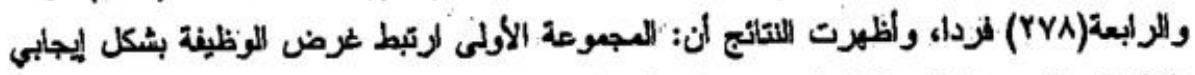

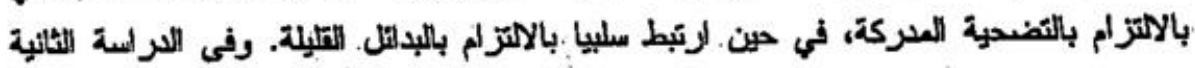

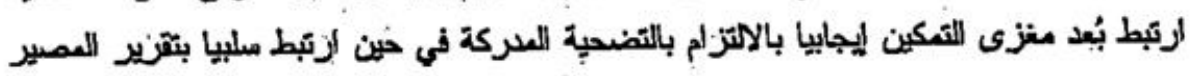

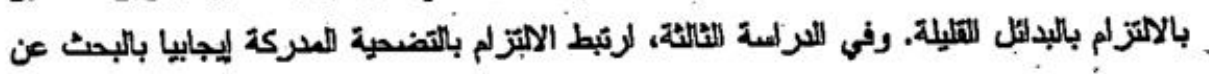

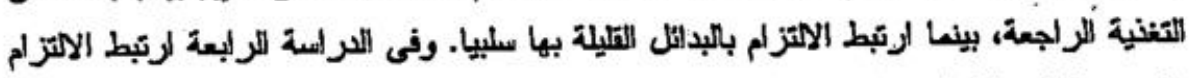

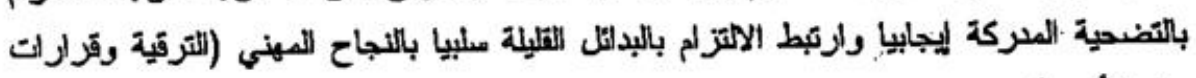
رفع الأجور).

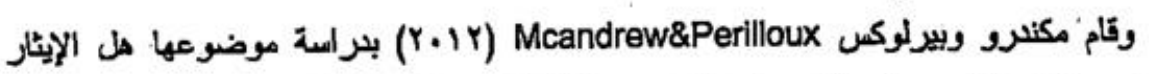

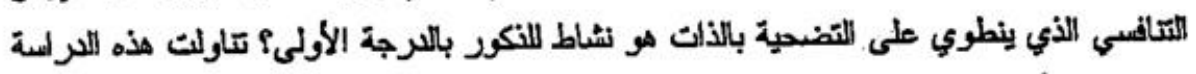

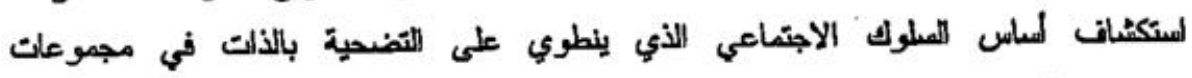

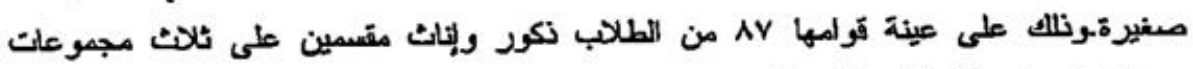

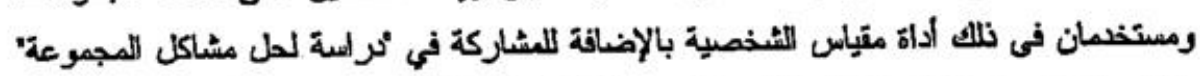

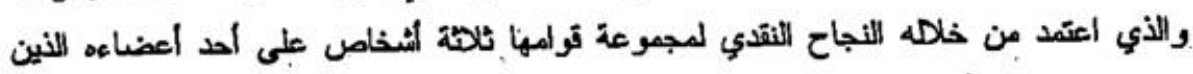

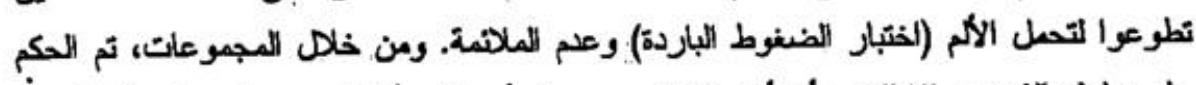

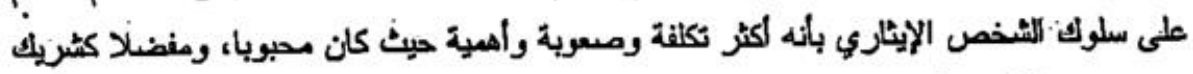

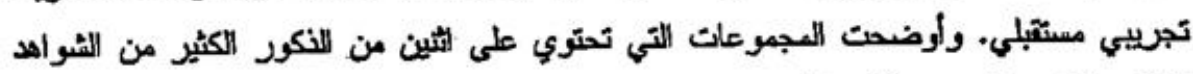

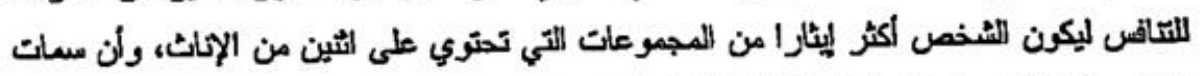

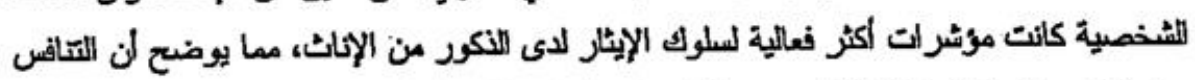

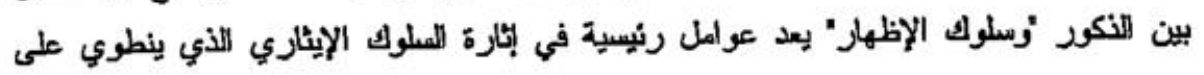

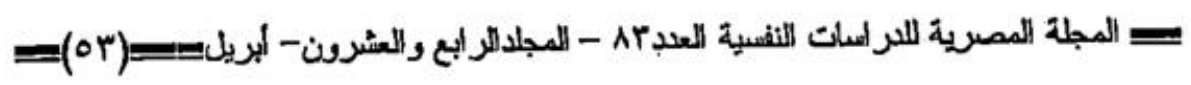




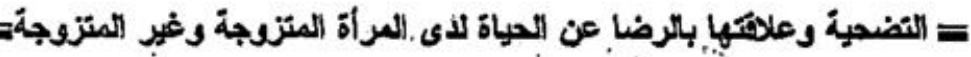

التضحية بالذات.

رابعأ - دراسات تباوكت الرضا عن الحباة:

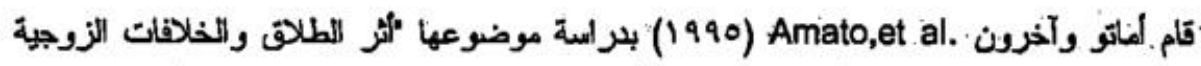

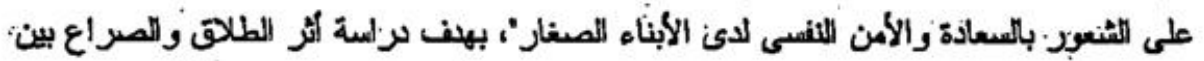

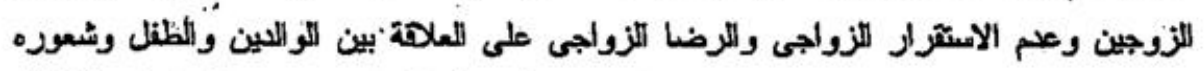

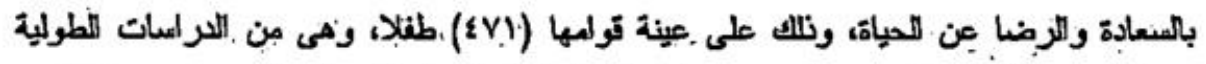

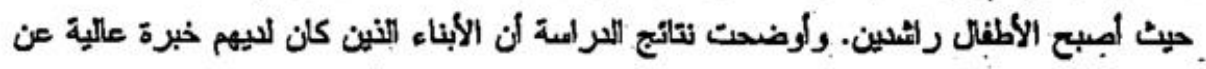

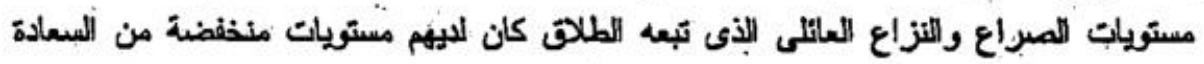
والرضبا عن الحياة بن الأسر التى لم يطلق فيها الوالثين وكائت الخلافات الأسرية بينهما التل.

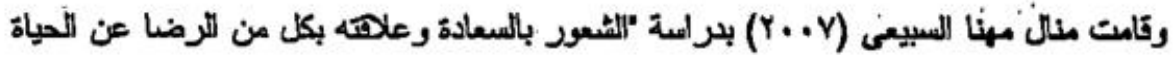

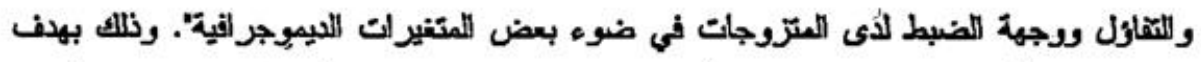

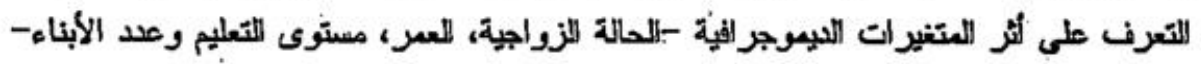

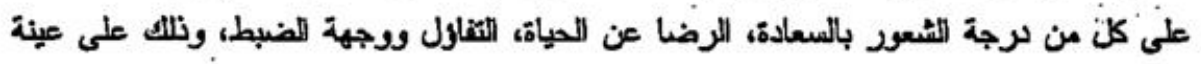

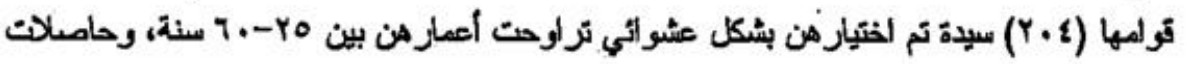

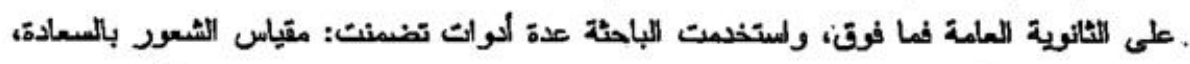

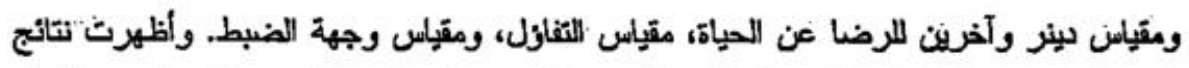

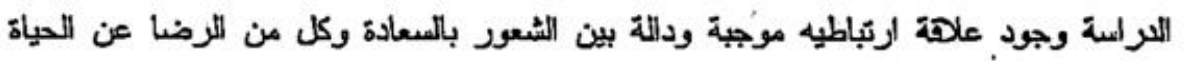

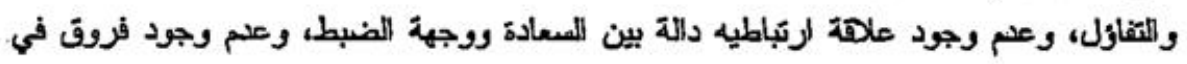

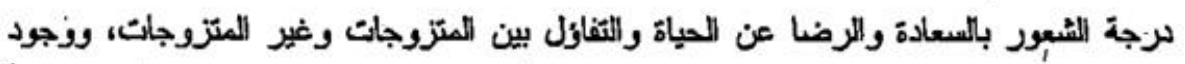

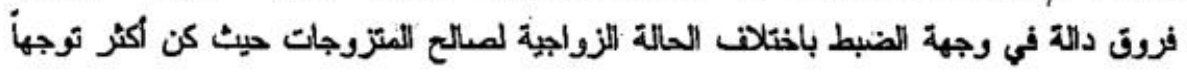

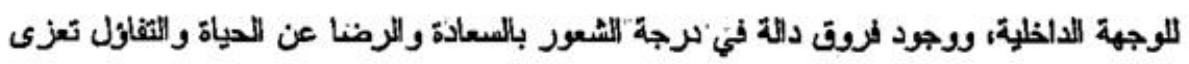

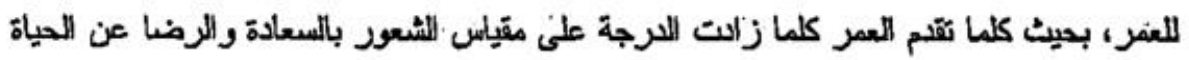
واللتفاول.

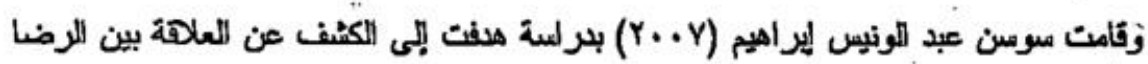

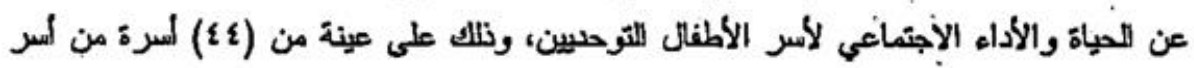

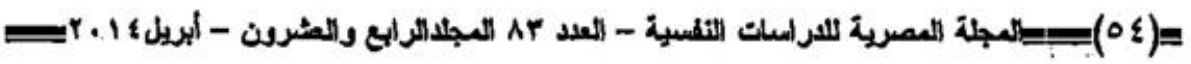




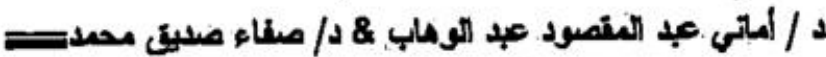

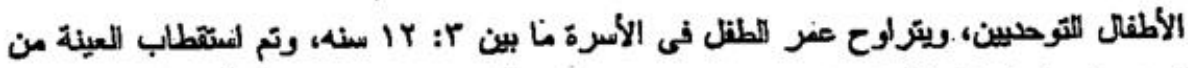

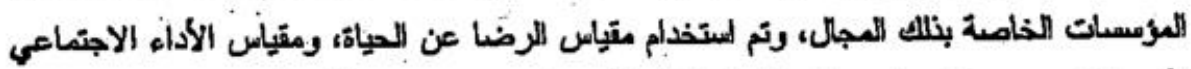

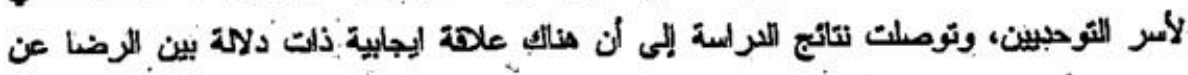
الحياة والأداء. الاجتماعى لأسر الأطفال الثوحنين.

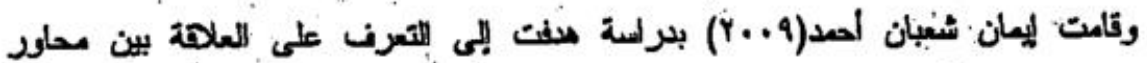

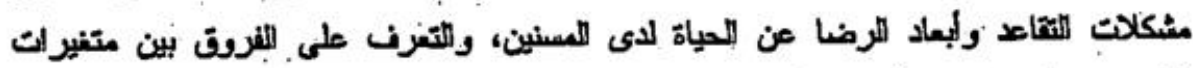

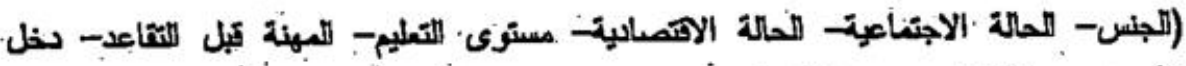

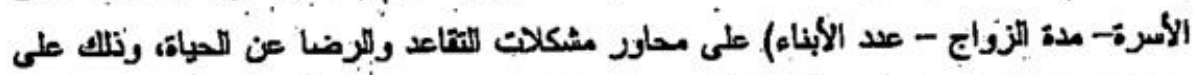

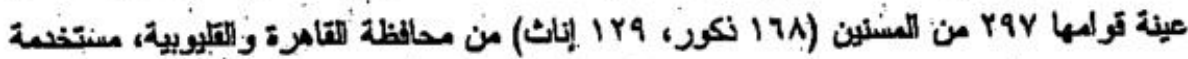

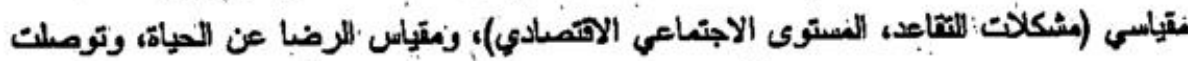

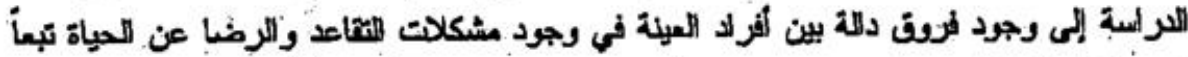

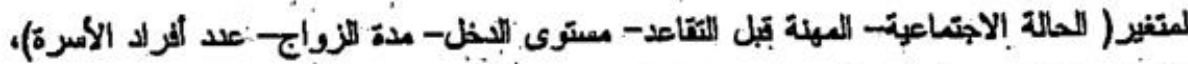

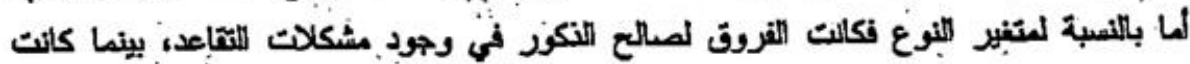

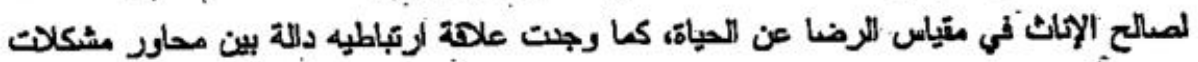

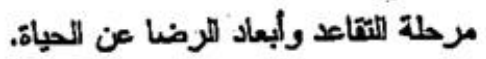

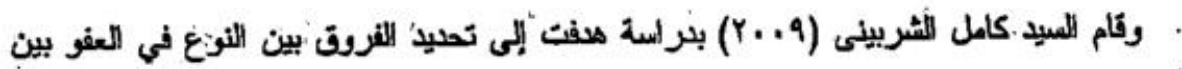

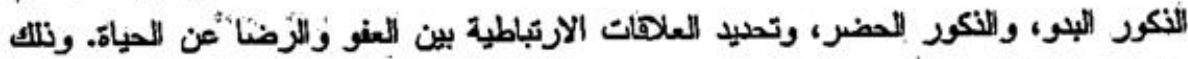

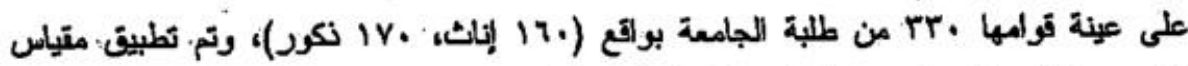

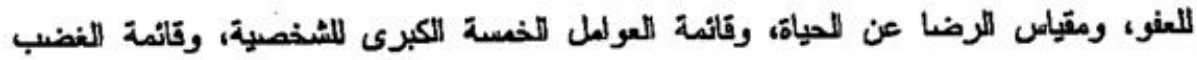

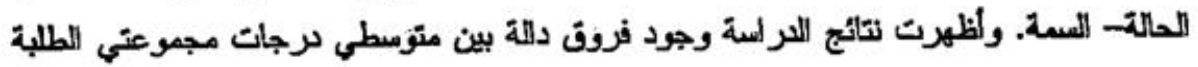

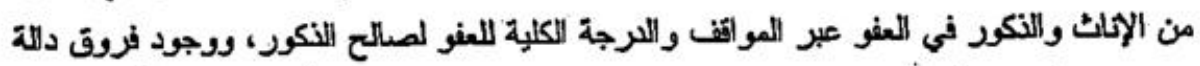

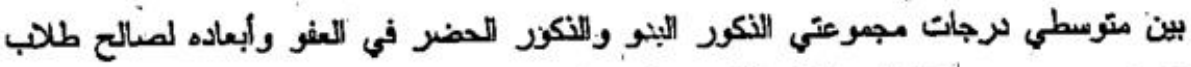

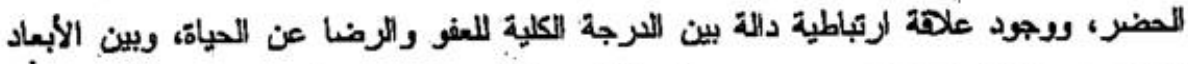

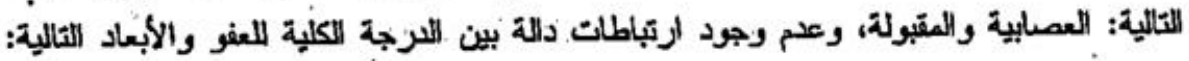

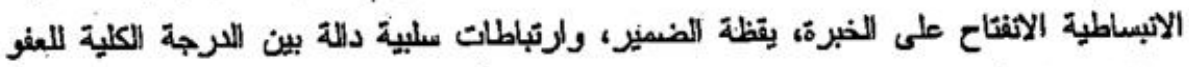

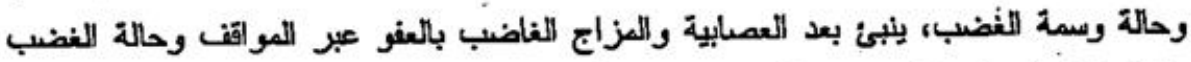
والمقتولية وللمعادة بالعفو عن الآخرين وبعد العنعادة بالعفو عن الذالت، وتتبئ اللععادة والعصايبية 
= التضفية زعلاتهبا بالرضا من الحهاة لدى العراة المتزوجة وغير. العتزوجة والمقبولية وحالة وسمة الغضب بالرجة الكلية للعفو.

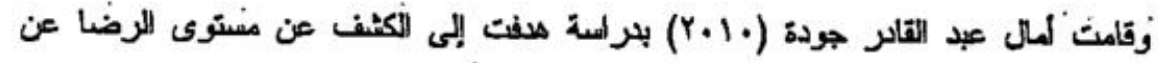

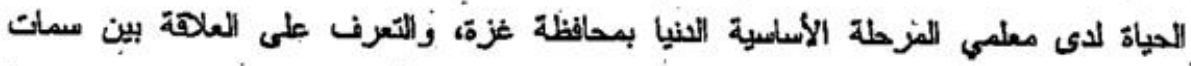

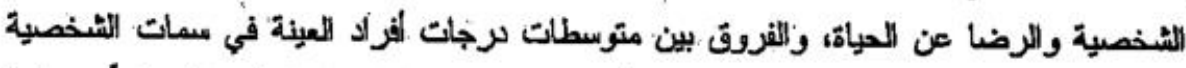

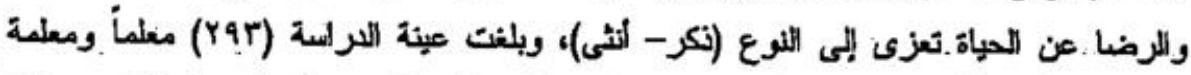

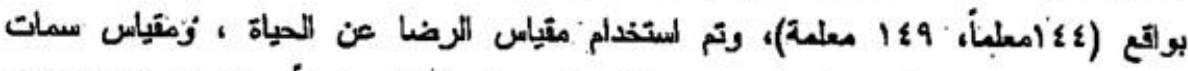

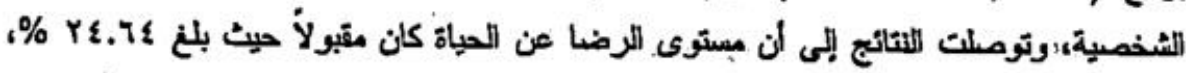

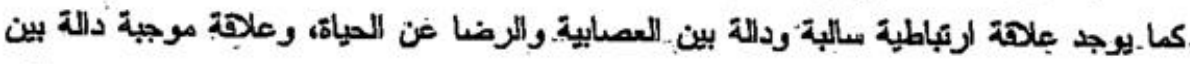

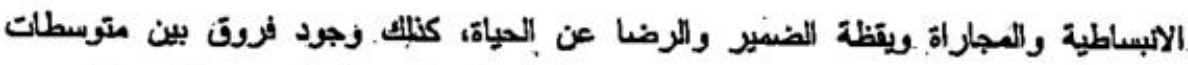

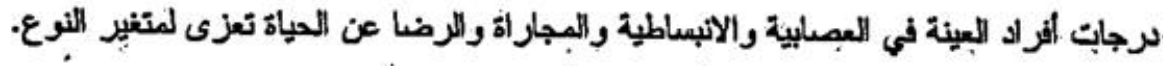

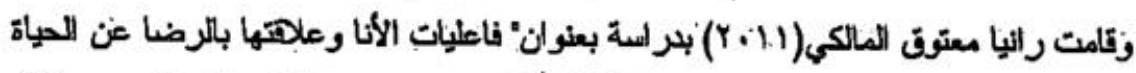

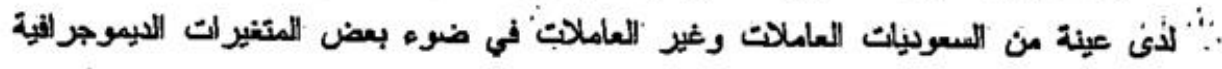

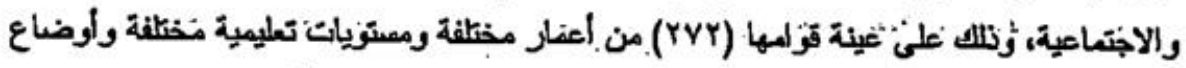

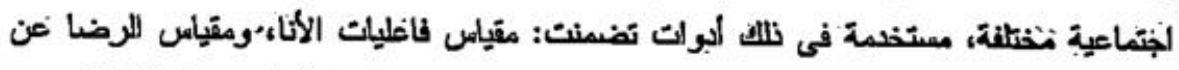

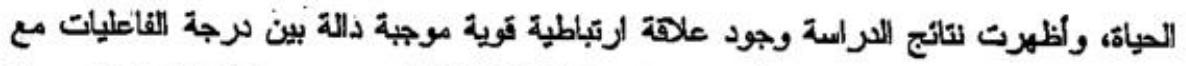

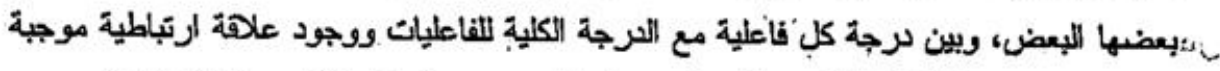

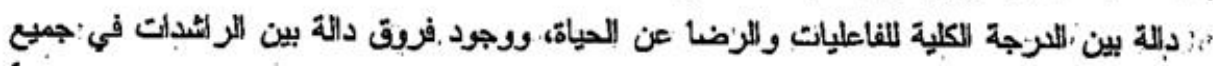

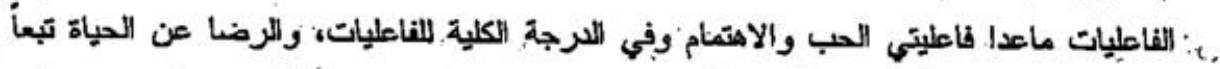

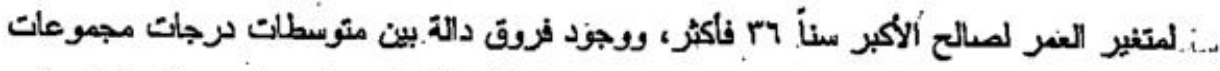

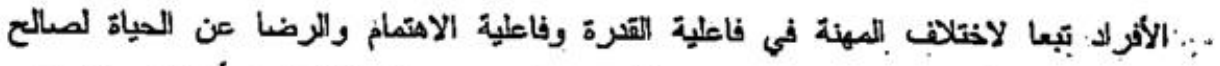

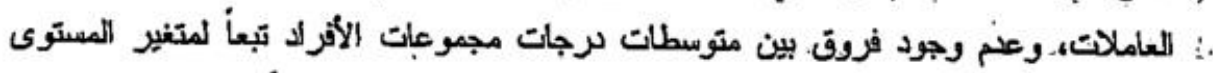

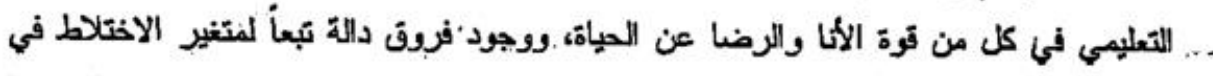

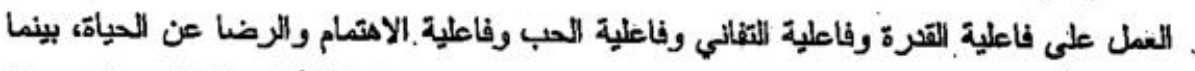

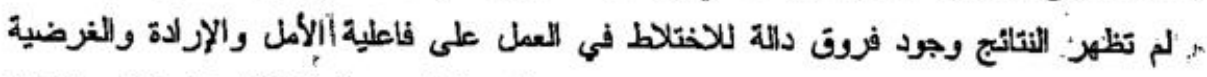

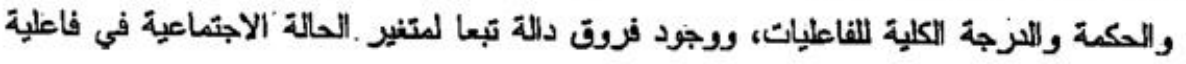

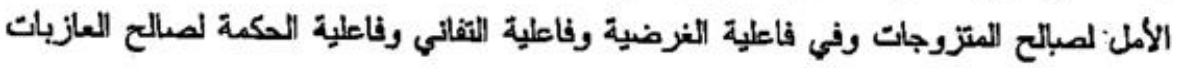
وفي قوة الأئا والرضا لمنز الحياة لصالح المتزوجات.

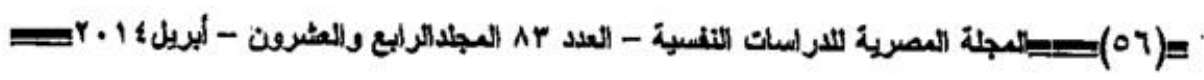




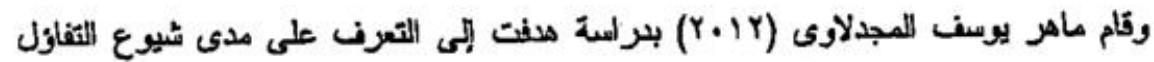

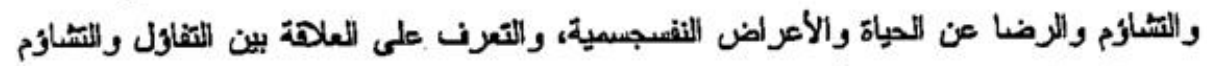

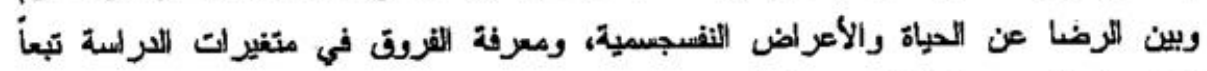

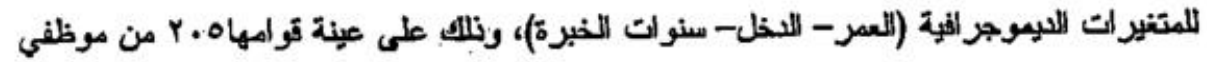

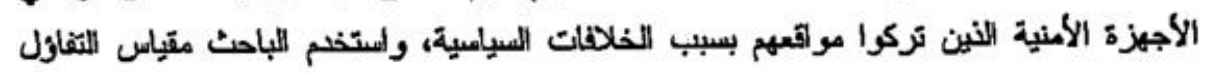

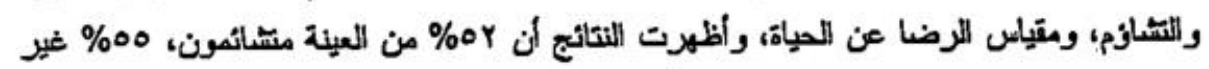

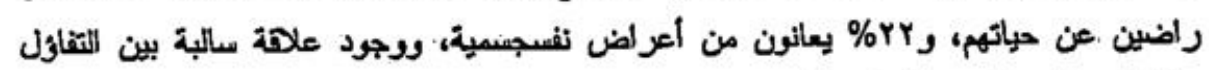

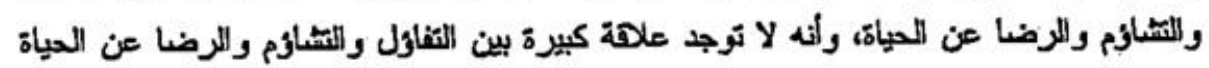

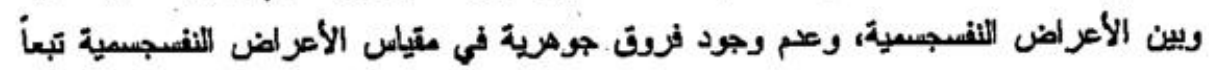

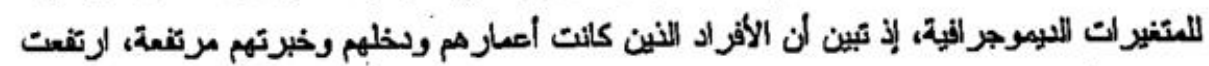

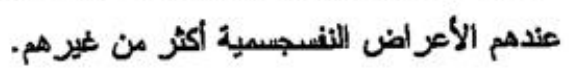

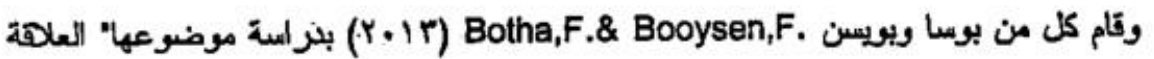

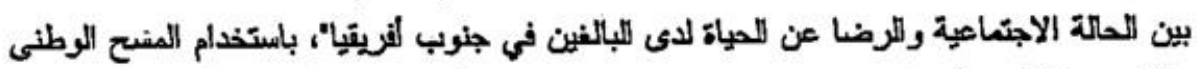

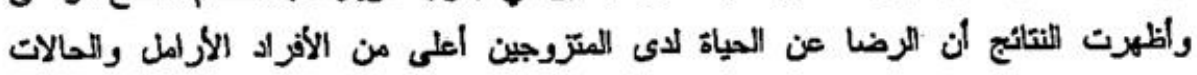

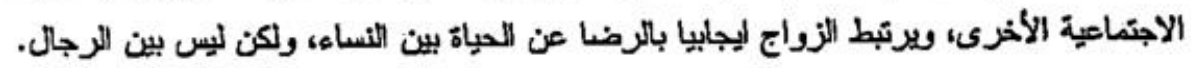

فرض البحث:

استوجد علاهة ارتباطية دالة إحصائيا بين التصضحية والرضا عن الحياة لدى المر أة المتزوجة وغير

المتزوجة.

ب-توجد فروق دالة إحصاثياً بين متوسطات مرجات المرأة المصرية (متزوجة- غير متزوجة) المقيمة في مصر على مقياس التصنية.

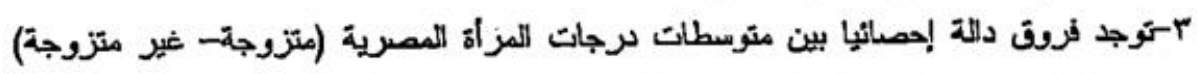
المقيمة في مصر على مقياس الرضا عن الحياة .

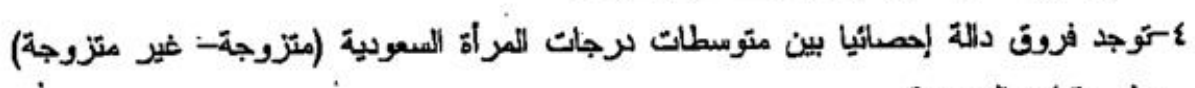
على مقياس التضصية.

ه-وجد فروق دالة إحصانبا بين متوسطات مرجات المرأة السعوبية (متزوجة- غير متزوجة) على مقياس اللرضا عن الحياة.

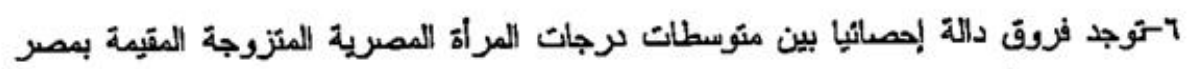

مقارنة بالمراة المصرية المتزوجة المقيمة بالسعودية على مقياس التضندية.

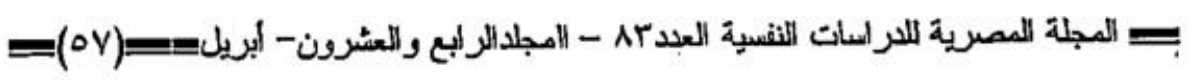


= [التضحة وعلاتكها بالرضا عن العباة لدى المرأة المتزوجة وفير المتزوجةت

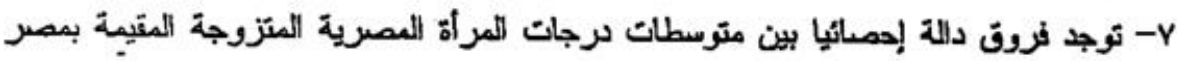
مقارنة بالمرأة المصرية المتزوجة المقيمة بالسعودية على مقياسن الرضا عن الحياة. 1-ميمن التبو بالرضا عن الحياة من خلال الابعاد اللفرعية لمقياسن التضدية لدى المرأة.

الإجراءوات المنهجية:

$$
\text { ( العنهج - العينة- الأكوات - الأساليب الإحمائية- الانتائج) }
$$

أولأ - النهنج:

يعتمذ البحث على المنهج الوصفى الارتباطى والمقارن، حيث يسعى لاكشاف العلهات

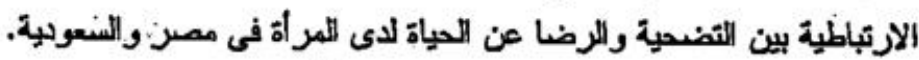

$$
\text { ثاتبا - العبنة: }
$$

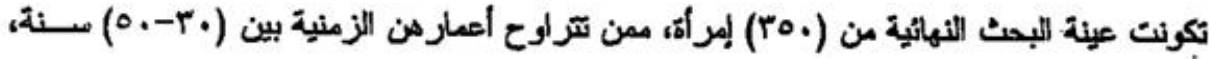

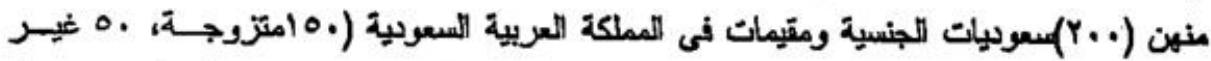

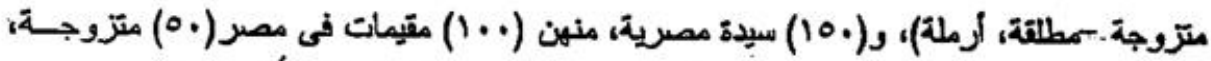

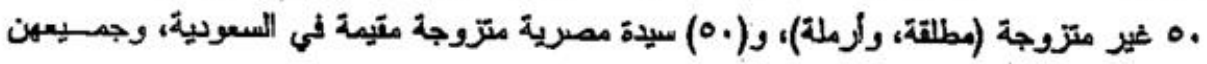

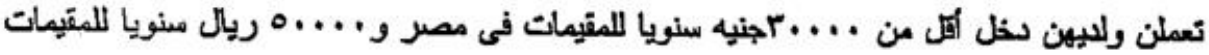

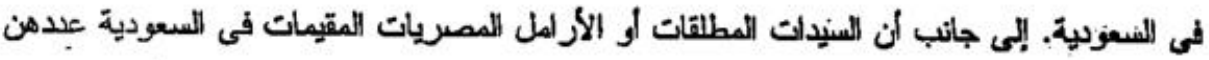
تليل ويداولن إخفاه نلك فى المجتمع السعودى.

$$
\text { ثالثاً - الألوات: }
$$

(إعداد: صقاء صدلي خريبة)

ا-مقياس التضحية التزجية: ينقسم المقياس إلى جزاين رئيسيين هما: 1) مقياس التضحية الزورجية، ويتم تطبيقه على المرأة المتزوجة. ب) مقياس التضحية للمرأة غير المتزوجة (مطلقة / الرملة). إعداد المتياس: - اس ا-متم لمنتّراء التراث اللظرى المعنى بالتضحية وتعريفاتها ومكوناتها للموقوف على تعريف إجراثى للمفهوم وتحليد مطامينه، وملامحه.

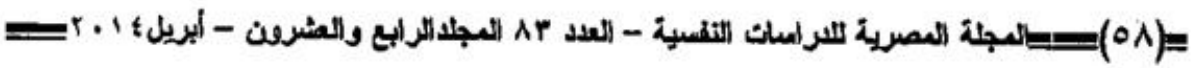




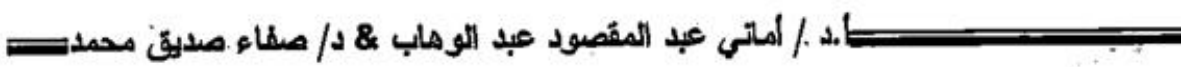
ب-تم الاطلاع على بعض المقاييس التىى تطرقت لهذا المفهوم حيث كان من بينهم دقياس

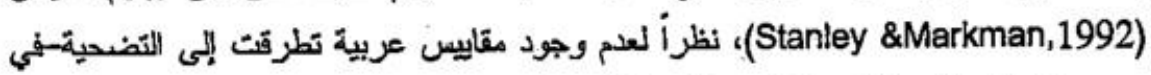
حلود علم الباحثة- وكانت المقاييس العربية قد تطرقت لمفهوم الإيثار وليس اللتضحية كمفهوم ينبثق منه الإيثار.

r-تم توزيع سؤال مفتوح من مفهوم اللتصية على عينة استطلاعية من السيدات المتزوجات

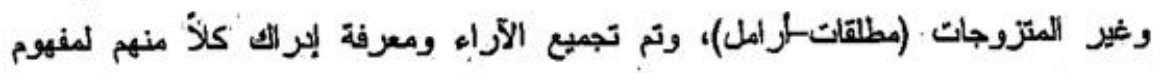
التضحية الزوجية.

الغمائص السبكومترية للمقياس:

أولا - العينة المصرية:

• مترباس التضصية الزوجية 'لامرأة المتزوجة":

تكون المقياس فى صورته الأونى من V9 عبارة هوز عة على بعدين هما: اللَضمية الثخمية

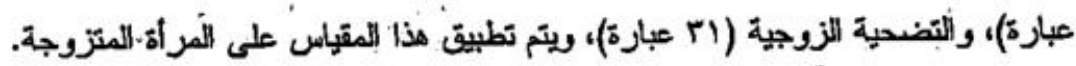
1- أبات المقياس: I. حساب معامل ألفا كرونباخ Alpha-Cronbach وأسبفرت تلك الخطوة عن أن جميع العبارات

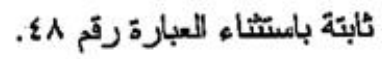
ب. الآساق الإخلى: تم حساب معاملات الارتباط' بين برجة العبارة وبرجة البعد القزعى الأىى

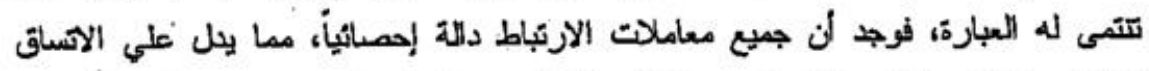
الداخلي وثبات عبارنت مقياس التضحية الزوجية التى تم الإيقاء عليها في الخطوة:اللسابقة.

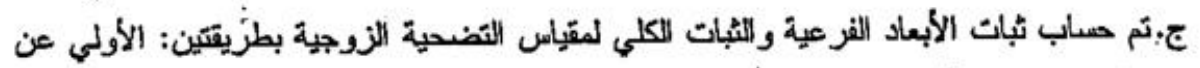

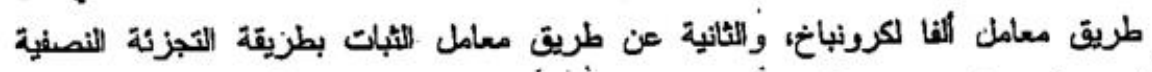

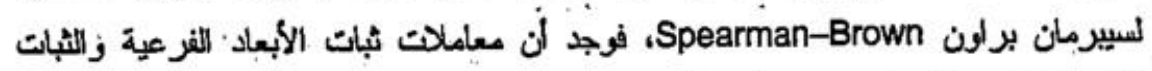

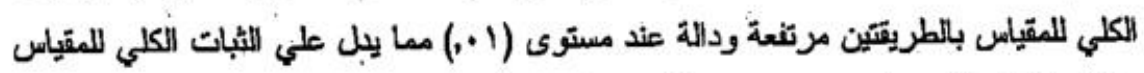

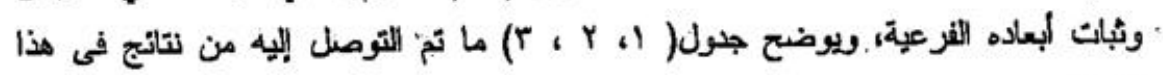
الصيل.

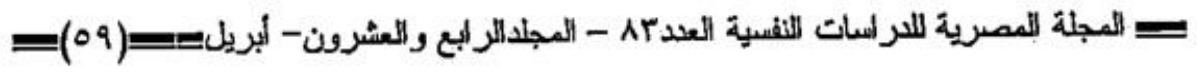


= التضمية وعلاتها بلإضا عن المياة لدى المرأة المتزوجة وغير المتزوجةت

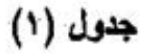

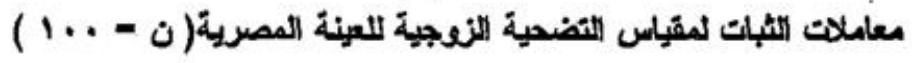

\begin{tabular}{|c|c|c|c|c|c|}
\hline \multicolumn{3}{|c|}{ معلعل الهبك } & \multirow[b]{2}{*}{ تم المداء طبرات التى } & \multirow{2}{*}{ اليمد التضموة } & \multirow[b]{2}{*}{$p$} \\
\hline معلدل جتملن & طرينة الاتهزية الثمطرة & ألـ كرونباخ & & & \\
\hline .YYA & .VAA & .APr & iv & 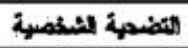 & 1 \\
\hline . १४. . * & .091 &.$A A A$ & $r$. & 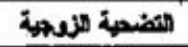 & $r$ \\
\hline ..A10 & .Aro & ..AYI & iv & . المتبل كلى & \\
\hline
\end{tabular}

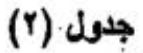

معاملات ارتباط درجة كل عبارة ودرجة البعد الذى تتمى إلبه

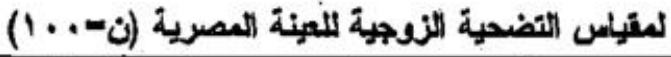

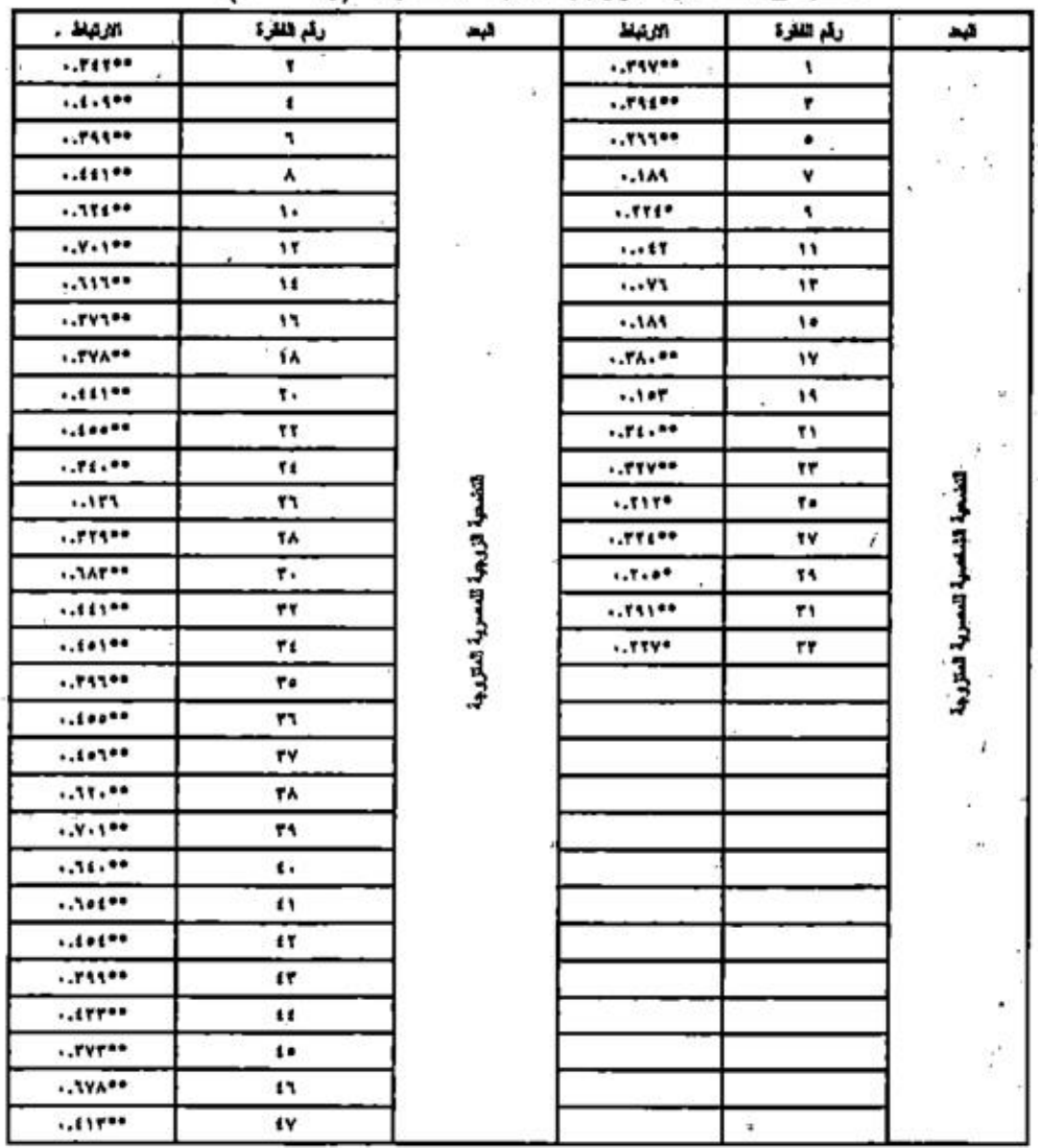

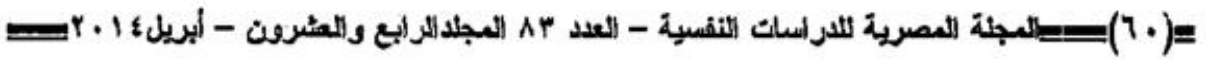




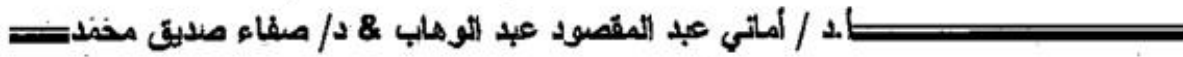

جدادل (r) )

معالم ارتهاط اليعاد مقيل التضصية الززوجة والثرجة الكلية على العينة العبرية

$(1 \cdots-0)$

\begin{tabular}{|c|c|c|}
\hline مستوى الادلانة & معامل الإرتهاط & الهع \\
\hline .1 & $\bullet \bullet, t \circ V$ & التضحية المخصية \\
\hline .1 & $\bullet \bullet, t, r$ & لمتضحوة القوحجة \\
\hline
\end{tabular}

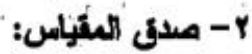

1. مسق المكمبن: حيث تم عرض المقياس على عشرة من المحكمين كما ورد نكره سابتا

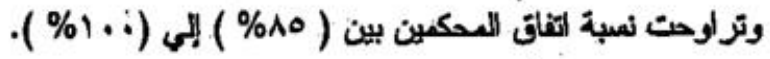

ب. إلمشق العاملى اللتصمية الزرجية:

تم حساب المبنق العاملى للتضحية الزوجية بهف التحتى من أن المقاييس الفرعية لمقياس

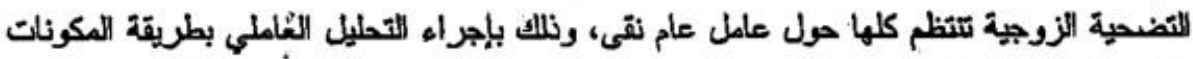

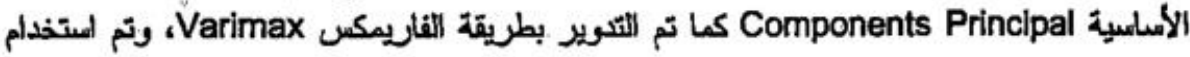
محك كايزر في الستخلاص العوامل، بحيث لا يقل الجنر الكامن لأى عامل من العوامل عن الواحد

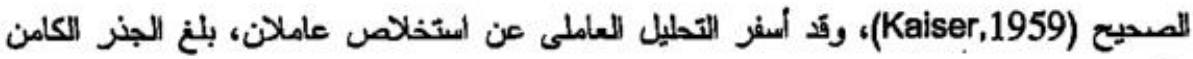

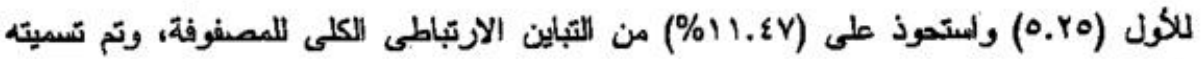

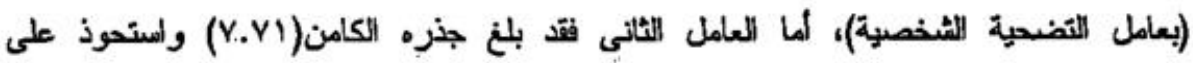

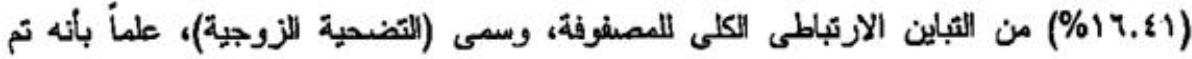

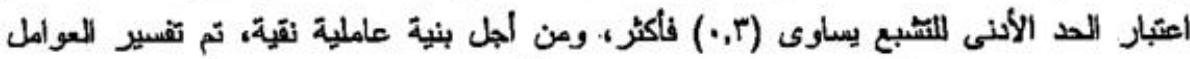

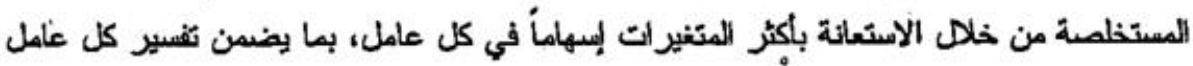

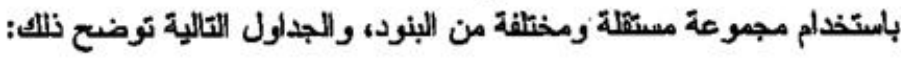

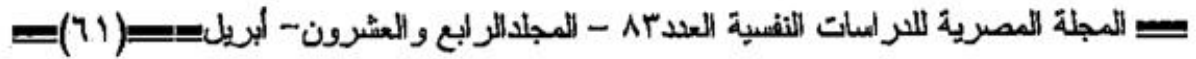


= التفحية وعلاقتها بالرضا عن لاحباة لدى المرأة المتزوجة وغيز المتزوجة= جلول (\&)

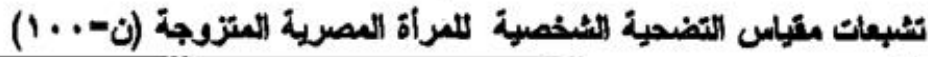

\begin{tabular}{|c|c|c|c|c|c|c|c|}
\hline هيt土 & كالs & 20 & مالم & 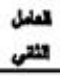 & Wintill & لعهرا & ind \\
\hline - & .rvit & 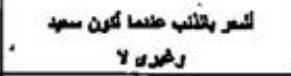 & 19 & - & $\infty \bullet 18$. & 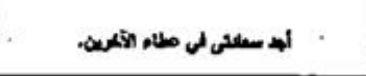 & 1 \\
\hline - & -.eor & 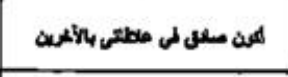 & ri & - & .,Pay & 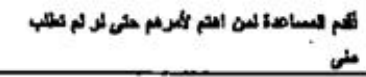 & $r$ \\
\hline - & .t.e & 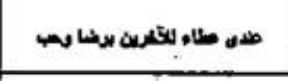 & sp & - & .trv & 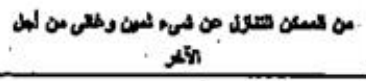 & - \\
\hline - & ., Dat & 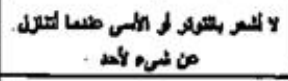 & T* & - &., 111 & 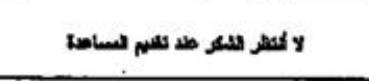 & $\gamma$ \\
\hline - & ..ras & 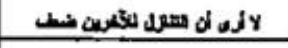 & ty & $\dot{-}$ & $\ldots+1$ & 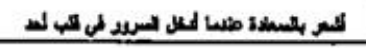 & 1 \\
\hline 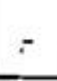 & $\cdots \bullet A 4$ & 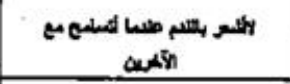 & 19 & & 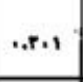 & 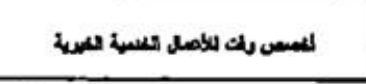 & 11 \\
\hline - & $\bullet . \bullet 4$ & 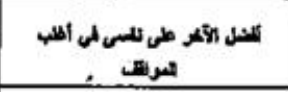 & pi & & .tr. & 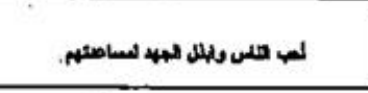 & ir \\
\hline - & ..०Y॰ & 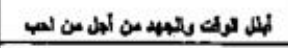 & $\mathrm{rr}$ & - &. .47 & 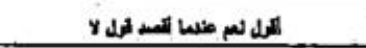 & 10 \\
\hline & & & & - & ..tra & 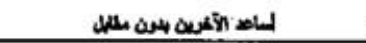 & in \\
\hline
\end{tabular}

جلمل (0)

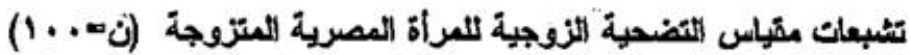

\begin{tabular}{|c|c|c|c|c|c|c|c|c|c|}
\hline \multicolumn{4}{|c|}{ 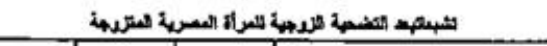 } & \multicolumn{6}{|c|}{ 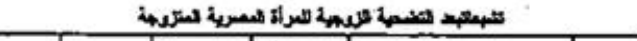 } \\
\hline (ה) & & Siln & 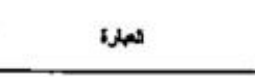 & ה & 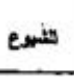 & Jales & $\begin{array}{l}\text { doll } \\
\text { dint }\end{array}$ & "العهلi & d \\
\hline .tr. & NFit & .,rts & 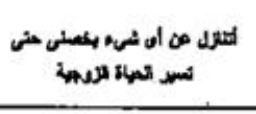 & Pr & ..1t & ..rYe & - & 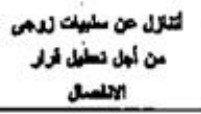 & $\uparrow$ \\
\hline - ler & ..pap & - & 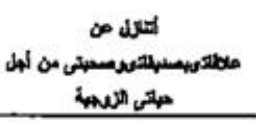 & $\mathrm{rt}$ & $\cdots 110$ & .rmi & - & 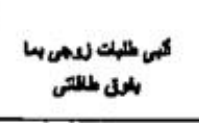 & \& \\
\hline$*$ ler & ..rit & $\cdot-$ & 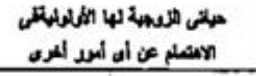 & $\mathbf{p \cdot}$ & .trtr & - & ..17. & 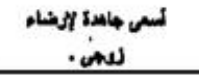 & 1 \\
\hline .rtet & .tr & - & 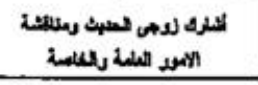 & $r$ & .tren & $\ldots 19$. & - & لمث كثر "اسطب & $\wedge$ \\
\hline NTAS & 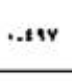 & - & 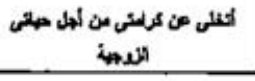 & rv & 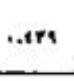 & $*$ vrr & - & 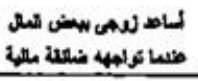 & 1. \\
\hline
\end{tabular}

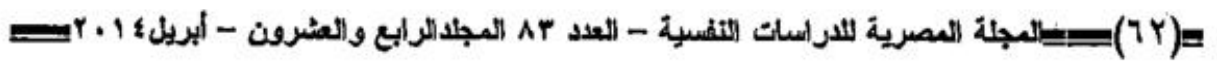




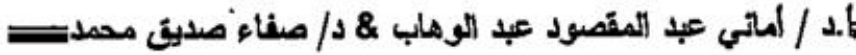

\begin{tabular}{|c|c|c|c|c|c|c|c|c|c|}
\hline \multicolumn{4}{|c|}{ 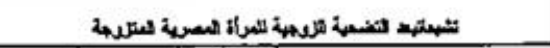 } & \multicolumn{6}{|c|}{ 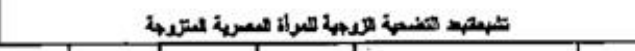 } \\
\hline תומש & 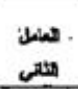 & in & لعهز3 & ה & ents & مئري & 4in & لعهزة & ر הر \\
\hline$\cdots \cdot \mathrm{r}$ & . . ate & - & 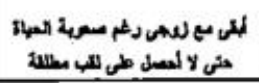 & $\mathrm{PA}$ & ...p & - rvav & - & 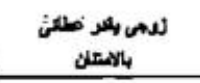 & $"$ \\
\hline$\ldots$ w4 & rvv & - & 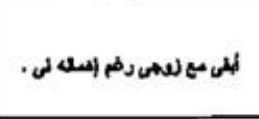 & ri & ..try & אירוי & - & 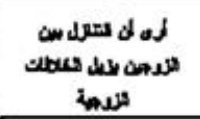 & " \\
\hline$\therefore$ isa. & ..."Y & - & 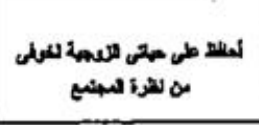 & 1. & .tit & ..rvr & - & 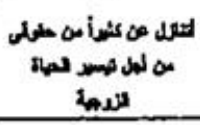 & $" 1$ \\
\hline$\ldots+14$ & $\therefore$.ris & $=$ & 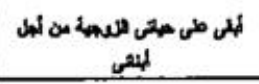 & "1 & ..tir & .tro & - & 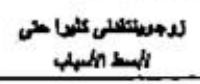 & in \\
\hline$\therefore$ rw & $\ldots+11$ & - & 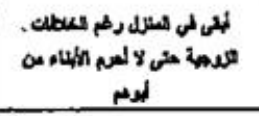 & $\because$ &., $\mathrm{rry}$ & יוג. & - & 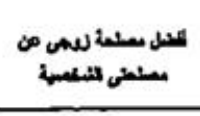 & r. \\
\hline .tur & - & 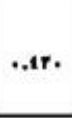 & 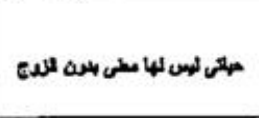 & ir & 4ו1 &. .154 & - & 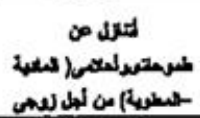 & $\pi$ \\
\hline ... & . Aav & - & 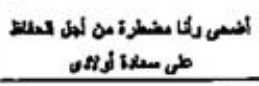 & 11 & . ו. & .r.t & - & 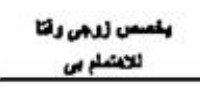 & $n$ \\
\hline ..ret & ..rol & - & 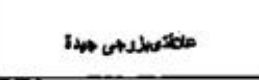 & 10 & $\cdots+r$ & $\cdots r+1$ & - & 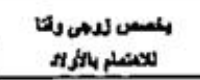 & n \\
\hline$\cdot . \mathrm{r}$ YA & זיו. & - & أشعى باظلى ما هذد من الملد & 11 & $\cdots+4$ & - r.r.4 & - & 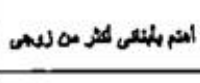 & in \\
\hline$\cdots 190$ & $\cdots, 41$ & - & 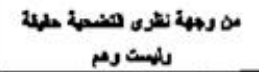 & sv & ..t4 & N.NA & - & 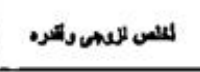 & P. \\
\hline
\end{tabular}

ويذاك تصبح الصورة النهاثية لمقياس التضحية المزوجية لدى الممرية المتزوجة تشكون من

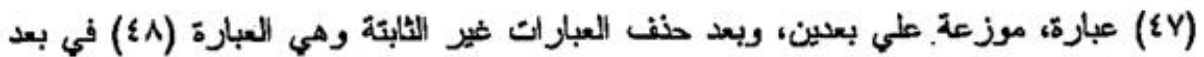
التضحية الزوجية، وإعادة ترقيم العبارلت تصبح الابعلد كما يلي:

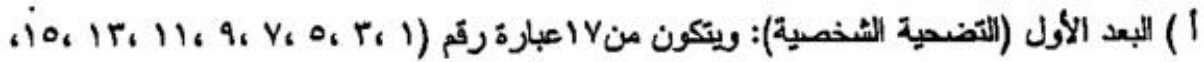
(r)، Yq، YV، YO، YY، YI، I9، IV

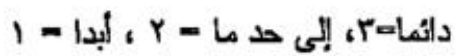

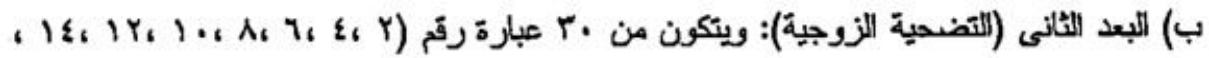

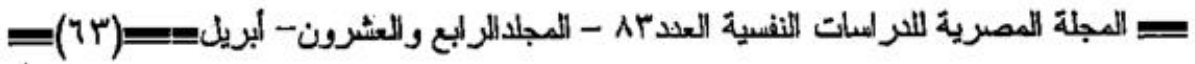


= التضمية وعلامتها بلرطا عن الحباة لدى العرأة العتروجة وغير المتزرجةت

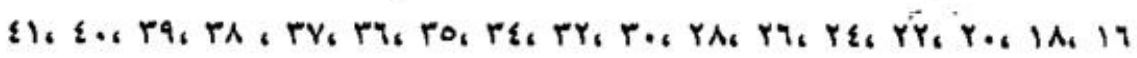

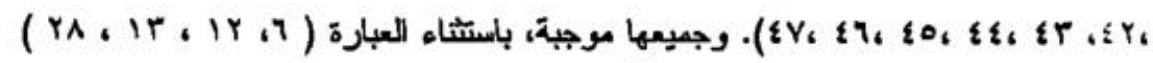

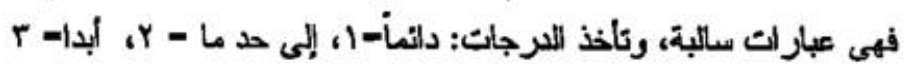

•متياس التضحية المرأة غير العتزوجة":

يثكون المتبام فى صورته الأولى من V9 عبارة موزعة على بعلين هما: التضحية الثخمية

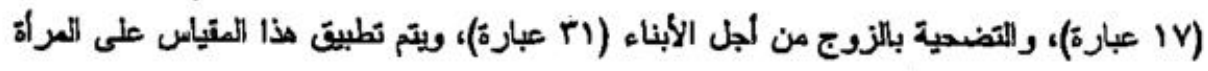
غير المتزوجةَ(مطلقة / أرملة). ا-ثبات المقياس:

(1) حساب معامل ألفا كرونباخ لعبارات كل بعد فرعي على حدة، وأسفرت ثلا الخطوة عن أن

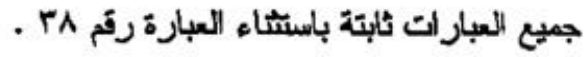

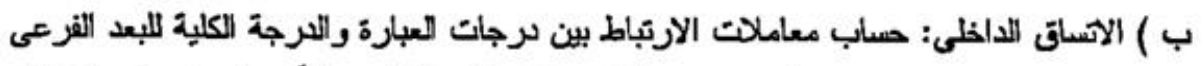

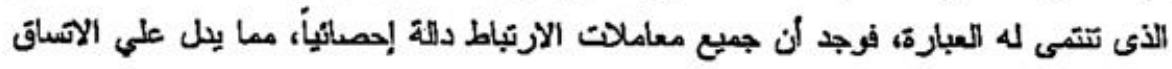
الأخلي وثبات عبارات المقياس.

ج ) تم حساب ثبات الأبعاد الفرعية والثبات الكلي للمقياس بطريقتين: الأوني عن طريق معامل

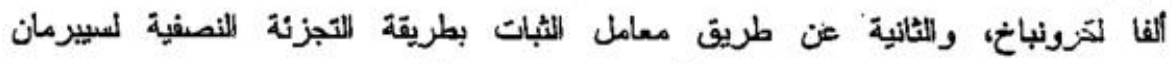

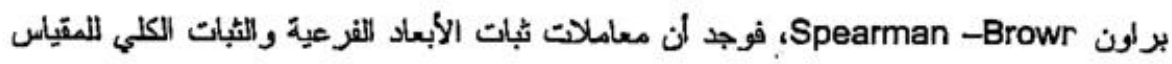

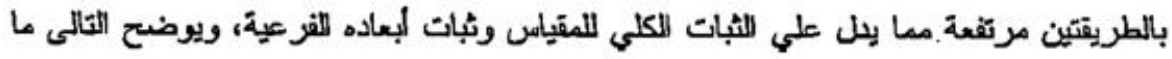

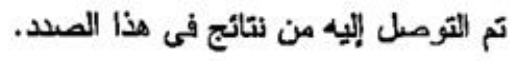




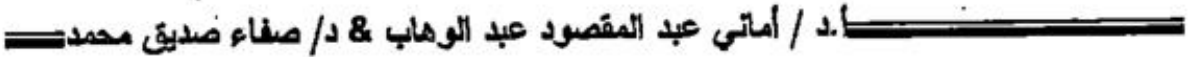

\section{جلول (ا)}

معاملات ثُبات الأبعاد للمرعية والثبات العلى لعقياس الثفصية لغير المتزوجات للعينة العصرية

$(0 .=0)$

\begin{tabular}{|c|c|c|c|c|c|}
\hline \multicolumn{3}{|c|}{ مسامل الثبات } & \multirow[b]{2}{*}{ عد تلعهارت } & \multirow[b]{2}{*}{ لبعاد التشعبة للعراء طير الثتزوجة } & \multirow[b]{2}{*}{$p$} \\
\hline معل جنمان & 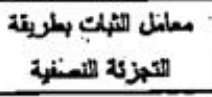 & كعلى كلئاخ & & & \\
\hline . .9TV & $. .911-. .914$ & ..AY9 & iv & لاتهمرية الثخصية & 1 \\
\hline .971 & -.9Yt & 0.9 .0 & $r$. & 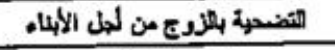 & $r$ \\
\hline ..AVr & . AYY &. $.91 \wedge$ & iv & لمقيل كکل & \\
\hline
\end{tabular}

(v) جلول

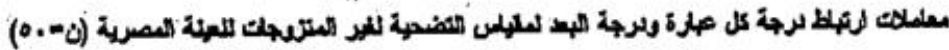

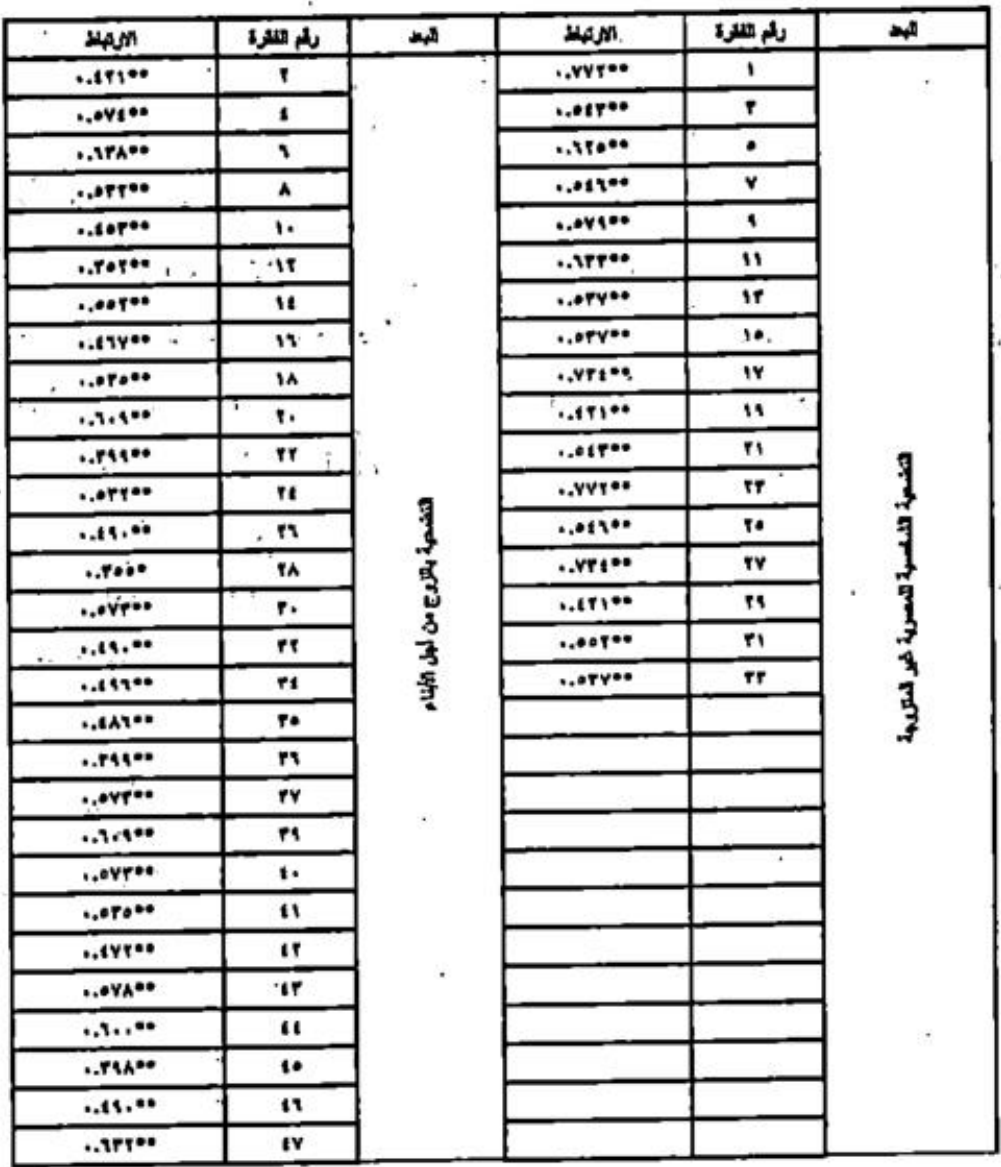

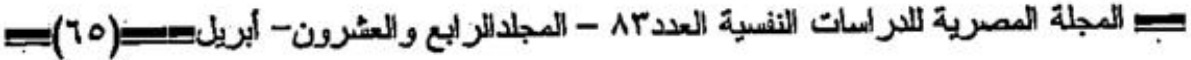


= التضحية وعلاتهها بالرضا عن الحياة لدى العراة المتزوجة وغير العتزوجةت

جدل جل

معامل ارتباط أبعاد العيكياس واللرجة العلية على العينة

\begin{tabular}{|c|c|c|}
\hline مستوى اللدلاة & معامل الارتباط & البعد \\
\hline. .1 & $\because, v \cdot r$ & التضمية الثخصية \\
\hline .1 & $\bullet \bullet$ & التفمية بالزرج من أجل الأبناه \\
\hline
\end{tabular}

ب- بدات العتراس:

| (1) مدق المكمين: حيث تم عرض المقياس على عشرة من المدكمين كما ورد سابقا، وتراوحت

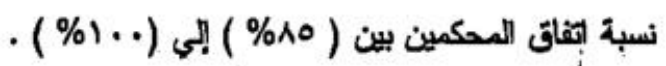

ب) الصنق العاملى: - (ب)

Components تم التحتق من ثلك بإجراء التحليل العاملى بطريقة المكونات الأسامية عrincipal

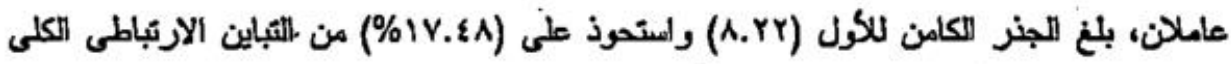

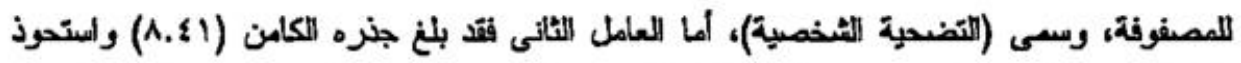
على (1V.14\%) من التباين الارتباطى الكلى للممفوفة، وسمى (التضحية بالزوج من أجل الأبناء)،

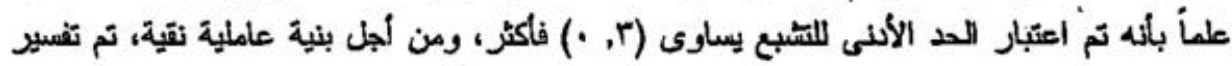

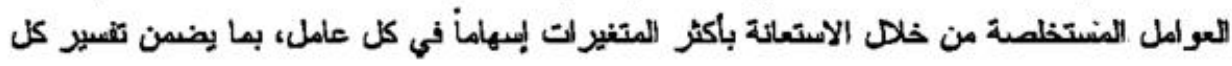

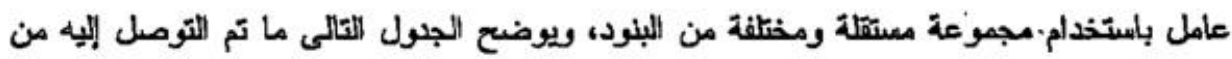
نتائج فى هذا المسند. 


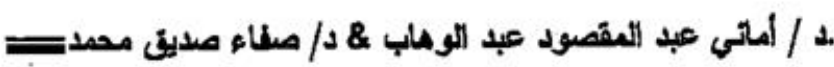

(१) هل

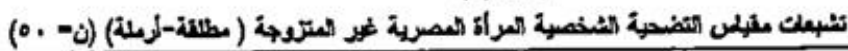

\begin{tabular}{|c|c|c|c|c|c|c|c|c|c|}
\hline \multicolumn{5}{|c|}{ 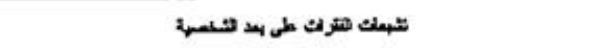 } & \multicolumn{5}{|c|}{ 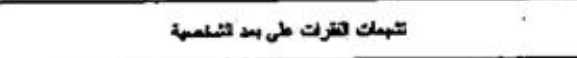 } \\
\hline העצع & لعلى & ה הلملف & "لعهلر5 & صدر: & 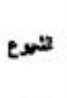 & הلمفل & الملول & تعهار: & رلمثم \\
\hline$\ldots 100$ & - & ..7.1 & 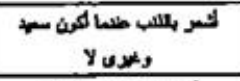 & 19 & -.700 & . ria & $\ldots, r$ & لهد سملثم فلم هلا. & 1 \\
\hline 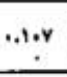 & ..r.1 & - & 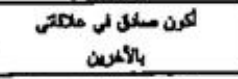 & 1 &. $.4 v$ & - & ..r.1 & 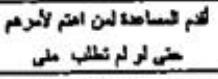 & $r$ \\
\hline .0700 & . FIA & $.0 .0 \%$ & 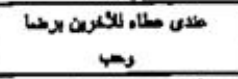 & $\mathrm{Tr}$ & $\theta+r \cdot r$ &., $4 t \mathrm{~T}$ & $\because \mathrm{rrr}$ & 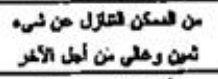 & 0 \\
\hline . $r$ rtr & - & . & 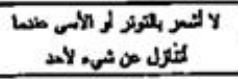 & ro & .trve & - & $\Rightarrow\{(\lambda)$ & 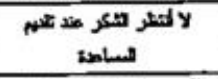 & $V$ \\
\hline - TAT & - & $\therefore$ ¿.010" & 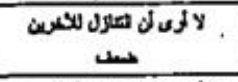 & ry & , rrv & .rri & $\cdot . t 4 t$ & 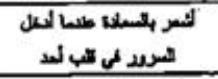 & 9 \\
\hline ,100 & i.tri & - & 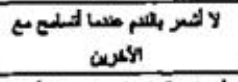 & rq & .114 & .091 & $\cdots r+1$ & لفمس ولت للأكل & 11 \\
\hline 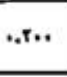 & , f.r & - & 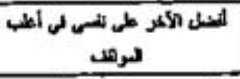 & n & ויויו & - & . TAA & 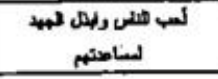 & ir \\
\hline צו14 & - & trAT & 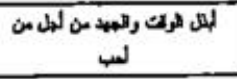 & $\mathrm{rr}$ & וזו. & - & \#AY & 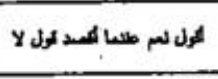 & 10 \\
\hline & & & & & . .rar & - & $\ldots 090$ & 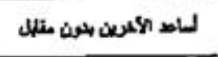 & IV \\
\hline
\end{tabular}

(1.) جله

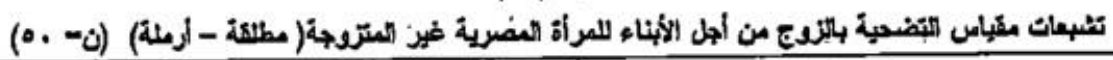

\begin{tabular}{|c|c|c|c|c|c|c|c|c|c|}
\hline \multicolumn{5}{|c|}{. } & \multicolumn{5}{|c|}{ 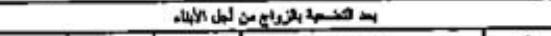 } \\
\hline تصع & הل & ה המנt & נהلי & 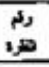 & قتوع & המה & Sold & 3als & 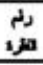 \\
\hline $.000 Y$ & - & $2, \mathrm{rt}$. & 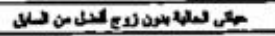 & $\pi$ &.. $\mathrm{mr}$ & $.0 \mathrm{nis}$ &., $0 n$ & 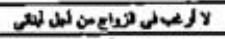 & $T$ \\
\hline. $.0 \% 1$ &.$v m$ & - & 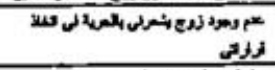 & $\mathrm{rt}$ & .0114 &..$t r i$ & ,., & ملى كلاه & 1 \\
\hline$\ldots+$. &. .61. & $=$ & 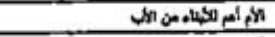 & ro &. .76 . & - & ..ott & 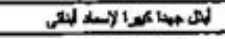 & 1 \\
\hline$.+1+1$ & .,tro & - & 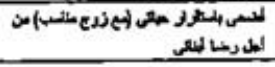 & $n$ & wivo & - & 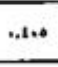 & 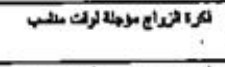 & A \\
\hline . & - & $*, v r$ & لU رلهن المسب & $\mathrm{rv}$ & wet & - & . & 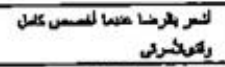 & I. \\
\hline. .198 & .Ave & - & 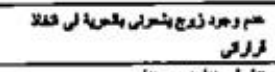 & $\mathrm{ra}$ & $, \quad, r \cdot y$ & - & .,etr & 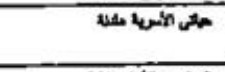 & "r \\
\hline$\ldots$ &., $147=$ &..$v v$. & Tho & $m$ &. $\mathrm{nit}$ & $\therefore \infty$ & - & 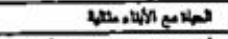 & 11 \\
\hline wrar &. $.1 n$ & - & 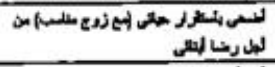 & t. &. .101 & , tat & $\because$ & (1) & $" 1$ \\
\hline-110 &..++1.1 & - & 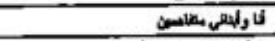 & ") & . . TAY &., 15 & - & NDE- & in \\
\hline .tor &..$t \mathrm{tv}$ & $=$ & 284 & t4 &. $.14 \%$ &., 19. & $=$ & 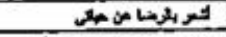 & t. \\
\hline . $.17 t$ & .,ur & - & 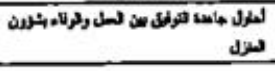 & ir &. $.1 \cdot 1$ & .tre & - & 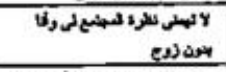 & rt \\
\hline ..ter & - & ... & 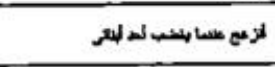 & II &,++180 & - & $\rightarrow 1.0$ & 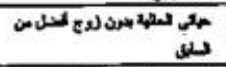 & it \\
\hline $.000 \mathrm{v}$ & $=$ &.,$v 1 \cdot$ & 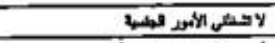 & 10 & $\therefore .00 y$ & - & s,vi. & 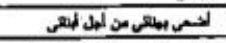 & $n$ \\
\hline. $.07 \mathrm{~A}$ &.., 4. & - & 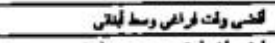 & 4 & $. .6+1$ &. $.5 \mathrm{sq}$ & - & 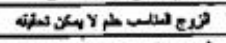 & Ta \\
\hline 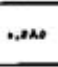 & .r.tin & - & 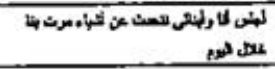 & ir & .,11r & - & $\omega \mathrm{rr}$. & 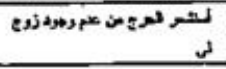 & T. \\
\hline
\end{tabular}

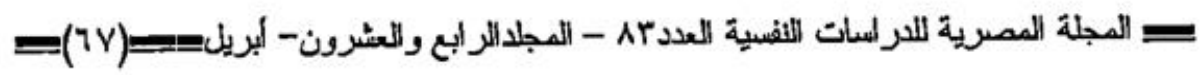


= = التفبِمية وعلاقتها بالرضا عن الحياة لدى العراة المتزوجة وغير المتزوجةَت ويذلك تمبح الصورة النهاثية لمقياس الثضحية لدى المرأة المصرية غير المتزوجة تٓكون من (IV)

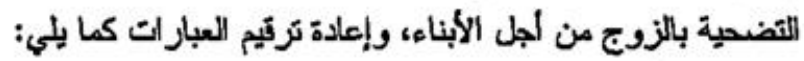

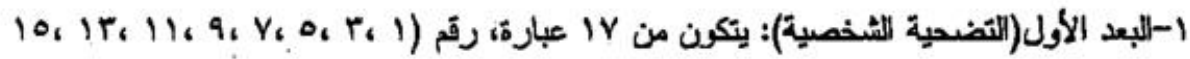
( rr، MI، Y9، YY، YO، Yr، YI، I9، , IV

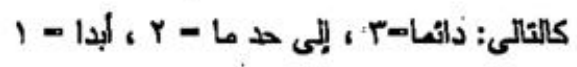

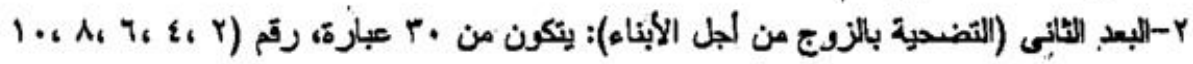

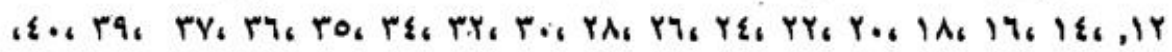
(Y)

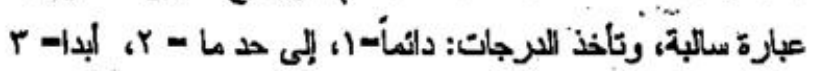

ثاتيا: العزية العسودية:

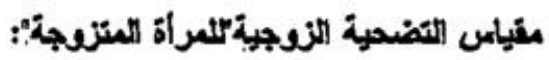

ا- أبات البتياس:

1) حساب معامل ألفا كرونباخ لعبارات كل بعد فرعى على حدة، وأسفرتب تلك الخطوة عن أن

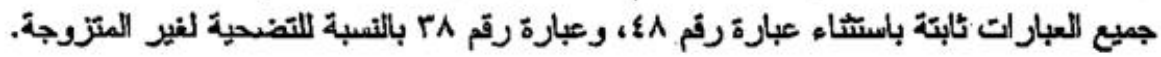

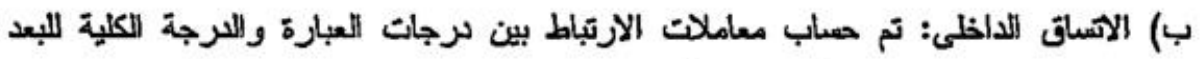

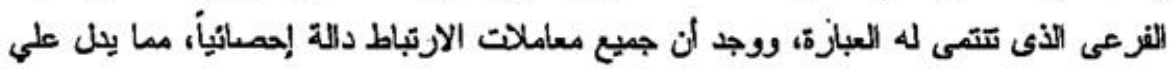

الآساق الاخلي وثبات عبارات مقياس التضحية للمرأة المتزوجة.

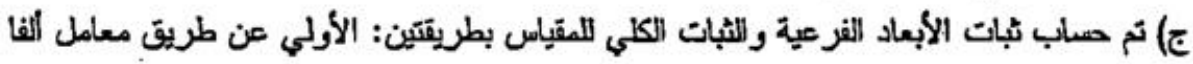

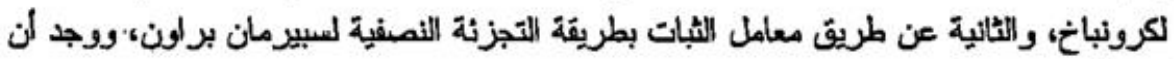

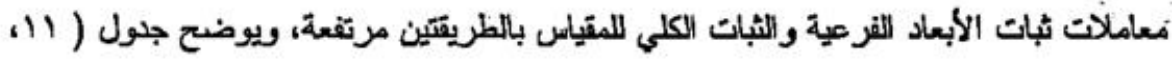

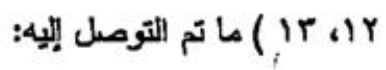

جلمل (ii)

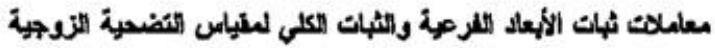

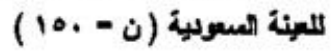

\begin{tabular}{|c|c|c|c|c|c|}
\hline \multicolumn{3}{|c|}{ مبلكل كيلك } & \multirow[b]{2}{*}{ عد الههرت } & \multirow[b]{2}{*}{ 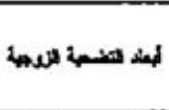 } & \multirow[b]{2}{*}{; } \\
\hline 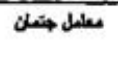 & 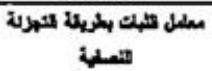 & 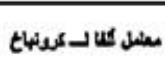 & & & \\
\hline$\therefore$ AAt. &..$A 11$ & .A.A4 & is & 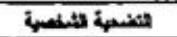 & 1 \\
\hline$. . A . Y$ & $., A, 9$ & $\therefore 11 A$ & $r$ & 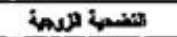 & $T$ \\
\hline ..vas. & . . &., $1+4$ & ty & 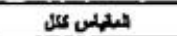 & \\
\hline
\end{tabular}

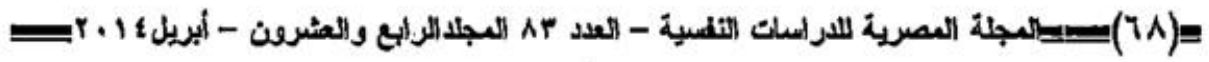




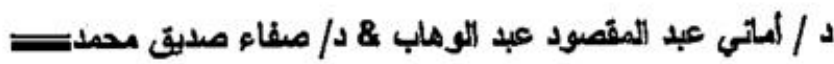

$$
\text { جلول (i ) }
$$

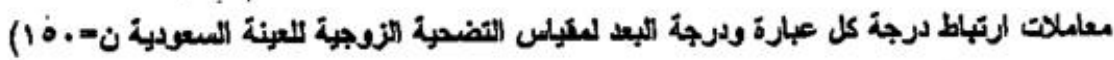

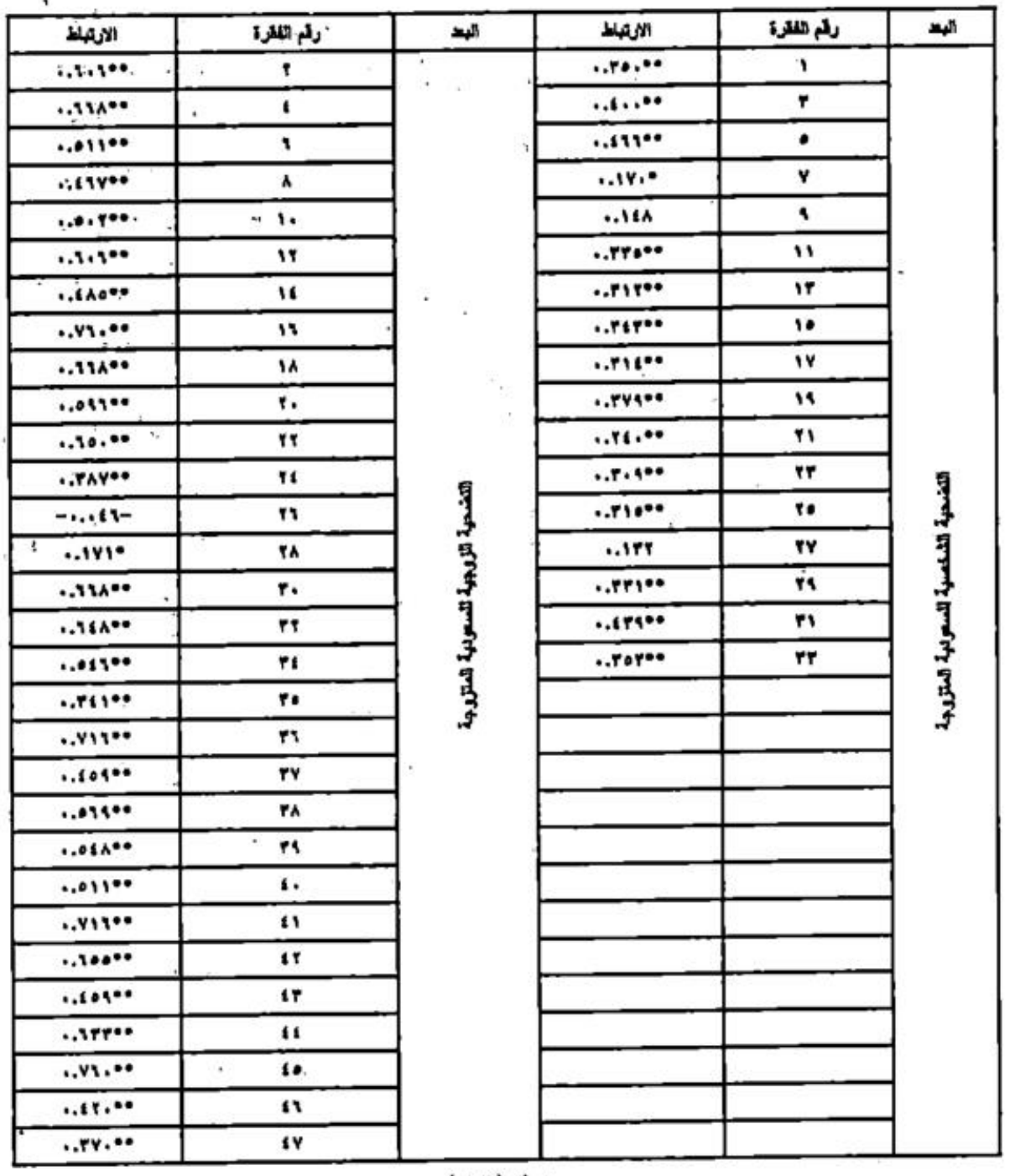

جلول (ir)

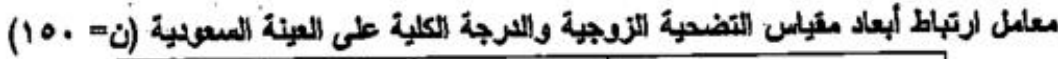

\begin{tabular}{|c|c|c|}
\hline ممتوى الدلالة & معاعل الأرتباط & البعد \\
\hline .1 & $\bullet \bullet, 0 \mathrm{VA}$ & التمنحية الثخصية \\
\hline .1 & •..qYr & التضفية الزوجية \\
\hline
\end{tabular}

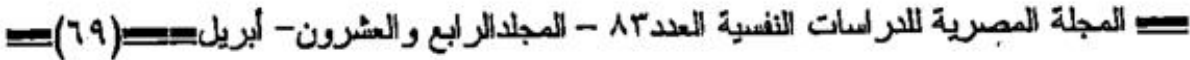


= التضصحية وعلاقتها بالرضا عن الحياة لدى المراة المتزوجة وغير المتزوجةت (1) صدق المحكمين: نفس الإجراء العابق، وقد تم حنف العبارات رقمبr (حياتى اليومية مليئة بالأشياء المهمة).

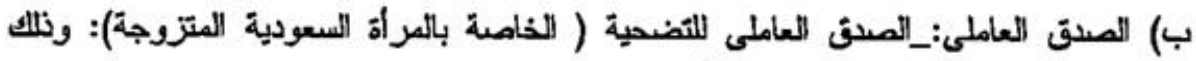
بهن التحتى من أن المقاييس. الفرعية لمقياس التضحية تتظم كلها حول عامل عام نقى، بإجراء التحليل العاملي بطريتة المكونات الأساسية كما تم التكوير بطريقة الفاريمكن، واسفر التحليل

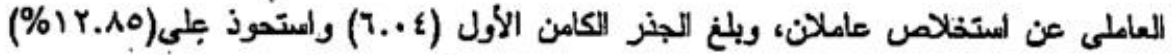

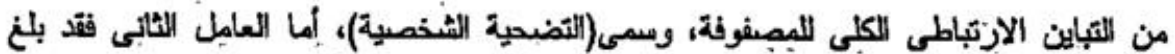

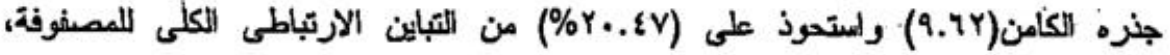

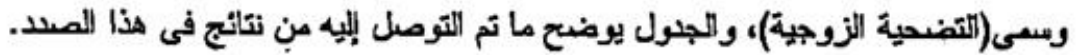

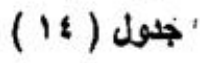

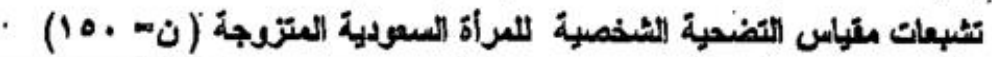

\begin{tabular}{|c|c|c|c|c|c|c|c|c|c|}
\hline \multicolumn{5}{|c|}{ تشيع همد الشفصبة للمرأة المتزوج2 } & \multicolumn{5}{|c|}{ 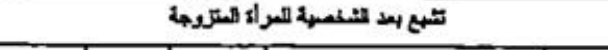 } \\
\hline الثروع & العالثل & الإلانل & ال الهار5 & دأل & لهويع & להוt) & الاولمل & لالهارة & קה \\
\hline.$r i$ & - & $.001 \mathrm{~A}$ & 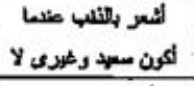 & $\stackrel{19}{?}$ & $\because$ ria & - & $\ldots t 74$ & إلهد سعانتى في مطلا. & 1 \\
\hline .ryi & - & $.01 \%$ & 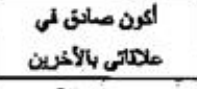 & YI & .rqI & - & $\cdots 1.1$ & 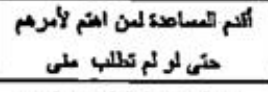 & $r$ \\
\hline 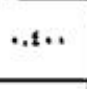 & - & $\cdots r r$ & عثلى عطاء للكلخرية & rT &. $.4 r$. & - & ."r! & 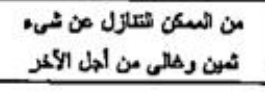 & - \\
\hline$\therefore$ rry & - &. .019 & 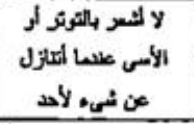 & ro & ar.o & - & $\cdot .80$ & 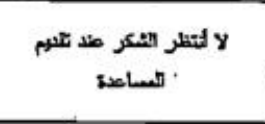 & $\mathrm{v}$ \\
\hline$\cdots 104$ & - & .rAr & 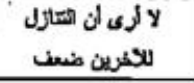 & rv & .rTi & - & . & 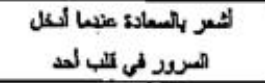 & 1 \\
\hline .rar & - &. .051 & 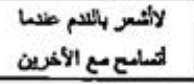 & ri & .ro9 & - & 0.0 .7 & أكمص ركت اللأعمال الخثبة & 11 \\
\hline . & - &. $.00 \mathrm{f}$ & 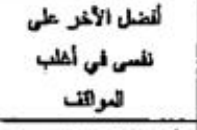 & $r$ & $\cdots 0 \$ 1$ & - &..$Y t$ & 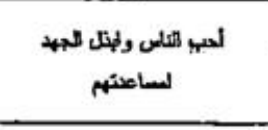 & ir \\
\hline irAT &.$^{-}$ & $\cdots .0 \% 0$ & 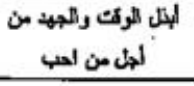 & rr & $\cdots 12 A$ & - & .rma & 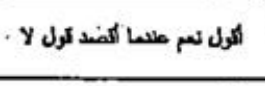 & 10 \\
\hline & & & & &..$t r y$ & - & .114 & لماء الأخرئ بهن مقالما & ir \\
\hline
\end{tabular}

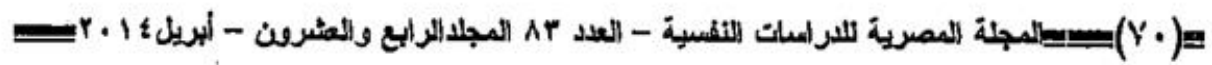




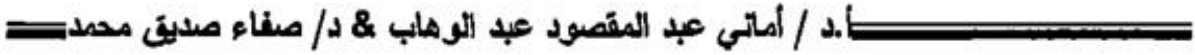

جلمل (10)

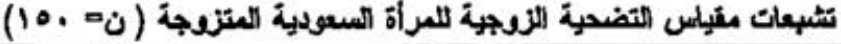

\begin{tabular}{|c|c|c|c|c|c|c|c|c|c|}
\hline \multicolumn{5}{|c|}{ 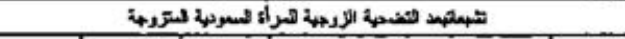 } & \multicolumn{5}{|c|}{ 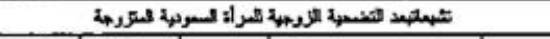 } \\
\hline העצr & لمالد & العلط & لالعهار: & ملرة & 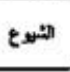 & تعلى & العلدل & 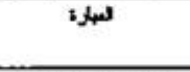 & ر5 \\
\hline 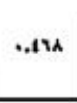 & iri & - & 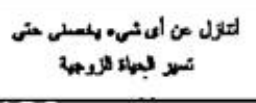 & $\mathrm{rT}$ &., $4 t$ &. $.04 \mathrm{Y}$ & - & 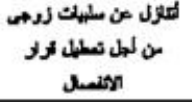 & r \\
\hline - rat & .011 & - & 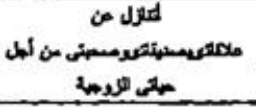 & $\mathrm{ri}$ &., 010 & •.ข1 & - & 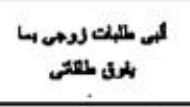 & $t$ \\
\hline$\bullet .110$ & $+r \cdot 1$ & - & 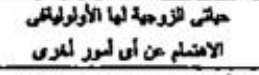 & ro & $\bullet, \mathrm{rrT}$ & .0 .199 & - & للمى جاسش لأرشا. & y \\
\hline., $0 \mathrm{r}$. &.. $\mathrm{YTO}$ & - & 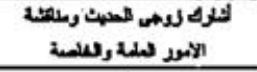 & $n$ &.. $\mathrm{Tr}$ & $\cdot, \mathbf{1 0 1}$ & - & لدمي كثر المطاب & $\wedge$ \\
\hline$\bullet, \mathrm{Ter}$ &., 018. & - & 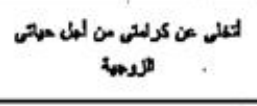 & $\mathbf{r y}$ & וז & $=.01$ & - & 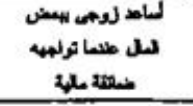 & 1. \\
\hline .trt & ..894 & $\because$ & 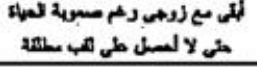 & ra & $\bullet .14$ &. $.04 Y$ & - & 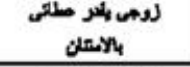 & ir \\
\hline. $.7 r i$ & $.09 \mathrm{~A}$ & - & 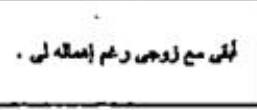 & ra & - rrrt & $\cdot .201$ & - & 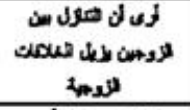 & it \\
\hline.$+r i t$ & ..०YI & - & 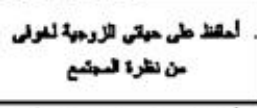 & s. & .tr9 & .nr & - & 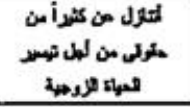 & 19 \\
\hline ..or. & , vrto & - & 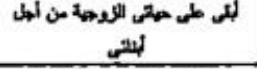 & 11 &., 010 & •.tרז & - & 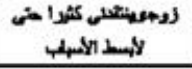 & iA \\
\hline .ttri & .201 & - & 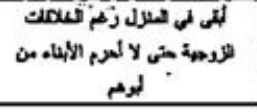 & ir & .tror &., 014 & - & 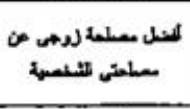 & r. \\
\hline int & .tev & - & 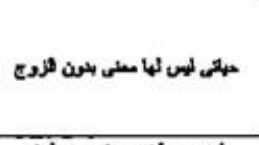 & IT & .ats & .WA & - & 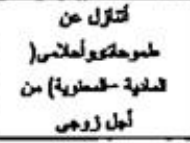 & r \\
\hline., 111 & $\rightarrow \mathrm{u}$. & - & 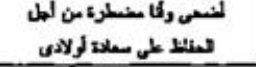 & if & .tro & $\bullet$ riv & - & 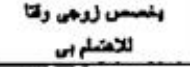 & VI \\
\hline *.ri & "nir & - & 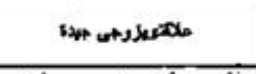 & 10 &. .110 & - tr. & - & 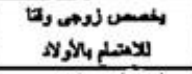 & $\mathrm{n}$ \\
\hline. $.1 r$ & -,Pat & - & 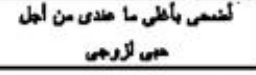 & (1) & 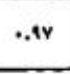 &.++1 & - & 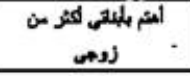 & ra \\
\hline$*, 1 n$ & $\rightarrow r 9$ & - & 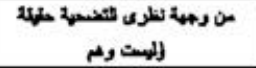 & IV & 010 & .tvr & - & لكامن لأوجم دالهر. & r. \\
\hline
\end{tabular}

وبنلك تصبح الصورة النهائية لمقياس اللتفحية لدى السعودية المتزوجة شكون من (Vأ) عبارة، موزعة علي بعلين، وبعد حفف العبارلت غير الثابتة، وهي العبارة (^؛) وإعادة ترقيم العبار ات تصبح الإبعاد كما يلي:

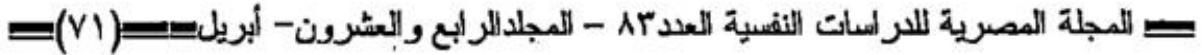


= التضحية وعلافتها بالرضا عن المراة لدى المراة المتزوجة وغير المتزوجة=

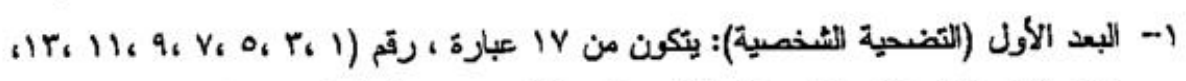
(Y)، Y9، YY، YO، YY، YI، I9، IY، 10

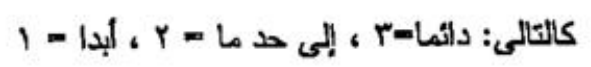

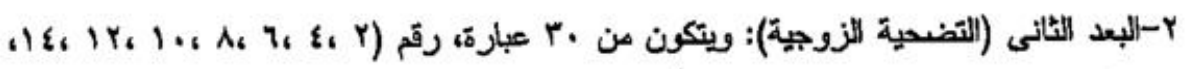

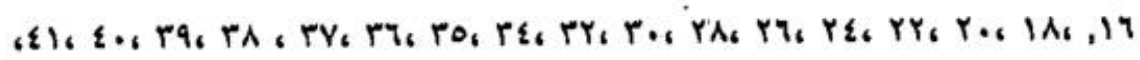

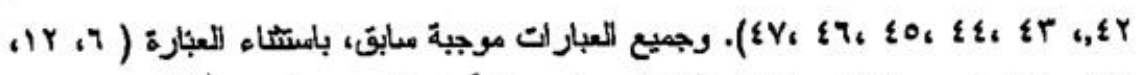

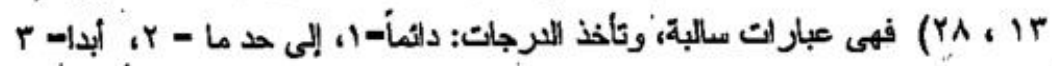

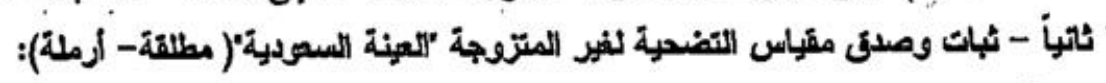
ا-ثبات المقتواس:

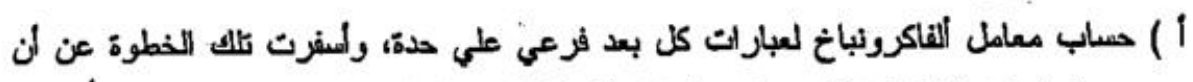

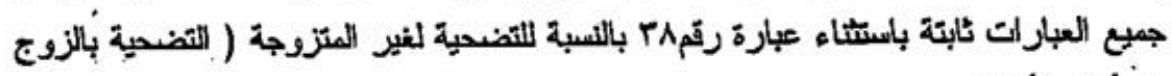
من أجل الأبناء).

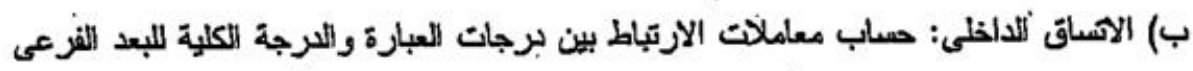

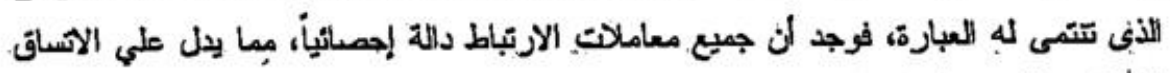

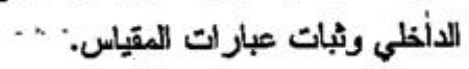

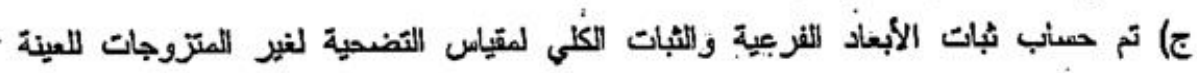

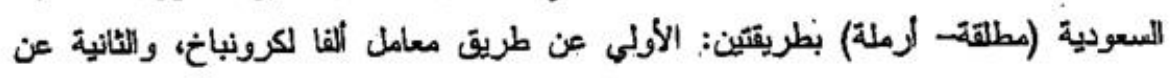

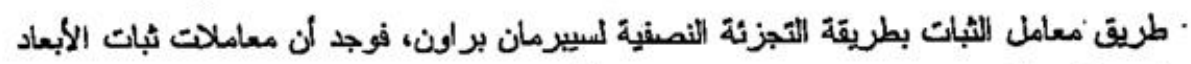

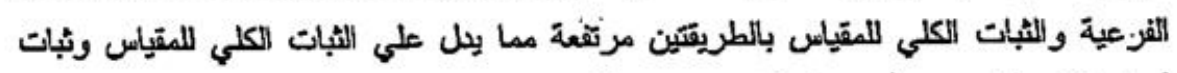

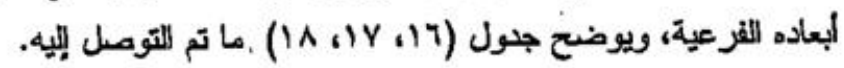

$$
\text { جلول (17) }
$$

\begin{tabular}{|c|c|c|c|c|c|}
\hline \multicolumn{3}{|c|}{ معامل الإبات } & \multirow[b]{2}{*}{ عد اللعبارات } & \multirow[b]{2}{*}{ البعاء التمنمبة لفير المتتوجات } & \multirow[b]{2}{*}{ P } \\
\hline متهان & معامل الثبات بطريتجة & كعرومل ألثالـ & & & \\
\hline . .१99 & 1 & $.91 \mathrm{~V}$ & iv & 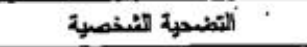 & 1 \\
\hline . . १А. & ..१A. & ..9Y. & r. & لتتشحية بلزّوع من لجل الائنا. & $r$ \\
\hline -.97ו & .911 & .971 & iv & "لمتياس كسن" & \\
\hline
\end{tabular}

مغاملات ثبات الأبعاد والثبات الكلى لمقياس التضحية لفير المتزوجات للمبنة السعودية( نه . م)

(VY)= 


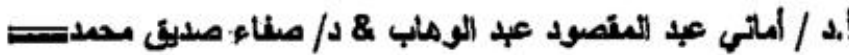

$$
\text { (IV) جلون }
$$

معاملات لرتباط رجة كل عبارة ودرجة لالبعد الأى تثتىى إلبه

\begin{tabular}{|c|c|c|c|c|c|}
\hline $40 \mathrm{~m}$ & 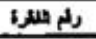 & $\Rightarrow$ & H4n & 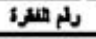 & A \\
\hline$\ldots \circ A A=0$ & 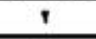 & \multirow{12}{*}{ 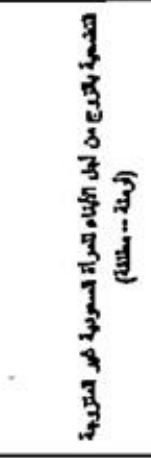 } & .010400 & 1 & \multirow{12}{*}{ 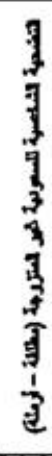 } \\
\hline ..opsioe & 1 & & \#AIV"0 & $\boldsymbol{r}$ & \\
\hline •.•v"•• & 1 & & $0.404^{\circ 0}$ & $\bullet$ & \\
\hline .,1.ver. & $A$ & & C.Aire* & $\checkmark$ & \\
\hline ..et100 & 1. & & 0.90400 & 1 & \\
\hline$+\infty 008$ & if & &., 90400 & 11 & \\
\hline ,.,10, & 11 & & .10s00 & ir & \\
\hline ..vFte* & 15 & & DAlyoe & 10 & \\
\hline ., tFver & in & & .96400 & iv & \\
\hline., 19.00 & r. & & 0.90900 & 14 & \\
\hline ., & ir & & 0.40900 & 11 & \\
\hline .214ter & $\mathrm{TI}$ & & 0,40400 & $\mathrm{Ir}$ & \\
\hline nOAA & $n$ & & .AIY"E & 10 & \\
\hline . .1010 & in & & •A1Y"0 & $\mathrm{rv}$ & \\
\hline ..0170* & $r$. & & 090900 & rs & \\
\hline . & $\mathrm{rT}$ & & .As? & PI & \\
\hline nurte. & $\mathbf{P i}$ & & n.109.0 & $\mathbf{T r}$ & \\
\hline norsec & $r$ & & & & \\
\hline$\ldots+1 \cdots$ & $\mathrm{rr}$ & &. & & \\
\hline . .179" & Fv & & & & \\
\hline ..erse. & $r$ & & & & \\
\hline \#1.ver & 1. & & & & \\
\hline ..1.1.. & 11 & & & & \\
\hline .,otev & 17 & & & & \\
\hline \#.r.t. & ir & & & & \\
\hline ..et19. & 11 & & & & \\
\hline ..tren & to & & & & \\
\hline ..19... & 14 & & & & \\
\hline$\ldots \bullet A A^{\prime} \bullet \bullet$ & ty & & & & \\
\hline
\end{tabular}

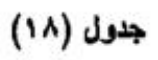

معامل ارتباط أبعاد المتباس والارجة العلية على المان

\begin{tabular}{|c|c|c|}
\hline مستوى الدلالة & معامل الارتباط & 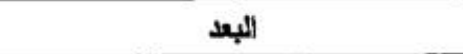 \\
\hline, 1 & $\bullet \bullet, 9$ YY & التضحية الثخمية للمرأة غبر المتزوجة \\
\hline.+1 & $\bullet 1$ & التضحية بالزوج من أجل الأبناه \\
\hline
\end{tabular}

$$
\text { العينة السعودية (ن) 10. }
$$

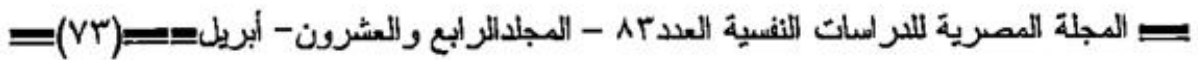


= التضحية وعلافتها بلرضا عن الحياة لدى المراة المتزوجة وغير المتزوجة= ثاتياً - مدت المقياس التفمية للمراة غير المتزوجة( المطلقة / الأرملة):

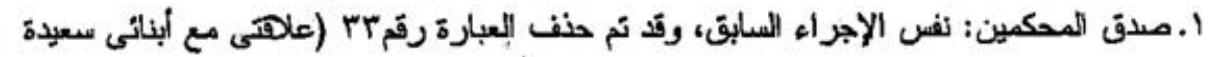

\section{ومحبية ).}

r. الصنق العاملى: السنر التحليل العاملى عن استخلاص عاملان، حيث بلغ الجذر الكامن الأول

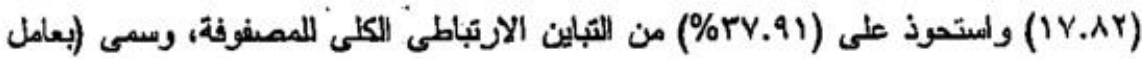

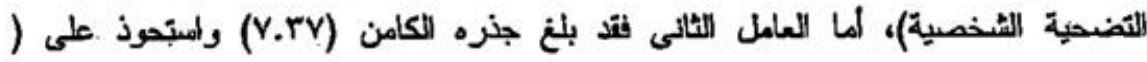

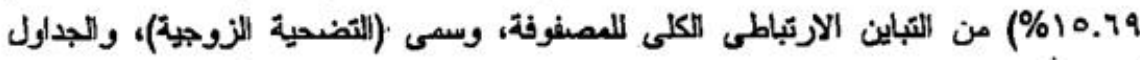
, ألثالية توضح ذلبك:

جلول (19)

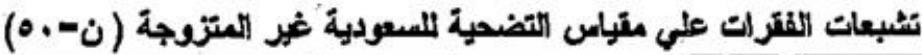

\begin{tabular}{|c|c|c|c|c|c|c|c|c|c|}
\hline \multicolumn{5}{|c|}{ 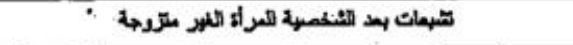 } & \multicolumn{5}{|c|}{ 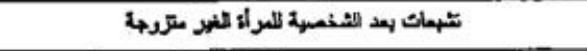 } \\
\hline ה ה4وع & الكالمل & الألأل & التهارن: & داند: & كוקوع & المثلى & الإلعل & 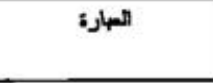 & لمثر: \\
\hline.. $\mathrm{AV} 9$ & - &. .119 & 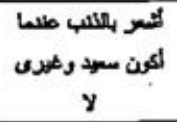 & 19 & ..AYY & - & .019 & الجد سماتكى فلم عطا. & 1 \\
\hline$\therefore$ AVG & - & - ANA & 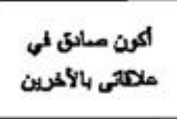 & r &. $.1 r i$ & - & TIVIT & 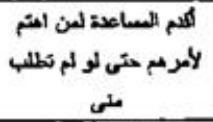 & $r$ \\
\hline$\cdot$. Avq & - &. .119 & علدى بطاء للكنين & $r r$ & $\cdot . \mathrm{AYq}$ & - & $\because 419$ & 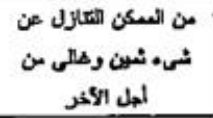 & - \\
\hline. .149 & - &. .var & الأمسم طنس التكارل & ro &. $.1 m$ & - &..$v a r$ & 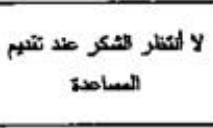 & $\mathbf{v}$ \\
\hline. $.1 \%$ & - & . .rar & لالأرى الن المبازل & TY & . AYY & - & .AMG & 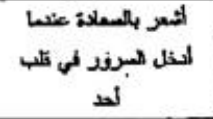 & 4 \\
\hline$\cdot$. Av9 & - &.. $\mathrm{AA9}$ & 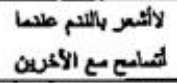 & Yq & $\therefore$ Av9 & - & $\therefore$ ANA & الكمصن ركت اللاعمنان & 11 \\
\hline 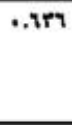 & - & . .var & 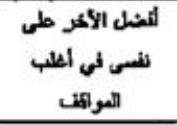 & $r i$ & ..Av9 & - & $\because$ As9 & الحب الثلاس وليتل الجها & ir \\
\hline ..AY9 & - & $\cdot .1199$ & أيلت تلوكت وللجهث . & $r r$ & ..tra & - & +.,Yar & المول نعم مثلعا أكمد كول & 10 \\
\hline & & & & &. .AYs & - &. .119 & أساع الأكرين يدون & ir \\
\hline
\end{tabular}

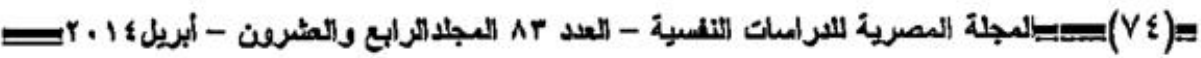




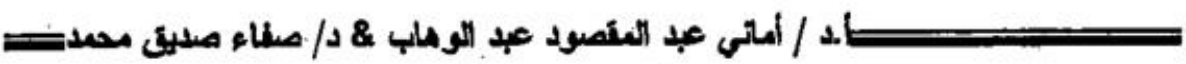

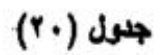

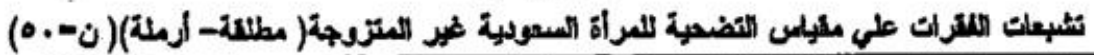

\begin{tabular}{|c|c|c|c|c|c|c|c|c|c|}
\hline \multicolumn{5}{|c|}{ 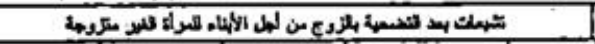 } & \multicolumn{5}{|c|}{ 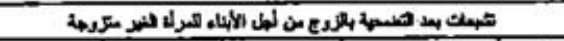 } \\
\hline ENis & لعلد الفعى & العلد الأول & 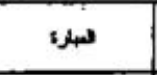 & رئم & ש & العلى هيك & لمدل الاورن & لسيرا & קהر \\
\hline .rir &..$t r$ & .0 .74 & 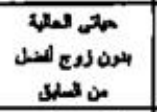 & $\dot{r}$ &., 0 ר &. vis & - & 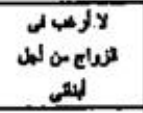 & r \\
\hline . otr. &. ril & $=$ & 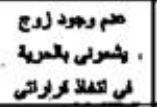 & Ti & , rar & . & - & مال & -1 \\
\hline .rar & 'וn & - & 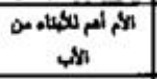 & ro & irir & .019 & - & 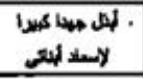 & 3 \\
\hline. .191 & .rmi & ..rit & 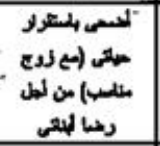 & $n$ &., 001 &. vre & $=$ & 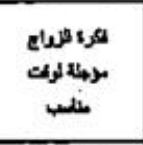 & $A$ \\
\hline .NAt & ..tor & - & مالمين & $\dot{r}$ & $\stackrel{\mathrm{rrt}}{\cdot}$ & .r.to9 & $\begin{array}{c}i \\
. .10 .\end{array}$ & 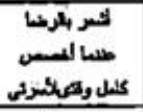 & 1. \\
\hline :.rar & ..vr & - & 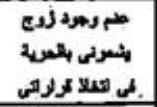 & ra & .trr. & .rus & $\because$ & 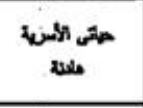 & ir \\
\hline .000 &. vrto & $\because$ & 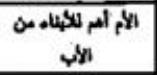 & m &. .149 & ווזr. & •,ril & 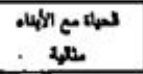 & 16 \\
\hline ..rrr & ..rrt & - & 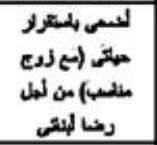 & t. & $\therefore$ orr & ו ו & - & 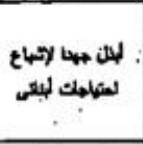 & 17 \\
\hline ..rir. & $\cdot, r a i$ & $-\cdots$ & الهمبث & (1) & +.1. &..$v v i$ & $-\cdots$ & طم ريود لدع & in \\
\hline ..ory & . Wht & - & 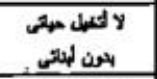 & ir & .,tYA & - tay & - & 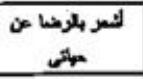 & T. \\
\hline. $\mathrm{rrr}$ & ..10. & "ron" & 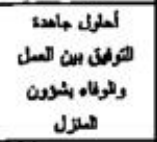 & ir &., $1 A 7$ & i.ror & - & 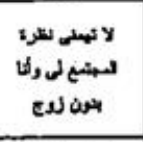 & Tr \\
\hline ..4r & ..trY & -1 & 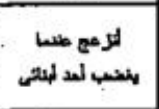 & it & .rir & וtrit & . & 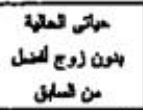 & Ti \\
\hline . IYA & .VAY & - & لا تشطئس الأبهد & 10 & .nis &. .09. & - & 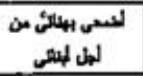 & T1 \\
\hline .. nn & '.ris & - & 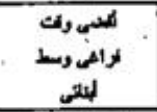 & ti & .tur & .10. & - & 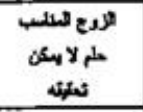 & $r A$ \\
\hline , 1. & '.rvt & - & 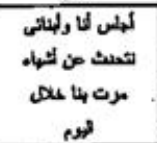 & tr & erir & צו. & - & 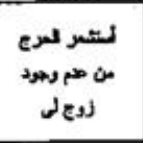 & r. \\
\hline
\end{tabular}

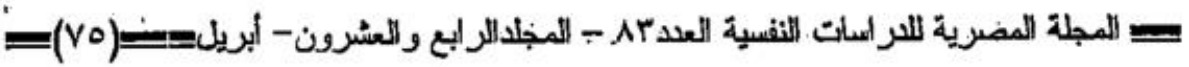


= التضحية وعلافتها بالرضا عن الحياة لدى المراة المتزوجة وغير المتزوجة=

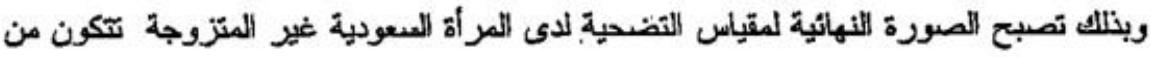
(\&V)

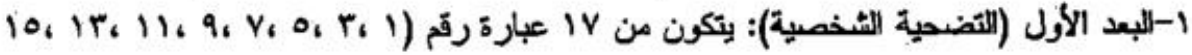

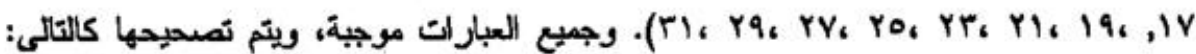

$$
\text { داثما-r ، إلى حد ما - Y ، أبدا - } 1 \text { ، }
$$

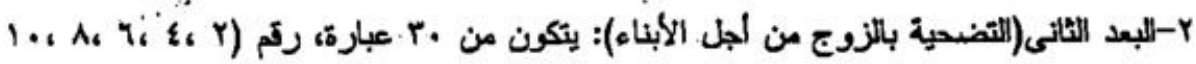

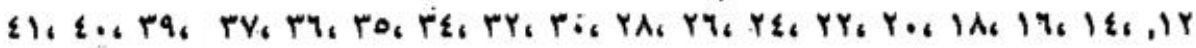
ف

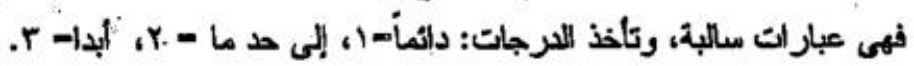

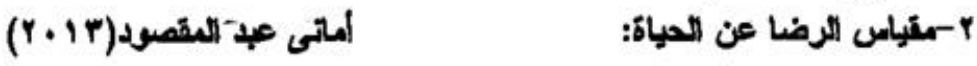

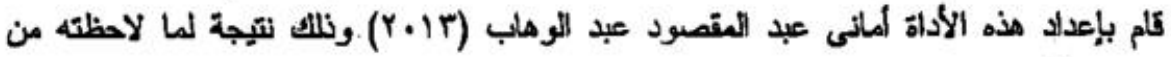

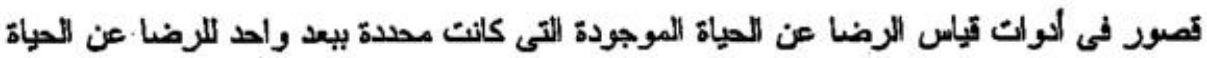

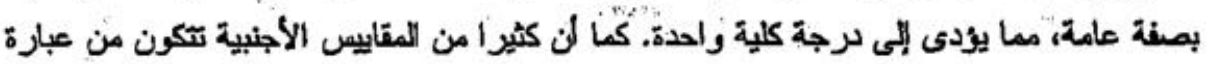

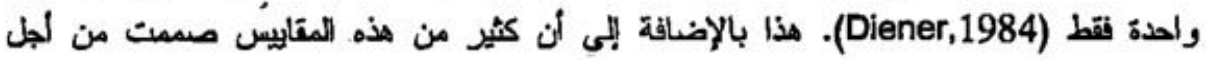

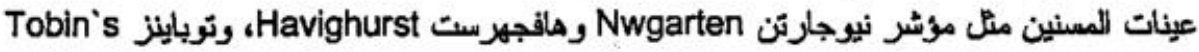

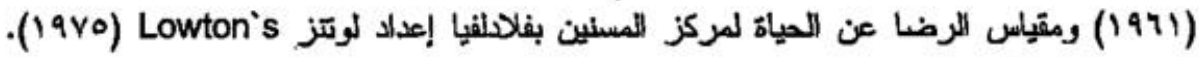

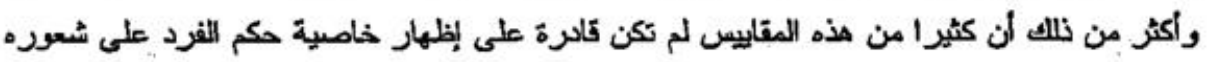

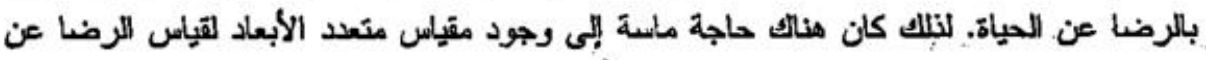

الحياة كعملية معرفية.

كما لاحظت الباحثة أن مقاييس الرضا عن الحياة فى المجتمعات العربية تكاد نكون نادرة،

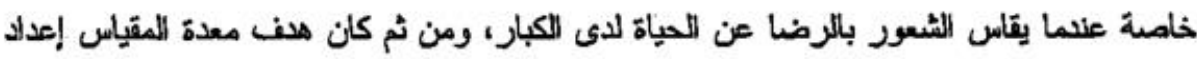

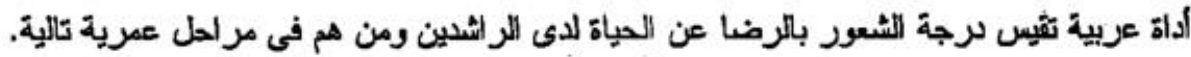

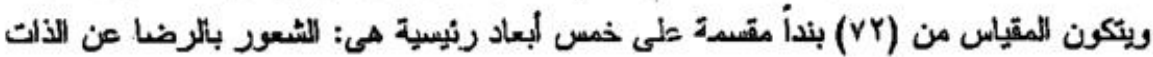

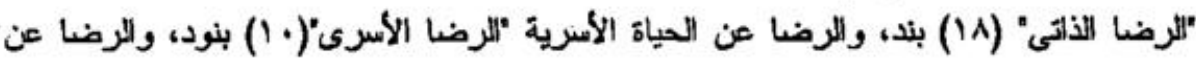

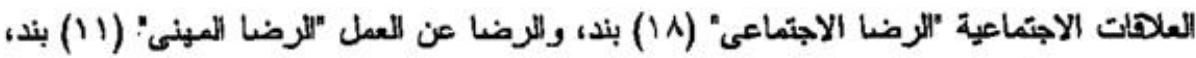

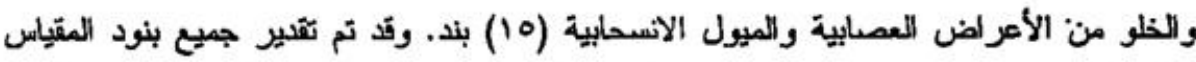

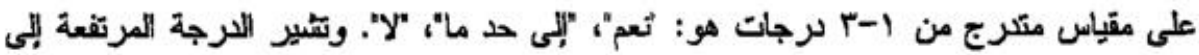




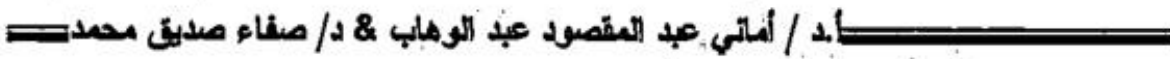

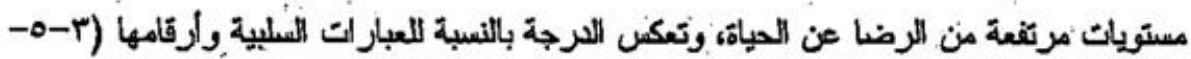
$-\varepsilon Y-\{Y-\varepsilon 1-\varepsilon:-r \Lambda-r q-Y 0-Y Y-Y Y-Y,-Y \Lambda-Y 0-Y Y-Y|-Y,-10-| r-11-1$.

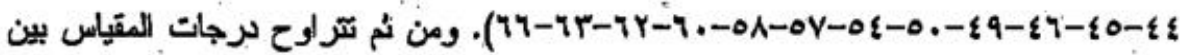

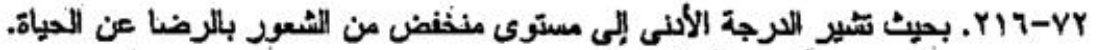
(Yi) جلون

البعاد متواس الرضتاعن المراة

\begin{tabular}{|c|c|c|}
\hline الالعحموع & الرمام العهارات & sleafl. \\
\hline 11 & 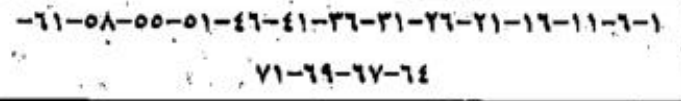 & 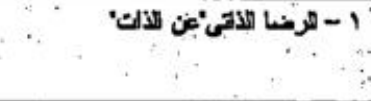 \\
\hline 1. & $\{Y-\{Y-Y Y-Y Y-Y Y-Y Y-1 Y-1 Y-Y-Y$ & ب- الرضعا الأكسى "عن المباء الأملرية" \\
\hline 11 & 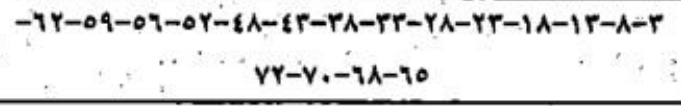 & الاجتماءير" \\
\hline 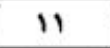 & or- $\{q-\varepsilon \varepsilon-r q-r\{-r q-r \varepsilon-1 q-1 \varepsilon-q-\varepsilon$ & "لارطا لعهى "عن العل" \\
\hline, 10 & 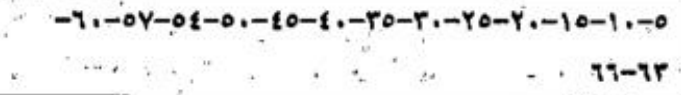 & 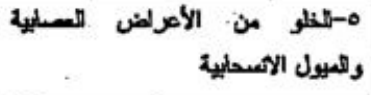 \\
\hline VY & sto & المجموع \\
\hline
\end{tabular}

وقد تم حساب المنق والثبات بطرق متعدة، حيث تم التوصل إلى معلملات صنق وثبات يمكن الاطمنان إليها عند العتخدام هذا المقياس فى البيئة الممرية.

تمثين المقياس على البيلة السعميلة: ا-ثبات المتئياس: 1-حساب معامل الفاكرونباخ Alpha-Cronbach لعبارات كل بعد فرعي علي خدة، وأسفرت تاك الخطوة عن أن جمبع العبارات ثابتة.

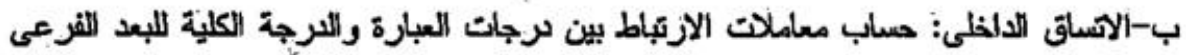

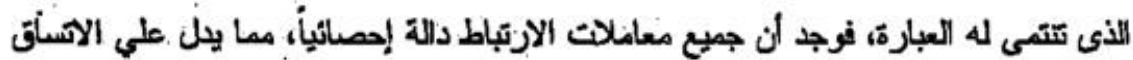

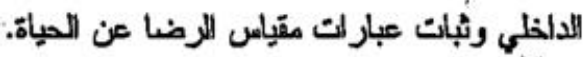

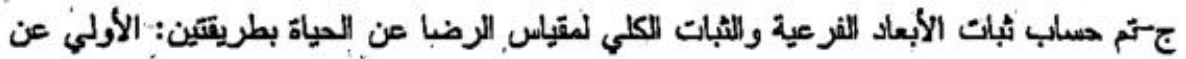

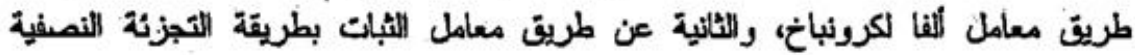

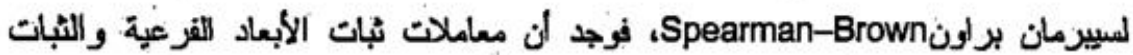
$=$ 
= التضحية وعلاتها بلرضا عن الحياة لدى المرأة المتزوجة وغير المتزوجة الكلي للمقياس بالطريقتين مرتفعة مما يدل علي الثبات الكلي للمقياس وثبات أبعاده

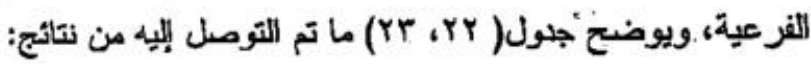
جلول (Yr)

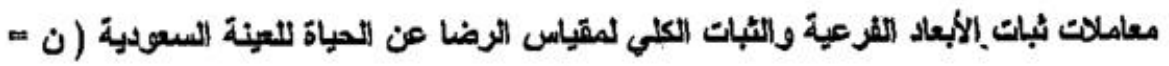
(r...

\begin{tabular}{|c|c|c|c|c|c|}
\hline \multicolumn{3}{|c|}{ 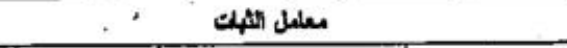 } & \multirow{2}{*}{ لالمهرات } & \multirow[b]{2}{*}{ ليعلد الترضا عن الخماة. } & \multirow[b]{2}{*}{ f } \\
\hline معلىل جتعلة & معامل الثهلك يطريكة & كعل كنلهاب الم & & & \\
\hline$\ldots y t$ & ..Yt. & ..A.r & in & 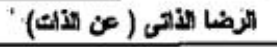 & 1 \\
\hline O.ATY & $0 . A \leq 8$ & $\ldots 119$ & 1. & للارضا الأكرى الالمري. & $i$ \\
\hline avey & ..YYi & $\therefore$.A1 & in & 'لرضا الاحشقاعى' & $r$ \\
\hline 20010 & .098 & $\because$.TAE & 11 & الريضا العشى . & 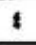 \\
\hline 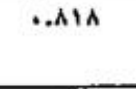 & .AYt &.$\wedge 11$ & 14 & المقلو من الأعراض المصلية & - \\
\hline . Ari & .Apr & .94. & vy & العقداب الكلى & 1 \\
\hline
\end{tabular}

جلول (YY)

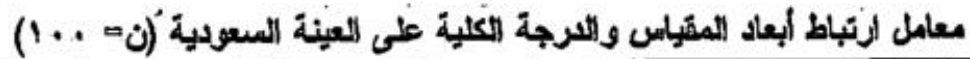

\begin{tabular}{|c|c|c|c|c|c|}
\hline معتوى لهلالة & معلل الربثلط & البيط & אمتوك: & معلمل الارتبلكا & I" \\
\hline. .1 & $\because, \wedge \vee A$ & الهبد الإجتَاعى & .1 & $\because, \wedge \vee t$ & آتب الثأتى \\
\hline$\because 1$ & $\cdots, \wedge \circ$ & ولالعبول الأمسليهية الأعراض العصلية &, 1 & •", Aזr & الألمبدى \\
\hline & & & .1 & ט... & "ليد العهنى \\
\hline
\end{tabular}

يتضح من الجدول السابق أن هناك ارتباط دال عند (1 ..) بين العرجة الكلية للمقياس والأبعاد المرغية الخاصة بالمقياس على العينة السعودية، مما يدل على ثبات الألى الأبعاد الفرعية للمقياس. نتلجّ البحث وتفهير ها:

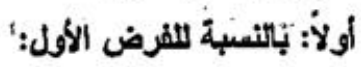

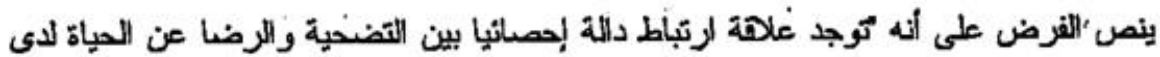
المراة المتزوجة وغير المتزوجة".

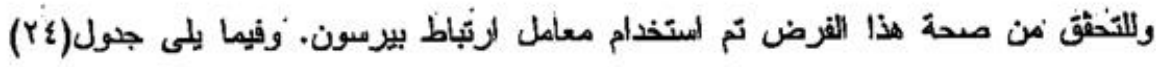

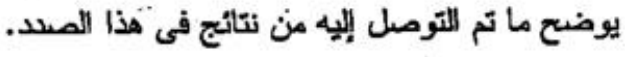

(VA)= 


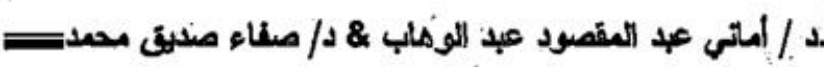

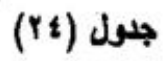

معاملات الارتباط بين درجات النساء المتزوجاتك وغزي العتزوجات على متياس التضحية

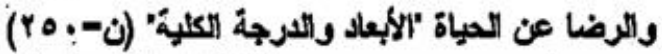

\begin{tabular}{|c|c|c|c|c|c|c|}
\hline \multicolumn{6}{|c|}{ الرضا عن الحواة } & \multirow{2}{*}{ 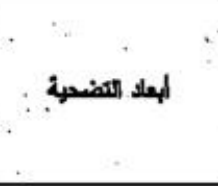 } \\
\hline الترجة الملية & 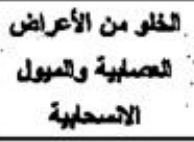 & "المشا: & 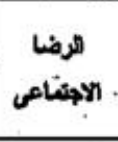 & الرأمسا & لأرطا & \\
\hline$\bullet . .19 r$ & $\cdots \cdot 1^{\prime}$ & $\bullet$. roo & $\bullet .194$ & •.trir & 0.110 & 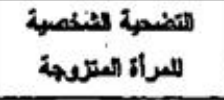 \\
\hline$\cdot 1,101-$ & $\bullet . .199-$ & $\ldots .018$ & -.,tra- & -..1YA- & $\because .1 \bullet A-$ & الثضنمة لالمئمة \\
\hline . IVA & .101 & .140 &..$|r|$ & $\cdot .$, Cin $^{\circ}$ & $0.1+4$ & 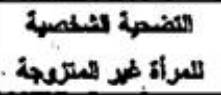 \\
\hline$\bullet ., 119$ & $\bullet . . t$ & $\bullet ., P, 8$ & •..PYI & •...rit & •.tril & 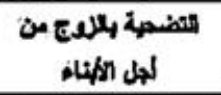 \\
\hline
\end{tabular}

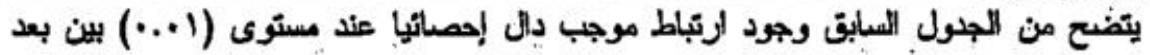

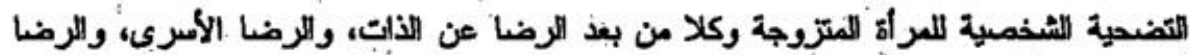

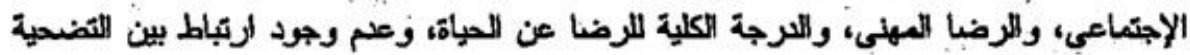
الشخمية ويغد" الخلو من الأعراض العمابية ولالميول الاتسحابية.

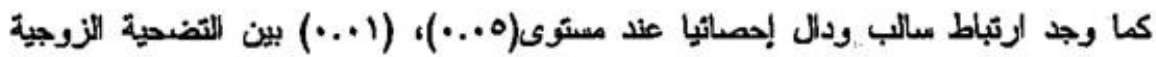

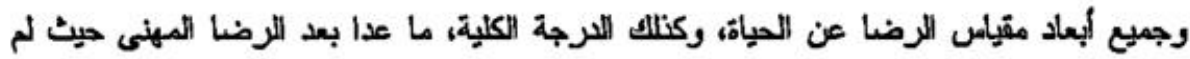

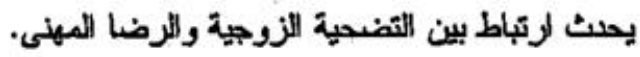

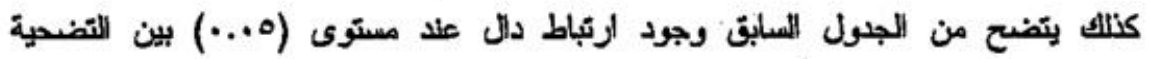

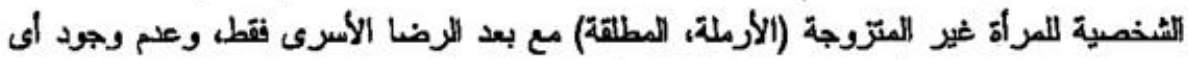

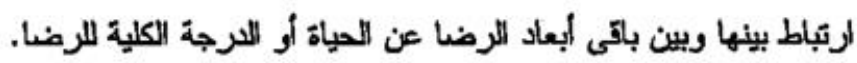

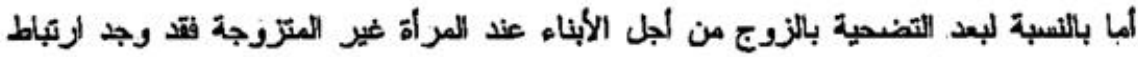

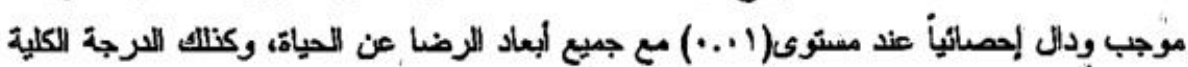
ل الرضا.

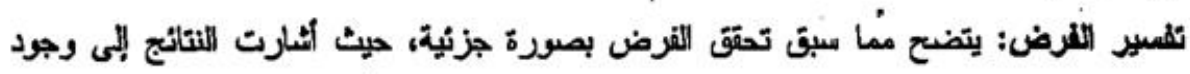

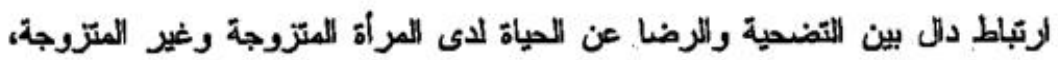
فالتضحية بالذات للمراة المتزوجة تعتبر أحد المكونات الخاصة للمشاعر اللوجدألثية بين

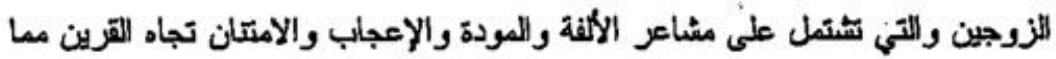

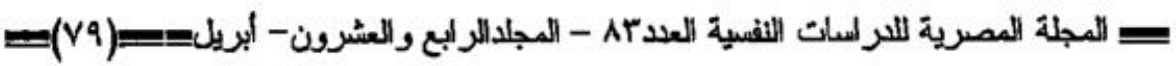


= التضعية وعلافتها بالرضبا عن المياة لاى المراة العتزوجة وغر المتزوجةت

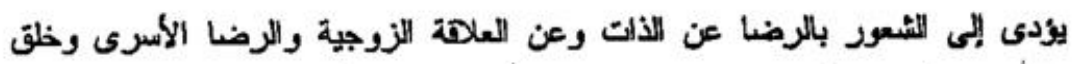

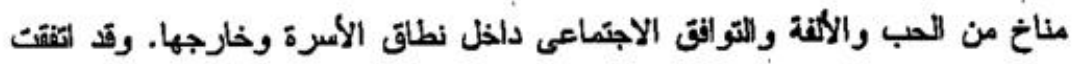

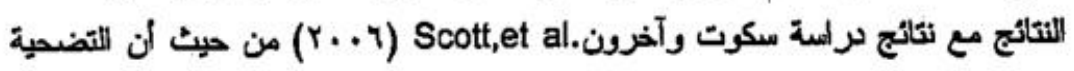

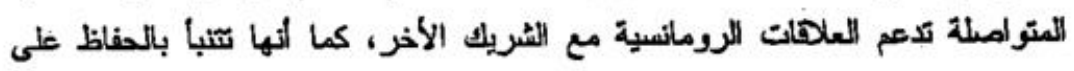

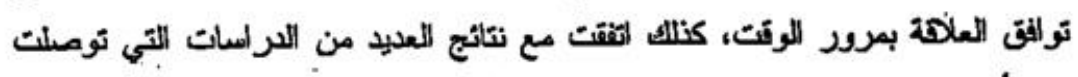

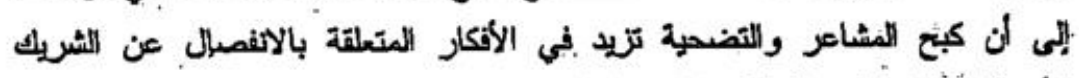

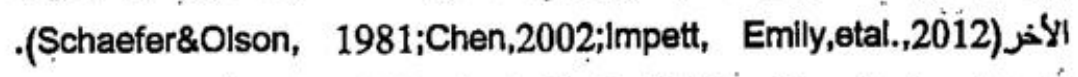

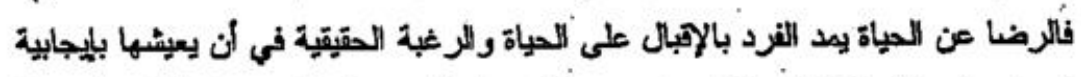

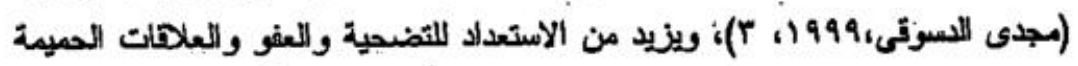

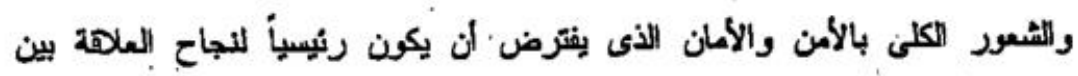

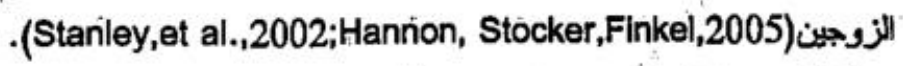

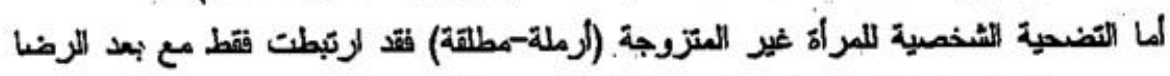

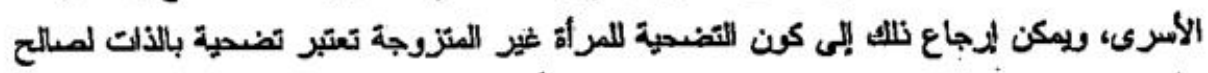

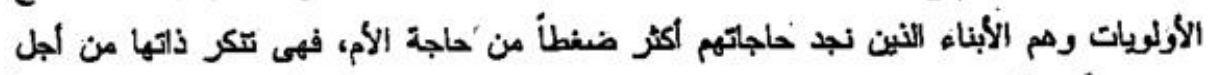

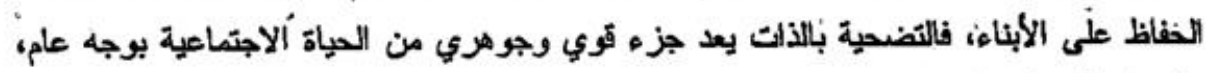

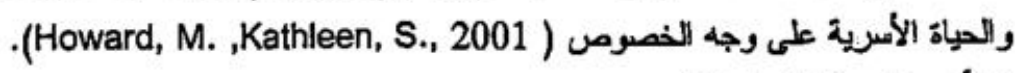

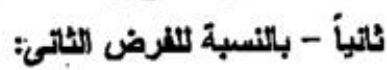

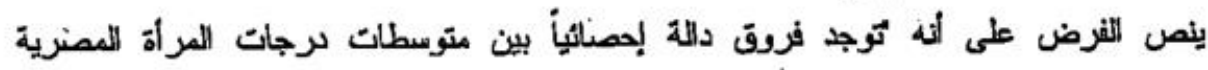

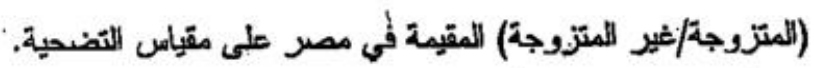

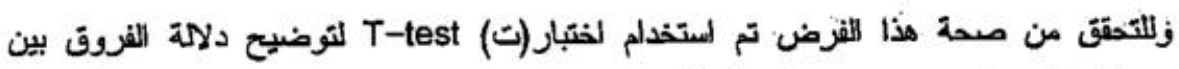

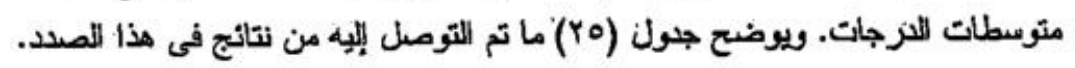

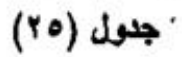

ليوضع المرعق بين العرأة المصرية (متزوجة / غير متزوجة)

على مقياسن التضحية

\begin{tabular}{|c|c|c|c|c|c|c|}
\hline الادلانة & قيمة 'ت" & C.s. & $\varepsilon$ & P. & ن & 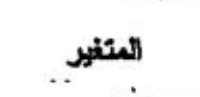 \\
\hline \multirow[b]{2}{*}{ غيز دال } & \multirow[b]{2}{*}{.01} & \multirow[b]{2}{*}{$90 . Y$} & 1.00 & IIr.A. & 0. & مصرية'متزوجة ' \\
\hline & & & Ir.or & IIr.Y. & 0 . & مصرية ميرز \\
\hline
\end{tabular}

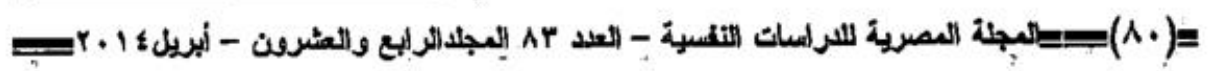




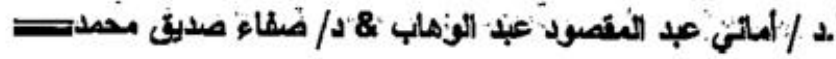

يتضح من الجدول السابث عنم وجود فروق بداله إحصائياً بين متوسط برجات المرأة

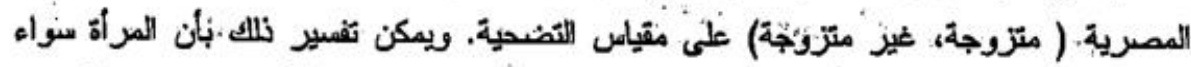

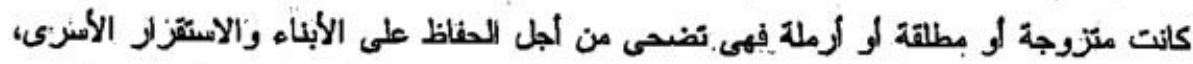

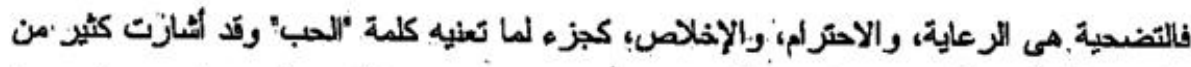

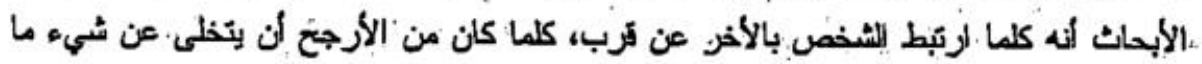

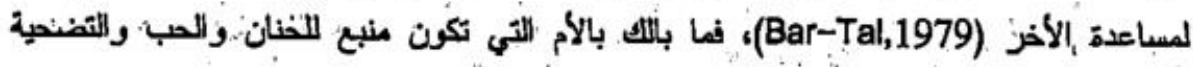

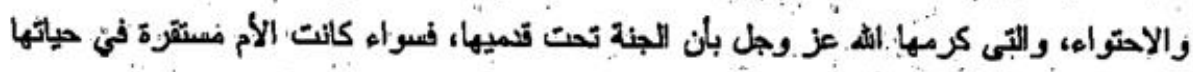

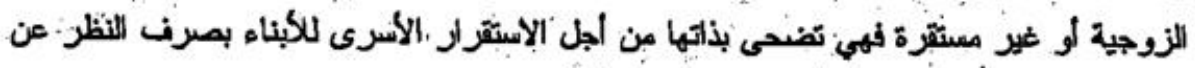
إستقر ارها الإفبى من عنينه

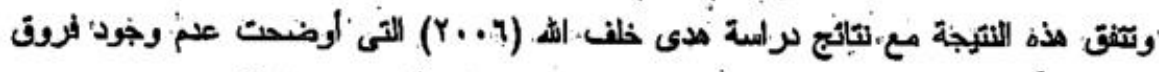

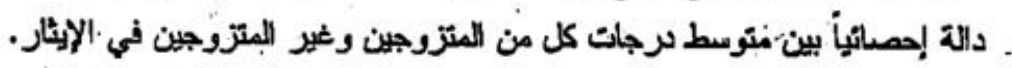

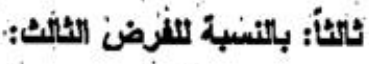

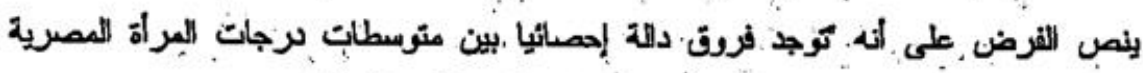

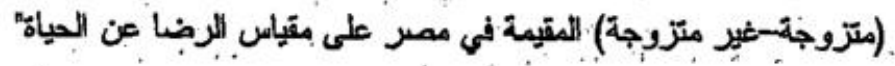

واللتحقت من طبحة هذا القرض تم استخدام اختبار (ت ) T-test التوضيح دلالة الفروق بين

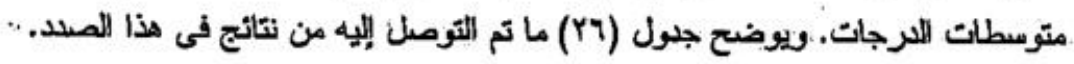
جلمول (YY)

. يوضع دلالة الشرفن بين المرأة المصريةز متزوجة/غير متزوجة) . في اللرضيا عن الحياة

\begin{tabular}{|c|c|c|c|c|c|c|}
\hline . الدالمة & كيمة تت" & $c \cdot a$ & $\varepsilon$ & P & $\dot{0}$ & المتغيز \\
\hline \multirow{2}{*}{ دال . } & \multirow[t]{2}{*}{$\varepsilon . \wedge \wedge$} & \multirow[t]{2}{*}{ qv. } & 1.0. & $100.0 Y$ & o: & مصرية متزوجة \\
\hline & & & A.IY & IEY.EY & 0. & ممرية غين متزونجة \\
\hline
\end{tabular}

يتضح من الجبول السابق وجود فروق داله إحضاثياً بين متوسطات مرجات عينة المرأة المصرية (متزوجة/غير متزوجة) على مقياس الرجبا عن الحياة لصالح المراة المصرية المتزوجة.

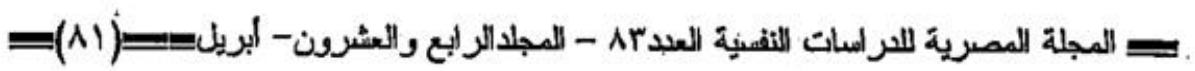




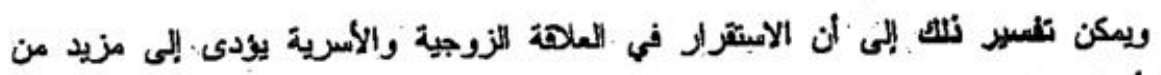

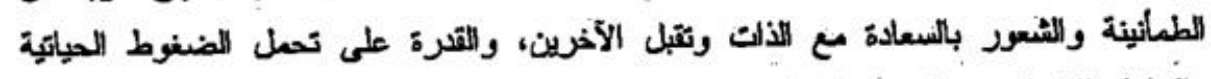

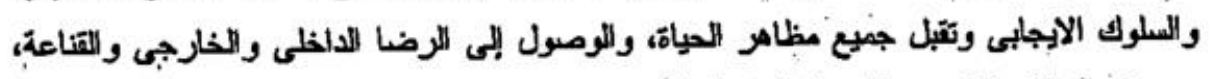

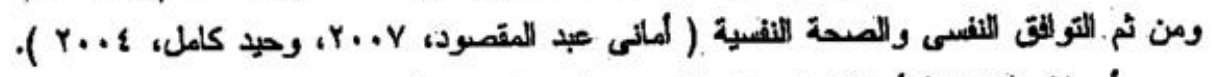

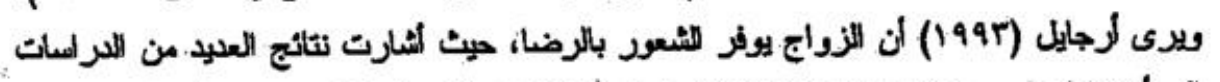

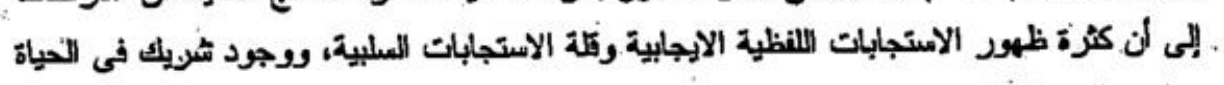

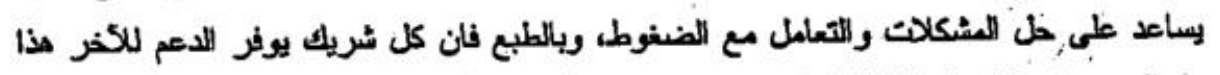
مع الوضع في الاعتبار تلة العلوك.

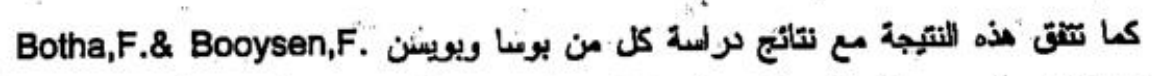

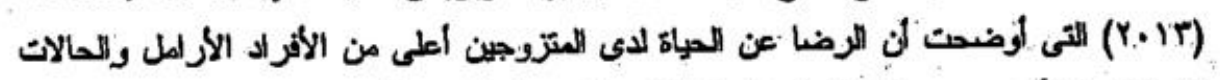

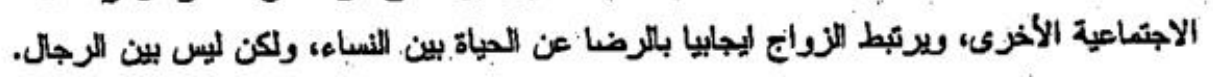

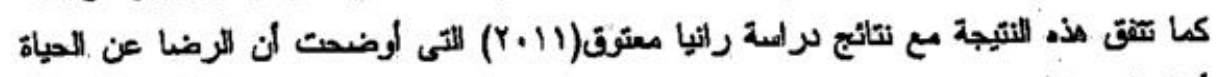

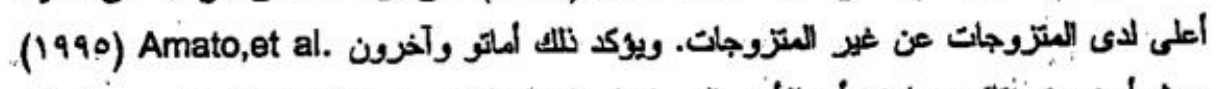

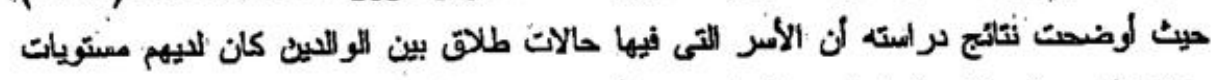

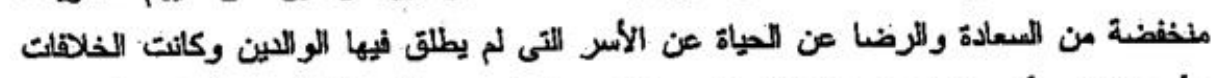

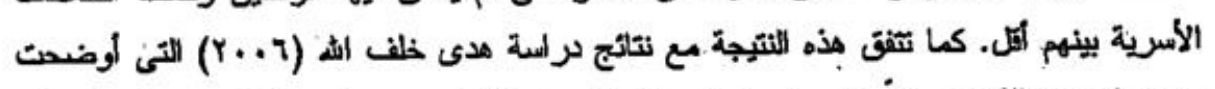

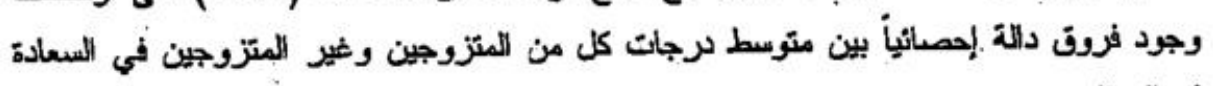
لمالح المتزوجين.

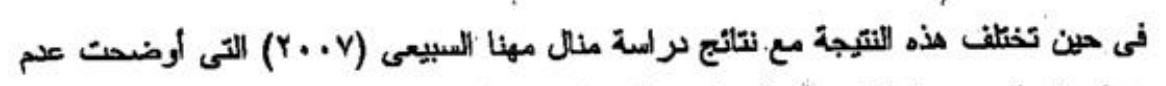

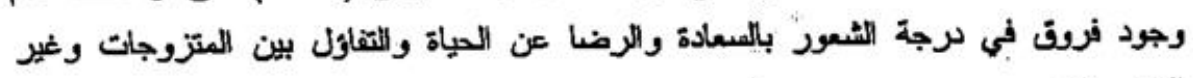
المتزوجات. راليعأ - بالتُبة لللهرض الرايع:

ينص القرض على أنه توجد فروق دالة إحماثيا بين مثوسطات مرجات المراة اللسعودية (متزوجةغير متزوجة) طلى مقياس التضشية".

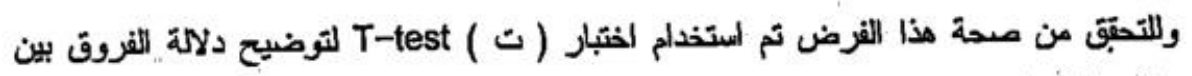

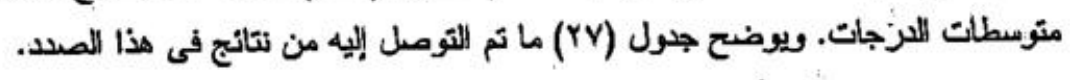

C)= 


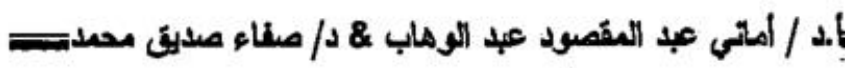

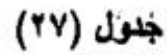

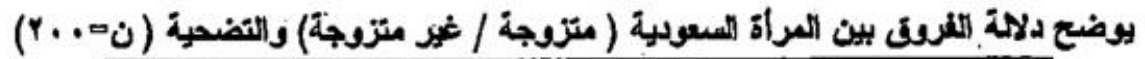

\begin{tabular}{|c|c|c|c|c|c|c|}
\hline الدلاة & قيبة تص" & r.د & $\varepsilon$ & $p$ & 0 & "العتخهر \\
\hline \multirow{2}{*}{ دال } & \multirow[t]{2}{*}{ r..4l } & \multirow[t]{2}{*}{191} & $\mid r, A v$ & 1.9 .00 & 10. & نسعودية متزرجة : \\
\hline & & & 19.10 & 111.9. & 0. & معودية غير مثزوجة \\
\hline
\end{tabular}

يتضع من الجنول اللعابت وجود فروف داله 'إحمانياً بين. متزمط سرجات المراة للسعودية

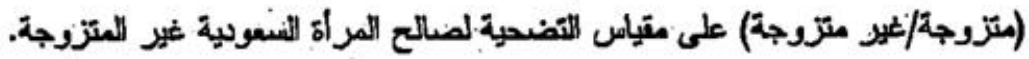
ويعن تلعسر نلك أن ثمافة المرأة المعوبية وما يقابلها من تشئة اجتماعية أبجابية يسودها التيم

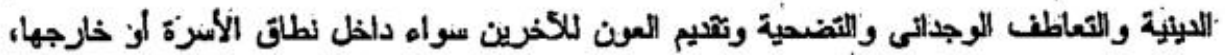

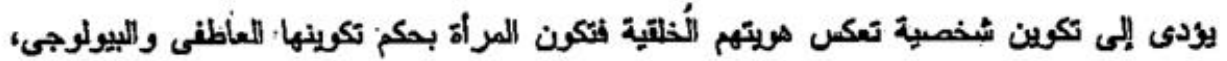

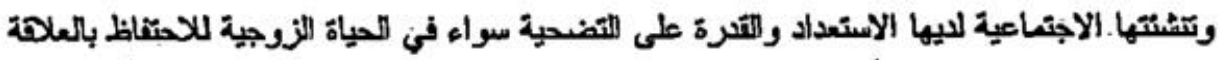

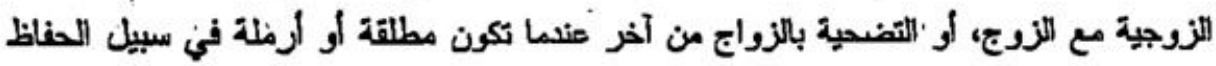
على المقر ار الأبناه والمفاظ على مشاعرهم.

Mcandrew, F:\& Perilloux, C. وتنفق هذه القتيجة مع نتائج ررامسة ماكثرو وبيرلوكس

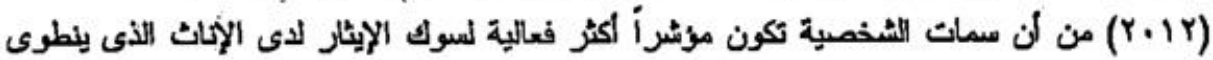

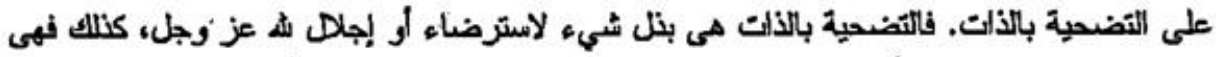

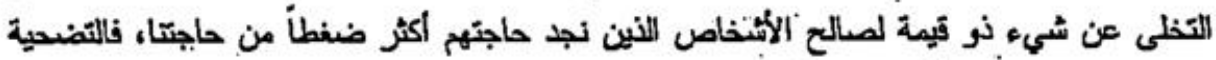

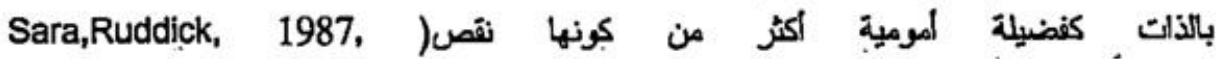
246;Mizruchi,1998,23)، والتضحية بالذلت من الفضائل، فهى تعتبر سمة اللثخمبية المتكاملة

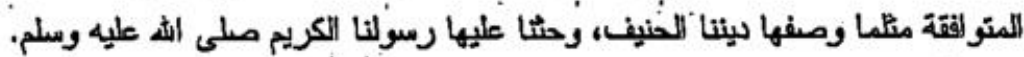

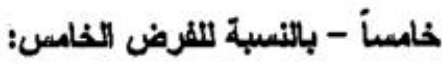
ينص القرض على أنه ثوجد فروب دالة إحصائيا بين متوسطات برجات المراة السعودية (متزوجة| غير متزوجة) على مقيام الرضنا عن الحياة.

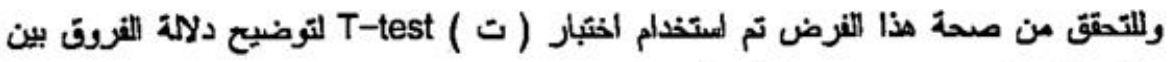

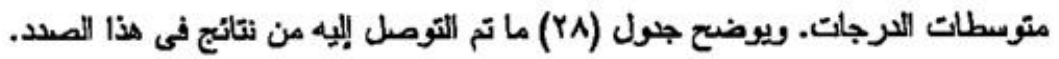

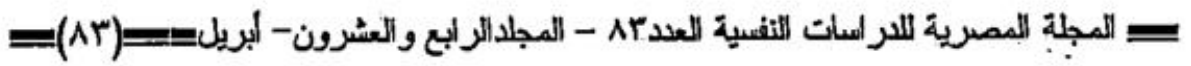


= التضحية وعلاتتها بالرضا عن الحباة لدى العرأة العتزوجة وغير العتزوجنت

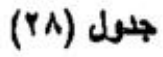

بوضح دلالة الثروق بين المرأة العسودية (متزوجة/غير متزوجة) فى الرضا عن العياة

\begin{tabular}{|c|c|c|c|c|c|c|}
\hline إلالآة & قوبة تت" & 2.د & $\varepsilon$ & $p$ & ن & المتثر \\
\hline \multirow{2}{*}{ غير دال } & \multirow{2}{*}{.099} & \multirow{2}{*}{ Y१.११ } & $r \cdot .01$ & IVE.YQ & 10. & معودية متزوجة. \\
\hline & & & YI.Y9 & IVE.TE & o. & سعونية طير. متزوجة \\
\hline
\end{tabular}

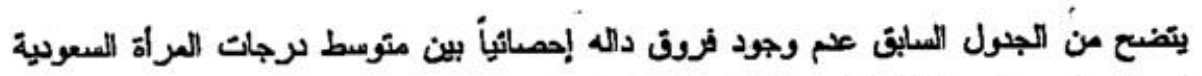

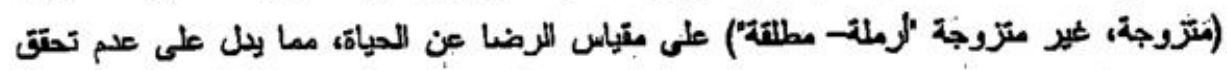
صحة القرضن الخمس.

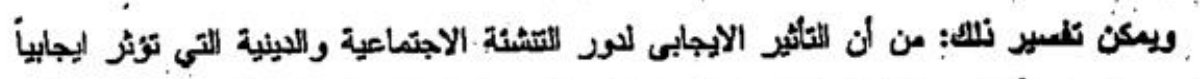

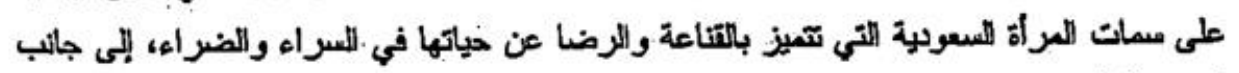

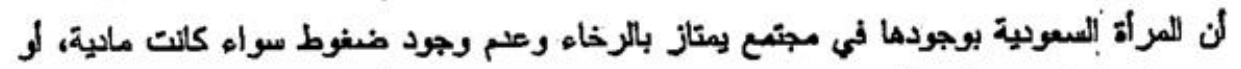

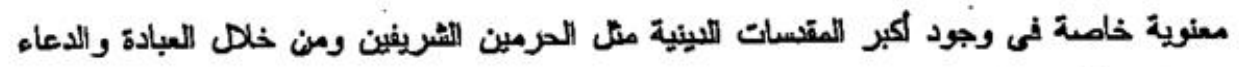

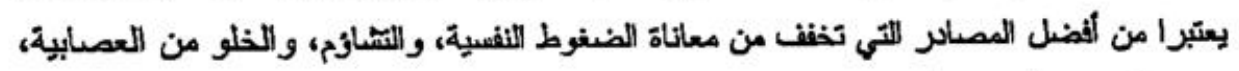

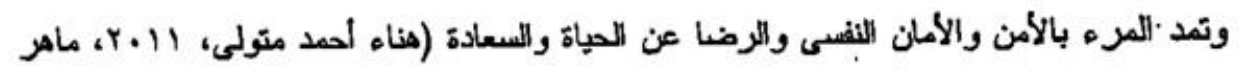
يوسف المجدلارى، بالاكن والكان. مالعسأ - بالنعبة للإرض العالس:

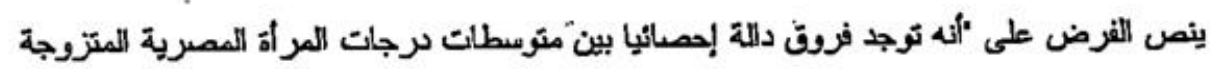
المقيمة بمصر مقارنة بالمراة المصرية المتزوجة المقيمة بالسعودية على مقياس التضنحية".

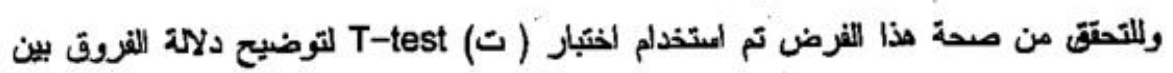

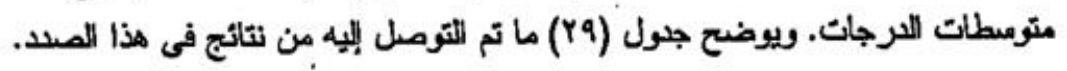

(A乏)= 


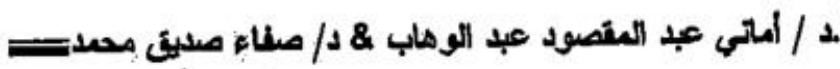

جلول (ra)

بوضح دلالة اللفرق بين البراة المصرية المتزوجة المتيمة بعصر

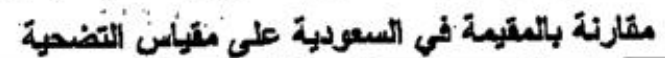

\begin{tabular}{|c|c|c|c|c|c|c|}
\hline الدلالة & ". كيمة تت" . & ; & $\varepsilon$ & p & ن & المتغير \\
\hline \multirow[b]{2}{*}{ دال } & \multirow{2}{*}{ Y.\&० } & \multirow{2}{*}{90.00} & 1.00 & IIr.A. & 0. & ممسرية متزوجة ومقيمة \\
\hline & & & IY.E & 1.0 .17 & 0. & ممسية متروجة ومقيمة \\
\hline
\end{tabular}

يتضع من الجبول للسابق وجود فروق دلله إمماثئياً بين متوسط برجات المراة الممرية

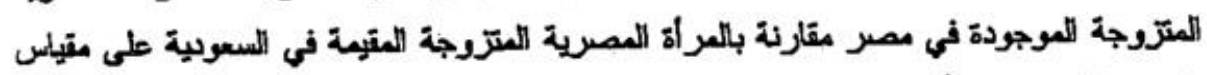

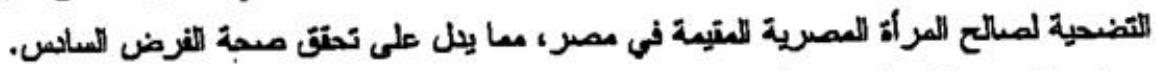

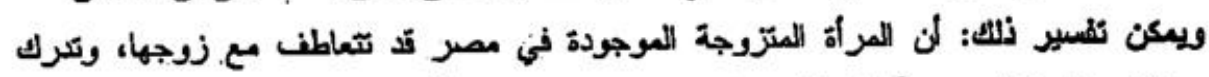

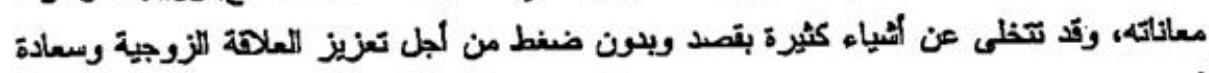

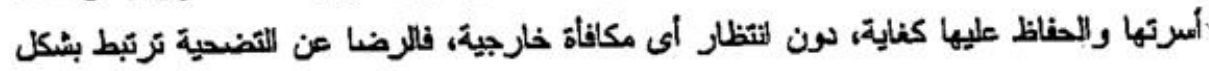

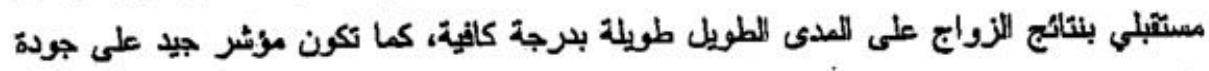

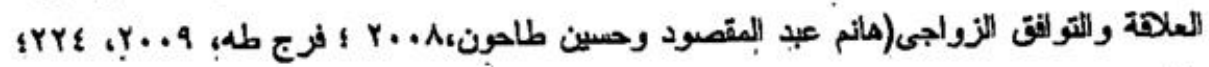

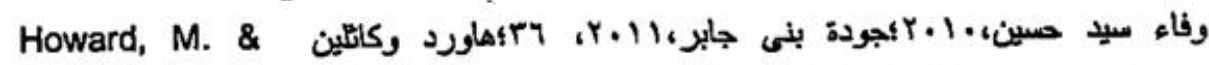

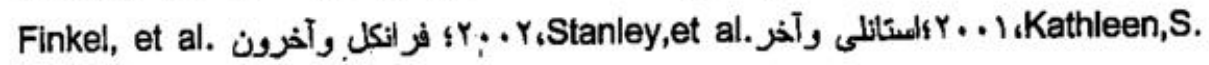

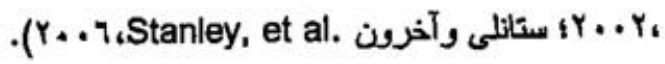

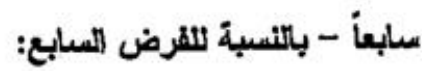

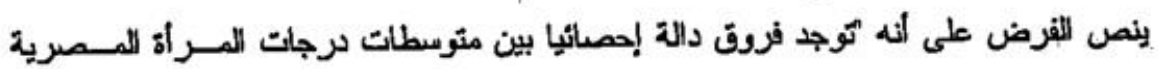

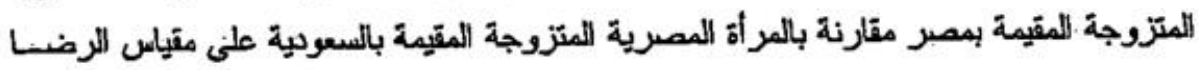

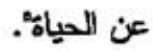

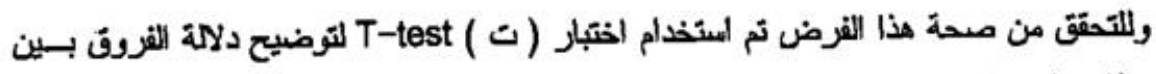

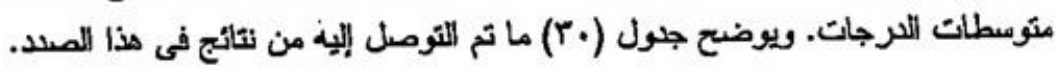

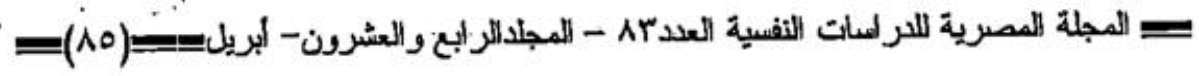


= التضحية وعلاتها بلالرضا عن المياة لاى المرأة المتزوجة وغير المتزوجة"

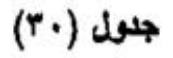

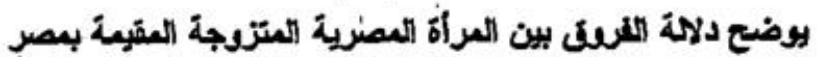

مثارنة بالمتيعة في السعدية على مقياس الرضا عن المباة

\begin{tabular}{|c|c|c|c|c|c|c|}
\hline 2yyst & كولة 'ت" & . .4 & $\varepsilon$ & f & 0 & لالغتخر \\
\hline \multirow{2}{*}{ دال } & \multirow{2}{*}{ " t.vr } & \multirow{2}{*}{ in. } & 1.0 & $100.0 Y$ & o. & المصنية المتزوجة لالمتيمة- \\
\hline & & & r.i. & IV..1k & o. & المصلية المتزوجة للمتوة المئورية \\
\hline
\end{tabular}

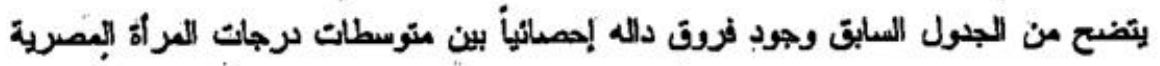

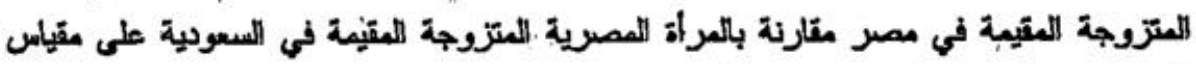

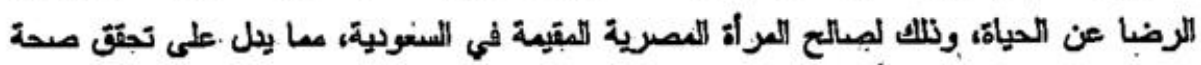
المرض السعابع.

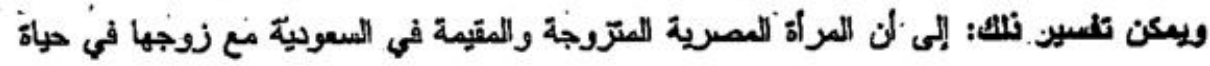

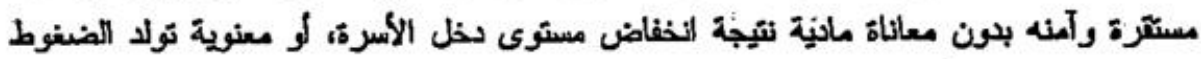

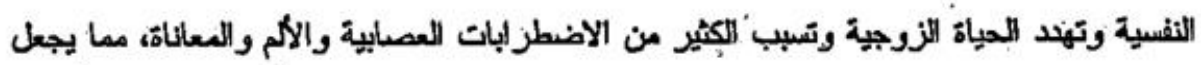

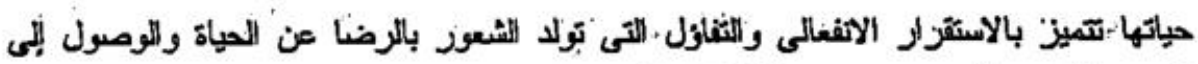

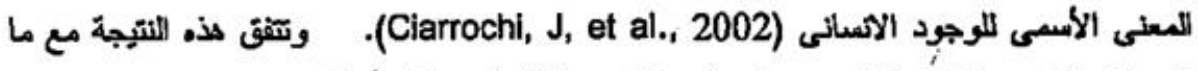

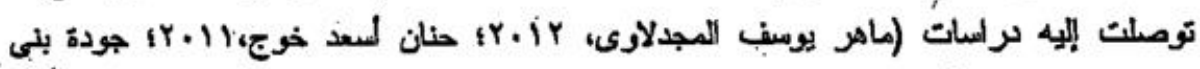

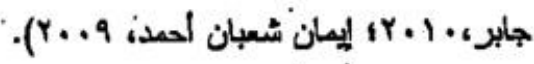
ثامنأ - بالنسبة للفرض الثامن:

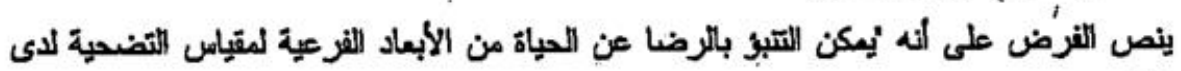

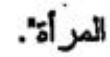

Stepwise ولالتحتق من صحة هذا الفرض تم امتخدلم تطليل الاتحدار المتعد المتكرج Multiple Regression Analysis من نتائج فى هذا الصند.

(ᄉT)= 


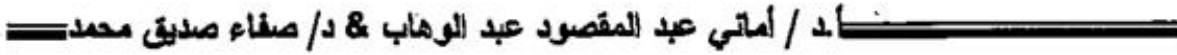

الوأ - التضصية اللزوجبة للمراة العتروجة:

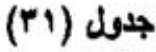

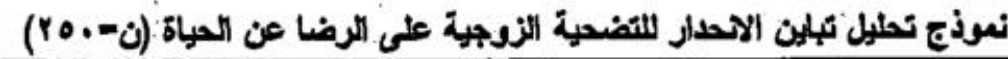

\begin{tabular}{|c|c|c|c|c|c|c|}
\hline $\begin{array}{l}\text { التططل } \\
\text { R2 }\end{array}$ & "لالالة & تهنة (ف) & اللمربعات & رلمريت & مجعوع المريعات & مصلر التباين \\
\hline \multirow[t]{3}{*}{$\ldots \mathrm{VY}$} & $\ldots . .1$ & १.०१Y & rova.00V & $r$ & Y109.118 & الاتحدار \\
\hline & & $\therefore$ & YrE.।క0 & rEY & QYEIY.YYY & البواتى \\
\hline & & & . & $r \& q$ & १৭०VY.AYY & المجعوع \\
\hline
\end{tabular}

جلم (rr)

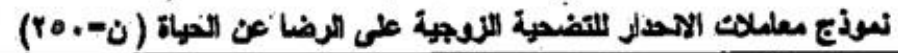

\begin{tabular}{|c|c|c|c|c|c|}
\hline مستوى & تصنة (ت) & بيتا B & المعارى الفطا & 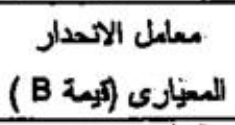 & المتنيرات المنبية \\
\hline$\ldots \ldots 1$ & II.Y & & 12.58. & $179.7 \mathrm{rA}$ & ثابت الاكدذار \\
\hline$\ldots . .1$ & r.vir & .rYo & דיצr. & - . $0 \xi$ & اللثضحبة اللشفصية \\
\hline$\ldots . .1$ &.$r .0 \varepsilon$ & $.19 .-$ &. .117 &..- Y०7- & الثضحية التزوجية \\
\hline
\end{tabular}

يتضنح من الجدولين العابتين رقم (آr، بr) وجود تاثير دال موجب إحمائبا عند مصتوى

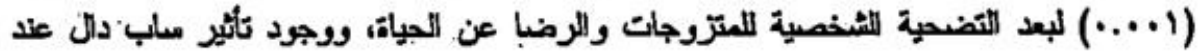

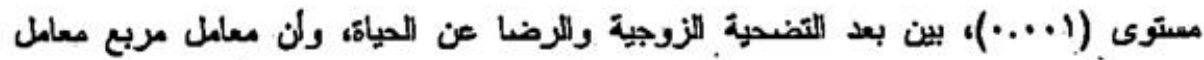

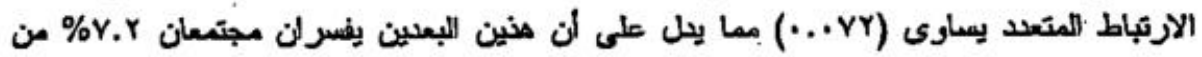

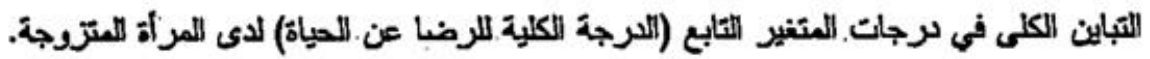
ومن هنا يعكن صياغة معادلة الاتحدلر العتعد التي تعين على التَبو بالسرجة الكلية للرضا

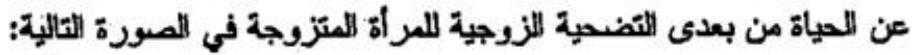

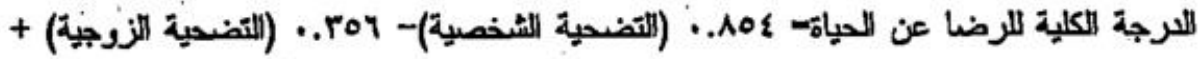
179.7YA واللترتيب السابت لبُعدي التضفية للمرأة المتزوجة في معاللة الانحدار المتعلد التي يعكس $=$ 
= التضحية و.علافتها بالرضا عن المياة لدى المراة المتزوجة وغير المتزوجةت

الأهمية التسبية لناثثر كل منها على المتغير التابع ( اللرجة الكلية للرضا عن الحياة). أى أنه كلما

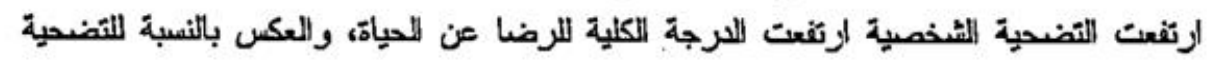

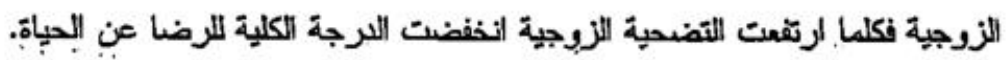
ويمكن تاسير ذلك يتضح مما سبق أنه كلما ارتقعت التضحية الشخصية ارتفعت الثرجة الكلية

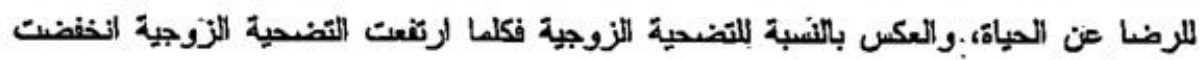

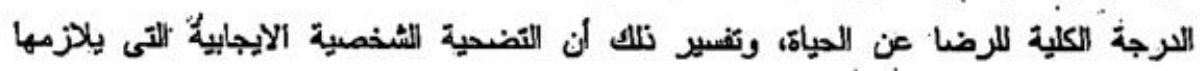

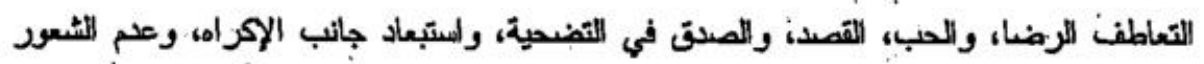

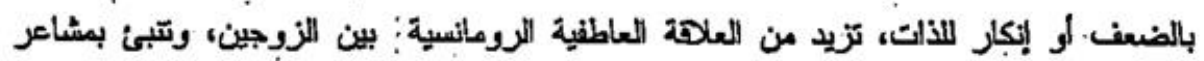

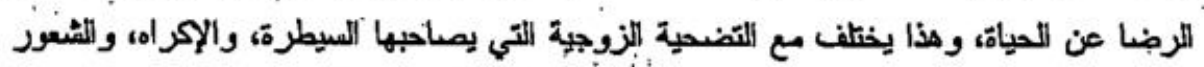

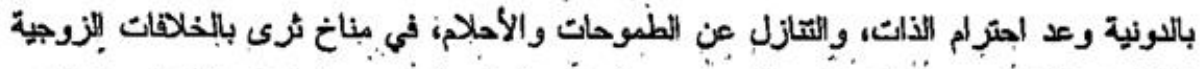

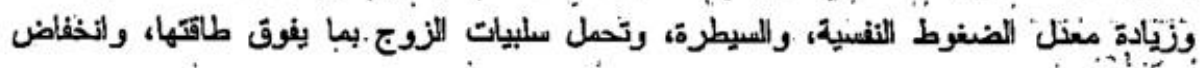

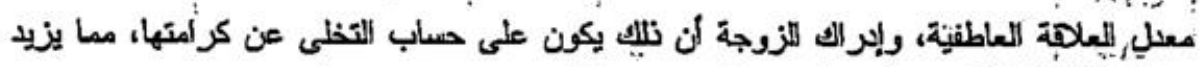

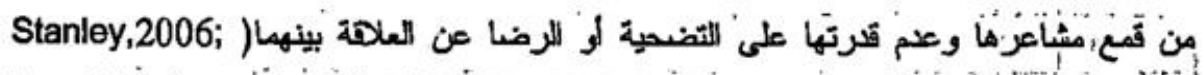
Impett,Emily, A.,etal.,2012;,Bar-Tal,1979; Noller, 1996; Derrida, S.\&Schillerthus, 1992a ,b, 1995; InMarey,S., 2011; Young, M.,et al.,1995; .( Stanley,et al. ,2002; Fujiwara \& Lee,2008, 29

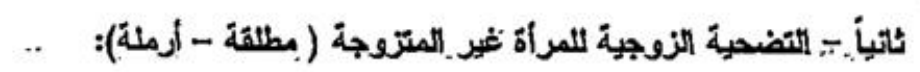

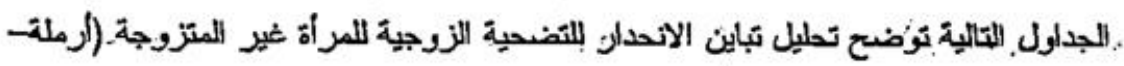

$$
\text { مطلقب)، وبرالرضا عن .الحياة. }
$$

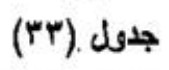

\begin{tabular}{|c|c|c|c|c|c|c|}
\hline 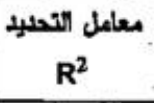 & مستوى & تيعة (ت) & المشريغات & لرجات الجرية & 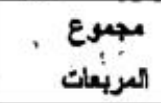 & 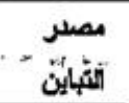 \\
\hline . ivo & $\because \ldots i$ & $1 . .+.0$ & 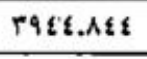 & $r$ & Vภังด.าง & الانتدالر \\
\hline & & & rAY.AlY & १ุ & ryirr.ỵ & اليواقى \\
\hline & & & & 99 & \{0.YY.91 & المجموع. \\
\hline
\end{tabular}

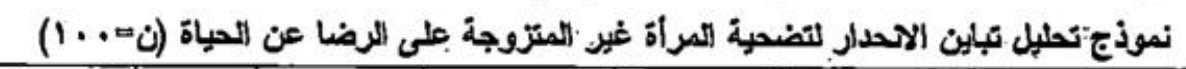

= 
|د / الماته عبد المقصود عبد الوهاب \& د / مشاء صديت محمد

جلول (rs)

نموذج معاملات الاحدار لتضصية المراة غير المتزوجة على الرضا عن المياة (ن- . 1 1)

\begin{tabular}{|c|c|c|c|c|c|}
\hline مالدالأ & تيعة (ت) & بيثا B بئ & الخطا المعبارى & 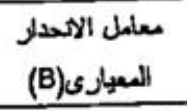 & المتغيرات العستجالة \\
\hline$\ldots \ldots 1$ & V.Y१q & & 18.941 & 1.1 .919 & ثابت الاثحدار \\
\hline هير دال & $.01 \%$ & $-\ldots 00$ & . rvr & $-\cdots 1 \varepsilon .-$ & التضسبة الثخصية \\
\hline$\cdots \cdot \cdot 1$ & $4.1,1$ & $\therefore \leqslant 0$ & .ris & . . A99 & 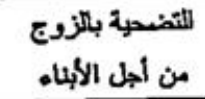 \\
\hline
\end{tabular}

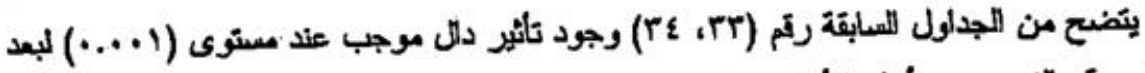

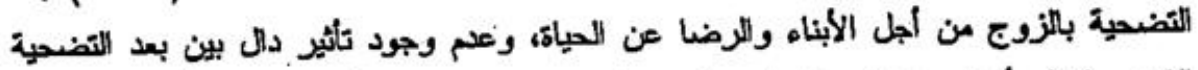

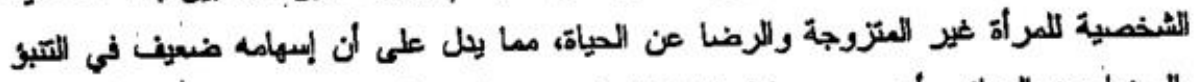

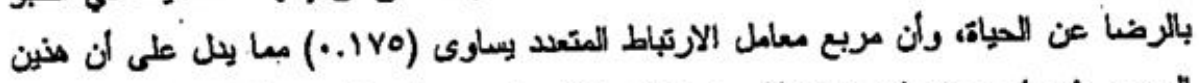

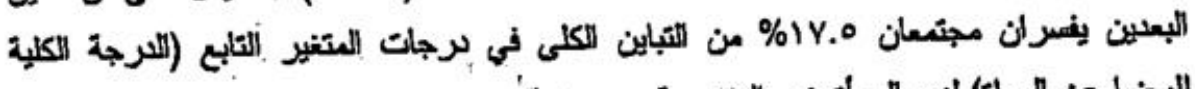

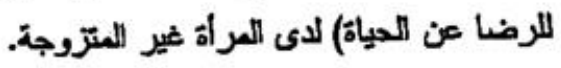

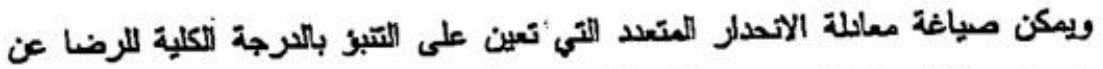

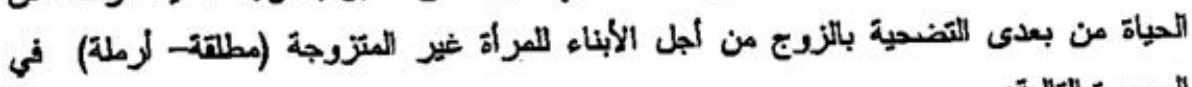

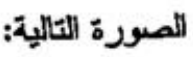
الرجة الكلية للرضا عن لالحياة-194..(التضحية الشخصية للمراة غير المتزوجة)-

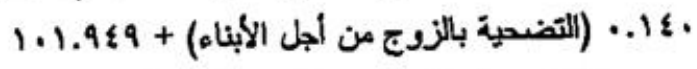

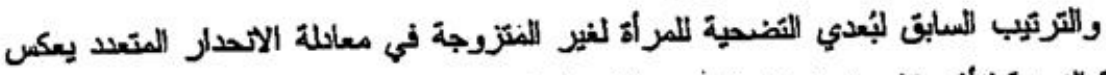

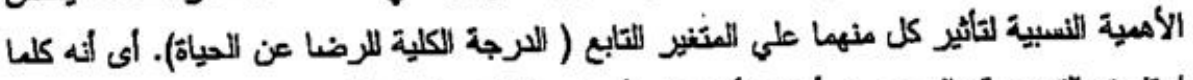

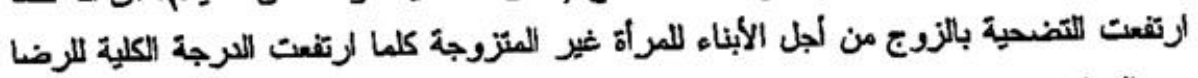
عن الحياة.

تفسير الفرض: يتضنح مما سبق أثه كلما ارتمعت للتصحية بالزوج من الجل الأبناه للمرأة

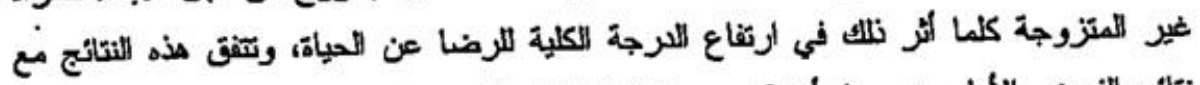

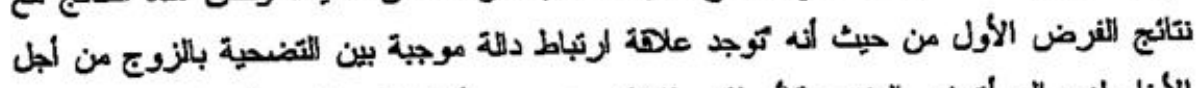

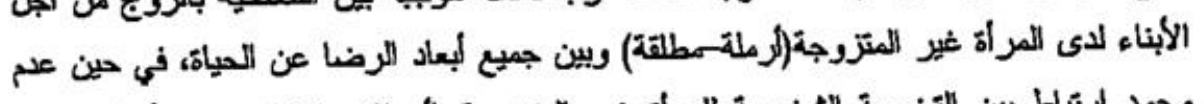

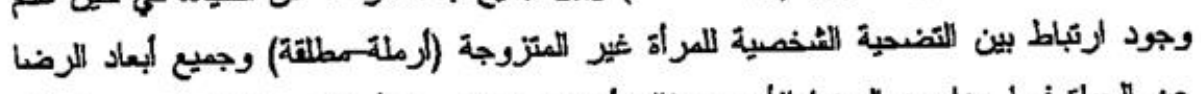

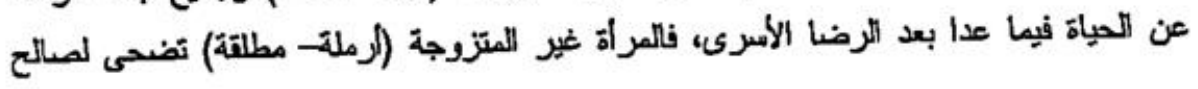

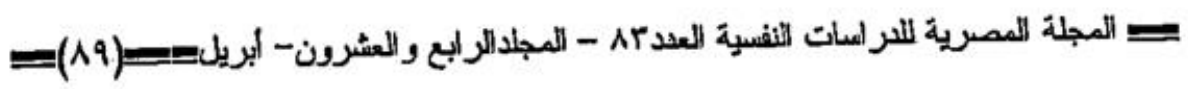


= التضحية وعلاثتها بالرضا عن المياة لدى المرأة المتزوجة وغيز المتزوجةت شيء آخر نو تيمة اكبر، وهنا يكون منهوم الغيرية في الأنا فتخرج الأم من مرحلة الاهتمام بالذات

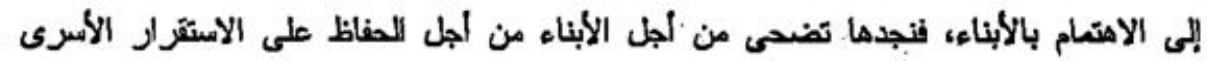

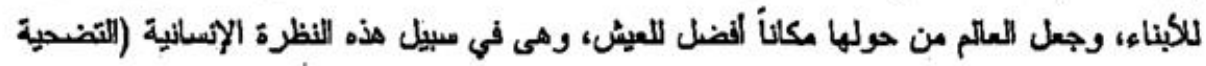

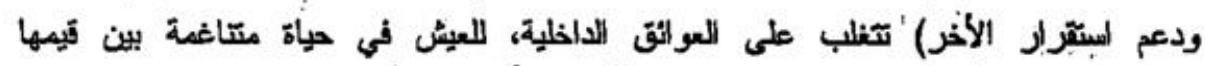

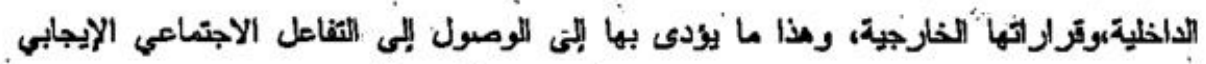

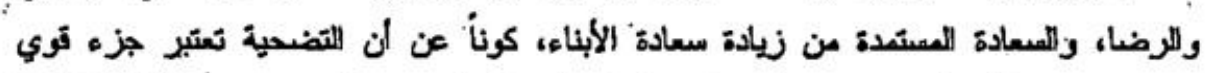

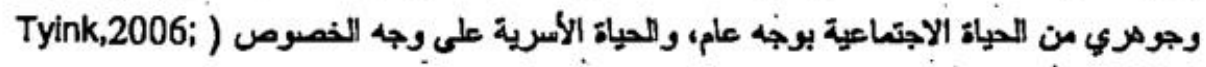
Batson,1991,Howard, M.\&Kathleen, S.,2001

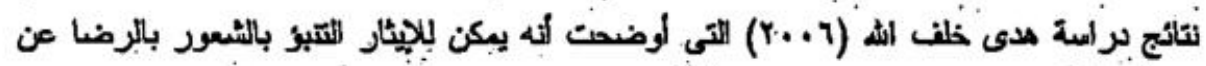
الحِيأة و اللسعادة. بحوث بمترجة:

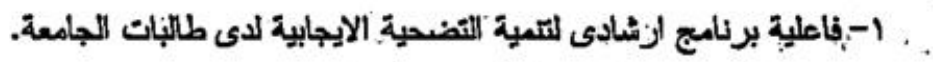

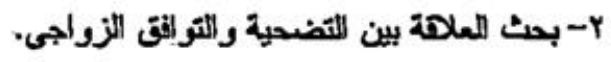

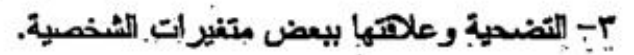

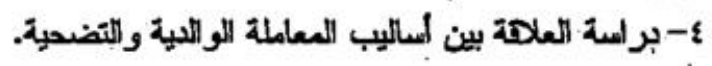
ه- العلاهة بين التضحية والاتتماء للوطن لدى اللمباب.

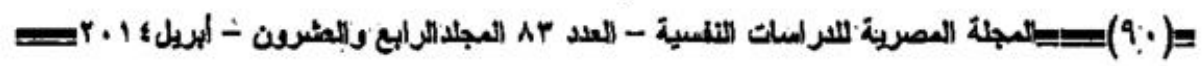




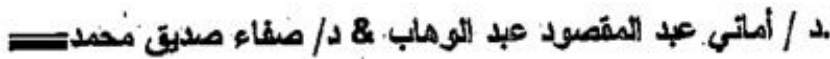

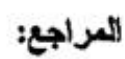

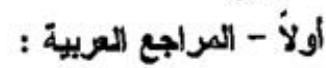

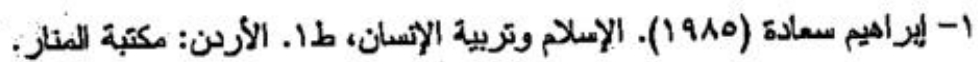

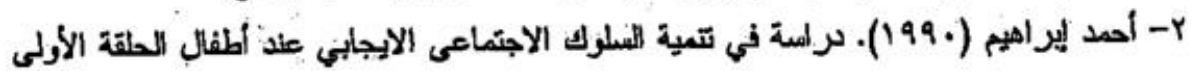

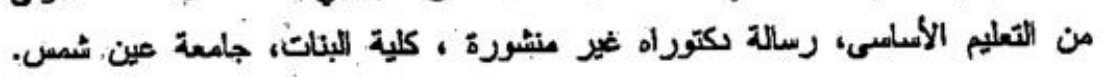
القاهزة.

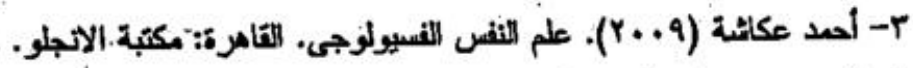

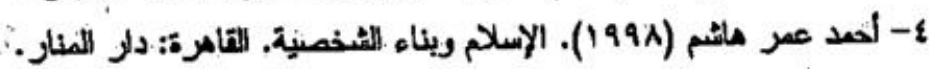

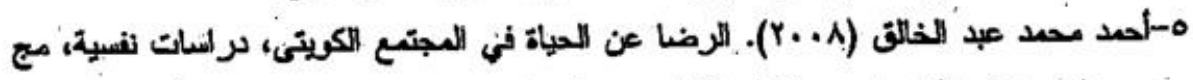

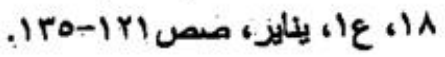

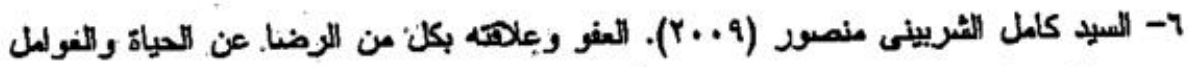

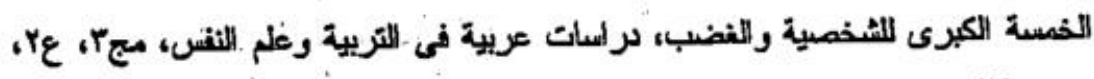

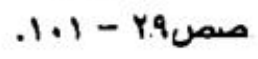

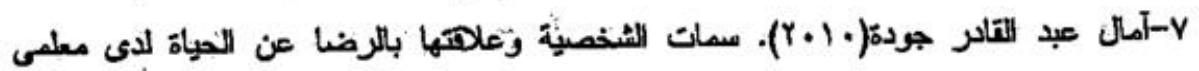

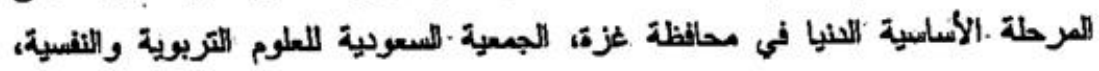

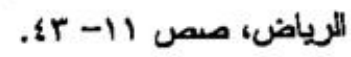

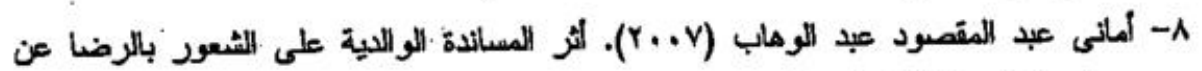

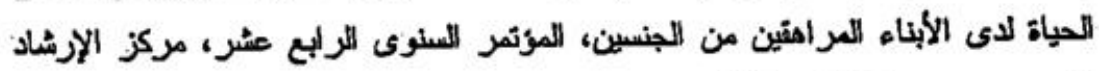

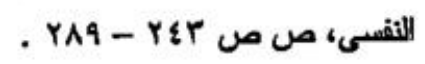

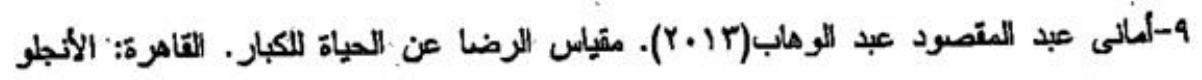

$$
\text { المصرية. }
$$

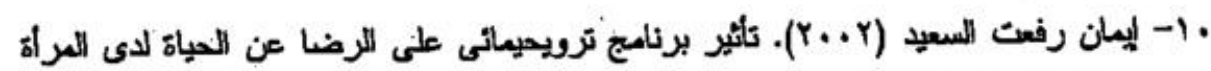

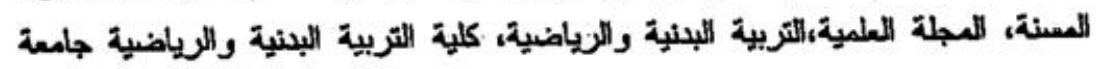

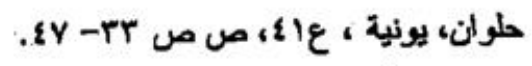

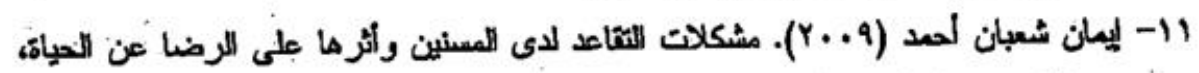

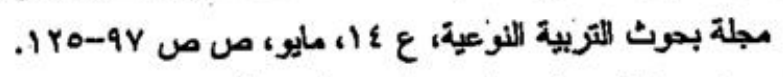

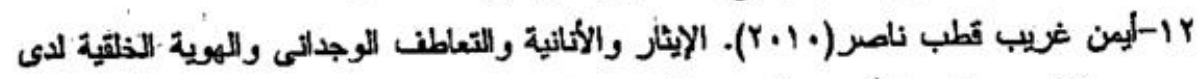

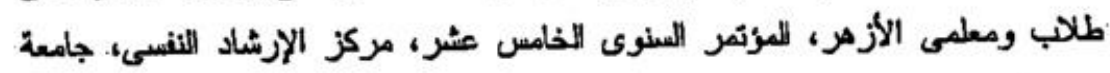

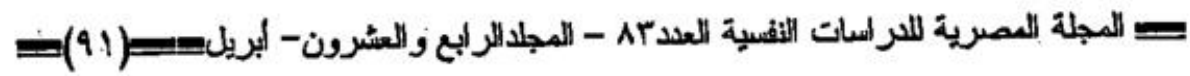


= التضصية وعلاثتها بلرضا عن العياة لاى المراة المتزوجة وغهر العتزوجةت

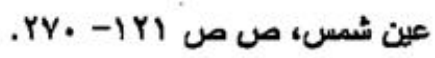

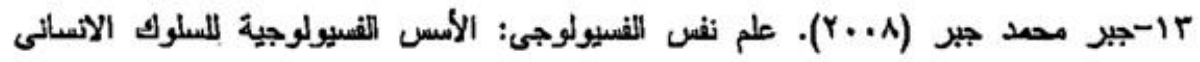
ودلالته النفسية. اللزياض: مكتبة الرمشيد-ناشرون.

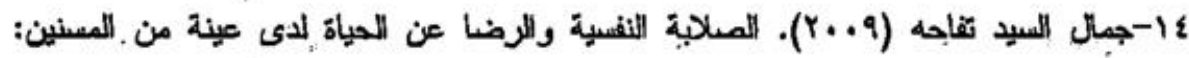

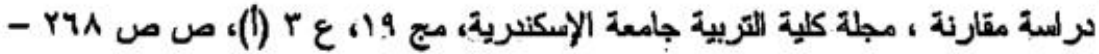
.ris

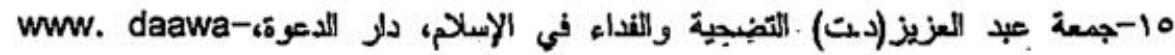
info.net

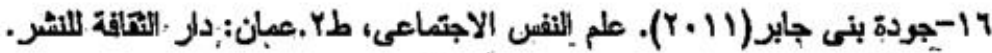

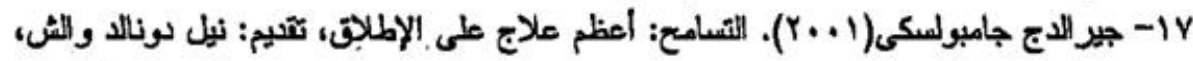
طا...الرياض: مكتبة جريل.

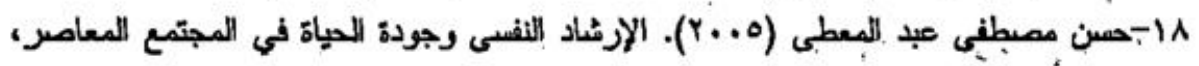

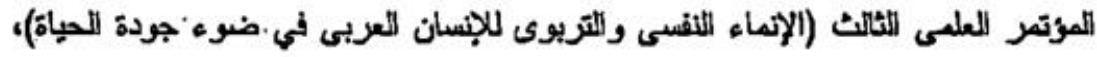

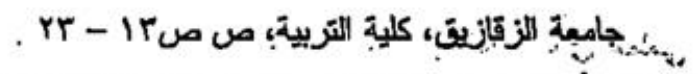

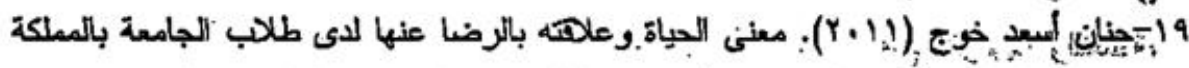

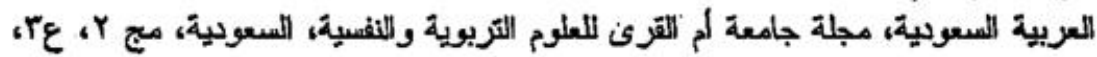

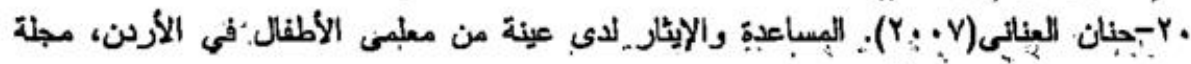

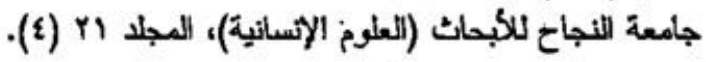

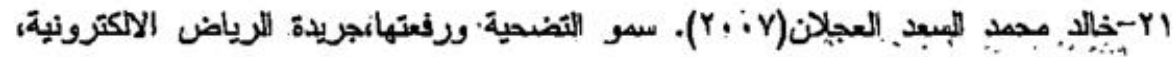
http://riy.cc/259187

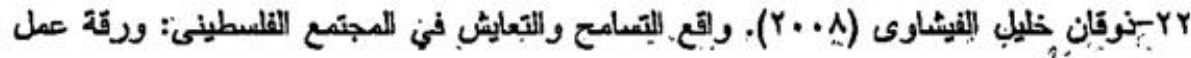
مقنمة إلى ملثقى البرِيات الثانى.

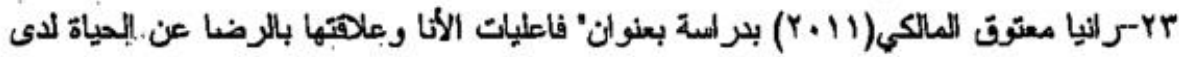

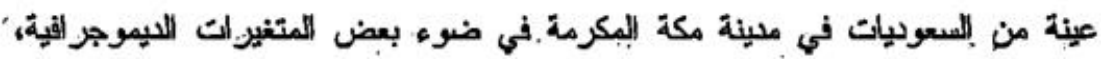

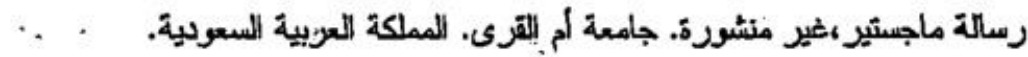

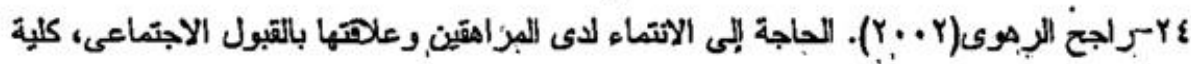

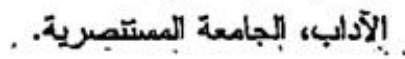

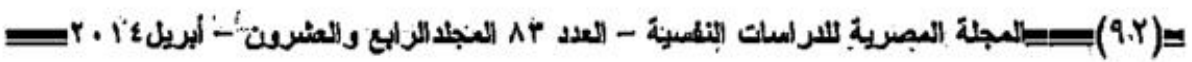




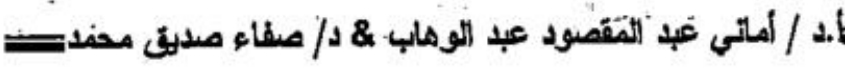

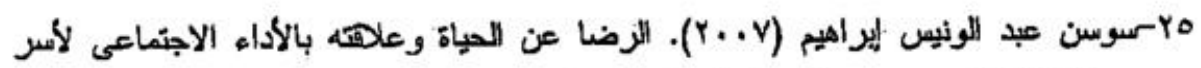

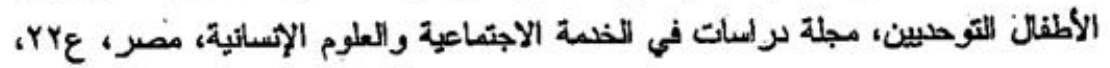

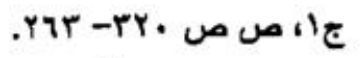

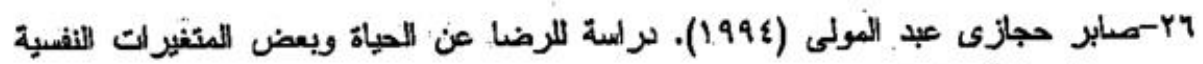

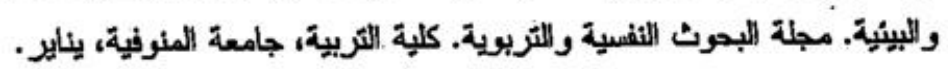

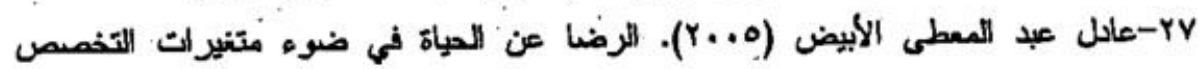

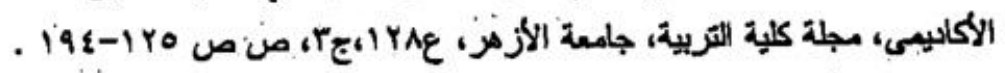

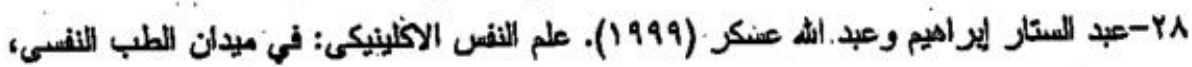
طץ. التاهزة: مكثبة الاتجلو.

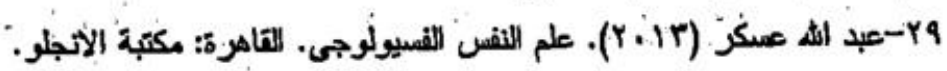

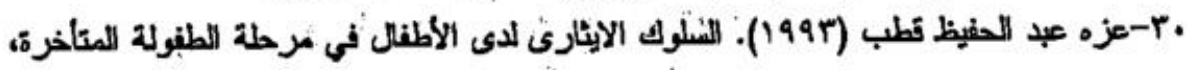

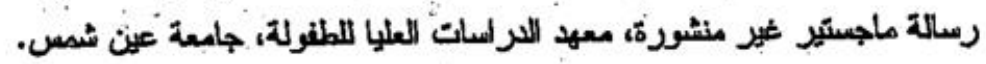

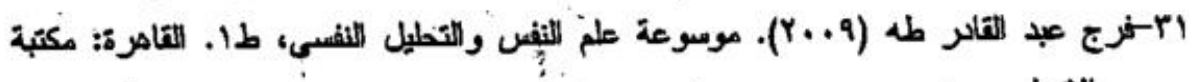
الاتجلو.

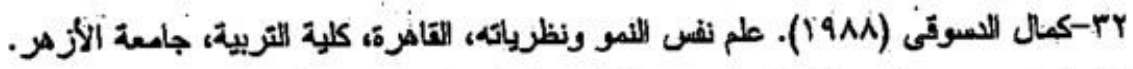

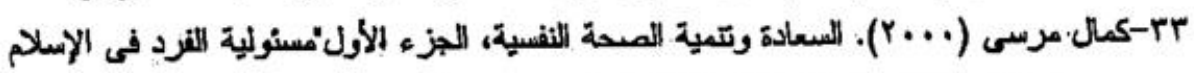
وعلم اللفف".القاهزة: دار الثطر اللجامعات.

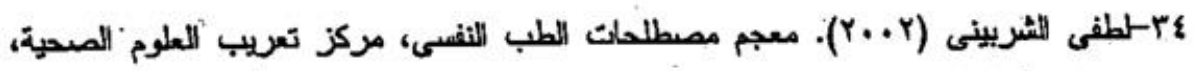
جامعة الثول العربية، الكويت.

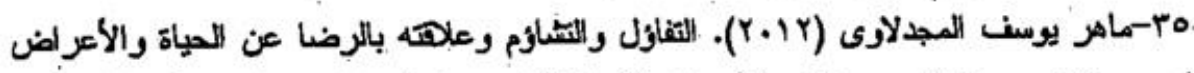

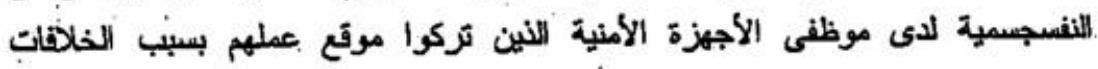

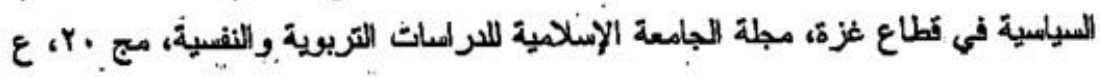

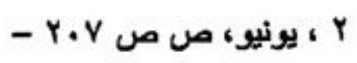

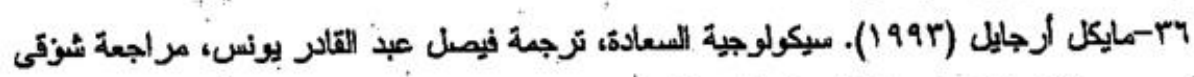
جله. الكويت: سلسلة عالم المعرفة. rr-ro

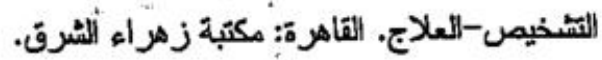

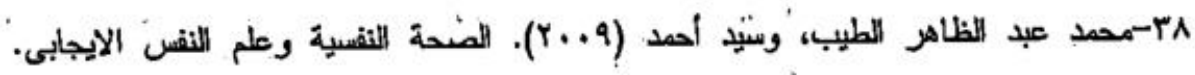

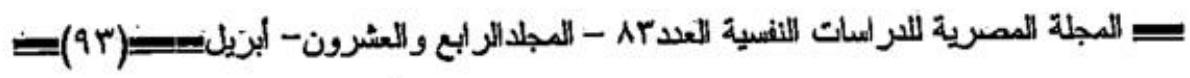


= = التضحية وعلانتها بلرضا عن الحياة لدى المراة المتزوجة رغير المتزوجة

التاهرة: مكتبة اللنهضة الممرية.

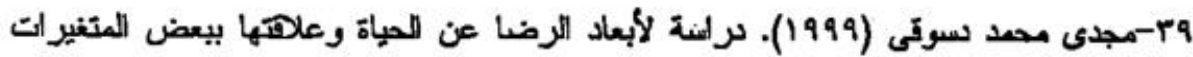

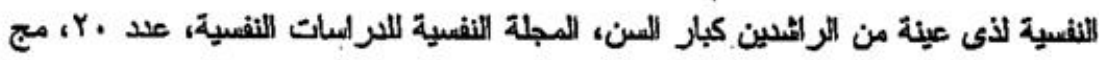

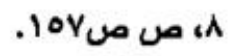

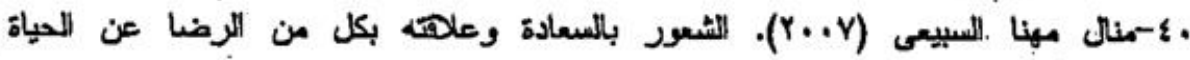

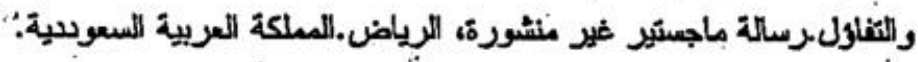

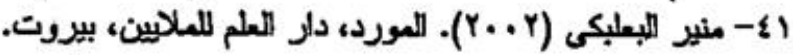

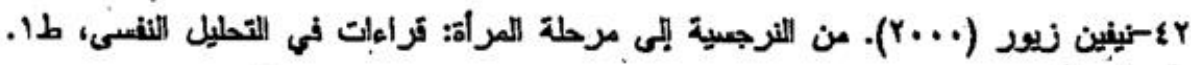
التقاهرة: مكثبة الاتجلو.

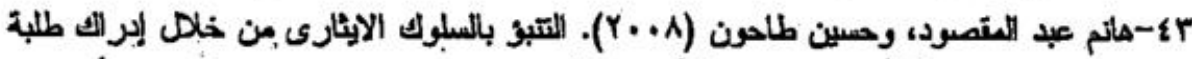

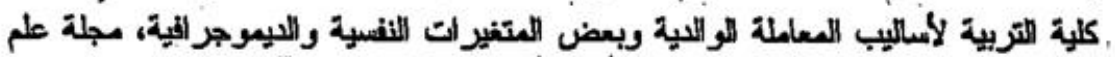

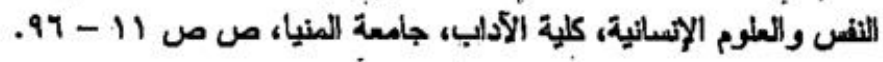

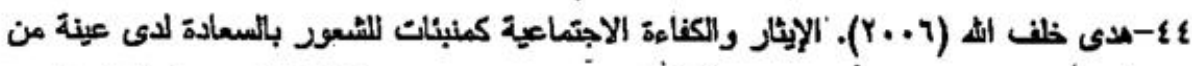
المتزوجين وغير للمتزوجين، رسالة ماجستير غير مثشورة، كلية الإدابه، جامعة المنيا.

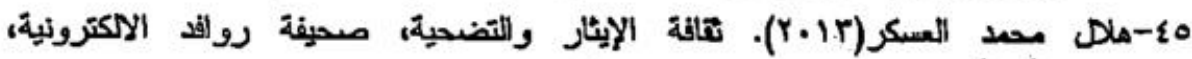
. com/tabeb/147841.htmlhttp://rwifd

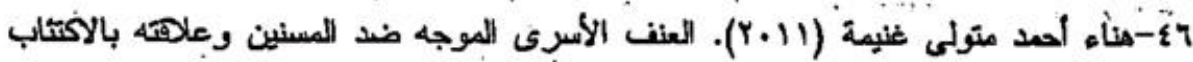

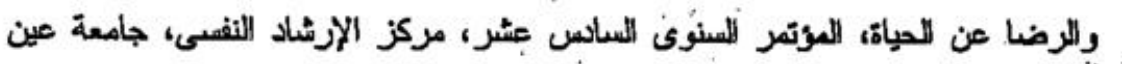

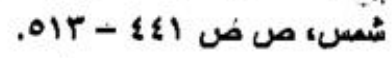

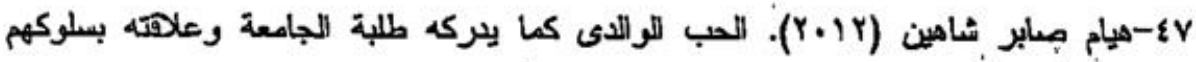

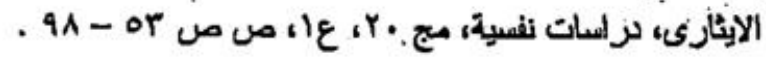

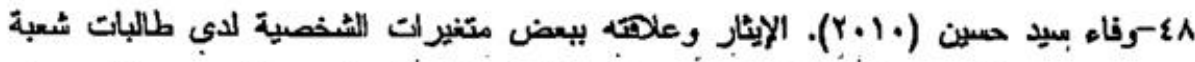

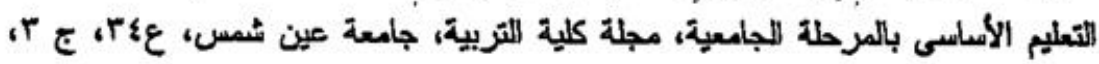

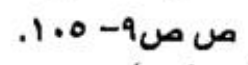

ثاتياً: المراجع الأجنيية:

49-Agnew,C.R;Van Large,P.A.M;Rusbult,C. E; \& Langston, C. A.(1998). Cognitive interdependence: Commitment and the mental 


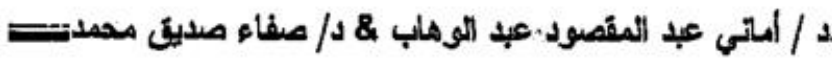

representation of close relationships . Journal of personality and Social psychology, 74, 939- 954.

50-Amato,Paul;Loomis,Laura\&Booth,A.(1994).Parental divorce, Marital conflict and offspring psychological well-being during early adulthood .Journal of Social Forces,Vol.73,n3,PP.895-915 Mar.

51-Aronson,E; Wilson,T .D; Akert, A. M.(2005). Social psychology, Upper Saddle River, N J: prentice Hall. ISBN 0-13-178686-5.

52-Bandura,A.(1961).Psychotherapy as a learning process .Psycho .Bull., 2, 143-157.

53-Bandura,A.(1973).Aggression: a social learning analysis.New York, Prentice-hall.

54-Bar-Tal, D.(1976). Prosocial behavior. Washington, D C: Hemisphere.

55-Bartal,D;\&Raviv,A.(1982).A cognitlve learning model helping behavior development possible implications and applications, In Eisenberg, N.(Ed) The development of prosocial behavior, New York;Academic Press,199- 227.

56-Batson,C.D.(1991).The altruism questio-toward a social-psychological answer, New Jersey, Hillsdale: Lawrence Erlbaum Associated, Inc.

57-Batson,C.D.(2002).Self other merging and the empathy altruism hypothesis : Reply to Newnerg ,Journal of Personality and Social Psychology, 73,517.

58-Bauman, Zygmunt .(1993). Postmodern Ethics , Bláckwell. 59-Chen,Fu-Mei\&Li,Tsui-Shan.(2007). Marital Ẹnqing: An Examination of Its Relationship to Spousal Contributions, Sacrifices, and Family Stress in Chinese Marriages, Journal of Social Psychology, Aug, Vol.147 issue 4, p393-412.

60-Ciarrochi,J;Deáne\&Anderson,S.(2002). Emotional intelligence Moderates the Relationship between Stress and Mental Health. Personality and

$=$ 


\section{= التضدحة وعلاتثها بلرضا عن العياة لدى العراة المتزوجة وغير المتزوجة"}

Individual Differences. 32, 197- 209.

61- Clement,Crace.(1996). Care, Autonomy, and Justice: Feminism and the Ethic of Care. West view Press.

62-Connie,S.,Rosati.(2009).EXV-Self-Interest and Self -Sacrifice,

Proceeding of the Aristotelian Society, Vol. cix,part3,Unversity of London.

63-Dawley,D.,Houghton,J.\&Bucklew,N.S.(2010).Perceived Organizational Support and Turnover Intention: The Mediating Effects of Personal Sacrifice and Job Fit, Social Psychology,150(3),238-257.

64-Derrida,J.(1992).Given time: Counterfeit money. Chicago/ London University of Chicago press.

65-Derrida,J.(1995).The gift of death .Chicago/London University of Chicago press.

66-Derrida,S.\&Schillerthus (1998).The tow sources of ' religion' at the limits of reason alone. In J. Derrida\& G. Vattimo (Eds.),Religion: Cultural memory in the present(pp,1 -78).Stanford: Stanford University press.

67-Desjariais,V.(2004).Forgiveness, Affect and life satisfaction among community, dwelling rural elders, a correlational study, Unpublished PHD,Capella University.

68-Diener,D.P.(1984).Life satisfaction and old age: A reexamination. Research on Aging,6,PP.432-448.

Dollahite,David,C;Layton,Emily;Bahr,Howard,M;Walker,Anthony,B.\&Th atcher, Jennifer,Y.(2009). Giving Up Something Good for Something Better: Sacred Sacrifices Made by Religious Youth. Journal of Adolescent Researh; Nov,Vol.24 Issue 6, p 691-725.

70-Eisenberger,R;Fasalo,P;\&Davis-LaMstro,V.(1990).Perceived organizational support and employee diligence, commitment ,and

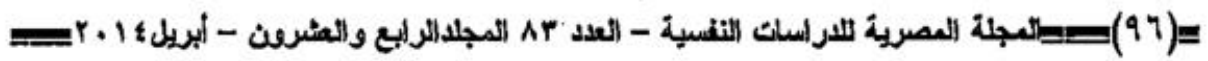




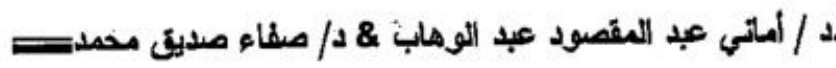

innovation, Journal of Applied Psychology, 75,51-59.

$7 \mathrm{i}$-Eisenberger,R;Stinglhamber,F;Vandenberge,C;Sucharski,l;\& Rhoades,

L.(2002). Perceived supervisor support: Contributions to perceived organizational support and employee retention. Journal of Applied psychology, 87;565-573.

72-Ernst,Fehr\&Suzann-Viola.(2004).Roots Of Altruism, from, WWW. Scientific American. Com.

73-Ferdi Botha; Frikkie Booysen(2013). The relationship between marital status and life satisfaction among South. African, adults. Acta Academica,Volume45, PP.150-178.

74-Finkel,E. J;Rusbult,C.E;Kumashior, M; \& Hannon, P.A.(2002).Dealing With betrayal in close relationships: Does commitment promote forgiveness? Journal of personality and Social psychology, 82, 956974.

75-Fujiwara,T.\&Lee,C .k.(2008). Association of parental psychiatric morbidity with their altruistic behaviors and sense of obligation to children in the United States, Clinical Medicine, psychiatry, 1,25- 35.

76-Gerrard,Eva\&Roberts,Ron(2006).Student parents, hardship and debt: a qualitative study. Journal of Further\& Higher Education, Nov, 30, Issue 4,p393-403.

77-Hair,Elizabeth,C.;Moorekristin;Garrett,Sarah,B.;Kinukawa,Akemi;

Lippman, Laura and Michelson Erik(2003).Psychometric analysis of the parent- adolescent relationship scale. Washington, DC, Child - Trends.

78-Hoogervorst,Niek;De Cremer, David, VanDijke, Marius \&Mayer, David M.(2012). When do leaders sacrifice?:The effects of sense of power and belongingness on leader self-sacrifice Leadership Quarterly ;oct, Vol. 23 Issue5,p884-896.

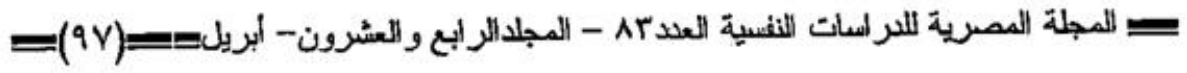


= التضحية وعلانتها بالرضا عن الحياة لدى المرأة المتزوجة وغير المتزوجة

79-Howard,M.\&Kathleen S.(2001). Families and Self-Sacrifice: Alternative Models and Meaning for Family Theory, Social Forces, June ,79(4): 1231- 1258.

82-Huebner,Scott(2001).Manual. for the multidimensional student's life satisfaction scale. University of south Carolina, Department of Psychology, Columbia, SC, 29208.

83-Huebner,E.;Suldo,S.;Smith,L.\&McKnight,C.(2004).Life satisfaction in children and youth: Empirical foundations and implications for school psychologists. Psychology in the Schools, 41, 81-93.

84-Huebner,E.S.;Suldo,S.M.;Valois,R.F.;Drane,J.W.,\&Zullig,K.(2004).Brief -multi- dimensional student's life satisfaction scale: Sex, race, and grade effects in a high school sample. Psychological Reports, 94,351-356.

85-Hwang,Se Kwang\&Charnley,Helen.(2010).Honourable Sacrifice: A Visual. Ethinography of the Family Lives of Korean Children with Autistic Siblings, Children \&Society; Nov, Vol.24 Issue 6, p 437-448. 86-Impett,Emily;Kogan,A;English,T;John,O;Gordon,A

;Keltner,D\&Oveis,C.(2012). Suppression Sours Sacrifice: Emotional and Relational Costs of Suppressing Emotions in Romantic Relationships. Social Psychology Bulletin,Jun,Vol,38 Issue 6,PP. 707-720.

87-Jarrette A. Lobell .(2012). Why the Chimú people of ancient Peru offered what was most valuable to them, Archaeological Institute of Americ ,Jan/Feb, Vol.65,Issue 1.

88-Kelley,H.\&Thibaut,J.W.(1978). Interpersonal relations: A theory of interdependence. New Yourk: Wiley.

89-Kohut,H.\&Wolfes (1975). The disorders of the self and there treatment : an outlines, international journal of psychoanalysis, 59, 413-425 .

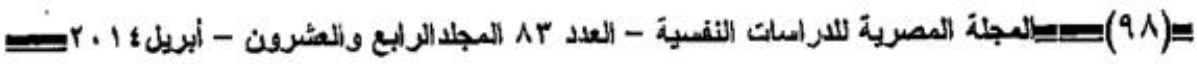




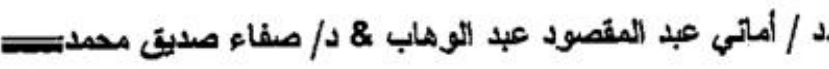

90-Kohut, H. (1977). Restoration of the self. New York : international universities press.

91-Lambert,Nathaniel;Fincham Frank;Stanley,Scott.( 2012). Prayer and satisfaction With sacrifice in close relationships,Journal of social\&Personal Relationships, Vol,29(8), p1058- 1070.

92-Leung,L.\&Leung,K.(1992).Life satisfaction, self-concept, and relationship with parents in adolescence. Journal of Youth and Adolescence, 21,PP.653-665.

93-Lewis,Denisce\&Seponski,Desiree.(2012).Transcendent Sacrifice and Spirituality: Cambodian Grandparents raising Orphaned Grandchildren,Journal of Intergenerational Relationships, Vol.10 Issue 4,p355-369.

94-Lucas,R.E.:Diener,E.\&Suh,E.(1996).Discriminate validity of well-being measures. Journal of Personality and Social Psychology, Vol. 71, PP.616.

95-Lyubomirsky,S;King,L ;Diener, E;.(2005) The benefits of frequent positive affect: does happiness Lead to Success? Psychol Bull,131(6),55- 803 .

96-Mayers,D.G.(1998). Psychology,5th (Ed), New York, Worth publishers, Inc.

97-Mcandrew,Francis,T.\&Perilloux,Carin.(201) .Self-Sacrificial Competitive Altruism Primarily a Male Activity?, Evolutionary psychology,Vol.10 Issue 1,P. 50-65.

98-Mizruch,Susan,L.(1998).The Science of Sacrifice: American Literature and Modern Social Theory .Princeton University Press.

99-Noller, P.(1996).What is this thing called love? Defining the love that supports marriage and family. Personal Relationships, 3 , 97-115.

100-Peperzak ,Adriaan T.(1993). To the Other: An introduction to the

= 
= التضحية وعلاتهها بالرضا عن الحياة لدى المرأة المتزوجة وغير العتزوجة

Philosophy of Emmanuel Levinas. Purdue University Press.

101-Ruppel,Erin, K.Curran\&Melissa, A.(2012). Relational sacrifices in romantic relationships: Satisfaction and the moderating role of attachment. Journal of Social \&Personal Relationships; Jun, Vol,29 Issue 4,P508-529.

$102-$

Rusbult,C.E.,Hannon,P.A.,Stocker,S.L.,\&Finkel,E.J.(2005).Forgivene ss and relational repair. in E. L.

103-Queiroz,M.\&Barroso, M.(1999). Quality of life of mother/companion [sic] of hospitalized child, Enfernmagen, Sep-Dec,8(3),147-61.

104-Rushton,J.P;Chrisjohn, R.D;\&Fekken,G.C.(1981).The altruistic personality and the self- report altruism Scale. Personality and individual Differences, 2(4), 293302 .

105-Schaefer,M.T.\&Olson,D.H.(1981).Assessing Intimacy: The pair inventory. Journal of Marital \& Family Therapy, 7, 47-60.

106-Schiller,Fr.(1975).philosophisch -AsthetischeSchniften, Theosophie des Julius. In SamtlicheWerke, Bd. 5 (pp. 344- 358).Munchen: Carl Hanser Verlag.

107-Seligman, Martin E. P.(2002). Positive psychology, positive prevention, and positive Therapy. In: Handbook of positive psychology, by Shane J. Lopez\& C .R. Snyder (eds), New York: Oxford University press.

108-Sharabany,R;\&Bartal.(1981). Theories of the development of altruism: Review, comparison and integration. International Journal of Behavioral Development, 5, 49.

109-Stanley,S.(1998). The heart of commitment: Compelling research that reveals the secrets of a Lifelong, intimate marriage. Nashville ,TN: Thomas Nelson.

110-Stanley,S.M;Markman, H.J;\&Whitton,S.(2002). Communication,

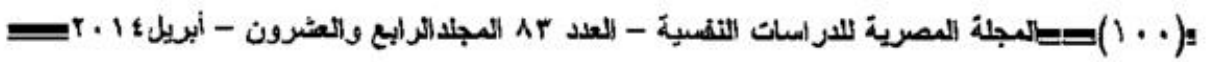




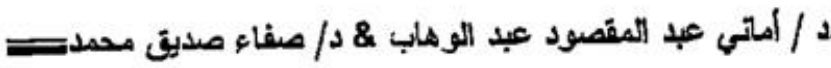

conflict, and commitment: Insights on the foundations of relationship success from a national survey. Survey. Family Process,41,659-675.

111-Stanley,Scott;Whitton,Sarah,W;Sadberry,Sabinam,Low;Clements,Mari,L;

Markman,Howard,J.(2006).Sacrifice as a Predictor of Marital

Outcomes. Family Process, Vol,45 (3),p289- 303.

112-Suldo,S.M.;Huebner,E.S.(2004b).Does life satisfaction moderate the

effects of stressful life events on psycho-pathological behavior during adolescence? School Psychology Quarterly ,19(2),93-105.

113-Todorov, Tzvetan.(1996). Facing the Extreme : Moral. Life in

Concentration Camp. Metropolitan Books.

114-Tyink,S.(2006)." Driven Altruism: A grounded theory studye. Ed. D;

Fielding Graduate University, from, http://proquest. Umi.Com/ dissertations / preview all 3230494.

115-Van Lang, P.A.; Rusbult, C.;Drigotas ,S.,Arruaga,X. B;Witcher,B.\&Cox, C. L.(1997). Willingness to sacrifice in close relationship. Journal of personality and Social psychology, 72, 1373- 1395.

116-V̌andenberghe,Chistian\&Panaccio,Alexandra.(2012).Perceived sacrifice and few alternatives commitments:The motivational underpinnings of contınuance commitment's sub dimensions. Journal of Vocational Behavior; Aug 2012, Vol. 81 Issue 1, p59-72.

117-Whitton,S:W;Stanley,S.M;\&Markman,H.J.(2005).Sacrifice - in romantic relationships: An exploration of relevant research and theory. In H.T.Reiss, M.A.Fitzpatrick,\& A.L.Van-gelisti (Eds.). Stability and change in relationship behavior across the Lifespan (pp.156 181). Cambridge, England: Cambridge University press.

118-Wieselquist,J;Rusbult,C.E; Foster, C .A; \& Agnew , C. R.(1999). Commitment, pro-relationship behavior, \& trust in close relationships. Jourrial of Personality and Social Psychology, 77, 942- 966.

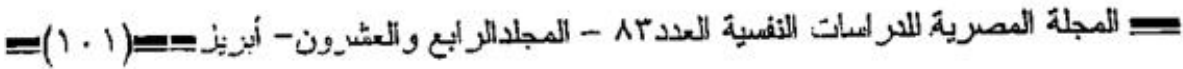


= التضحية وعلاتها بالرضا عن الحياة لدى المرأة المتزوجة وغير المتزوجةت=

\section{Sacrifice and its relation to life satisfaction among married women and unmarried in Egypt and Saudi Arabia}

\section{Prof.Dr.Amany Abd El Maksoud Dr.Safaa,Mohamed khreba}

The current research aims to study the correlation between sacrifice among Egyptian women and Saudi Arabia, married and non-married to divorcees \&widows; and the impact on the degree of their sense of satisfaction with life , and test the effect of the differences between married women and unmarried in sacrifice, as well as in the life satisfaction, in addition to the disclosure of the differences between each of the Egyptian woman living in Egypt and living in Saudi Arabia as well as between each of Egyptian women and Saudi women in sacrifice and life satisfaction. And predictability good about the life of the sub-dimensions of the scale of sacrifice among women .

The results showed the following:

1-There is a positive correlation between personal sacrifice of married women and both dimensions of life satisfaction represented in:complacency, satisfaction prisoners, social satisfaction , satisfaction with vocational, and the overall degree of satisfaction with life, and there is no correlation between personal sacrifice and Symptoms neurotic tendencies and withdrawal .And found a negative correlation between marital sacrifice and all dimensions of life satisfaction, except vocational satisfaction. As for the pair after sacrificing for their children when unmarried women were found positive correlation and with all dimensions of life satisfaction.

2-There are no differences between the average scores of Egyptian women (married, unmarried) on a scale of sacrifice.

3-The presence of significant differences between the mean scores of a sample of Egyptian women (married/unmarried) on a scale of satisfaction with life for the benefit of Egyptian women married .

4- presence of significant differences between the average scores of Saudi women (married/unmarried) on a scale of sacrifice for the benefit of Saudi women are unmarried.

5-There are no differences between the average scores of Saudi women (married, not married) on a scale of satisfaction with life.

6-There are differences between the average scores of Egyptian women married in Egypt compared to their counterparts living in Saudi Arabia on a scale of sacrifice for the benefit of Egyptian women in Egypt .

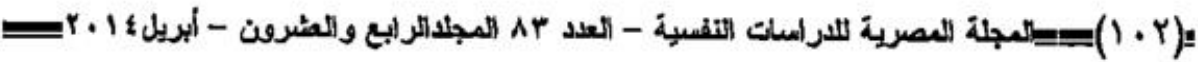


عيد المقصود عبد التوهاب \& د/ صماء صديق محمد

7-There are differences between the mean scores of Egyptian women married resident in Egypt compared to women married to Egyptian living in Saudi Arabia on a scale of satisfaction with life, and for the benefit of the Egyptian woman living in Saudi Arabia .

8-The higher the personal sacrifice increased the overall degree of satisfaction about life, and vice versa for the sacrifice marital higher the sacrifice marital decreased the overall degree of satisfaction about life .

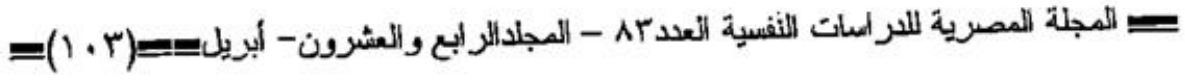

